\title{
Beyond the Hinterland: Exploring the International Actorness of China's Yunnan Province
}

\author{
Song Yao \\ Submitted in total fulfilment of \\ the requirements of the Degree of Doctor of Philosophy
}

Asia Institute

The University of Melbourne

September 2019

ORCID: 0000-0002-7720-3266 


\section{Abstract}

This study analyses the international relations of subnational governments, a phenomenon conceptualized as paradiplomacy. The scholarly literature on paradiplomacy tends to focus overly on subnational governments in federal systems, rather than those in unitary and centralized countries whose subnational governments have been increasingly proactive in international relations. China is one of these countries. Among the limited numbers of works on Chinese paradiplomacy, the majority are framed within the central-local interactions on foreign affairs and pay inadequate attention to how these provinces have participated directly in external cooperation, in line with their local interests. This body of works also displays a geographical bias, showing more interest in the prosperous coastal regions of China than its inland and border regions. This study, therefore, seeks to address the question of how Yunnan, a border province in the southwest of China, has become an international actor by exploring its international actorness.

The thesis develops an original analytical framework. In contrast with previous analytical paradiplomacy frameworks, it combines the concept of paradiplomacy with the theory of actorness. After reviewing the relevant scholarly works, four dimensions of actorness have been considered: motivation, opportunity, capability, and presence. First, this study argues that, in the face of profound domestic developments and a complex external environment, Yunnan has been motivated to engage in cross-border cooperation and to consolidate its external affairs powers. This is followed by a discussion of how external affairs powers have enabled Yunnan to leverage three broad instruments to incentivise neighbouring countries to cooperate with it: infrastructure development, economic statecraft, and diplomatic efforts. Lastly, it is argued that the increased external powers of Yunnan have propelled its role as an international relations actor towards recognition by both neighbouring countries and the Chinese central government.

The primary empirical data informing this study was collected through qualitative interviews with those involved in the implementation of Yunnan's foreign agenda, representatives from province-owned enterprises, universities, and think tanks, and officials and experts from the neighbouring countries of Yunnan. Relevant information was also collected from official documents, gazettes, almanacs, and media reports. Participant observation was conducted as a complement to interviews and content analyses. Consequently, this thesis 
contributes to the paradiplomacy literature by providing in-depth insights into the international actorness of an under-researched border Chinese province. It has contributed to the extant paradiplomacy literature by proposing a new analytical framework that provides an opening to explore the international actorness of a subnational government. Among previous works, few analytical frameworks have been able to account fully for the evolution of the paradiplomatic activities of subnational governments, whether in federal or unitary states. Through this analysis, therefore, this study demonstrates that a Chinese case can, for the most part, fit within the broader context of paradiplomacy scholarship based on Western cases. 


\section{Declaration}

This thesis comprises only my original work towards the Degree of Doctor of Philosophy, and due acknowledgement has been made in the text to all other material used. The thesis is fewer than 100,000 words in length, exclusive of tables, bibliography and appendices.

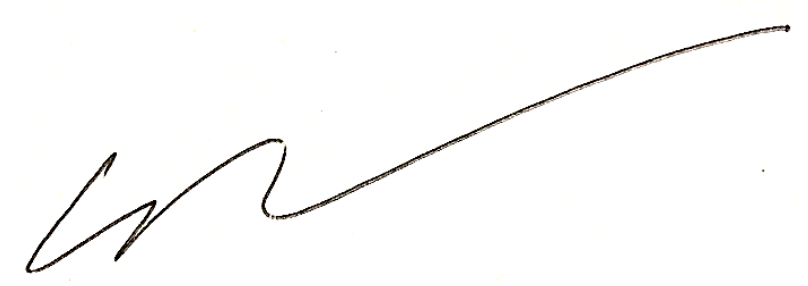

Song Yao

April 2019 


\section{Acknowledgments}

I am fortunate to have been supervised by Dr.Pradeep Taneja. During the past four to five years, he has not only provided me boundless instructions on the completion of my PhD research, but also broadened my horizons and endeavoured to draw my attention to a general picture of world geopolitics which is certainly not limited to the Greater Mekong Subregion. As his student, I feel privileged to have had more chances than others to learn about his insightful and comprehensive perspectives on many global issues, which has been genuinely inspiring. He even made me understand China more deeply.

I am very much obliged to Associate Prof.Gao Jia. As the chair of my supervision committee, he teamed with my supervisor to ensure my data collection and completion of the whole thesis was smooth and punctual. His professionalism, East Asian values, and lasting enthusiasm for work reminded me of some traditional Chinese masters who has succeeded overseas, especially Mr.Qian Zhongshu. All of them are characterized by their patriotism, modesty, and uprightness.

I am thankful to Prof.Vedi Hadiz who brought new virtues into the Asia Institute. Since he took office as the head of the Al, all the students and I sensed the difference. I do believe the new students will find the Asia Institute under Vedi's leadership, with greater influence, upgraded facilities, and more harmonious cooperation between supervisors and PhD researchers, the best choice to make their dreams come true.

In the course of researching and writing this thesis, I have also benefited from the following friends, relatives, scholars, and government officials: James Seymour, Sow Keat Tok, Luo Yongxian, Abdul-Samad Abdullah, Muhammad Kamal, Roybn Borg, Leena Sookramanien, Zheng Ruiqiang, Xu Qingduo, Yu Li, Yao Yang, Li Mingjiang, David Goodman, Tim Summers, Czeslaw Tubilewicz, Sun Bin, Wu Lei, Jin Cheng, Bi Shihong, Lv Xing, Liu Jinxing, Sun Baoquan, Khin Maung Lynn, Tin Htoo Naing, Khin Maung Nyo, Watcharas Leelawath, Simon Shen, Patrick Wong, Willy Lam, Zhang Baohui, Deng Su'e, Song Chaopeng, Deng Lin, Zhang Qianjin, Song Rui, Guan Tianru, Qiao Guangyu, Tan Xiao, Liu Tianyang, Yuan Zhenjie, Pan Qiuping, Yang Yilu, Yang Yunying, Huang Biao, Zhu Yuzhu, Zhi Haotong, Kevin Ge, Yu Lei, Ran Dong, Jiang Liu, Li Chen, Li Xing, Song Ke, Erica Li, Zhang Weipeng, Cheng Xiao.

Last, as a young researcher in China's foreign affairs, I want to take this opportunity to express my deep concern about China's relations with the United States and its ways of dealing with the international community. As I drafted this thesis in the last two years, China was dragged into a trade war with America. Thus far, China has yet to work out a visible, firm grand strategy, and many countries have already lost their confidence in China's commitments to fair trade, equal treatment for foreign investors, the opening of domestic markets, and the undertaking of tangible economic, financial, and political reforms. As a young international relations student from China, I hope that the attainment of my PhD might be a new starting point, and that I will join numerous young Chinese researchers and 
practitioners, in particular those who have attained their doctoral degrees from overseas institutions, in devoting our knowledge, global vision, and new insights to the country. 


\section{Table of Contents}

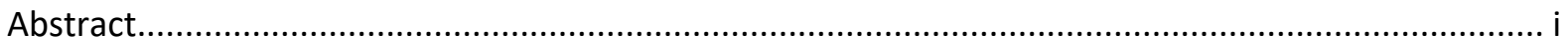

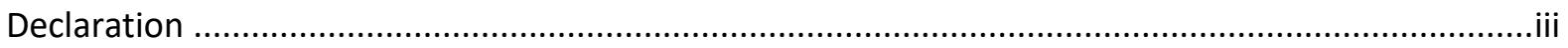

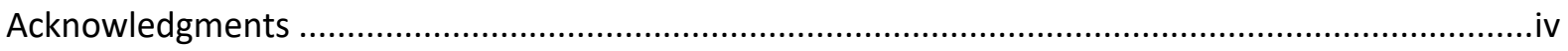

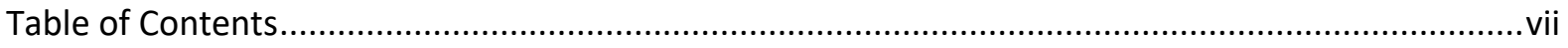

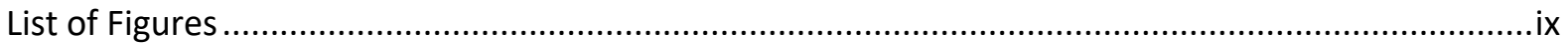

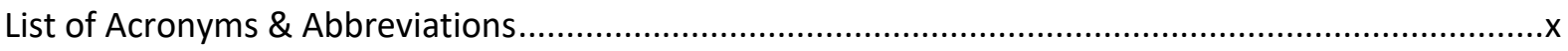

Chapter 1 Introduction $\quad 1$

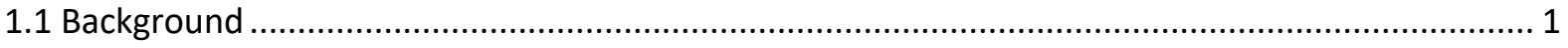

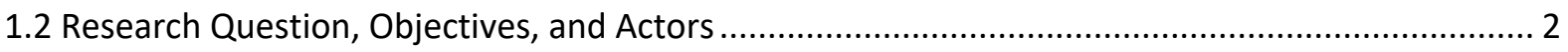

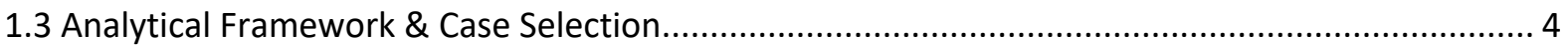

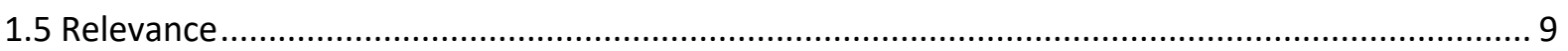

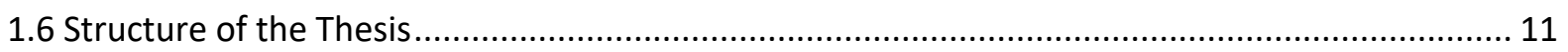

Chapter 2 Literature Review \& Analytical Framework $\quad 14$

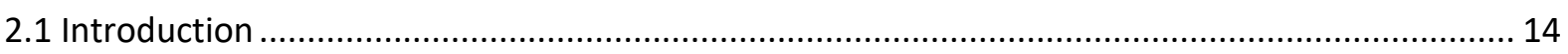

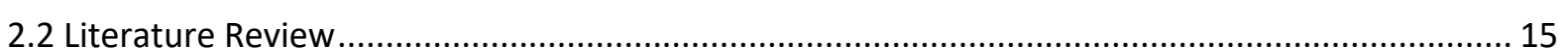

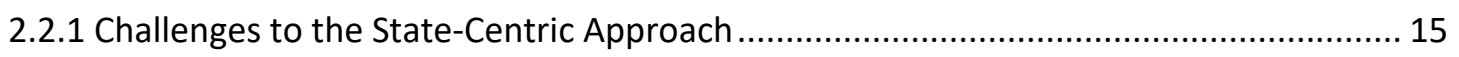

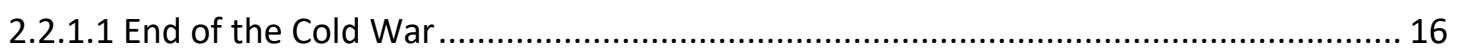

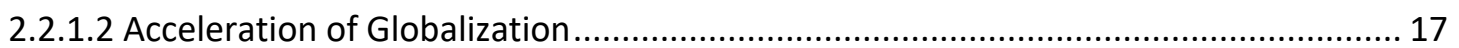

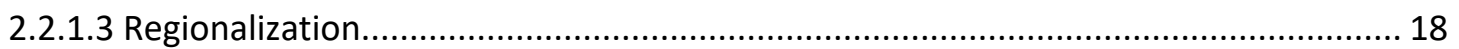

2.2.2 Emergence of Non-State Actors in International Relations ......................................... 19

2.2.3 Paradiplomacy Studies as an IR Subdiscipline ........................................................... 22

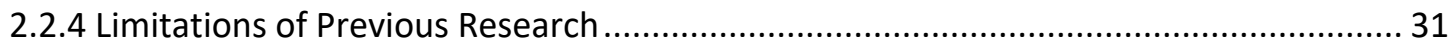

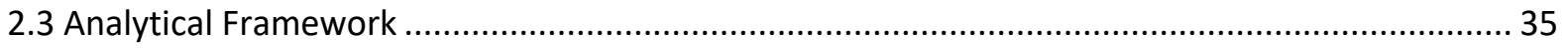

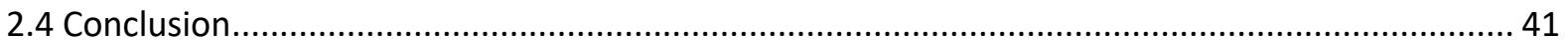

Chapter 3 Methodological Framework 43

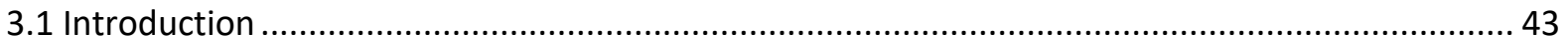

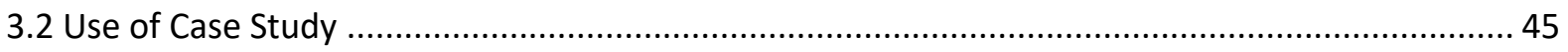

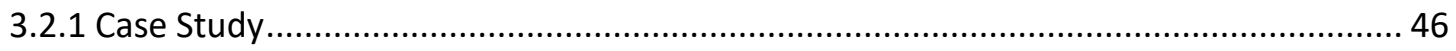

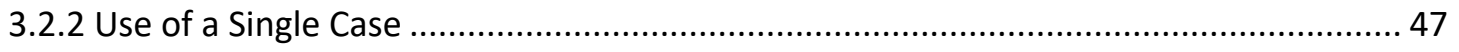

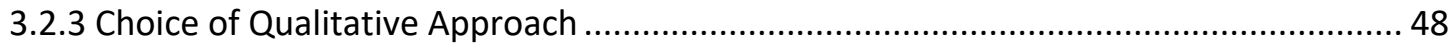

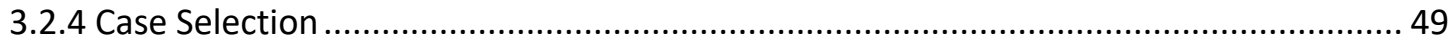

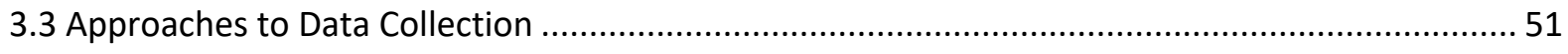

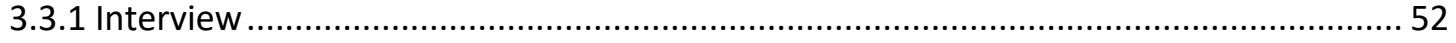




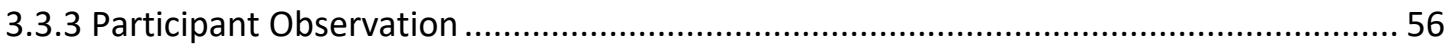

3.3.4 Additional Explanations \& Ethical Considerations ............................................. 58

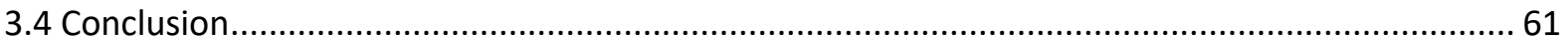

Chapter 4 Dimensions of Yunnan's Actorness: Motivation 62

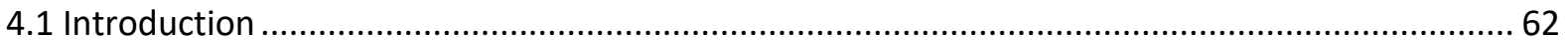

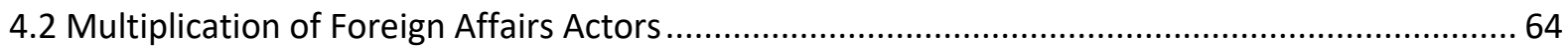

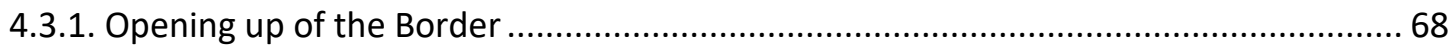

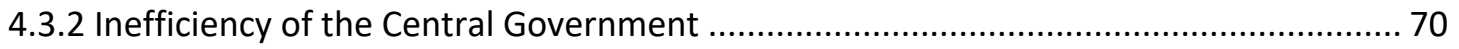

4.3.3 Response to Domestic Competition ....................................................... 74

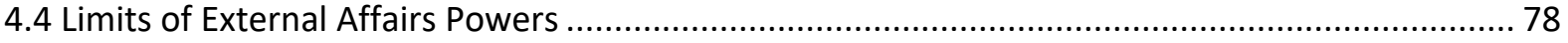

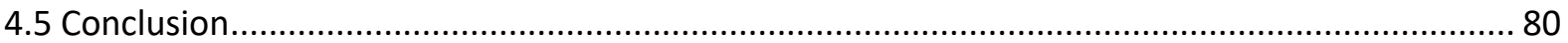

Chapter 5 Dimensions of Yunnan's Actorness: Opportunity 81

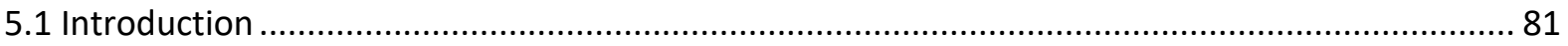

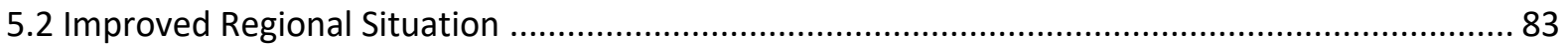

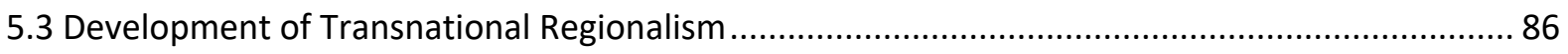

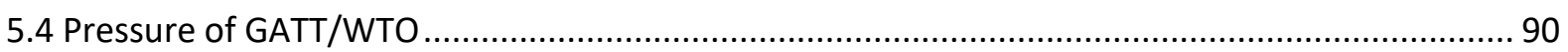

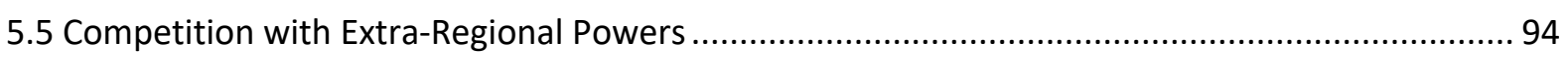

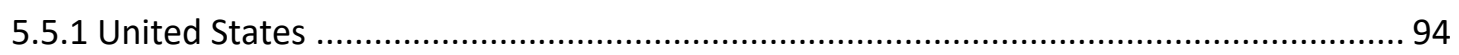

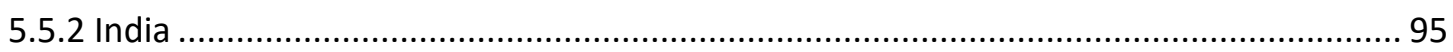

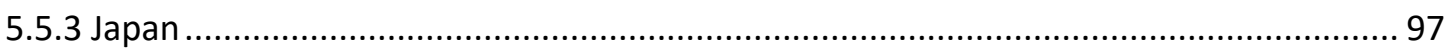

5.5.4 China's Response to Competition .................................................................. 102

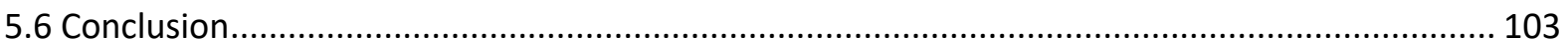

Chapter 6 Dimensions of Yunnan's International Actorness: Capability 104

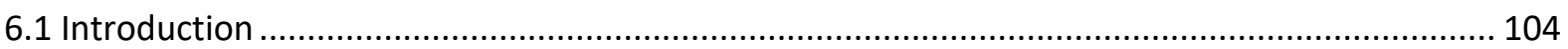

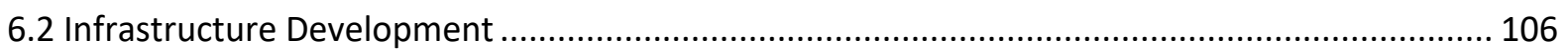

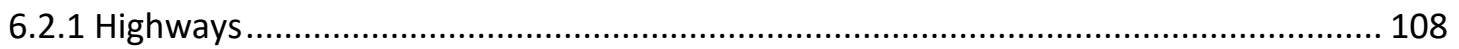

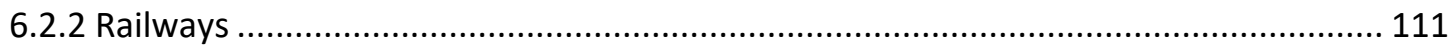

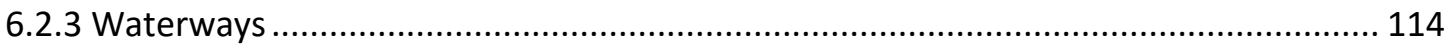

6.2.4 Telecommunications ....................................................................... 115

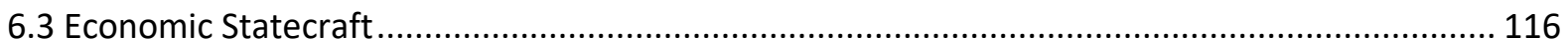

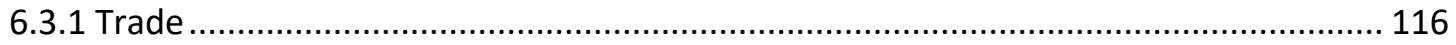

6.3 .2 Investment Relations ............................................................................. 119

6.3.3 Manpower Exchanges ......................................................................... 121

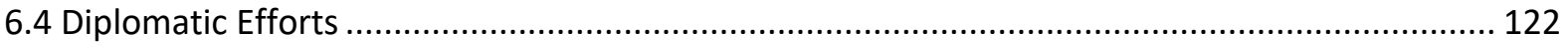




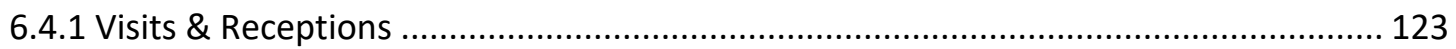

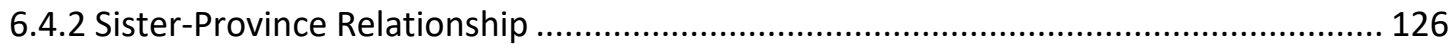

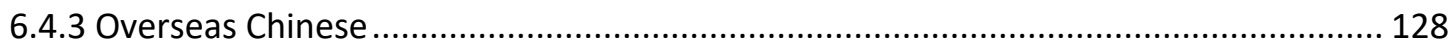

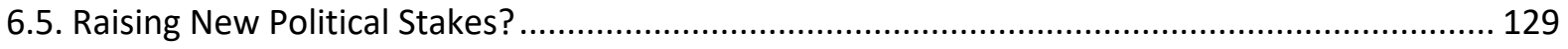

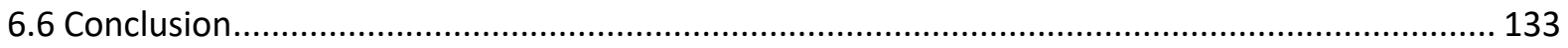

Chapter 7 Dimensions of Yunnan's Actorness: Presence $\quad 134$

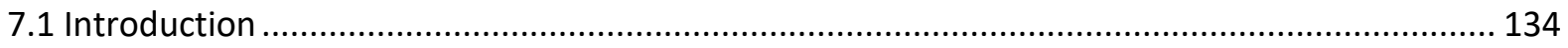

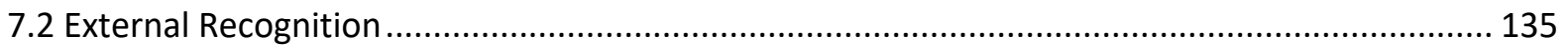

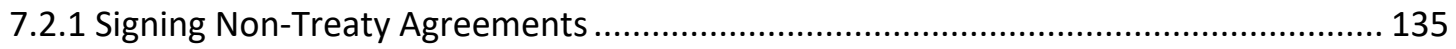

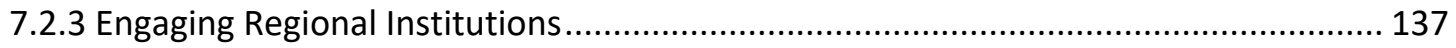

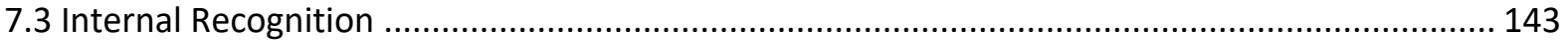

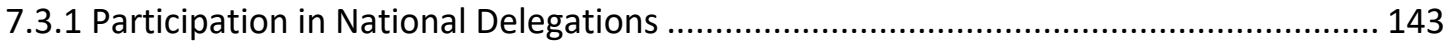

7.3.2 Becoming a Host for Major External Events ........................................................... 145

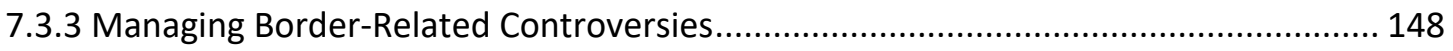

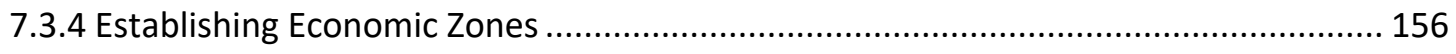

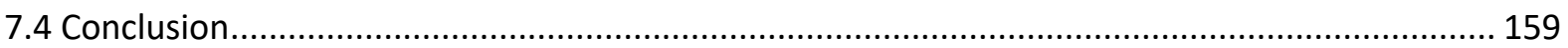

Chapter 8 Conclusion $\quad 161$

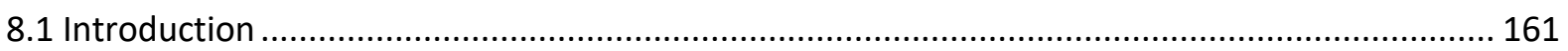

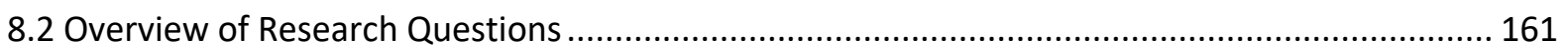

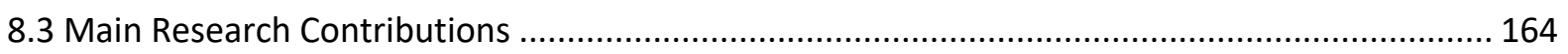

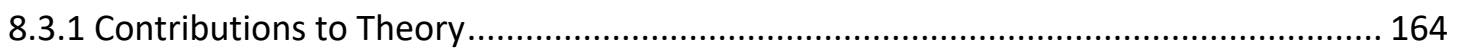

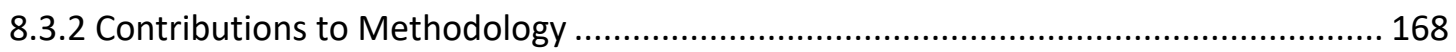

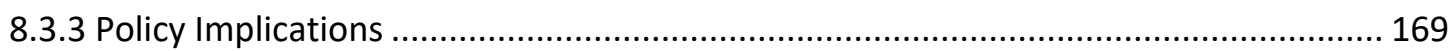

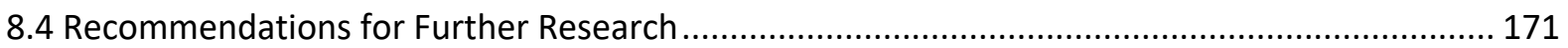

$\begin{array}{ll}\text { References } & 173\end{array}$

$\begin{array}{ll}\text { Appendices } & 208\end{array}$

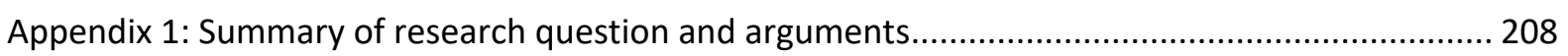

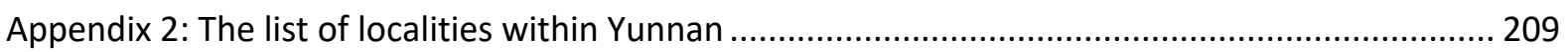

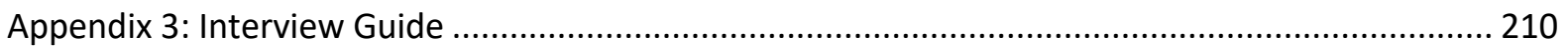

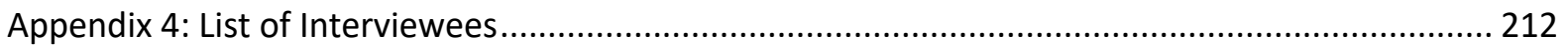

Appendix 5: Gross Development Project (GDP) (billion in RMB) in Yunnan and some coastal provinces

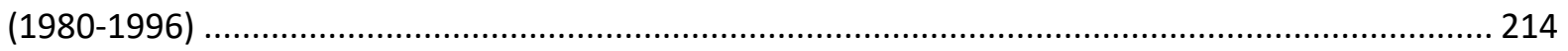

Appendix 6: The list of Growth Triangles in East and Southeast Asia ............................................ 215 


\section{List of Figures}

Figure 1.1 Map of China - highlighted is the province of Yunnan .................................................. 7

Figure 1.2 Political administrative map of the province of Yunnan ................................................ 7

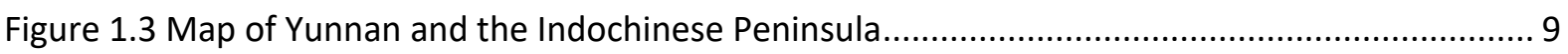

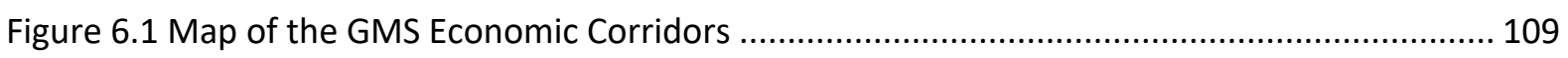

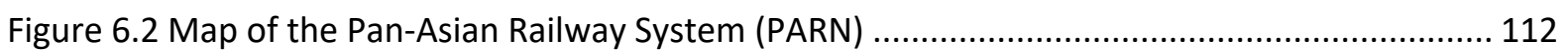

Figure 7.1 The Mekong Institute (MI) in Khon Kaen, Thailand .................................................. 142

Figure 7.2 The pavilion of the South \& Southeast Asia Commodity Exposition and Investment Fair

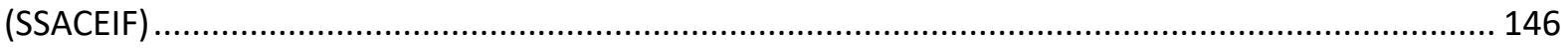

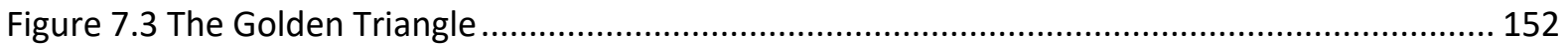




\section{List of Acronyms \& Abbreviations}

ABC - Agricultural Bank of China

ADB - Asian Development Bank

AFTA - ASEAN Free Trade Area

AllB - Asian Infrastructure Investment Bank

APEC - Asia-Pacific Economic Cooperation

APT - ASEAN Plus Three cooperation

AS - Actor segmentation

ASEAB - Association of Southeast Asian Nations

BCIM - Bangladesh-China-India-Myanmar Forum for Regional Cooperation

$\mathrm{BCP}$ - Burmese Communist Party

BIMSTEC - Bay of Bengal Initiative for Multi-Sectoral Technical and Economic Cooperation

CAExpo - China-ASEAN Trade Fair

CAFTA - China-ASEAN Free Trade Agreement

CAREC - Central Asia Regional Economic Cooperation Programme

CCB - China Construction Bank

CEZ - Cross-Border Economic Cooperation Zone

$\mathrm{CFI}$ - Commission for Investment

CIFCA - China International Friendship Cities Association

CIS - Commonwealth of Independent States

CITIC - China International Trust and investment Corporation

CNPC - China National Petroleum Corporation

CNSC - Central National Security Commission

COFCO - China National Cereals, Oils and Foodstuffs Corporation

CoR-Committee of Regions

$\mathrm{CPC}-$ Communist Party of China

CPI - China Power Investment Corporation

CPPCC - Committee of Chinese People's Political Consultative Conference

CSAE - China-South Asia Exposition 
CUHK - Chinese University of Hong Kong

DOC - Department of Commerce

DRC - Development and Reform Commission

EC - European Community

ECASC - Economic Coordination Association for Southeast China

ESCAP - Economic and Social Commission for Asia and the Pacific

EU - European Union

FAO - Foreign Affairs Office

FTEC - Foreign Trade and Economic Cooperation Commission

GATT - General Agreement on Tariffs and Trade

GDP - Gross domestic product

GMS - Greater Mekong Subregion economic cooperation programme

HNP - Huanang Power International

ICBC - Industrial and Commercial Bank of China

ICB - Investment and Cooperation Bureau

IRCO - International Regional Cooperation Office

JCPDMR - Japan-China Policy Dialogue on Mekong Region

K2K - Kunming-Kolkata cooperative forum

KIEF - Kunming Import \& Export Fair

$\mathrm{KIO}$ - Kachin Independence Organization

KMT-Kuomintang

KRG - Kurdistan Regional Government

KWP - Korean Workers' Party

LFNC - Lao Front for National Construction

LMC - Lancang-Mekong Cooperation

LMI - Lower Mekong Initiative

LOT - Letter of intent

MAF - Myanmar Armed Forces

$\mathrm{MCCl}$ - Union of Myanmar Federation of Chambers of Commerce and Industry

MFN - Most-favoured-nation 
MGC - Mekong-Ganga Cooperation

MHRSS - Ministry of Human Resources and Social Security

$\mathrm{Ml}$ - Mekong Institute

MNDAA - Myanmar Nationalities Democratic Alliance Army

MOFCOM - Ministry of Commerce

MOFTEC - Ministry of Foreign Trade and Economic Cooperation

MOF - Ministry of Finance

MOFA - Ministry of Foreign Affairs

MONS - Ministry of National Security

MOU - Memorandum of understanding

MUSDP - Myanmar Union Solidarity and Development Party

NATO - North Atlantic Treaty Organization

NDRC - National Development and Reform Commission

NNCC - National Narcotics Control Commission

NPC - National People's Congress

NSD - National Security Department

NSD - National Security Department

NYC - New York City

OCAO - Overseas Chinese Affairs Office

OEZ - Overseas Economic Cooperation Zone

OFDI - Outward foreign direct investment

ORO - Overseas Representative Office

PACA - Provence-Alpes-Côte d'Azur

PARN - Pan-Asian Railway Network

PBGEC - Pan-Beibu Gulf Economic Cooperation

PBOC - People's Bank of China

PLA - People's Liberation Army

PoS - Policy segmentation

PRC - People's Republic of China

PSD - Public Security Department 
$\mathrm{RMB}-$ Renminbi

RTA - Regional Technical Assistance

SEZ - Special Economic Zone

Sinograin - China Grain Reserve Corporation

SLGFA - Small Leading Group on Foreign Affairs

SOEs - State-owned enterprises

SPC - Social Democratic Party

SPIC - State Power Investment Corporation

SSACEIF - South \& Southeast Asia Commodity Exposition and Investment Fair

STCF - Telecommunications Forum

TARDP - Tumen River Area Development Programme

TAT - Tourism Authority of Thailand

TF - Task force

UFWD - United Front Work Department

UGC - User-generated content

UMNO - United Malays National Organization

UNDP - United Nations Development Programme

UNSC - United Nations Security Council

USC - User-selected content

VIMICO - Vietnam National Minerals Corporation

WTO - World Trade Organization

XJTLU - Xi'an Jiaotong-Liverpool University

YASS - Yunnan Academy of Social Science

$\mathrm{YCIH}-$ Yunnan Construction and Investment Holding Group

YFIC - Yunnan Federation of Industry and Commerce

YNIH - Yunnan Construction and Investment Holding Group

YTA - Yunnan Tourism Administration 


\section{Chapter 1}

\section{Introduction}

\subsection{Background}

In 1992, Francis Fukuyama predicted, in his influential work The End of History and the Last Man, that with the end of the Cold War and the rapid integration process in Europe, the power of nation states would decrease. Such norms as sovereignty and nationalism were also challenged by intensifying economic interdependence from the 1990s onwards. In global trade, nation states have lost their lustre as arbiters between enterprises and markets in the wake of the growth of multinational corporations and the free movement of capital (Ohmae 1995). The proliferation of regional cooperation and integrative mechanisms has dealt a further blow to the monopoly of nation states over global affairs (Hettne 1999). It is against this background that a group of new actors has emerged in the international arena, in which nation states are no longer the primary or the sole participants.

This phenomenon denotes a great transnational revolution that has received considerable attention from international relations (IR) scholars from various schools. Robert Keohane and Joseph Nye (1974), two central figures in the liberal school, make explicit that there are two forms of external interactions along with the diplomacy conducted by nation states: transgovernmental relationships and transnational relationships. For structural neorealists, nation states are obligated to discuss issues with their domestic actors ahead of making foreign policy, and such actors even directly project themselves overseas (Posen 1986; Walt 1990; Snyder 1991; Evera 1999). Innenpolitik theorists, who consider domestic factors to be the most crucial, suggest a group of domestic actors shape the foreign agendas of their countries; these include political parties, economic organizations, and influential individuals. The external activism of all these domestic actors demonstrates that the state-centred approach is inadequate and somewhat out-dated.

Apart from these non-nation state actors, subnational governments around the world have become more active in transnational activities, independently of their national authorities. This phenomenon is conceptualized as 'paradiplomacy', a contraction of 'parallel diplomacy' 
(Soldatos 1990). Early works on paradiplomacy were based on examples from the United States and Canada (Atkey 1970; Leach, Walker and Levy 1973; Holsti and Levy 1974; Roff 1978). In the 1980s, a growing number of works on paradiplomacy began to focus on the external activities of subnational entities in European countries. This period also witnessed efforts to theorize this phenomenon, instead of merely depicting it. It is worth pointing out that although the majority of paradiplomacy-related works focused on the external activism of subnational governments in Western federal systems, this trend gradually changed during the early 2000s, as more paradiplomacy scholars demonstrated an interest in nonWestern unitary states and even in countries whose foreign affairs powers were once widely considered as highly centralized.

However, relatively few scholarly studies exist on the paradiplomacy of Chinese provinces. This can most likely be attributed to the stereotype that it is barely possible for subnational governments in a country with a top-down system to be independent actors within international relations (Perkins 1966; Schurmann 1971; Barnett 1967, 1985; O'Leary 1980; Garver 1993). Nonetheless, Chinese provinces have keenly pursued their external economic and security interests since the advent of the 'opening up' policy in the late 1970s. The earlier limited number of works on Chinese paradiplomacy tended to be contextualized within a central-provincial relations framework, rather than presenting a full picture of the paradiplomatic activities of Chinese provinces (Chen 2005; Chen, Jian and Chen 2010; Li 2017; Wong 2018). What is more, a geographic bias exists within this body of literature: those interested in Chinese paradiplomacy prefer to investigate the external interactions of better-off coastal provinces rather than border provinces.

\subsection{Research Question, Objectives, and Actors}

Given the research gap briefly outlined above, this thesis is primarily concerned with the question of how Chinese border provinces have become international relations actors. Specifically, it analyses the international actorness - the inherent characteristics of a subnational entity as an international player - of these provinces, as demonstrated in their dealings with neighbouring countries in the reform era, from both domestic and international perspectives.

In an effort to address this question, this thesis seeks to accomplish the following objectives: 
1. Determine the domestic economic and legislative circumstances that motivated Yunnan to conduct cross-border engagements;

2. Assess the external geopolitical and geoeconomic environment faced by China and how this environment is linked to the empowerment of Yunnan in external affairs;

3. Analyse the efforts of Yunnan to turn its external affairs powers into economic and diplomatic instruments to incentivize neighbouring countries to cooperate with it;

4. Trace specific examples of cooperation between Yunnan and neighbouring countries in such fields as trade, investment, and non-traditional security;

5. Explain the leveraging of diplomatic resources by Yunnan to boost cross-border cooperation.

This thesis deals with the external activities of a subnational government and recognizes this as a "territorial and administrative unit on the first level of authority after the central government in both federal and unitary state systems" (Kuznetsov 2014: 22) or, put more simply, "public authorities at the regional level, below the sovereign state" (Aldecoa and Keating 1999: Introduction). These definitions of subnational government correlate to the category of 'region' used in other works. For instance, as Kepa Sodupe (1999: 59) defines, a region is "a territorial unit immediately below the sovereign state, with a system of selfgovernment, that has its own constitution, state of autonomy or other law." Liesbet Hooghe, Gary Marks, and Arjan Schakel (2010: 4) also treat a region as a "coherent territorial entity situated between the local and national levels with a capability for authoritative decision making." Nonetheless, the reason why this thesis does not use the term 'region' is because of its ambiguity, since at least three levels of jurisdiction can be referred to as a region (continental level, subcontinental level, and subnational level). In addition to 'subnational government', there are myriad alternative terms used in the paradiplomacy literature, which include 'constituent government' (Kincaid 1990), 'non-central government' (NCG) (Duchacek 1990; Hocking 1999; Cornago 1999; Aguirre 1999), and 'federated unit' (Soldatos 1990). Despite these terms serving as acceptable synonyms for the concept, the term 'subnational government' is more concise and widely-used.

As with nation states, subnational governments are not monolithic; instead, they may encompass a superagency and a range of sub-actors attempting to pursue their own external interests. In the case study chosen, relevant sub-actors are the provincial leaders 
and bureaucrats of Yunnan. Although they habitually take orders from the central government, these people are either chief provincial policymakers or implementers. To some extent, both could exert substantial influences on the execution and orientation of provincial external agendas. At the top of the provincial organizational structure are the Party Secretary and the governor of the provincial government, both of which are considered primary decision-makers, although the Party Secretary is more powerful than the governor. Additionally, the vice-governor tasked with external affairs is treated as a main actor. The provincial-level agencies in this field include a few small provincial leading groups, led by the governor or vice-governor and composed of the heads of relevant provincial departments. These groups are the Yunnan provincial Small Leading Group on Foreign Affairs (SLGFA), the Yunnan Commission for Investment (CFI), and the provincial Coordinating Small Group of Lancang-Mekong Cooperation. Below the provincial-level agencies are various departments that participate in the creation or execution of Yunnan's external policies. Affiliated either to the provincial Party Committee or to the provincial government, these agencies are the Yunnan provincial Foreign Affairs Office (FAO), the Department of Commerce (DOC), the Development and Reform Commission (DRC), the Foreign Trade and Economic Cooperation Commission (FTEC), the Investment and Cooperation Bureau (ICB), the National Security Department (NSD), and the Overseas Chinese Affairs Office (OCAO). One deputy department-level agency to be studied is the International Regional Cooperation Office (IRCO).

\subsection{Analytical Framework \& Case Selection}

Few conceptual frameworks account completely for the international actorness of a subnational government - the inherent characteristics of a subnational entity as an international relations player - within either federal or unitary systems. Considering the limitations of the earlier analytical frameworks within paradiplomacy studies, this thesis puts forward a four-dimensional analytical framework to combine the concept of paradiplomacy and the theory of actorness. These dimensions incorporate both internal and external aspects related to the paradiplomacy of Yunnan, as indicated in Table 1.2. Some of these dimensions are less explored, while others are widespread. However, considering that none of these dimensions has been discussed in the context of China, a separate chapter is dedicated to each of them. 
Table 1.2: The analytical framework

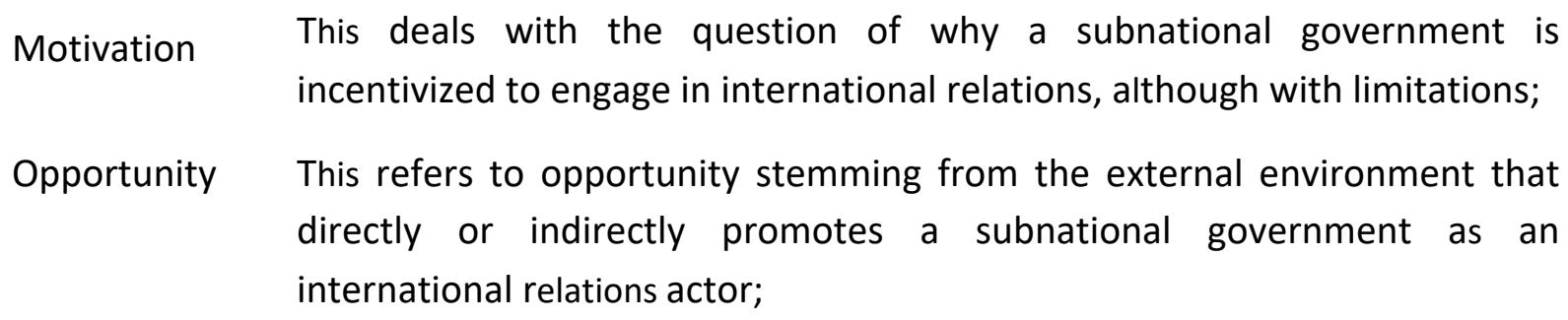

Capability This indicates the strengths of a subnational government to incentivize foreign countries to cooperate with it;

Presence This concerns the external and internal recognition of subnational governments as international actors by third parties.

Through the case of Yunnan, this four-dimensional analytical framework provides a structure for the thesis. Chapter 4 provides an overview of the powers of Yunnan within international relations, with a focus on the question of why the central government has provided Yunnan with limited external affairs powers from an internal angle. The limitations of this power are also discussed. Chapter 5 discusses the influence of the external environment on the engagement of Yunnan in international relations, concluding that external opportunities have shaped the role of Yunnan in foreign affairs through the involvement of the central government which encountered the changing regional situation, the burgeoning of transnational regionalization, the pressure of international institutions, and the competition with extra-regional powers. Chapters 6 and 7 assess the last two dimensions of actorness - capability and presence - and respectively address the questions of how Yunnan encouraged neighbouring countries to work with it, and how its international actorness has been recognized by the third parties.

The analytical framework in this thesis is empirically applied to the single instrumental case study - the cross-border paradiplomacy of the province of Yunnan since the early 1990s. The selection of this case study follows several criteria. First, the thesis expects to cover all the four dimensions of actorness. After a preliminary review of the literature, Yunnan is widely believed to have more established, comprehensive cross-border connections, when compared with Xinjiang, Tibet, and Guangxi. The second criterion relates to logistical 
considerations. Compared with other border provinces, whose external interactions are often highly politicized and confidential, Yunnan provides relatively open, convenient data access for independent researchers, especially from overseas institutions. Furthermore, the author maintains a good network with governmental officials, semi-official think tank members, and university academics in Yunnan, which is very helpful for the collection of data.

Located in the far south of China, Yunnan is one of the 34 provincial-level jurisdictions, which include 23 provinces, 4 municipalities, 5 autonomous regions, and 2 special administrative regions (Figure 1.1 and Appendix 2). With an area of 394,100 square kilometres, Yunnan is the $8^{\text {th }}$ largest province in China, occupying 4.1 per cent of the country's surface. Domestically, the province is adjacent to four provincial-level entities, with Guangxi and Guizhou in the east, Sichuan in the north, and Tibet in the northwest. The province consists of 16 prefecture-level entities, which can be divided into 8 prefecture-level cities and 8 autonomous prefectures (Figure 1.2). Yunnan has a population of 46 million people, ranking $12^{\text {th }}$ among the Chinese provincial entities, almost 40 per cent of whom are members of ethnic minorities. This demographic condition makes Yunnan the most ethnically diverse region in China. The influential ethnic groups located in Yunnan involve Yi, Bai, Hani, Tai, Dai, Miao, and more. Some of these peoples straddle the international border. 


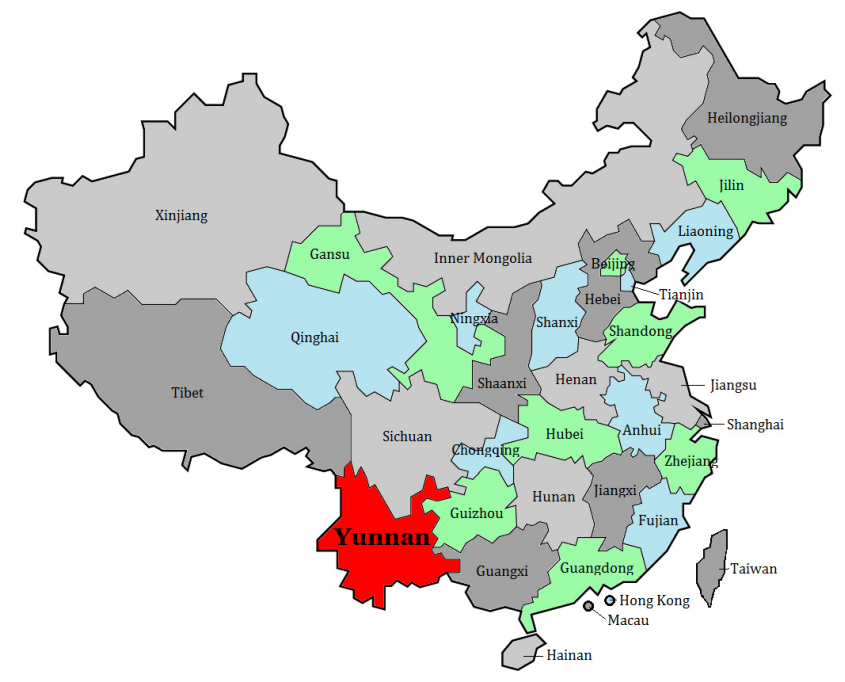

Figure 1.1 Map of China - highlighted is the province of Yunnan

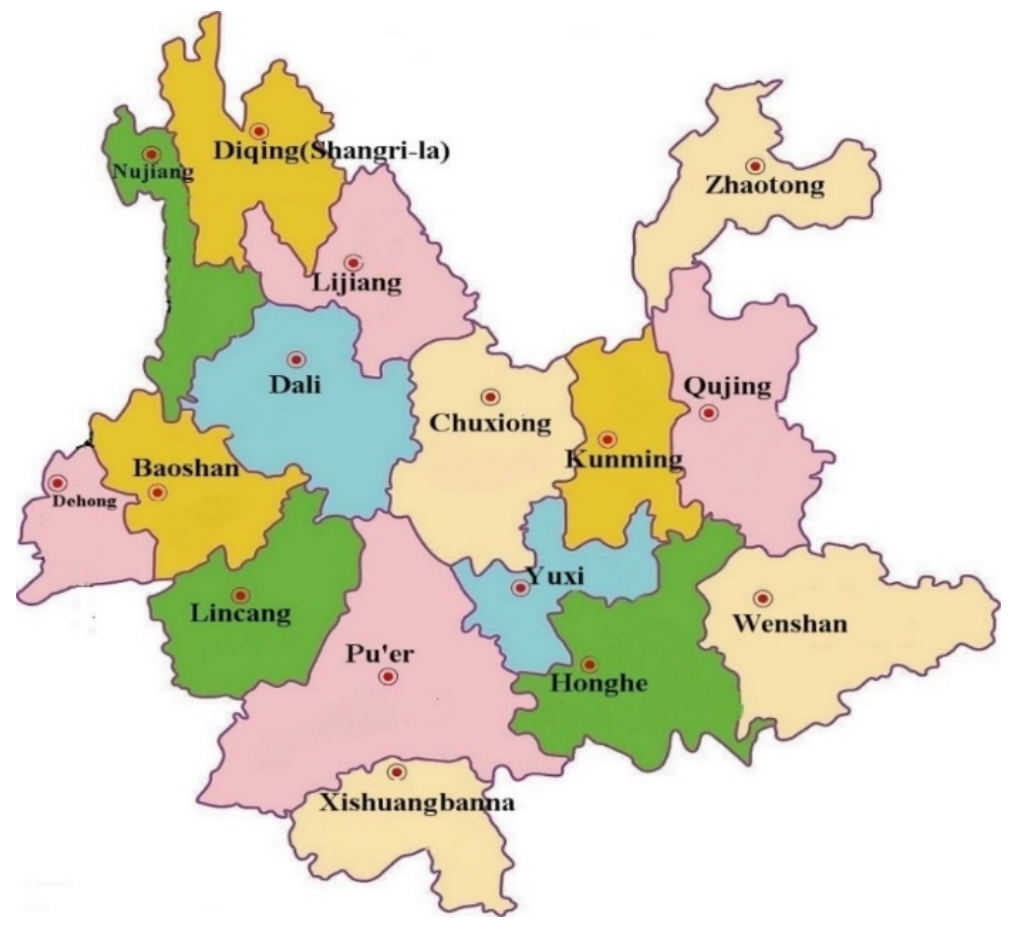

Figure 1.2 Political administrative map of the province of Yunnan

Yunnan shares a 4,060-kilometre-long border with Myanmar in the west and Laos and Vietnam in the south; Thailand and Cambodia are also reachable over land or via the Mekong River (Figure 1.3). This locational condition has allowed Yunnan to have a strong international focus, which is evident in its cross-border cooperation in investment. Thus far, Yunnan has been the top recipient of investment from the Indochinese countries. One year after the founding of the Great Mekong Subregion (GMS) economic cooperation 
programme, a regional programme involving six countries in the Mekong Basin, Yunnan has achieved a visible improvement in attracting foreign funds: actual investment in Yunnan from these countries has surged to US\$165 million, twice the actual investment it received over the previous 9 years (Yunnan provincial government 1994). The number of projects funded by Thailand and Myanmar rose to 23 and 39 respectively, with most of these in the industrial and service sectors (Yunnan provincial government 1994). During the following years, the GMS members continued to be the primary investors in Yunnan, among the Southeast Asian countries: of the 34 projects funded by Southeast Asian countries during 2001 and 2002, 21 were from the GMS countries (Yunnan provincial government 2002, 2003).

Since the mid-1990s, the top three destinations for Yunnan's investment have also been the countries in the Mekong subregion. Together, they received 84 per cent of Yunnan's overall investment, with 77 per cent of the newly-launched Yunnanese overseas enterprises located there (Yunnan provincial government 2010). Laos was the biggest single recipient of Yunnan's funds. During 2000 and 2006, the province invested US\$72.56 in the Laotian rubber plantation industry (Yunnan provincial government 2001-2006). In 2010, it also agreed to invest in the megaproject of That Luang Lake in the centre of the Laotian capital, Vientiane (although the biggest OFDI project carried out by Yunnan was to fill the Boeung Lake in the capital city of Cambodia, Phnom Penh, to make way for lucrative commercial developments) (Qu 2008). The momentum of Yunnan's OFDI in neighbouring countries was sustained during the 2008 economic crisis, with its actual OFDI to these countries climbing to US\$270 million in 2009, a tenfold increase when compared with 2005 (Yunnan provincial government 2006-2010). 


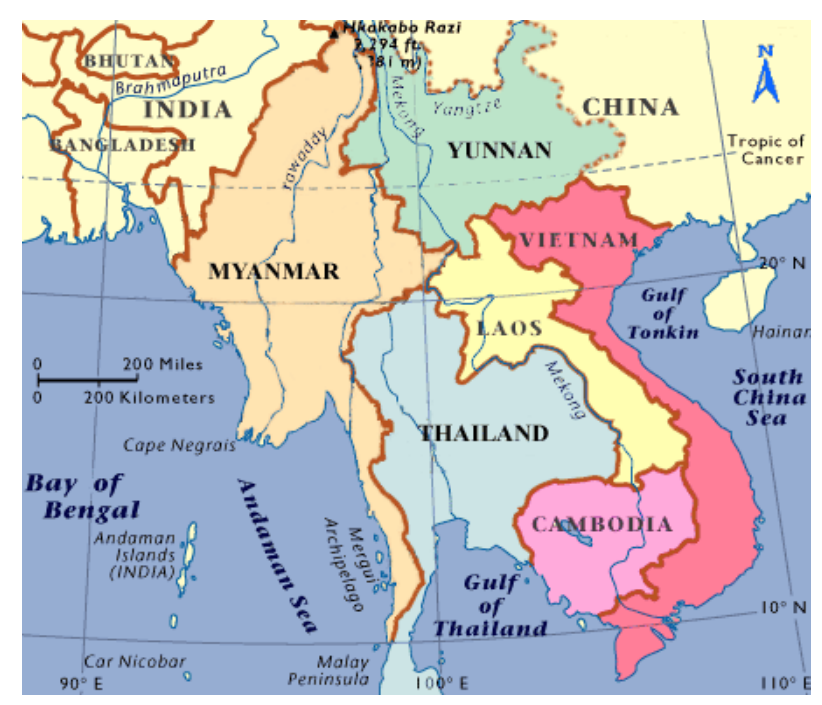

Figure 1.3 Map of Yunnan and the Indochinese Peninsula

It should be mentioned that the economic exchanges between Yunnan and the neighbouring Indochinese countries have produced some negative effects, which had to be patched up through cooperation. Yunnan was the most convenient passage for illicit drugs from the Golden Triangle, the globally notorious drug production centre in mainland Southeast Asia, to the market in China (Su 2015). As a consequence, the province has become a home to half of the registered drug addicts in China. It is against this background that Yunnan and neighbouring countries have agreed to conduct joint anti-drug campaigns and an opium substitution programme. In addition, stability in the border region of Yunnan has occasionally been affected by sporadic conflicts between ethnic minority armed groups in northern Myanmar and Tatmadaw, the Myanmar Armed Forces (MAF). Yunnan has engaged with all the relevant factions in Myanmar in the course of peacebuilding. The province was also delegated by the central government to provide necessary humanitarian support to refugees entering Yunnan.

\subsection{Relevance}

Dedicating a thesis to the study of paradiplomacy of a border province in China allows for an in-depth exploration of this phenomenon. Although cross-border cooperation is not new for China's provinces, it remains inadequately explored. At the time of commencing this research, there was a dearth of works on this topic (Yahuda 1994; Lampton 2001; Su 2012; Summers 2013; Li 2014; Mackerras 2015). The following section introduces the theoretical, methodological, and empirical relevance of this thesis. 
With regard to theoretical contributions, first, the thesis advances the previous research on the engagement of Chinese subnational governments in international relations. To date, scholarly interest in the paradiplomacy of Chinese provinces has been relatively scant. The exploration of the international actorness of Yunnan in this thesis further provided an opening to an understanding of the paradiplomacy of Chinese border provinces, a rather undervalued phenomenon. Second, as China was considered highly centralized and restrictive, it was assumed that Chinese border provinces had neither the external affairs powers nor the diplomatic resources to engage in international relations. Through analysis, this thesis found that, at least in Yunnan, the Chinese provinces are able to derive a certain amount of external affairs powers, even though they are not semi-autonomous or discrete entities, as the central government has the ability to lend or take back any delegated power anytime.

The methodological implications of this thesis can be found in three aspects. First, the thesis proves that the selection of a single case study can be used for advancing the understanding of a general picture of paradiplomacy in an examined country. Related to this point, the thesis entails new thoughts on the use of sampling in paradiplomacy studies. Although random sampling should reduce bias and subjectivism, purposive sampling can facilitate the inferential process by enabling researchers to choose the most typical cases, and therefore derive more generalized knowledge. Third, compared with the existing literature based on other studies of the external interactions of Yunnan, this thesis has the great advantage of access to government officials and local experts who have the ears of provincial policymakers. Neither did previous studies acquire data from diplomats and experts in the Indochinese countries and key regional institutions.

When it comes to empirical implications, for Yunnan and other Chinese border provinces, their successes in the pursuits of external interests depend on their cooperation with Beijing. However, this is not to say that these provinces are merely passive recipients with little room to manoeuvre within external relations. Given that there was no opportunity for border provinces to capitalize on their external linkages to seek separation, the central government is expected to devolve greater foreign affairs powers to border provinces whose interests in and familiarity with border-related issues are hard to match by the central government. Neighbouring countries are expected to take good advantage of the 
growing external activism among Chinese border provinces alongside their state-to-state diplomacy vis-à-vis Beijing, and redouble their cooperation with these provinces in the construction of cross-border projects, thus avoiding pressure stemming from domestic resistance in the event of their direct cooperation with the Chinese central representatives.

\subsection{Structure of the Thesis}

This thesis is composed of eight chapters. Chapter 1 is an introduction to and an outline of this thesis on the international actorness of Yunnan. It provides background to the study of paradiplomacy, identifying the main gaps in the research, and setting out the objective of the study. This chapter also sets out a research question, hypotheses, and the establishment of a four-dimensional analytical framework based on the concept of paradiplomacy and the theory of actorness. It further introduces the fundamental information about Yunnan. This introductory chapter then describes the implications of this thesis in both theoretical and empirical terms and concludes by presenting an outline of a thesis structure.

Chapter 2 presents a review of the literature and theoretical framework in detail. First, three strands of literature related to paradiplomacy are reviewed and evaluated. These involve the challenges to the state-centric approach, the emergence of non-nation-state actors, and the evolution of paradiplomacy as a sub-discipline of IR. The objective of this review is to map the main theoretical issues and themes within this research area and to uncover some research gaps. It is demonstrated that although existing scholarship has provided invaluable insights on subnational governments taking part in international relations, this literature could not fully account for this phenomenon within the Chinese context. Subsequently, this chapter outlines the limitations of previous efforts in constructing an analytical framework to investigate the international actorness of subnational governments. The final part of this chapter provides a four-dimensional analytical framework to combine the concept of paradiplomacy and the theory of actorness.

In Chapter 3, the methodological approach of this thesis is outlined. This chapter explains the selection of the case study approach. Some relevant questions are addressed, concerning what a case study is, why use a single case, and why the qualitative approach was chosen to analyse the case. This is followed by the introduction of the data collection methods employed in this research: interview, content analysis, and participant observation. 
Special attention is extended to the peculiarities of interviewing elites who are governmental officials, academics, and think tank members in Yunnan and its neighbouring countries, all of whom contributed a great deal to the completion of this project. This chapter concludes by raising some ethical considerations.

The subsequent two chapters (Chapters 4-5) are concerned with the first two dimensions of actorness - its motivation and opportunity. Chapter 4 argues that Yunnan has been incentivized to conduct paradiplomacy through the decision of Beijing to open borders, the inefficiency of the central government in managing macroeconomic and border issues, and the growing competition with Guangxi Zhuang Autonomous Region (hereafter Guangxi) over economic influence in the Mekong subregion. Chapter 5 turns to the second dimension of opportunity, arguing that external opportunities have shaped the cross-border paradiplomacy of Yunnan in an indirect manner, mostly through the central government. These challenges were presented by the improvement of the regional situation in the Indochinese peninsula, the burgeoning of transnational regionalization in Southeast Asia, the pressure from international institutions, and competition with extra-regional powers.

Chapter 6 explores the third dimension of the actorness of Yunnan - capability - to address the question of how Yunnan has incentivized neighbouring countries to cooperate with it. The research finds that Yunnan has leveraged three broad instruments for this purpose. These instruments are infrastructure development, economic statecraft, and diplomatic efforts. On the infrastructural side, Yunnan has substantially invested in the building of a cross-border transportation infrastructure. On the economic side, Yunnan has taken advantage of its autonomy in foreign trade and investment to enhance economic interdependence between itself and neighbouring countries. And, lastly, on the diplomatic side, Yunnan has capitalized on the conducting of foreign visits and receptions, the establishment of sister-province relationships, and engagement in outreach to the overseas Chinese to expand its network in neighbouring countries. All these instruments are indispensable for Yunnan to raise its attractiveness for neighbouring countries. The chapter concludes by addressing the question of whether Yunnan, with burgeoning external influence, would be likely to seek secession from China.

Chapter 6 reveals that Yunnan has made use of three broad instruments to influence the decision-making of neighbouring countries, Chapter 7 further explores how the province has 
leveraged its increased external capability to achieve recognition as an international actor by the third parties. For one thing, this chapter argues that the international stature of Yunnan can be deduced from the actions of external partners. By allowing Yunnan to sign international agreements, to join multilateral institutions (such as the GMS and the Mekong Institute), and to engage in regional economic exchanges, the entities in the Mekong subregion recognized the role of Yunnan as an international player. Also discussed is how the Chinese central government has recognized Yunnan's role in both pursuing its own its interests and assisting Beijing in handling various border-related issues. This can be deduced from the fact that the central government has approved Yunnan to send representatives in national delegations to certain international occasions, to organize high-profile external events, to manage some border-related controversies, and to cooperate with neighbouring countries to establish various types of cross-border economic zones.

Chapter 8 concludes by arguing that the test of the four hypotheses introduced in Chapter 1 provides an opening to an understanding of the international actorness of Chinese border provinces through the case of Yunnan, made possible using an analytical framework which combines the concept of paradiplomacy and the theory of actorness. Following the demonstration of the main arguments of the thesis, the theoretical, methodological, and policy implications of this thesis are outlined. The last part of this chapter sets out future research directions for understanding the paradiplomacy of China and its foreign policies toward neighbouring countries. 


\section{Chapter 2}

\section{Literature Review \& Analytical Framework}

\subsection{Introduction}

This chapter looks at how, during the last three to four decades, the study of paradiplomacy has evolved. The scholarly works on this phenomenon were at first concerned with the United States and Canada and then covered the European continent and beyond. As identified in the Introduction, three strands of literature have direct relevance to the analysis of the paradiplomacy of Chinese border provinces. Therefore, this chapter reviews the following streams of scholarly works: IR works on the challenges faced by nation states, the theoretical scholarship on the emergence of non-state actors in international relations, and the theoretical and empirical literature concerning paradiplomacy in the world in general, and in China in particular.

The literature review suggests that the existing scholarship has provided invaluable insights on subnational governments taking part in international relations; however, it has failed to account fully for this phenomenon. This limitation means that the topic of external interactions conducted by subnational governments has received little attention, in comparison with other non-state actors; the aspects which constitute the full picture of paradiplomacy have not been exhaustively explored; paradiplomacy studies have been mostly based on Western country cases; the analyses of subnational foreign agendas in unitary, centralized states have been insufficient; the works on Chinese paradiplomacy have overwhelmingly been contextualized within the central-provincial frameworks; and the preponderance of the works on Chinese paradiplomacy have been concerned with better-off coastal regions rather than border regions.

Taking into account these shortcomings, this research is aimed at addressing the question in relation to international actorness - a comprehensive set of characteristics of being an international relations actor - inherent in Chinese border provinces. Furthermore, to tackle this question more systematically, an appropriate analytical framework is indispensable. Few existing analytical frameworks within paradiplomacy scholarship are satisfactory. In general, 
the weaknesses of these analytical frameworks include focusing only on one or two aspects of paradiplomacy without presenting a complete picture of the international actorness of subnational governments, and also not being very applicable to cross-border paradiplomacy. Therefore, this thesis combines the concept of paradiplomacy and the theory of actorness to develop a framework that seeks to overcome the above shortcomings and help analyse the international actorness of Yunnan, a Chinese border province, through the prisms of authority, opportunity, capability, and presence. These four dimensions have not been derived from scratch, but based on the awareness of bodies of theoretical and empirical works on paradiplomacy and actorness. This four-dimensional analytical framework structures the whole thesis.

Following this brief introduction, Section 2.2 reviews the body of works on the challenges to nation states in international relations, thereby presenting a general picture within which numerous non-state actors, especially subnational governments, have formulated their own foreign agendas. The blows to nation states, including the end of the Cold War (Subsection 2.2.1), the acceleration of globalization (Subsection 2.2.2), and of decentralization (Subsection 2.2.3) are each discussed, respectively. This literature review continues to look back at how mainstream IR theories, such as neorealism and neoliberalism, respond to the emergence of non-nation state actors. The evolution of paradiplomacy studies is traced in Section 2.3 from its origin in the United States and Canada in the 1970s, to its development in European countries in the 1980s and 1990s, and to its extension to more non-Western states around the turn of the century. Given the research question of this thesis, more critical scholarly works on paradiplomacy in China are reviewed in this section. After assessing the relevant literature, the limitations on these scholarly works are identified and elaborated in Subsection 2.3.4. The last part of this chapter sets out the four-dimensional analytical framework in detail in Section 2.4.

\subsection{Literature Review}

\subsubsection{Challenges to the State-Centric Approach}

This section aims to review the scholarship that analyses the challenges faced by the statecentric approach in IR studies. In so doing, it provides a general context within which numerous non-state actors, including subnational governments, have formulated their own 
foreign agendas. The following sections discuss three factors that are widely believed to account for the demise of the nation state as the sole international actor: the end of the Cold War, the acceleration of globalization, and regionalization.

\subsubsection{End of the Cold War}

Classical realists have held that nation states tended to be exclusive international actors. However, the détente between the United States and the Soviet Union partly led to a blurring of distinctions between so-called high and low politics (Manning 1977). International actors were no longer limited to nation states, but "proliferated in number far beyond anything remotely existing in the past; individually grew in size far beyond anything existing in the past; performed functions which they never performed in the past; and operated on a truly global scale such as was never possible in the past" (Huntington 1973: 333).

This phenomenon was also widely discussed among neoliberals. For instance, Robert Keohane and Joseph Nye (1973) revealed the appearance of the 'transnational relationship' during this period. This refers to "contacts, coalitions, and interactions across state boundaries that are not controlled by the central foreign policy organs of government" (Keohane and Nye 1973: xi). Within the networks of a 'transnational relationship', the global paradigm is modified into one constituted by nation states with myriad non-nation state transnational actors. This view is echoed by Seyom Brown (1974) who further identified the existence of 'polyarchy' in global society, where "nation-states, subnational groups, and transnational special interests and communities would all be vying for the support and loyalty of individuals" (Brown 1974: 186).

Years later, the détente between Washington and Moscow came to an end when both sides ratcheted up defence budgets and relaxed nuclear arms control. Largely for this reason, a scholarly debate was rekindled between the view that nation states remain primary in a global system (Waltz 1979) and the view that developments in the international economy and institutions permanently overshadow the predominance of states (Ruggie 1986). This debate was sustained from the late 1980s, when non-nation state actors became more evident in international affairs, whereas the end of the Cold War increased the number of nation states. 
In the post-Cold War years, although a handful of scholars, such as John Mearsheimer (1990), reiterated the function of nation states as watchmen within the anarchic international system, more saw nation states as no longer predominant. They contended that the bourgeois-constitutional order was built as the top stage of social order and that authoritarian states were in decline worldwide (Fukuyama 1992). Some scholars were of the view that nation states had started to decline as international actors, especially in Europe, which was in the process of economic and political integration, despite the violence in the Balkans after the dissolution of Yugoslavia (Wunderlich 2008). Some even asserted that nation states were no longer the centre of global conflicts and had little capability to solve them, in that the post-Cold War conflicts were primarily motivated by civilizational as opposed to commercial or ideological forces (Huntington 1996).

\subsubsection{Acceleration of Globalization}

The second force leading to the weakening of the state-centric approach has been globalization. Despite the daily usage of the term 'globalization', it does not have a universally agreed definition. Some oft-cited definitions depict globalization as a process which "embodies a transformation in the spatial organization of social relations and transactions - assessed in terms of their extensity, intensity, velocity, and impact generating transcontinental or interregional flows and networks of activity, interaction, and the exercise of power" (Held et al. 1999: 16). Or, in the words of George Ritzer (2016: 1), globalization means "an accelerating set of processes involving flows that encompass evergreater numbers of the world's spaces and that lead to increased integration and interconnectivity among those spaces." By some other scholars (Luard 1990; Rosenau 1997; Giddens 2000), globalization is simply referred to as a process bringing radical changes to existing social structures.

Driven by economic interdependence and volatile global circumstances, in the 1990s, such norms as sovereignty and nationalism were lacklustre, although the opposite seems true today as protectionism is rising, the EU is in disarray, and globalization is under attack. Back then, nonetheless, "the impersonal forces of world markets, integrated over the post-war period more by private enterprises in finance, industry and, trade than by the cooperative decision of governments, are now more powerful than the states to whom ultimate political authority over society and economy is supposed to belong" (Strange 1996: 4). The role of 
nation states as a 'middleman' between enterprises and global markets was eclipsed by the booming of multinational corporations with borderless exchanges of commodities, investment, individuals, and information (Ohmae 1995).

A debate between hyperglobalizers and sceptics of globalization heated up in the late 1990s. The former believed that globalization publicized knowledge that used to be exclusively possessed by nation states and thus affected their authority, especially in foreign affairs (Giddens 2000). Nonetheless, a group of scholars took issue with these hyperglobalizers by arguing that the current phase of globalization is neither new nor distinctive, but that it is merely a continuation of the longue durée of the development of the capitalist economy dominated by nation states (Sachs and Warner 1995; Rodrik 1998). In the words of Nick Bisley (2007: 68), for instance, "globalization does not present a fundamental challenge to the political and moral dominance of the practice of modern statehood, rather it provides circumstances which contribute to a slight strengthening of the international position of the state." Bisley further claimed that had nation states lost their lustre, people from the former Soviet Union, East Timor, and Palestine would have treated states as a passé system of political rule, rather than the other way round.

\subsubsection{Regionalization}

The tendency towards regionalization has further dealt a blow to the role of nation states in international relations (Baylis, Smith and Owens 2008). With the aim of establishing regional cooperative and integrative mechanisms, regionalization would not constrain globalization. Instead, regionalization, to some extent, could solve the glitches stemming from globalization, and thus further stimulate its progress (Baylis, Smith and Owens 2008). For example, the first wave of regionalization occurred in Latin American countries, which attempted to adopt import substitution policies to rid themselves of excessive dependence on exports of primary commodities, which has been brought about by the globalized economy. However, it is the second wave of regionalization that has attracted more scholarly attention.

Named 'new regionalism', the second wave originated in the late 1980s, against the background of US economic influence declining from a third to a quarter of world economic output, international trade booming dramatically, and transnational corporations growing 
commercially and politically (Keating 2000; Schirm 2002; Grugel 2004). Compared with the previous wave of regionalization, 'new regionalism' has produced greater global influences and led to the emerging number of regional cooperation mechanisms built to promote peace and socioeconomic cooperation (Hettne 1999). It not only marks the beginning of more regional mechanisms taking a role on the international stage, but also makes it difficult for national governments to continue their exclusive industrial policies or the creation of national 'champions' (Hurrell 1995).

The most evident blow dealt by 'new regionalism' to nation states can be found in the case of European integration. In order to weaken the predominance of the state-centric orthodoxy and make itself more globally influential, the EU integrated the functions of three executive bodies - the European Economic Community, the European Community for Steel and Coal, and the European Atomic Energy Community, while establishing the Customs Union and releasing the Werner Report on Economic and Monetary Union (EMU). The adoption of the Davignon Report on European Political Cooperation (EPC) even directly called for greater participation in EU projects by the subregions within the member states (Doidge 2008).

\subsubsection{Emergence of Non-State Actors in International Relations}

As foreign policy is no longer the preserve of nation states, a 'great transnational revolution' has taken place in IR theory since the early 1970s. The following section discusses how IR scholars interpret the emergence of non-state actors on the international scene. In retrospect, classical realists employed the rational/unitary actor model in analysing the making of foreign policies (Ripsman, Taliaferro and Lobell 2016). It was not until the appearance of neoclassical realism that the participation of non-state actors in international relations came to be acknowledged. Neoclassical realists argued that the messages from the global system received by nation states have to be translated through various domestic international relations actors, such as policymakers, executive branches, and interest groups, before being worked out as a foreign agenda (Posen 1986; Walt 1990; Snyder 1991; Evera 1999).

Neoliberals have explicitly pointed out that a slew of non-state actors are active in international affairs. For example, by dividing the external activities by non-central 
governments into transgovernmental relationships and transnational relationships, Robert Keohane and Joseph Nye (1974: 41) explained that, in the former type of relationship, a variety of sub-units of government agencies engage in international relations autonomously from the higher authorities, while the latter type is limited solely to nongovernmental actors. Both types of relationships can find expression in the interactions between the United States and Canada, as "different issues are handled by separate bureaucracies, frequently without central coordination from foreign offices or politically responsible officials" (Keohane and Nye 1974: 595-597).

The influence of domestic actors on foreign policy outputs has been studied in particular by Innenpolitik theorists, who have contended that the theoretical works dedicated to the question of how internal actors within nation states, such as political parties, economic agencies, and grassroots, shape their foreign relations are inadequate. The Democratic Peace Theory is one of the prominent theories within Innenpolitik. After investigating the major conflicts in the world after 1815, the Democratic Peace theorists pointed out that no wars took place between two democratic countries (Spiro 1994; Farber and Gowa; 1995; Gowa 2011). The reason consists chiefly of the influence of a slew of domestic actors from democratic countries in foreign affairs, although in an indirect way. More accurately, democracies would like to bow to pressures from their social institutions and interest groups, which prefer to avoid wars and to seek alliance with other democracies, and dislike staging conflicts at the cost of their citizens (Doyle 1983). However, this theory is not convincing in explaining why democracies occasionally enter into war with non-democracies; nor does it disaggregate the domestic structures within democracies (Peterson 1995; Elman 2000).

The linkage between one country's diplomatic output and its domestic actors continues to be generalized within the two-level game theory. Robert Putnam (1988) examined the impact of a country's lawmakers on the performances of its delegations to the negotiation table. By naming the degree to which factions within a congress reach a consensus ' win-set', Putnam suggested that the larger the 'win-set' within each signatory country, the higher the likelihood is of an international deal being concluded. That is to say, if a deal were to be less favourable than the minimum expectation of the lawmakers of a country, its negotiators may pull out of the meeting, much less bring the deal home for ratification. Negotiators can thus take advantage of the scale of 'win-set' to exchange for an advantage in bargaining. For 
instance, they may ask for more concessions during the negotiation by reiterating the difficulty facing them in having a deal approved at home.

Within empirical works, countless domestic international relations actors have been identified. In some authoritarian countries, their adversary or isolated foreign policies were largely determined by the attitudes of governing elites who control the politics, economy, and civil society of their country. For example, Russian political elites saw Moscow's national foreign agenda as less a regime strategy than an embodiment of their determination to monopolize the state and economy for personal power and wealth (Wallander 2007). And in North Korea, its capricious policies toward South Korea and some great powers are caused by its supreme leader and other senior leaders of the Korean Workers' Party (KWP) (Kim 2007).

Ruling elites in democratic countries are also very influential in international relations. The influence of the then-Prime Minister Najib Razak and other elites within the United Malays National Organization (UMNO) over Malaysia's choice to tilt toward the United States is a telling instance. This is because Najib and his followers believed that they had to rely on Washington to improve the country's economic performance and to claw back the support extended by the United States to their opposition forces led by Anwar Ibrahim (Kuik 2013). It is also the case in South Korea, whose Presidents have always played a disproportionate role in national foreign relations, especially North Korean policies (Kim 2007).

The participation of opposition parties, governmental agencies, and interest groups in international relations has been discussed, although many of these adopt an indirect approach. The existence of powerful opposition parties in Japan and India, for instance, narrowed the space for their Prime Ministers to enact foreign policies (Mohan 2007). In Japan in particular, although partisan politics affected Tokyo's pursuit of united diplomatic goals, it was useful in preventing the country from adopting excessively tough or excessively soft policies toward neighbouring countries, especially China and South Korea, which had maintained sensitive relationships with Japan (Mochizuki 2007). The relationship between the executive and the legislature within a country can shape its foreign relations too, especially in North American and European countries (Milner 1997). Thus, international cooperation might take place more smoothly should the administrative bodies within a country have no need to share the decision-making power with the legislature or should 
they share information more transparently. Regarding the influence of domestic interest groups, this is evident in the case of Russia. Despite the strong authority of the Putin administration, Moscow's China policy has been constrained by powerful interest groups: on the one hand, Russian energy oligarchies encouraged the Kremlin to be more engaged with China; on the other hand, the Kremlin faced pressure from a military-industrial network which is troubled by the growing fear of China (Wallander 2007).

With reference to civil society and grassroots organizations, East Asian countries provide some typical instances. Seen from the cases below, civil societies and grassroots could exert their utmost influences on national foreign policymaking when they remind state leaders of the parameters of foreign policies and the dangers of overstepping them. As the Japanese public was strongly opposed to any attempts to circumvent the Article 9 of the Constitution, which prevents the country from resorting to war, Tokyo decided not to take any military role in the Gulf War (Noureddine and Ismail 2017). Likewise, the growing anti-American sentiment among the new generation of South Koreans complicated Seoul's handling of its alliance relationship with Washington (Kim 2007).

\subsubsection{Paradiplomacy Studies as an IR Subdiscipline}

This section examines paradiplomacy literature. As mentioned above, the state-centric approach that sees the nation state as the primary and even sole international actor has been challenged by the end of the Cold War, the acceleration of globalization, and regionalization. Along with this tendency, scholarly interests have shifted to the participation of non-nation state actors in international relations in both direct and indirect ways. However, few theoretical and empirical works since the 1970s have mentioned subnational governments, and what they have discussed is mainly limited to national-level actors, such as sub-units of ministries (Keohane and Nye 1974), legislature (Milner 1997), officials in national governments (Slaughter 2004), and state-run oligarchies (Wallander 2007). Given that not many works account for the external activities carried out by subnational governments, the literature on paradiplomacy provides a lens to understand this phenomenon instead.

Investigation into the role of subnational governments as international players has experienced three distinct phases. The first phase marked the inception of paradiplomacy 
studies in the 1970s. At the time, almost all influential studies were based on the United States and Canada. The 1980s saw the start of the second phase, and progress in the quality of paradiplomacy studies. Despite the fact that most notable paradiplomacy scholars still came from North America, new cases based on paradiplomatic initiatives in European countries started appearing. This phase also saw the efforts of paradiplomacy scholars to theorize and conceptualize this phenomenon. The cases selected during the first two phases, however, were limited to subnational governments in Western federal states. Only after the early 2000s did the scope of research extend to non-Western federal and unitary states.

More accurately, the genesis of paradiplomacy studies began in the early 1970s, with a focus on cases in North America (Atkey 1970; Leach, Walker and Levy 1973; Holsti and Levy 1974; Roff 1978). The reasons for this North America-centric approach are twofold. First, it was stimulated by the 'new federalism' policies put forth by the Richard Nixon administration. The rationale behind this new doctrine was to redistribute governmental functions between the federal government and state governments, including the functions of handing external issues (Nathan 1975; Conlan 1988). Secondly, scholarly interests in North America were stimulated by the independence movement in Quebec. This can be traced back to the 1960s when a liberal government under Jean Lesage launched the Quiet Revolution in Quebec (Bélanger 2000). The main goal of this revolution was for Quebec to achieve full rights to conclude international agreements. Consequently, not only did Quebec gain access to treatysigning power, but it was also allowed to set up provincial missions in many cities around the world (Lalande 1973). However, it has to be pointed out that the works produced during this period were more concerned with describing how subnational governments lay claim to international competence rather than conceptualizing this new phenomenon (Kuznetsov 2014).

It was not until the 1980s, the second phase of paradiplomacy studies, that scholars started shifting their focus from description and case studies to making theoretical and terminological contributions. This phase firstly witnessed attempts to find a proper term to describe the phenomenon where subnational governments engage in external interactions. The term paradiplomacy was originally coined by Panayotis Soldatos (1990). However, it does not mean that there had been no paradiplomatic activities before. As has been shown, academic works discussing the international role of subnational government even started to 
appear in the 1970s, but these were poorly conceptualized and lacked a specific term back then.

Although widely accepted, this notion of paradiplomacy was challenged by other academics. The most vigorous critic was John Kincaid (1990) who proposed replacing the notion of paradiplomacy with constituent diplomacy. For Kincaid, paradiplomacy implies that the diplomacy of subnational governments was undoubtedly inferior to that of federal governments because of its origin in parallel diplomacy. This view is shared by Brian Hocking (1993: 69). In proposing the use of the term multilayered diplomacy, Hocking contended that paradiplomacy fails to acknowledge subnational governments that "are capable of performing a variety of roles at different points in the negotiating process... and may become opponents of national objectives, but, equally, they can serve as allies and agents in pursuit of those objectives." Ivo Duchacek (1990) suggested using microdiplomacy to describe this phenomenon.

The concept of paradiplomacy per se was further substantiated during this period. It was once categorized as transborder regionalism and global micro-diplomacy (Duchacek 1984). The difference between the two is that the former takes place among neighbouring countries, while the latter exists far beyond neighbourhood and establishes contact with distant foreign states or subnational governments. A more sophisticated categorization was subsequently produced when different types of global micro-diplomacy were added (Duchacek 1990). The concept of transregional paradiplomacy was coined to refer to international relations between subnational governments that are not neighbours, but whose nation states are, while the concept of global paradiplomacy was proposed to represent the direct engagement between provinces with distant foreign partners. Paradiplomatic activities were further divided into policy segmentation (PoS) and actor segmentation (AS) (Soldatos 1990). PoS refers to the efforts to shape national foreign policy by subnational governments, while AS means their direct participation in international relations. AS can supplement PoS, whereas PoS does not necessarily lead local governments to engage in foreign affairs directly.

In the following years, interactions between paradiplomacy and national diplomacy were discussed. On the one hand, it is argued that the reason why subnational governments have become more interested in engaging with foreign partners is because their central 
authorities failed to effectively promote their local external interest through the established diplomatic channels of the state level (Keating 1999). On the other hand, some are opposed to this argument, refuting it by suggesting, for example, that "such a belief ignores the processes which are rendering the boundaries demarcating state and non-state actors far more permeable than hitherto and creating ambiguities about the status and characteristic of each" (Hocking 1993: 3). In the cases of many European countries, Francisco Aldecoa (1999) further identified the existence of 'double loyalty' in these countries. This phenomenon means that the "Foreign agenda of the state must pay attention to the international needs of the regional government... (and) regional governments must respect the state's position when forging their own external policies" (Aldecoa 1999: 92). To some extent, national diplomacy could benefit from paradiplomatic activities in terms of smoothing out ethnoterritorial conflicts, prompting regional cooperation, and managing non-conventional security issues (Cornago 1999).

In addition to these theoretical endeavours, the second phase marked a shift of academic interests in paradiplomacy from North America to Europe. Galvanized by the progress in European integration and the signing of the Maastricht Treaty, the development of regionalism was accelerated, while the Committee of Regions (CoR) was established specially to institutionalize the involvement of subnational governments of the Member States in global affairs (Kuznetsov 2014).

Among various European subnational entities, the foreign activities of the Länder (autonomous states) in Austria were analysed, for example. Due to a long history of the Austrian Länder as self-governing territorial communities, Vienna was challenged by subnational entities in two ways. First, Austrian Länder are active in joining in regional working groups with their foreign counterparts. Second, the Länder, such as Tyrol and Carinthia, interact with their foreign neighbours directly. However, it turns out that the activeness of the Länder in foreign affairs did not affect the unity of Austria; instead, it became a tool of domestic partisan struggle (Pelinka 1990). Like Austria, constitutionally speaking, Belgium prevented the governments of communities and regions from enacting their own foreign agendas, retaining international relations prerogatives in the hands of the King. However, as a matter of fact, the subnational entities in Belgium were allowed to set up branches for economic and cultural promotion beyond the national border, which can be 
seen from Walloon region and Flemish community, which succeeded in publicizing their political and cultural identities to improve their international presence (Lejeune 1990).

During this period, paradiplomacy scholars were also enthusiastic about the foreign agendas of subnational governments in the post-Soviet space, particularly the Russian Federation. This was partly influenced by the prediction that Russia was likely to be disintegrated within several years (Stern 1994; McFaul 2000; Perovic and Makarychev 2000). At the time, Moscow sought to pacify ethnic tensions and nationalist demands through showing tolerance towards the foreign actions of oblasts (Cornago 2000). It was against this backdrop that Tatarstan employed protodiplomacy (a type of paradiplomacy resorted for a nationbuilding purpose) as a tool to achieve greater autonomy from Moscow in terms of economic policymaking (Makarychev and Valuev 2001). Kursk also took advantage of its integration into the Commonwealth of Independent States (CIS), engagement with the EU Member States, and the promotion of cross-border cooperation with Ukraine to express its displeasure at Moscow's lack of support for Kursk's development (Sarychev 2001). Sakhalin, through playing a role in the bilateral territorial dispute negotiations between Russia and Japan, even had access to more economic incentives from both countries (Zinberg 1995).

As we have seen, in the past two phases, scholarly interests were mainly limited to Western federations. However, a host of new geographical points in the 'map of paradiplomacy studies' have appeared in the third phase, since the 2000s. This breakthrough is a result of the improved position of non-Western countries in world politics and the economy. For instance, the question of how the paradiplomacy conducted by South African provinces, including Gauteng, the North West, and the Western Cape, has contributed to the democratization of Pretoria's foreign policy was addressed by Fritz Nganje (2014). How the influence of globalization and regionalization made it possible for Indian subnational governments to undertake high-profile investment-promotion campaigns abroad was also analysed (Mattoo and Jacob 2009; Jha 2014).

Some paradiplomacy scholars were further concerned with paradiplomatic activities taking place in unitary states. The reason why these works are considered ground-breaking is that there used to be a strong presumption that paradiplomacy, an attribute of federal or semifederal states, cannot exist in a country without democratic sharing of international relations prerogatives (Kuznetsov 2014). The paradiplomacy of Iraq's Kurdistan was said to be 
unprecedented in terms of scope and autonomy, in that this restive region took advantage of security issues and energy exports in developing foreign ties, in order to gain a stronger position than other Iraqi regions (el-Dessouki 2012; Mohammed and Owtram 2014; Akreyi 2017). It has also been shown that the subnational governments in Malaysia, a centralized unitary with certain federal features, were allowed to engage in paradiplomatic activities through their own administrative machinery, as Putrajaya could not effectively look after their local external interests (Loh 2009). In Japan, its prefecture governments were found to integrate directly with the international community to avoid being constrained by some domestic financial policies and attract external financial support after the Second World War (Jain 2006).

Before analysing the shift of scholarly interest to Chinese paradiplomacy, it should be noted that China has long been regarded as a typical centralized state (Hameiri and Jones 2016), with a monolithic grand strategy (Goldstein 2003). The central government in Beijing monopolized every aspect of political, economic and social activities, leaving non-state actors, including provincial governments, with no say in foreign policymaking (Perkins 1966; Barnett 1967, 1985; O'Leary 1980; Garver 1993). In addition, it was deemed that, under an inward-looking economic system, Chinese provinces had no incentive to conduct foreign economic relations (Chen, Jian, Chen 2010). Therefore, the appearance of a body of literature on the external interactions of Chinese provinces is revolutionary. However, these works were largely dedicated to the external economic activities of Chinese provinces within the framework of the central-provincial relations, short of giving insights into their actorness in international relations - a set of fundamental characteristics of a political and economic entity as an international player.

In retrospect, during the first three decades of the People's Republic of China (PRC), there had not been many works that talked about the external activities carried out by provincial government which was thought as the central government's preserve. Since the launch of the 'opening up' and reform policy in 1978, the central party-state system has no longer been a monolith in foreign affairs, with provincial authorities, especially in coastal areas, becoming more active in foreign economic cooperation (Zheng 1994). As the core task of China's foreign policy in the reform era consists of creating a favourable external environment for economic development, foreign economic policy has been of critical 
importance to China's selection of direction and strategy in managing its international relations. Hence, the implications of the provincial foreign agenda might not only weigh on China's external economy, but even on the country's overall foreign policy (Chen 2005).

Still, the growing autonomy in foreign economic affairs enjoyed by Chinese provincial governments does not necessarily mean that they are in confrontation with Beijing (Womack and Zhao 1994). In the past couple of decades, whenever the central government felt that the conduct of external affairs by provincial governments went so far as to erode central authority and state unity, it opted for clawing back the autonomy of provinces in terms of making foreign economic policies (Su 2008). The macromanagement of the central authorities over the paradiplomatic activities of provinces will be more effective in the future, thanks to the progress of technology (Hameiri and Jones 2016). This view was echoed by Chen Zhimin, Jian Junbo, and Chen Diyu (2010: 355):

With the development of a modern state structure and the revolution in transportation and communication, China's central government has been in an even stronger position to exert direct control over provincial external activities, making it possible for centralization of Chinese foreign policy and proactive provincial international involvement to be achieved at the same time.

In reality, provincial governments have become partners or agents of the central government in the conduct of foreign policy agendas. In forging external links, provinces can facilitate the deepening of China's economic footprint abroad, while boosting its national profile in local communities of foreign countries through proffering medical teams and developing sister-provincial relationships. Any attempts to challenge national foreign policy could easily be suppressed, with provincial governments being able to "only push for specific policies that are permitted within the larger policy framework or when the central government's policy appears to be uncertain" (Li 2017: 210).

In the case of Guangdong, during the reform era, it has strengthened its economic and cultural integration with Hong Kong, achieved considerable autonomy in domestic and foreign issues, and significantly reduced its dependence on the economic subsidy from the central government. Even so, the province hardly strayed openly from the parameters of the central government's policy (Jones, King and Klein 1993). Instead, the objective of the paradiplomatic activities of Guangdong was not only to benefit from taking advantage of 
economic resources in Hong Kong, but also to assist the central government in smoothing the 1997 handover of Hong Kong to China (Goodman and Feng 1994; Roger and Sun 1998). Apart from Guangdong, the provincial-level cities of Beijing and Shanghai were purposively used by the central government to cope with some external affairs that it was not prepared to face. After the of Paris city council planned to pass a resolution to grant honorary citizenship to the Dalai Lama, who is globally honoured but politically controversial in China, the municipal government of Beijing and its people's congress issued an open opposition against Paris (Li 2017). A similar incident occurred between Shanghai and Osaka which have been locked in a sister-relationship. Shanghai officials raised the issue with their counterparts from Osaka in the midst of Sino-Japanese tension over Diaoyu/Senkaku islands (Wang 2013).

This cooperative relationship between the central and provincial governments in foreign affairs is more evident in inland provinces. As interpreted by Su Xiaobo (2013: 1217), the central government has forged an alliance relationship with border provinces to "turn its borderlands into new spaces of development beyond its conventional territorial fix" and it "eagerly harnesses transnational regionalization to promote the geographical expansion of capital and labour in Asia and elsewhere." The latitude granted by the central government to border provinces is also referred to as 'local liberalism', when border provinces are probably "striving to push for transnational collaboration and cooperation in the economic, social, cultural and non-traditional security arenas" (Li 2014: 276).

Empirically speaking, for instance, in the construction of the Great Northeast Asian Economic Circle, the northwestern provinces opted to ask for more preferential policies and economic subsidy from the central government after they could not attract considerable investment from Mongolia and Russia's Far East, much less North Korea. At the same time, the central government would take advantage of the operation of this project to create more opportunities to work with neighbouring countries (Yahuda 1994). Guangxi and Yunnan have made similar endeavours. They have benefited from Beijing's relations with Southeast Asia by being able to cooperate with their counterparts in the Mekong subregion (Summers 2013). With reference to Xinjiang, the most northwestern region of China, the central government asked the region to implement the new Silk Road scheme, to penetrate China's economic influence into Central Asia and beyond, while contributing to the prosperity and 
stability of Xinjiang (Mackerras 2015). Around the 1990s, the economic interactions between border provinces and neighbouring countries which Beijing had historically dealt with carefully - Vietnam, Russia, North Korea, and South Korea - also facilitated the normalization of the relationship of Beijing with these countries (Lampton 2001).

Even so, some scholars observed that provincial activism in relation to foreign affairs can be a mixed blessing to Beijing. The first problem is that the deepening interdependence between Chinese provinces and foreign partners might enable the former to channel their external economic forces into shaping the decision-making of the central government (Zheng 1994). This was taking place against a background in which Beijing deliberately devolved power to provinces, with the latter enjoying much autonomy in the fields linked closely to their local interests that might not have been the priorities of the central government. In analysing the Sino-Japanese relationship, for instance, Gerald Segal (1994) suspected that when China and Japan are locked in a heated rivalry over regional economic and diplomatic clout, Chinese coastal provinces, which have been increasingly dependent on the market and investment of Japan, would take the initiative to moderate Beijing's political ambitions.

Second, what further concerned the central government is the provincial resistance to enforcing national foreign policies or international commitments. This is evident in the cases of Hainan and Yunnan. At the cost of China's relationship with Southeast Asian countries, the former took an assertive initiative to upgrade its fishing activities in the South China Sea, while the latter was implicated in the exploitation and smuggling of Myanmar's timber and precious stones, which forced the central government to have to recentralize its authority over the policy toward Naypyidaw (Hameiri and Jones 2016). Other examples are related to the fact that some provinces capitalize on the decentralization and loosening of the border to support drug trade, human trafficking, and smuggling. These local initiatives wreaked havoc on China's economy and social stability, even preventing it from playing its full part in upholding the rule-based international system (Chen 2005). It is also a concern of the central government that provincial governments adopted protectionist economic policies within their jurisdictions, regardless of Beijing's agreed concessions across the fields of service, industry, investment, trade, and intellectual property, to re-enter the World Trade Organization (Kewalram 2004). The provincial resistance to Beijing's decision not to devalue the renminbi (RMB) during the 1998 Asian Financial Crisis provided one more instance. By 
keeping their earnings in hard currencies or even overseas, a handful of provincial governments weakened the pledge of Beijing to Southeast Asian countries and forced Beijing to impose tight foreign currency control regulations (Lampton 2001).

The third problem is that the central and provincial authorities might hold different views on the sequence of external interests. The most typical example is provided by Fujian province, which had a disagreement with the central government on provincial external economic expansion. Despite being one of two pioneer provinces designated by the central government to open up to the world market, Beijing habitually discouraged Fujian officials from attracting foreign investment. The rationale of the central government was twofold, which failed to convince the officials and businessperson in Fujian. Beijing was worried about the province's proximity to Taiwan, seen by Beijing as a breakaway province to be brought back into the fold - if necessary, by force; another concern was that Fujian would be likely to face severe inflation and social unrest, should the central government relax its control over its macroeconomy (Long 1994).

\subsubsection{Limitations of Previous Research}

This section sets out the problems with the existing paradiplomacy literature and explains why this thesis will add significant value to the literature. As reviewed above, since its genesis in the 1970s, paradiplomacy theoretical works have gradually provided a lens through which the foreign agendas of subnational governments are revealed. Along with this trend, paradiplomacy scholars were no longer limited to North Americans, who tended to focus on federal states. Over the years, we have seen the enthusiasm of paradiplomacy scholars from all over the world to depict this phenomenon, while the geographic scope of the study of paradiplomacy has further extended to unitary, centralized states. Even so, some limitations can still be identified after a careful examination of the large body of paradiplomacy work.

First, compared with works on the participation of some other non-nation state players in foreign affairs, the topic of subnational diplomacy has received little attention to date. In reality, the emergence of paradiplomacy scholarship has been set against a background in which the role of nation states relatively declined, alongside the proliferation of a slew of non-state stakeholders in world politics. But the phenomenon through which subnational 
governments play an increasingly important role in foreign affairs has not been adequately studied by IR specialists and diplomatic practitioners (Cornago 2012). Identified reasons include a lack of interest in the influence of subnational participation on the international stage by internationalists; the assumption that subnational governments make very little impact on world politics; and scepticism regarding the influence of localities on the progress of globalization (Paul 2002). For some scholars, in addition, the reason why paradiplomacy studies have been treated without due regard is that "these micro-diplomatic relationships lack the glamour, the impact, and most often the importance of international relations of the first rank" (Rutan 1988: 163). This is also the case within the Chinese context. As outlined above, there is a substantial bulk of academic work that sheds light on the external participation of some non-central government players in China. However, the international actorness of provincial governments has yet to achieve the attention it deserves. The reasons are likely to be based on a pair of misjudgements. First, the outputs of provincial governments in international relations have been very limited, if not zero. Second, talking about local external activism in China may be too politically controversial, as it is always linked to separatism. Therefore, as a general contribution, this thesis would like to add substance to the literature on paradiplomacy studies.

Additionally, within the limited number of works that relate to the external activities of subnational governments, there has been a dearth of research on the paradiplomacy of nonWestern states. As mentioned above, scholarly interest in paradiplomacy started with a predominant focus on North American cases in the 1970s, motivated by 'new federalism' in the United States and separatist movements in Canada. In tandem with the progress of European integration, the geographic scope of paradiplomacy studies extended to European countries. It was not until the 1990s that the paradiplomacy of non-western countries was given a certain amount of attention. This was reflected in the publication of works on subnational foreign agendas in Japan (Jain 2006), India (Mattoo and Jacob 2009; Jha 2014; Jacob 2016), and Russia (Albina 2010; Kuznetsov 2014; Joenniemi and Sergunin 2014). However, until recently, a preponderance of discussions on the subnational external interactions of Western countries was still apparent. In one of the latest edited volumes on paradiplomacy, for instance, all its conceptual and empirical contributions were based on the 
cases of Quebec (Lecours 2010), Scotland (Jeffery 2010), Bavaria (Nagel 2010), and Flanders (Criekemans 2010).

Third, and related to the previous point, paradiplomacy in unitary, centralized states has not been exhaustively explored. The recent decade has witnessed scholarly interests shifting to some centralized countries (Cornago 2000; Cheung and Tang 2001; Chen 2005; Jain 2006). Some have even called sparing judgement on whether paradiplomatic activities exist in a country by a cursory look at its constitution alone; instead, they have emphasized the importance of observing the extraconstitutional actions of the subnational governments of an examined country (Hocking 1999; Michelmann 2009). Even so, it must be noted that compared to paradiplomacy literature on federal states, the attention paid to unitary systems has been sparse. This neglect has resulted from the long-held view among paradiplomacy researchers that paradiplomacy is more observable in Western federations or federal-like countries (Kincaid 1990; Elazar 1997), in that "the locally elected officials and their staffs possess a considerable degree of jurisdictional autonomy in domestic affairs, which they now tend to expand to include closely connected international issues" (Duchacek 1990: 2). One of the direct repercussions of this neglect is that IR specialists and practitioners failed to take into account growing local factors when analysing the foreign policies of some quintessential centralized states. As China has long been considered highly centralized in its making and execution of foreign policy, at least constitutionally speaking, this thesis, by looking at the external initiatives of Chinese provinces, would like to enrich the existing paradiplomacy scholarship and call for more scholarly attention to local external dynamics not just in China, but also in many other states that do not belong to Western democratic blocs.

Fourth, there has been a growing literature on the foreign agendas formulated by Chinese provinces, much of it highly valuable; however, this body of work tends to be contextualized within discussions of the general central-provincial relationship, rather than getting to the bottom of the international actorness of provincial government - the set of fundamental characteristics of an international relations actor. They tend to attribute the role of agency or partner of the central government to provincial governments, in that Chinese provinces are habitually tasked with providing hospitality and managing certain external issues that Beijing is not well-prepared to face directly (Li 2017). By the exploration of the international 
actorness of Chinese provincial authorities, this thesis aims to address a neglect in relation to questions about whether Chinese provinces could be regarded as autonomous international actors, how they have pursued their external interests, and to what extent their paradiplomacy might conform to the characteristics presented within the mainstream of paradiplomacy literature.

Finally, a limited number of scholarly works on the foreign agendas of Chinese provincial governments have been constrained by a geographic bias. From the early 1990s, the scholarly spotlight has been fixed on the coastal regions, leaving other areas rather like a huge tract of underdeveloped landmass. For instance, oft-cited cases include Guangdong's economic links with Hong Kong before 1997 (Jones, King and Klein 1993; Goodman and Feng 1994), the role of Shanghai officials in facilitating Sino-American relations (Lampton 2001; Zhu 2005), Fujian's building of links with 'Greater China' (Long 1994), the efforts of Shandong and Liaoning in normalizing the relationship between Beijing and Seoul (Kim 2007), and the leveraging of international occasions by Shanghai, in order to improve its profile (Wang 2013). The reason for this geographic bias is twofold. One is that the 'opening up' policy was initially practiced among these provincial-level entities, which, in turn, provided them with more opportunities to connect to the globalized market. Another is that the opening up of coastal regions would have made it easier for researchers, in term of data accessibility. In recent years, despite the publication of a number of paradiplomacy works with a focus on 'non-traditional' provincial entities in China, situated at a distance from the well-researched rich coast (Clarke 2003; Mackerras and Clarke 2009; Mackerras 2015; Colin 2014; Su 2015, 2016; Tubilewicz 2016), the number of these works is still eclipsed by the literature on Chinese coastal provinces. However, it cannot be denied that, since the early 1990s, Chinese border provinces have been authorized with greater external power by the central government and become more active in cross-border cooperation. In order to pave the way for more paradiplomacy scholars to study the international role of non-coastal provinces in China, this thesis provides an analytical framework, and attempts to apply it to the crossborder paradiplomacy of Yunnan, located in southwestern China and contiguous to Myanmar, Laos, and Vietnam, three countries on the Indochinese peninsula. 


\subsection{Analytical Framework}

Within the previous paradiplomacy literature, there has been a dearth of appropriate analytical frameworks to provide an opening through which the international actorness of subnational governments, no matter whether they are federal or unitary systems, can be comprehensively studied. This view finds expression in the work by André Lecours (2002: 94), who has argued that "there has been little effort to ground the study of paradiplomacy in a theoretical perspective that could serve as the foundation for a general explanatory framework." A host of paradiplomacy scholars have also drawn attention to this phenomenon. From the perspective of Joachim Blatter et al. (2008: 469), instead of demonstrating the full range of international actorness in an examined subnational region, many paradiplomacy works "either have no theoretical framework or use quite different ones, making it very difficult systematically to derive general conclusions." Alexander Kuznetsov (2014) ascribed the absence of explanatory frameworks to the multidimensional nature of scholarly perception of paradiplomacy, since the various approaches to paradiplomacy complicate comprehensive application.

Even so, some paradiplomacy scholars have still offered a few analytical frameworks (Duchacek 1990; Soldatos 1990; Cohn and Smith 1996; Keating 1999; Hocking 1999; and Lecours 2002). However, this thesis will not directly employ any of these. As shown in this section, none were constructed in an entirely satisfactory way. In order to better understand the international actorness of the Chinese province of Yunnan, the thesis proposes an analytical framework that combines the concept of paradiplomacy and the theory of actorness.

From the perspective of international law, "there is no necessary correspondence between the achievement of legal personality and actorness in behavioural terms" (Bretherton and Vogler 2006). For instance, a weak state might serve as an insignificant actor in the international arena, but still have legal personality, while powerful groupings, such as the EU and the Association of Southeast Asian Nations (ASEAB), among others, find it hard to obtain de jure recognition, even though they are represented in many international and regional organizations, operate delegations to numerous third states, and enjoy observatory status in the United Nations (UN) (Kratochvíl 2013). 
In the early IR literature, the analysis of actorness amounts to addressing the question of who can be recognized as an international player. In other words, the prime mission for IR theorists might be to decide what is to be studied. Since the 1970s, a few IR scholars have been keen to investigate the actorness of the EU in a context in which the economic and military predominance of the United States has been in question since the Vietnam War (Sjöstedt 1977; Rosenau 1990; Hocking and Smith 1990). For instance, Gunnar Sjöstedt (1977) has suggested two aspects of actorness in his analysis of the external role of the European Community (EC): autonomy and capability. For Sjöstedt, these two dimensions are essential to judge whether a political or economic entity is an international actor. However, this framework of actorness is oversimplified and not well-defined. For example, the jury is still out on whether an autonomous and capable actor implementing an isolationist foreign policy is a full international actor. In terms of capability, we have seen throughout history that less capable countries have exerted a sizeable influence on world politics. Can we say that a free rider or bandwagon country is not an international player? We should also think twice about autonomy if we are to make it a fundamental dimension of the actorness of subnational governments. Most subnational actors are not entirely free from their central authorities, although they have a range of strategies to side-step national policy and make their voice heard by the international community. So, can we deny subnational government's international role simply because they are not politically autonomous?

From the early 1990s, the abrupt ending of the Cold War and the conflicts in Eastern Europe propelled more scholars to analyse the actorness of the EU, to see whether it could be counted on to contribute to regional stability. One of the typical works in this vein was by David Allen and Michael Smith (1990), who particularly highlighted presence as one of the important dimensions of actorness. For Allen and Smith (1990: 21), presence is "defined by a combination of factors: credentials and legitimacy, the capability to act and mobilize resources, the place it occupies in the perceptions and expectations of policy makers." Presence is also proposed within the framework of actorness advanced by Charlotte Bretherton and John Vogler (2006). According to their definition, presence denotes the ability to shape another's actions not by purposeful external activities action, but by the simple consequence of existence. In addition to presence, opportunity and capability are also often presented as constitutional parts of the dimensions of actorness. For Bretherton 
and Vogler, opportunity refers to the external environment which enables or prevents the engagement of subnational governments in international relations, while capability should be measured according to the availability of policy instruments and the effect of policies. In a monograph by Petr Kratochvíl (2013) on the EU, they defined four dimensions of actorness and conducted a few empirical case studies based on this set of dimensions: legitimacy, external recognition, attractiveness, and the power to frame policy.

Brian Hocking (1999) was the first paradiplomacy scholar to apply the theory of actorness to the analysis of subnational governments. After re-defining actorness as a group of characteristics of subnational governments that is indictive of international relations players, Hocking suggested a framework that was constituted of five dimensions: motivation, extent of involvement, resources, level of participation, and strategy. For Hocking, the motivation for a subnational government to engage in international relations should be traced from both domestic and external reasons. With regard to extent of involvement, this denotes the degree of international presence of a subnational government; the direction of its external involvement; and its opportunity to pursue international interests. As a precondition for the realization of these two criteria, the possession of resource amounts to the capability of a subnational government to manoeuvre internationally. The fourth dimension refers to the level of the international stage on which a subnational government decided to engage in, to best serve its external interests. Finally, Hocking divided the strategy of subnational diplomacy into two types: primary strategy and mediating strategy. The former denotes that subnational governments involved themselves in interactions with foreign partners, while the latter means that they count on national governments to make foreign policies suited to their local interests.

In his analysis of the external role of the French region of Provence-Alpes-Côte d'Azur (PACA), Manuel Duran (2011) continued to list four dimensions for the exploration of the actorness of subnational governments: authority, presence, autonomy, and opportunity. Duran (2011: 346) interpreted each dimension in detail:

Authority deals with the legal competences that allow PACA to engage in international relations. By presence we mean both the external recognition, by which other actors acknowledge PACA's international role and the internal identity or self-perception as an international actor. Autonomy is the ability to 
set up and develop an institutional diplomatic structure, while opportunity refers to the external environment enabling PACA's international activities.

After applying this framework, Duran argued that PACA should be considered as an international relations actor. The dimension of authority is met when PACA has been allowed to engage in international relations with other regional authorities by the French government. The dimension of presence is met after the PACA has been awarded the right to conclude international agreements and the PACA was internally recognized as an international player, especially in the management of the relationship with the Mediterranean region. The third dimension of autonomy is met when the PACA has established its own foreign affairs agency - Relations Internationales et Affaires Européennes - to handle its involvement in European and Mediterranean affairs. The last dimension, of opportunity, is met since the cross-border acts of the PACA have been facilitated by its involvement in a few institutional niches (like the Committee of the Regions), transnational cooperation frameworks (like the European Territorial Cooperation), and geographical partnerships (like the Euro-Mediterranean partnership).

Although clearly-defined, Duran's framework still has some conceptual shortcomings. First, there is an apparent overlap between authority and autonomy according to Duran's definition, as the autonomy of subnational governments will always be a result of the authorization of national authorities. Second, it is interesting to explore the external environment within which a subnational government was directly or indirectly stimulated to be an international actor through substantiating the last dimension, of opportunity. However, only paying attention to the question of whether and how the involvement of a subnational government in international institutions boosts its paradiplomacy is neglecting the general regional environment and the influence of state-level diplomacy on the development of paradiplomacy.

This thesis will combine the concept of paradiplomacy and the theory of actorness, applying the following dimensions to explore the international actorness of Chinese border provinces (Table 2.1). Through the case of Yunnan, the following four-dimensional analytical framework structures this thesis: 
Table 2.1: Analytical framework

Motivation This deals with the question of why a subnational government is incentivized to engage in cross-border engagements, although with limitations;

Opportunity This refers to opportunity stemming from the external environment that directly or indirectly promotes a subnational government as an international relations actor;

Capability This indicates the strengths of a subnational government to incentivize foreign countries to cooperate with it;

Presence This concerns the external and internal recognition of subnational governments as international actors by third parties.

This framework expects to address the shortcomings of previous frameworks of paradiplomacy. First, it aims to present a whole picture of international actorness. In contrast, past frameworks often pay excessive attention to one or two aspects rather than presenting the full complexities of the international actorness of a subnational government. For example, Panayotis Soldatos (1990) claimed to build an explanatory framework, only to find that his framework is overly preoccupied with the question of what derives paradiplomacy, leaving many other essential questions untouched. Peter Bursens and Jana Deforche (2010) employed the concepts of historical institutionalism, such as critical junctures, path dependence, and 'lock in', to examine paradiplomacy in Belgium, consequently proposing a framework that, nonetheless, can be used only to explain the evolution of subnational foreign competences. Much the same can be said of André Lecours (2002), who also suggested a framework based on historical institutionalism, which ended up merely accounting for the choice of paradiplomatic activities by subregional governments.

It can be seen then that although the four dimensions proposed in this framework are interconnected, they are not repetitive. Still, the dimensions in some earlier frameworks were found to overlap with one another. Take the framework by Ivo Duchacek (1990), for 
instance. Partly included in his framework are the dimensions of channel and the level of paradiplomacy. Duchacek rounded out the dimension of channels by suggesting various options, such as the establishment of permanent offices in foreign regions, visits, short-term and professional fact-finding missions, and commercial shows, while fleshing out the dimension of the level of participation by categorizing all paradiplomatic activities into transborder regional activity, transregional activity, and global activity. In fact, discussing channels selected by a subnational government to undertake its paradiplomacy must indicate the level at which its paradiplomacy activities take place. Another example is provided by the framework of Theodore Cohn and Patrick Smith (1996), which focuses on the questions of how (mediating and primary roles) and with whom (international, national, provincial, state, and city actors) paradiplomacy is conducted. Its flaws consist in the fact that these questions, overlapping with one another, are hardly to be answered in a separate way. Much the same can be said about the framework of Brian Hocking (1999), in which he suggested examining the paradiplomacy of any subnational government via three somewhat repetitive elements: extent, level, and strategy.

Third, this framework is more suited to the study of cross-border paradiplomacy. The existing frameworks, however, have largely been based on general paradiplomatic activities, and have failed to consider the full gamut of characteristics of the external interactions undertaken by border provinces. The framework by Alexander Kuznetsov (2014) is one of the more comprehensive, involving six crucial dimensions. Still, it cannot be directly applied to cross-border paradiplomacy. For instance, within the interpretation of the influence of paradiplomacy on national foreign policy, for one dimension in this framework, Kuznetsov provided three potential outcomes. These outcomes are: the rationalization of national foreign policy, the democratization of the process of foreign policymaking, and the disintegration of state sovereignty. Even if the third outcome were to take place when border subnational units seek international support for their independence, the first two outcomes are unlikely to be realized, as cross-border issues are always considered too peripheral to have such implications (Keating 1999).

As we will see later in this thesis, Chapter 4 provides an overview of Yunnan's motivation for becoming an international relations actor, especially from a domestic perspective. The limitations of the province's external interests are also discussed. Chapter 5 sheds light on 
how the opportunities stemming from the external environment has influenced the engagement of Yunnan in international relations, and concludes that Yunnan's external activism has been sustained by a set of external opportunities, although in an indirect way. These opportunities were derived from the shift in the regional situation, the pressure of international institutions, and the competition between China and the extra-regional powers. Chapters 6 and 7 assess the last two dimensions of actorness - capability and presence, addressing the questions of how Yunnan enhanced its appeal as a province that neighbouring countries might work with, and whether and how the international role of Yunnan has been recognized by foreign partners and the Chinese central government.

\subsection{Conclusion}

This chapter laid the theoretical and analytical foundations for an analysis of the international actorness inherent in a Chinese border province - Yunnan. The review of the first strand of works was aimed at outlining the historical context within which scholars have discussed the status of nation states and the advent of non-state actors in world politics especially subnational governments. The majority of the literature reviewed in the second part has been written by international relations theorists who either believe in state centralism or in the growing importance of non-state actors. In presenting this long-held debate among international relations theorists, this section has aimed to draw readers' attention to the fact that nation states are no longer the exclusive players in the global arena. With regard to the scholarship on paradiplomatic activities, three important periods were identified. The intensity and scope of paradiplomatic activities have multiplied during these periods. The literature on the engagement of Chinese provinces in world politics was reviewed as well, although these works were mainly framed within the central-provincial relations and susceptible to a geographic bias (the majority of these works focus on the coastal provinces of China). The limitations of these bodies of literature were discussed following the review of relevant academic works. These limitations reveal the necessity of studying international actorness - the characteristics of being an international relations player - inherent in border provinces in a centralized China. In order to build up a proper analytical framework to guide the exploration of the international actorness of Chinese border provinces, this thesis points out that the theory of actorness can be applied alongside the concept of paradiplomacy to comprehensively demonstrate a picture of 
external interactions conducted by an examined subnational government. Thus, in the last part of this chapter, a four-dimensional analytical framework was put forward. 


\section{Chapter 3}

\section{Methodological Framework}

\subsection{Introduction}

As revealed in the introduction chapter, the main purpose of this study is to analyse the international actorness of Yunnan, exploring why the Chinese central government granted Yunnan external affairs power, how this power was influenced by the regional geopolitical and economic environment, how Yunnan projected its new external affairs power across the border, and whether its international role was recognized by third parties. The review of the previous literature in relation to the external participation of Chinese border provinces in Chapter 2 suggested that this phenomenon is inadequate, both theoretically and empirically. In the second half of Chapter 2, an analytical framework based partly on the theory of actorness was proposed after taking into account the strengths and weaknesses of existing analytical frameworks.

A majority of empirical studies on paradiplomacy make use of the qualitative case study approach to trace the foreign engagements of subnational governments around the world. One of the few exceptions is the work by Samuel McMillan (2012), who used statistical analysis to show how US states and governors have been linked to foreign policymaking in Washington D.C. The present study draws on a single instrumental case study of the paradiplomatic activities of Yunnan in the post-reform era, using a qualitative approach to analyse this case. To meet this goal, the data were gathered through interviews, content analysis, and participant observation. The use of a typical case study, a qualitative approach, and data collection methods are justified as follows.

First, the main rationale for this thesis to adopt a case study approach lies in the fact that this approach can better address the research question proposed in Chapter 1, which took the form of 'how'. Even though the characterisation of the international actorness of all Chinese border provinces is not the primary goal, the study seeks to provide an opening to the understanding of the general pattern of Chinese cross-border paradiplomacy. This objective could be achieved through a single instrumental case study or through multiple 
case studies. However, time constraints and funding limits necessitated a single instrumental case study. Taking into account the research, and for logistical reasons, Yunnan was eventually chosen as the focus of this study, as its engagement in cross-border cooperation is considered more comprehensive and institutionalized than other Chinese border provinces. The author also had greater access to information there.

A qualitative approach was used in analysing this case study. Despite the strengths and weaknesses of qualitative and quantitative approaches, within the case study literature both approaches were welcomed. Therefore, the decision to use the qualitative approach was made because this type of research is better suited to this study. First, the thesis looked into contextual conditions by examining the influences of internal and external developments on Yunnan's engagement with its foreign neighbours. Second, it should be noted that the thesis is not merely a diary or chronicle of events; instead, it seeks to contribute insights into Yunnan's external interactions with surrounding countries, in order to broaden understanding of paradiplomacy studies contextualized in China. Third, given the complexity of the external interactions between Yunnan and neighbouring countries, the thesis makes use of qualitative data collection approaches to uncover the entire picture relevant to this topic.

With reference to data collection, the first method this thesis used was interviews. Specifically, semi-structured qualitative interviews were conducted during the fieldwork. The rationale for this was the ontological and epistemological positions taken by the author. First, the author not only gathered information from interviewees but also immersed himself in a dialogue to encourage interviewees to speak freely and at length. Second, the author preferred an informal form of interview, believing that participants would be more willing to share their experiences in a relaxed atmosphere. Third, all the interviews were conducted in a flexible way, in that no pre-set questions and suggested responses were given to participants in advance. Lastly, the author paid attention to the background information relevant to interviewees' chosen topics of discussion, which made the use of the qualitative approach more suitable.

Additionally, the thesis incorporates data collected content analysis from both primary and secondary sources. The content studied included written texts and various media formats. 
The written texts involved non-confidential policy files and internal reports on the external interactions between Yunnan and neighbouring countries, while the media content was accessed through the databases available on the webpages of the Yunnan provincial government and its agencies. Data access was facilitated by some officials at the Yunnan provincial Foreign Affairs Office (FAO). The author was given free access to non-confidential policy files and internal reports on the external interactions of Yunnan. The online information was reached through portal websites run by many provincial administrative units. In addition to interviews and content analysis, this thesis used participant observation to capture more evidence relevant to Yunnan's cross-border cooperation. As participant observation is always time- and resource-consuming, the motivations for choosing this method were very pragmatic.

The rest of this chapter is organized as follows. The use of case study in research is justified in Section 3.2, with a focus on the questions related to what a case study is (Subsection 3.2.1), whether to use single case or multiple cases (Subsection 3.2.2), and also why Yunnan was selected as a case study (Subsection 3.2.3). This section also explains why the qualitative method was chosen to analyse this case study (Subsection 3.2.4). The second half of this chapter deals with the data collection (Section 3.3). It discusses issues related to interviews (Subsection 3.3.1), content analysis (Subsection 3.3.2), and participant observation (Subsection 3.3.3), with reflections on why and how these methods fitted this research. This section concludes with some related issues and ethical considerations (Subsection 3.3.4). A summary of the chapter is presented in Section 3.4.

\subsection{Use of Case Study}

This thesis is a case study on the role of Yunnan as an international actor. The following section sheds light on various misunderstandings of the use of case study as a method and the rationale for this thesis to adopt this approach (Subsection 3.2.1). The choice of a case study is based on comparisons with other qualitative methods, notably survey and experiment. Of the three most-used types of case study, this study opted for a single instrumental case study. Also addressed is the question of why a qualitative approach was employed in the analysis of this case study in Subsection 3.2.2. It concludes with an explanation of the choice of Yunnan as a case study in Subsection 3.2.3. 


\subsubsection{Case Study}

There has been a misconception that a case study is nothing more than the collection of data and thus a "less desirable form of inquiry" (Yin 2003: 10-11). This method has even been criticized for lack of rigour, reliability, and generalizability (Hartley 1994). Jennifer Platt (1992: 46), however, argued that a case study has its own "logic of design" and is "a strategy to be preferred when circumstances and research problems are appropriate rather than an ideological commitment to be followed whatever the circumstances." Robert Stake (2000: 443) argued that "case study is not a methodological choice but a choice of what is to be studied." In the words of Florian Kohlbacher (2006:3), "case studies are widely used in organizational studies and across the social sciences... with a growing confidence in the case study as a rigorous research strategy in its own right." Wilbur Schramm (1971:1) also pointed out that cases study is not necessarily less scientific than an experiment, in that "(just as) an experiment abstracts life toward laws, (so) a case study organizes the details of life in search of patterns and insights."

The reasons for selecting case study as a method are based on its characteristics vis-à-vis other qualitative research strategies. According to Robert Yin (1994), each qualitative strategy brings with its own blessings and curses, depending on the type of research questions, the control over the units of research, and the focus on contemporary or historical events. In the use of case study, first, compared with 'what' questions that might indicate the use of surveys or the examination of archival records, questions in the forms of 'why' or 'how' are more likely to lead to the use of experiment and case study (Yin 1994). These strategies are therefore preferable for the central question of this research, which takes the forms of 'how' to trace the formation and development of the international actorness of Yunnan. Second, this thesis exerted little control over the units to be studied. In contrast, experiment is more ideal for investigators who manipulate the actions of participants and the environment within which an experiment takes place. According to Wilbur Schramm (1971: 2), "in making a case study, one accepts the situation and tries to apprehend it", which is different from experiments in which "one can decide upon the situation and so far as possible control the elements within it." Given the nature of this thesis, which controls neither the responses nor actions of participants nor the internal and 
external environment of Yunnan's external interactions, experiment as a method was excluded.

\subsubsection{Use of a Single Case}

Thus far, questions about common misconceptions concerning a case study approach, and why the researcher chose this approach have been addressed. However, we have yet to discuss how many cases are needed to formulate convincing evidence. To begin with, it has to be made clear that the selection of either a single case or multiple cases depends on the purpose of a case study. In reality, there have been three types of case study in terms of the number of cases and the research purposes. The first is a case study whose purpose is not to "understand some abstract construct or generic phenomenon" (Stake 2000: 445-446). Rather, for instance, if researchers are particularly interested in something, they are likely to conduct a case study in which they are not required to generalize at all.

If researchers simply want to satisfy their 'general' or 'external' interests, they are more likely to carry out a single instrumental case study or multiple case studies (Stake 2000). A single instrumental case study does not focus merely on a research unit per se; instead, it starts from a single case in order to apprehend something bigger. Its value was summarized by David Silverman (2013: 280), stating that "most supervisors of student qualitative research would expect your study of a case to be based upon some concept(s) which are developed as a result of your study." Similarly, multiple case studies are aimed at theorizing a phenomenon and generating broader understandings. At the same time, the cases in this type of study are either similar to or dissimilar from one another. In other words, a group of cases are "chosen because it is believed that examining them will lead to better understanding, and perhaps better theorizing" (Stake 2000: 445-446).

Of all the three types of case study mentioned above, the second and third types were more applicable to this research, as it attempts to reflect the general thrust of Chinese crossborder paradiplomacy. Given the constraints of time and funds, however, this thesis would only be able to pursue a single instrument case study. Consequently, another question naturally arises: Is a single case study really generalizable, even to a minor degree, or on what basis could the author generalize to a lesser extent from a single case? In fact, scepticism about the generalizability of a single case study approach has never been 
assuaged, since multiple case studies are considered superior (Yin 1994; Casey and Houghton 2010).

However, a single case study is not unavoidably inferior to multiple case studies, since the former can be "multiple in most research efforts because ideas and evidence may be linked in different ways" (Flyvbjerg 2006: 225). In other words, as long as researchers can complete the examination of a case as deeply as possible, the use of one case cannot be viewed as a waste of time (Punch 1998). William Beveridge (1951: 95) put this more explicitly when he said, "more discoveries have arisen from intense observation than from statistics applied to a large group", which resonated with Robert Yin (1994), who stated that case studies are generalizable to theoretical propositions, instead of populations or universe. In other words, the number of cases can be important, but researchers should focus on generalizing, expanding, and refuting theories rather than on enumerating frequencies.

\subsubsection{Choice of Qualitative Approach}

The case study in this thesis has been analysed using a qualitative approach. However, this does not mean that only qualitative means are available. There have been disputes between those who support qualitative and quantitative research studies. For instance, Cassell and Symon (1994: 7) hold rather dichotomous attitudes toward the two approaches. For them, compared to a quantitative approach, a qualitative approach is:

a focus on interpretation rather than quantification; an emphasis on subjectivity rather than objectivity; a flexibility in the process of conducting research; an orientation towards process rather than outcome; a concern with contextregarding behaviour and situation as inextricably linked in forming experience; and finally, an explicit recognition of the impact of the research process on the research situation.

Some have even gone so far as to insist that qualitative and quantitative approaches are thoroughly incompatible, with the former drawing on written and visual data and the latter on numbers (Neuman 1997). These distinctions, however, are over-simplistic and superficial. Past decades have seen scholarly efforts in maximizing the strengths of the two approaches and making them complementary to one another (Tashakkori and Teddlie 1998; Mayring 2000; Kohlbacher 2006). For Bent Flyvbjerg (2006: 241-242), 
The separation (between qualitative and quantitative approaches) is an unfortunate artefact of power relations and time constraints in graduate training; it is not a logical consequence of what graduates and scholars need to know to do their studies and do them well. In my interpretation, good social science is opposed to an either/or and stands for a both/and on the question of qualitative versus quantitative methods.

As for the analysis of case studies, a consensus has been reached that both approaches are functional. Pamela Baxter and Susan Jack (2008: 554) are of the view that "unique in comparison to other qualitative approaches, within case study research, investigators can collect and integrate quantitative survey data, which facilitates reaching a holistic understanding of the phenomenon being studied." This has been echoed by the argument that "case studies are a common way to do qualitative inquiry... (but) is neither new nor essentially qualitative" (Stake 2000: 443). Robert Yin (1994) has further stated that case study can even be restricted to quantitative evidence.

Given this debate, the selection of a qualitative approach for this research is not predestined, nor is it based on what Howard Becker (1998:6) called an "ideological choice". Instead, the decision to use qualitative approach was to better serve research objectives that could not be effectively realized in a quantitative way. First, qualitative research needs to consider the contextual conditions in which research takes place. The present study examined the influences of external and domestic developments on the empowerment of Yunnan in dealing with cross-border issues. Second, this research was not a diary or chronicle of events instead, it sought to contribute insights on Yunnan's external interactions with surrounding countries. Lastly, owing to the complexity and diversity of the interactions between Yunnan and neighbouring countries, this research made use of qualitative approaches with the aim of uncovering the complete picture relevant to this topic; these approaches involve interview, content analysis, and participant observation.

\subsubsection{Case Selection}

The selection of a single instrumental case is analogous to the method of purposive sampling, which is "perhaps the most unusual aspect of case study in the social science and human service" (Stake 2000: 450). It should be noted that the method of purposive sampling is inappropriate to intrinsic case study, in that the latter is based on the interest of 
researchers who feel no need to select a case from a pool of samples. Given that this research has attempted to use a single case to provide an opening to an understanding of the international actorness of all Chinese border provinces, the method of purposive sampling was selected to derive something more general (Seawright and Gerring 2008). This view has been supported by Bent Flyvbjerg (2006), who thought that a case study researcher with the objective of delving deeply into a case and generating more information about a given problem or phenomenon should consider purposive sampling. This is because a random sample with higher representativeness might not be the one richest in information.

Before explaining why Yunnan was chosen as an object of this study, we need to consider how a case should be selected through the means of purposive sampling. The first method is to identify a representative case that best exemplifies the characteristics of a population of cases. This method is suitable for a case study which is seen "as typification of other cases, as exploration leading up to generalization-producing studies, or as an occasional early step in theory building" (Stake 2000: 448) ${ }^{1}$. The second is to select at least two cases that have maximal variances from one another. The merit of this method is that it is "likely to enhance the representativeness of the sample of cases chosen by the researcher" (Seawright and Gerring 2008: 301). A third is to find an extreme case. Under these circumstances, a case is identified because its independent or dependent variables are extreme. The fourth is to use a critical case, as has been widely used in both qualitative and quantitative studies. However, this method means that if one observation fails to support the proposition, the whole proposition will become invalid and must be revised or even rejected ${ }^{2}$. In addition to these case selection methods, what might be helpful for researchers is to provide a methodological justification for why case $A$ is preferable to case $B$. A wide range of pragmatic or logistical elements, such as location, time, and the availability of data, might well have shaped the decisions of researchers.

\footnotetext{
${ }^{1}$ Stake (2000: 447) further pointed out a number of criteria for the selection of a typical case, which this research has taken into account; i.e. "the nature of the case, particularly its activity and functioning", "its historical background", "its physical setting", "other context, such as economic, political, legal, and aesthetic", "other case through which this case is recognized", as well as "those informants through whom the case can be known".

2 Galileo's rejection of the law of gravity proposed by Aristotle is a typical instance. Given that Galileo chose the extremes of metal and feathers in his research, it means that his research findings could be seen as deriving from the selection of all, or almost all, groups of materials. Therefore, Galileo did not have to conduct observations "across a wide range" or "carried out in some numbers" (Flyvbjerg 2006: 225). In this case, the extremes of metal and feathers were considered as critical cases.
} 
The author originally became interested in Yunnan's external interactions while working towards his MSSc at the Chinese University of Hong Kong (CUHK) in 2013-2014. Back then, the author studied modules about Western China and the new Silk Road by James Seymour and Patrick Wong Yuk-tung, whose emphases on Yunnan as a culturally-colourful, geopolitically-rich region aroused the author's academic interest. Before starting his PhD, the author spent two months in Kunming and talked with some local experts. Three of these particularly deepened his understanding of this province and its cross-border cooperation. One was the deputy director of the Yunnan provincial FAO, who recalled the important participation of Yunnan within the Greater Mekong Subregion (GMS) economic cooperation. Another was a think-tanker, whose views on how Yunnan officials have used various mechanisms to maintain exchanges with their neighbouring counterparts and how commercial chambers have benefited the province's external relations further broadened the author's horizon. The opinion of a scholar at Yunnan University on aspects where Yunnan would be advised to perform better in future dealings with foreign neighbours rounded out the author's curiosity about this topic.

The choice of Yunnan as a case study has been the result of the value of the case per se, but also for some pragmatic reasons. From the review of relevant scholarly works at the early stages of research, the cross-border interactions of other Chinese provinces were considered less institutionalized than those undertaken by Yunnan. In addition, the author had relatively strong networks of contacts within this province. Most crucial to the author's decision was the fact that the cross-border interactions of Yunnan paid equal attention to the building of border stability, socioeconomic development, institution building, and people-to-people exchanges. Since one of the objectives of the thesis was to gain an insight into the international actorness of Chinese border provinces, it seemed appropriate to study subnational governments with more comprehensive external agendas.

\subsection{Approaches to Data Collection}

This section sets out the approaches used to gather the empirical data used for this study. The following section begins with the justification of the three data collection methods: interview (Subsection 3.4.1), content analysis (Subsection 3.4.2), and participant 
observation (Subsection 3.4.3). These methods have been used in examining the question of its motivation, opportunity, capability, and presence. This section concludes with some further explanation of data collection and ethical issues (Subsection 3.4.4).

\subsubsection{Interview}

Interviewing was adopted for this research as one of the data collection methods. This method has been used widely within the social sciences in the wake of technological breakthroughs: the invention of the portable tape recorder made interviews much easier to record from the 1950s onwards, and computer-based programs facilitating the analysis of transcribed interviews added another useful tool for researchers in the 1980s (Steinar 2007). The extensive use of interviews also came about because socially-constructed knowledge from dialogues, discourses, and narratives have been increasingly recognized (Gibbs 2007; Rapley 2007). There are several merits inherent in the interview as a research method. Just as Earl Babbie has suggested (2013: 274), interviewers can attain a higher response rate, reduce the number of "do not knows" and "no comments", clarify the intent of questions to acquire more useful answers if respondents clearly misunderstand them, and observe respondents, adjusting questions accordingly.

Prior to designing an interview guide, the researcher was faced with having to select between structured interviews and qualitative interviews. This selection was made in accordance with the ontological and epistemological positions held by many researchers (Mason 2002). Ontologically, the author believes that people's thoughts, interactions, and experiences are meaningful social properties that can be explored during qualitative fieldwork. The author also held an epistemological position that the data relevant to these ontological properties could be generated from interacting with people, asking questions, and analysing their use of language. Furthermore, the author sees knowledge as situational, interactional, and contextual, which has enabled the author to pose situational and specific questions during interviews, rather than abstract and one-size-fits-all questions. Related to the three aspects, the author believes that the construction of social explanations and arguments can be achieved through the depth, complexity, and roundedness of a study, rather than broad understanding of a superficial phenomenon. 
Bearing these ideological factors in mind, the author preferred qualitative interviews. First, the qualitative interview is generally interactional (Silverman 2013). In carrying out this case study, the author sought not only relevant information from interviewees, but also engaged in dialogue and encouraged interviewees to speak freely and at length. Second, qualitative researchers prefer an informal form of interview (Burgess 2006). To create a more relaxed atmosphere, the author conducted interviews like a conversation with a purpose, rather than an 'interrogation'. At the same time, the degree of formality also varied, depending on the participant. It is hardly surprising that the atmosphere of an interview was somewhat different between interviews with officials from the Yunnan provincial FAO and local experts specializing in Yunnan's water cooperation with the countries along the Mekong River. Third, a qualitative interview is more flexible (Rubin and Rubin 1995; Mason 2002). In this research, the author did not provide interviewees with any pre-set questions and a set of potential responses, which is quite a common technique in research based on a poll or survey. Although the author had devised questions in the preparation phase, these were not articulated to the participant verbatim, but were subject to adjustment and reorganizing before and during interviews. Last, just as qualitative interviews involve the construction or reconstruction of knowledge within a specific context (Kvale 2007), so this research emphasized understanding of the setting in which an interview took place.

Since qualitative interviewing is "time consuming, privacy endangering, and intellectually and emotionally demanding" (McCracken 1988: 27), further logistical issues had to be considered to ensure the quality of an interview. Among these, the most crucial was the selection of interview models. Specifically, this research adopted face-to-face interview as a method. The reasons are that they often yield a better response rate (de Vaus 1991), that they reduce the concerns of participants about the confidentiality and legitimacy of research (Aquilino 1991), and that could well may make participants feel more secure while discussing certain sensitive topics. The strength of this type of interview also lies in its being a "synchronous communication in time and place" (Opdenakker 2006). For instance, engaged in a synchronous communication, the author managed to register particular nuances during the interviews, such as the participants' tone, intonation, and body language. Furthermore, the author's experience accorded with that of previous scholars, in that faceto-face interview fostered a more harmonious ambiance, and a setting within which 
participants were more willing to share their stories and opinions (Groves and Kahn 1979; Jordan, Marcus and Reeder 1980; Sturges and Hanrahan 2004).

A few groups of interviews were carried out by telephone/Skype. This was neither for increasing interviewees' perceptions of anonymity (Schwarz et al. 1991) nor for conducting a short (Harvey 1988), structured (Fontana and Frey 1994), and situation-specific interview (Rubin and Rubin 1995). Given that the respondents reached by telephone/Skype were officials in the Manila-based Asian Development Bank (ADB) and Khon Kaen-based Mekong Institute (MI), scholars from the CUHK, the University of Adelaide, Xi'an Jiaotong-Liverpool University (XJTLU), and Columbia University, the selection of telephone/Skype interview was mainly for convenience. Specifically, it was either because the interviewees were difficult to access in person, because they were out of the geographic scope of this research (Fenig et al. 1993) or because the author made a decision to preserve research endeavours by avoiding excessive travel costs and improving the amount of time dedicated to data collection (Dillman 1978; de Vaus 1991; Wilson, Roe and Wright 1998).

The entire interview process allocated to this research included two rounds. During the first round, from October 2016 to December 2016, the majority of interviewees worked in Yunnan foreign affairs agencies, at provincial and prefecture levels. For instance, knowledge of Yunnan's management of cross-border relations was derived from interviews with officials in Yunnan provincial FAO; knowledge of Yunnan's benefits from its economic complementarity with neighbouring countries was derived from interviews with officials in the Yunnan provincial Commerce Department, and knowledge of Yunnan's connections with overseas Chinese in the Mekong subregion was derived from interviews with officials in the Yunnan Provincial United Front Work Department. The author also conducted interviews with scholars and think-tankers associated with some Kunming-based research institutions, such as Yunnan University. In order to gain access to more comprehensive, objective knowledge, the author also interviewed several government officials and experts in Myanmar and Thailand. The second round of interviews took place between June 2017 and July 2017. During this period, the author met up with three key Yunnanese officials again, and also interviewed two experts from two leading institutions in Beijing with whom the author failed to make an appointment the previous time. The purpose of this second round of interviews was to verify the information the author collected during the previous 
interviews with foreign officials in neighbouring countries, and to strengthen some knowledge regarding Yunnan's involvement in a few cross-border and regional mechanisms. Even though the author did not expect to acquire more new insights at this time, his understanding of the decisive role of the Chinese central government in shaping Yunnan's foreign agenda was deepened.

The initial contacts with the Yunnan provincial FAO were established with the help of a scholar at Yunnan University, who had been acquainted with a teacher of the author's undergraduate programme since they studied together at Tsinghua University two decades previously. The contact information included names, telephone numbers, and WeChat usernames. The author attempted to contact these potential interviewees, and managed to conduct conversations with most of them. Starting with this step, the author employed a snowballing technique, and managed to reach more government officials working in various agencies. The author's contacts with Southeast Asian scholars and officials were facilitated by Simon Shen Xuhui from CUHK, and his supervisor Pradeep Taneja. The officials associated with $\mathrm{ADB}$ and $\mathrm{MI}$ were reached by the author himself, via email. Since most interviewees were associated with one of the public sectors within Yunnan, interviews were chiefly conducted in Mandarin, then translated into English before analysing and comparing. The interviews with government officials and experts in the Indochinese countries were undertaken in English (Appendix 3-4).

\subsubsection{Content Analysis}

In addition to interviews, this thesis is based on extensive examination of written content from both primary and secondary sources. As a research methodology, content analysis originated from studies in the field of mass communication since the 1950s (Berelson 1952). It was then used ubiquitously by researchers in anthropology, management, psychology, sociology, and political sciences (White and Marsh 2006). Ole Holsti (1969: 14) conceptualized content analysis as a "technique for making inferences by objectively and systematically identifying specified characteristics of messages." This view was echoed by Richard Kolbe and Melissa Burnett (1991: 243) who considered content analysis as "an observational research method that is used to systematically evaluate the symbolic content of all forms of recorded communication." 
Data access was facilitated by support from some officials at the Yunnan provincial FAO. They allowed the author free access to non-confidential policy files and internal reports on the external interactions between Yunnan and the GMS countries. These documents offered crucial information and insights on the motivations and outcomes of the paradiplomatic activities carried out by Yunnan. Legal documents, accessed through Yunnan Provincial Library and Yunnan University, were also very important primary data, including the bilateral agreements signed by Yunnan and its foreign counterparts and the legislative documents released by the provincial congress. This information was not available elsewhere. The Yunnan-related archives at the University Service Centre of CUHK also helped map the general characteristics of Yunnan's paradiplomacy, although in a somewhat incomplete way.

As traditional media and communication modes, such as newspapers, magazines, and television news, are being rapidly replaced by interactive media (Skalski, Neuendorf and Cajigas 2002), this thesis drew on such modern technology to gain access to a huge body of media materials, including the external exchanges of Yunnan's provincial leaders, the major Yunnan-invested projects beyond the border, the participation of Yunnan's representatives in bilateral and multilateral mechanisms, and so forth. For this purpose, this thesis employed webpages run by the Yunnan provincial government and its agencies to undertake systematic research. These webpages include a wealth of information in written, visual, and audio formats. Via the Internet, moreover, the author accessed brochures, pamphlets, gazettes, and annual/monthly reports released by the agencies under the provincial government, official think tanks, universities and various multilateral institutions (such as $\mathrm{ADB}$ and $\mathrm{MI}$ ).

\subsubsection{Participant Observation}

However, conducting interviews and content analysis alone would have been inadequate to achieve the "richness and complexity of human life and get closer to understanding the ways people interpret and experience the world" (Lees 2003: 110). This is why a growing number of social scientists and human geographers have emphasized the value of fieldwork and ethnography (Setzer 2013). For many ethnographers, the acquisition of knowledge solely from interviews "remains only a partial contribution to the construction of a fuller understanding of the spatiality of political processes" (Megoran 2006: 625). This indicates 
that even the study of paradiplomacy needs to take into account how subnational officials experience both domestic and international arenas. In this study, the method of participant observation was chosen, therefore, to capture the evidence relevant to Yunnan's external interactions. This method was used to generate data, entailing the author immersing himself into the research setting, experiencing and observing a wide range of information first-hand (Mason 2002). Through the participant observation, the author therefore managed to gain access to the daily lives of people or the operations of institutions involved in either an open or disguised way, while observing what actually happened, listening to what was said, and questioning participants over a rather long haul (Kluckhohn 1940; Vidich 1955).

As participant observation is always time- and resource-consuming, the reasons for choosing this method were very pragmatic. First, after collecting data through interviews and content analysis, it was found that not all meaningful information was articulable, which necessitated having access to 'real-life' settings to derive reliable knowledge. Another rationale was the pursuit of more complex, rounded arguments. In order to avoid conducting a 'superficial' analysis or comparison, the research was aimed at accruing a more profound understanding of the foreign agenda of Yunnan in dealing with neighbouring countries. Still, it was not assumed that access to observational settings should be taken for granted. When the author organized the field trip to Kunming, one local scholar became the author's contact person and offered the author the opportunity to reach various officials involved in the external interactions of Yunnan. Through familiarity with these officials, the author was able to visit frequently the workplaces of the officials from Yunnan provincial FAO, talking with them at various conferences and seminars and at the South \& Southeast Asia Commodity Exposition and Investment Fair (SSACEIF).

A typical instance of participant observation in this research took place as follows. On the understanding that the author would not be exposed to any classified information, it was arranged for him to accompany some staff members from Yunnan provincial FAO to various external events, to watch their interactions with their foreign officials and businesspeople, and to sit in on non-confidential discussion groups. The author remained with one small group of officials responsible for organizing the SSACEIF, spending many days with them during this event. At the SSACEIF, the author closely observed the presentations of Yunnan 
export enterprises and their counterparts from neighbouring countries, and the foci and interests of Chinese and foreign participants. The event also provided the author with a useful opportunity to converse with staff from a number of key enterprises based in Yunnan. It is worth mentioning that, unlike the interviews introduced in the previous subsection, the discussions during participant observation enabled the author to examine the contents of conversation through the study of the context, and to detect misrepresentations which might have gone unrecognized during a normal face-to-face interview (Becker and Geer 1957).

\subsubsection{Additional Explanations \& Ethical Considerations}

This research has been approved by the University of Melbourne's Human Ethics Research Committee. It should be noted, firstly, that one group of interviews was conducted by telephone and Skype. However, some concerns were inherent in this type of interview. One of these is that a telephone/Skype interview deprives interviewers of a chance to observe nonverbal communication (Creswell 1998) and visual cues (Miller 1995). However, this research accorded with many other researchers, who found that this type of interview was not necessarily inferior to in-person interview in terms of the generation of quality data (Aquilino 1991; Sturges and Hanrahan 2004). To a great extent, what telephone/Skype interview lacks in visual cues, it makes up for in verbal cues via telephone communication, such as sigh, hesitation, and repetition.

The findings of this research were derived substantially from interviews carried out with 'elite' members of society. It needs to be made clear what might constitute an 'elite' within social sciences. Although most commentators tend to limit the term 'elites' to those who hold position or power ${ }^{3}$, this research favours the definition offered by Linda McDowell (1998: 2153), classifying elites as those who are "highly skilled, professionally competent, and class-specific." Therefore, the so-called elite interviews in this research were not restricted to policymakers, but include business leaders of state-owned enterprises (SOEs),

\footnotetext{
${ }^{3}$ Evanston Dexter (1970: 5), in his groundbreaking work Elite and Specialized Interviewing, conceptualized elites as "people in important or exposed position (who) may require VIP interviewing treatment on the topics which relate to their importance or exposure." By David Richard (1996: 199), similarly, elites were referred to "a group of individuals, who hold, or have held, a privileged position in society... and are likely to have had more influence on political outcomes than general members of the public." Katherine Smith (2006) even differentiated 'elites' from 'non-elites' in terms of whether they possess power to which only a few individuals gain access. Harriet Zuckerman (1972) further coined the term 'ultra elites' to depict those who hold a significant amount of power within a certain group.
} 
influential academics, and semi-official think-tank members. The advantages of elite interviews as suggested by David Richard (1996: 200) largely represents the reasons why the author sought more information from these participants. First, these participants, whether from administrative units or universities, possessed first-hand information that was difficult to access through public channels. Also, these participants were very close to the provincial authorities; for instance, some took part in the drafting of provincial policies or were habitually consulted by policymakers. The conversations with them, therefore, deepened the author's understanding of the motives behind provincial external moves, beyond the official propaganda. More profoundly, as this research indicates, a 'collateral' benefit from elite interviews was to build up networks, thereby offering opportunities to reach people who might otherwise be inaccessible.

Third, more discretion is required concerning participant observation. For one thing, to reduce bias in substantiating or repudiating a hypothesis, participant observation should be conducted in a neutral 'unthinking' fashion by simply recording what is observed in the field (Becker 1958). This research, as with other similar projects, was based on formulating hypotheses before data collection. It is also, arguably, acceptable because preconceived knowledge of subjects could lead to a purposive observation. In addition, some questions might be raised concerning whether people being 'observed' actually had a chance to witness the occurrence they depicted, whether their private perspectives or feelings about a particular event or person might have shaped the authenticity of their stories, and to what extent the statements or behaviours of informants are the same when they are not being observed (Becker 1958). These problems are clearly more evident within the setting of China, where both national and local officials exercise self-scrutiny, especially when they are dealing with overseas researchers. However, this research found that, even if some statements provided were somewhat misleading, they were still useful for reaching a different kind of conclusion, and for becoming aware of reasons why such false statements might be produced.

Fourth, with reference to content analysis, credibility is everything. Within quantitative content analysis, credibility refers to numeric value, which can be increased with an improvement in the degree of agreement between two independent coders (Strijbos et al. 2006). For this research, as with other qualitative analysis studies, credibility was improved 
by triangulating with information from other sources or from quantitative data (Elliott, Ficher and Rennie 1999; Madill, Jordan and Shirley 2000). Great importance has been attached within this thesis to selecting a strong case and to self-reflection since the beginning of the study (Potter and Levine-Donnerstein 1999; Sandelowski 1995). At the same time, as this research also depended on some official webpages where a vast amount of content was digitized and allowed easy downloading, the author clearly differentiated user-generated content (UGC) from user-selected content (USC). This is because the UGC, the original information, rather than being re-posted or shared online, was considered more reliable.

With regard to ethical risk, it is crucial to acknowledge that it was generally minimal within this research. Even so, I have noted that controversial issues could not be avoided during participant observation and interview. During participant observation, the worst scenario, as suggested by Elizabeth Murphy and Robert Dingwall (2001: 340) is that "research participants may experience anxiety, stress, guilt and damage to self-esteem during data collection." The more common scenario is that participant observation might cause harm to the people who might be 'on view' for much longer periods of time (Mason 2002). Therefore, before observation studies, the author sought consent from participants with whom he intended to build relationships based on reciprocity, equality, and respect. Despite the fact that the author did not resort to covert observation, it was inevitable that overt observations still involved covert elements. For instance, it was almost impossible for the author to gain permissions from everyone who might become participants surreptitiously and unintentionally. Another issue was that the author had to carefully identify what could be counted as usable data, and what could not be, to protect the safety of participants, even though the author's observation was already endorsed by them.

During interviews, generally considered less 'risky' than participant observation, one of the controversial points that came up was the maritime dispute between China and the Southeast Asian countries over the South China Sea. Another was China's dam-building along the Mekong River. It was relatively safe for participants living outside China to criticize the moves of Beijing or Yunnan in relation to these issues. When it came to Chinese participants, however, it became quite sensitive during interviews. The author took various measures, therefore, to minimize risks to participants: almost all participants were reached via email or 
phone call privately; they were made completely aware of the subject of this research and the objective of the interviews, and allowed to decide whether to participate or not. Once they agreed, interviews were held in quiet and safe venues, such as conference rooms and offices.

\subsection{Conclusion}

The main purpose of this chapter has been to lay out a methodological foundation for the empirical chapters that follow. To address the research question in an effective way, this thesis is based on a typical case study, analysed using a qualitative approach. Of all the border Chinese provinces, Yunnan was chosen as the focus of study because of the academic and logistical considerations outlined above. This thesis has employed interview, content analysis, and participant observation to collect data. The next four chapters apply this methodological framework to the empirical study of the paradiplomatic agenda of Yunnan in dealing with neighbouring countries. 


\section{Chapter 4}

\section{Dimensions of Yunnan's Actorness: Motivation}

\subsection{Introduction}

This chapter will discuss the first dimension of Yunnan's actorness: its motivation. The main question this chapter will address concerns what incentive or motivation there has been for Yunnan to be active in cross-border engagements. Through examining the domestic setting within which Yunnan has been driven to become an international relations actor, this chapter argues that the opening up of the border regions in China has provided a policy space for Yunnan to forge a closer economic relationship with its neighbouring countries. Furthermore, it is argued that the increasing ineffectiveness of the central government in coping with macroeconomic and border issues pushed Yunnan to consolidate its own international connections, and the growing competition between Yunnan and Guangxi over economic interests in the Mekong subregion has stimulated Yunnan to increase its own leverage there.

Beijing began its 'opening up' policy in the late 1970s, and this in turn gradually motivated its provincial governments to play proactive roles in foreign economic relations. As for Yunnan and other border provinces, although their border trade rose during the initial phase of the 'opening up' policy direction, it was only after Deng Xiaoping's southern tour in 1992 that they were officially allowed to pursue their interests in the world market. The opening up of the nation border has further paved the way for Yunnan to represent China in the Greater Mekong Subregion (GMS) economic cooperation framework, a regional grouping of nation states in the Mekong Basin. Yunnan's interest in external affairs has not diminished after the eighteenth congress of China's Communist Party (CCP), despite Beijing's efforts to recentralize powers across various fields under President Xi Jinping.

This chapter further argues that Yunnan has been stimulated to cooperate with the Mekong countries when the central government in Beijing had failed to effectively reduce regional developmental disparities and manage certain border-related issues. In the first place, a lopsided developmental strategy has resulted in a widening gap between the coastal and 
non-coastal provinces in China. In the case of Yunnan, the central government failed to help the province effectively catch up with the development of the coastal regions, such as Guangdong and Fujian, which placed Yunnan in a situation in which it has had to boost its economy by engaging proactively in economic exchanges with neighbouring countries. Furthermore, the problems of the central government in managing some border-related issues have pushed Yunnan to interact with foreign neighbours in order to create a stable regional environment.

The last factor that has motivated Yunnan to redouble its diplomatic efforts is the intensifying competition between Yunnan and Guangxi. Yunnan had been the primary participant in the cooperation between China and the Mekong countries since the 1990s, but its salience declined with the growing external trade and investment activism of Guangxi. This caused discontent with the central government among the political and academic circles within Yunnan, especially after the decision by Beijing to make Nanning, the capital city of Guangxi, the permanent host city of the China-ASEAN Trade Fair (CAExpo) and to deprive Yunnan of its status as the sole Chinese participant in the GMS. In part to deescalate the rivalry between Yunnan and Guangxi, the central government has set about redistributing the benefits of external engagement between the two provincial entities, thereby revitalizing Yunnan's external role by other means.

Through the present analysis, however, it has been found that the Yunnan's motivation to pursue external interests has been constrained by the central government through the configuration of the provincial agencies responsible for external interactions. Some prominent departments have been under so-called 'dual leadership'. This means that, despite the fact that these departments were created to fulfil a wide range of provincial tasks, they must also answer to the central government. In the light of the existence of various government departments and local authorities within Yunnan with their own external interests, the provincial government has established a range of superagencies in the name of small leading groups, to ensure that the external activities within the province are in line with the central and provincial policies.

This chapter is divided into five main sections. A comparison between foreign policymaking in the Mao era and the reform era is briefly presented in Section 4.2. Among innumerable changes during these two periods, the multiplication of domestic actors in international 
relations, particularly provincial governments, is identified in this section. Section 4.3 discusses a few domestic developments that have incentivized Yunnan to conduct crossborder engagements. These developments are the opening up of the border (Subsection 4.3.1), the ineffectiveness of the central government in managing some macroeconomic and border-related issues (Subsection 4.3.2), and intensifying competition between Yunnan and Guangxi over external interests in the Mekong subregion (Subsection 4.3.3). This chapter ends in Section 4.4 with an examination of the limitations of Yunnan's external motivation by looking at the configuration of relevant provincial agencies.

\subsection{Multiplication of Foreign Affairs Actors}

This section begins with a comparison of the domestic environments in relation to the making of foreign policy during and after the rule of Chairman Mao Zedong, identifying one of the most apparent differences: the multiplication of foreign affairs actors in China during the post-Mao era. The objective of this section is to provide a historical background within which Yunnan and other Chinese border provinces have become international actors.

In the first three decades of the People's Republic of China (PRC), its political system was rather coercive and, some would say, totalitarian (Lewis 1963; Perkins 1966). Although there were two rounds of devolution of powers from the central government to the provinces in the Mao era, they were considered by many scholars as an effort by Mao to reduce the influence of bureaucrats in state ministries, which had threatened the powers of the Central Party Committee and Mao himself (Zheng 2007; Hameiri and Jones 2016). In other words, these rounds of decentralization were not meant for the empowerment of provinces for their own economic development. In foreign policymaking, Beijing maintained a tight grip over relations with other countries, negotiating foreign treaties, and commanding the People's Liberation Army (PLA), all of which turned other subnational entities and non-state agencies at all levels into passive actors (Chu 2008). This tightening of power in the hands of the central authorities was evident in the statement by Premier Zhou Enlai that "there are no small matters in foreign affairs (外交无小事)" and “the authority of foreign policy decision rests with the CCP with very limited power delegated (to other Party and State Council's agencies or local authorities)" (Yang 1995: 91). At the time, although provincial governments had established guiding committees for international issues, they were tasked 
only to assist in national diplomatic work, rather than pursuing their local external interests (Li 2017). The very limited external interactions initiated by provincial governments were largely conducted for political and strategic reasons, such as granting foreign aid to underdeveloped, socialist countries in Southeast Asia and Africa (Harris 2005).

However, this is not to say that Chinese provinces made no input into foreign affairs in the Mao era. Provincial governments were asked to sponsor the PLA during the Korean War in the 1950s and in border conflicts against India and the Soviet Union in the 1960s (Cheung and Tang 2001). Provincial governments were also active in external affairs in the late 1960s when the Cultural Revolution paralysed the operation of the central government. At other times, nonetheless, provinces were tasked only with clearing the remaining forces of the Kuomintang (KMT), which had ruled mainland China (1911-1949) and was defeated by the $\mathrm{CCP}$, and were occasionally tasked with some ceremonial issues, such as receiving visiting foreign guests and building friendship province relationships (Chen, Jian and Chen 2010; Jersild 2014).

The exclusion of provinces from international relations, however, ended with the third plenum of the CCP's Eleventh Congress in December 1978. In order to sustain economic growth and improve the transparency of foreign policymaking, the central government decided to restrict the influence of senior leaders in the making and execution of foreign policies, while authorizing more administrative bodies and social groups to pursue their external interests (Lieberthal 2007). Consequently, a number of ministries have been approved to pursue foreign agendas themselves, which, however, entails parallel responsibilities in foreign affairs, for example between the Foreign Ministry and the Ministry of Commerce. The lack of clear division of labour between these ministries frequently sends contradictory messages about some hot-button regional issues, such as the maritime territorial dispute over the South China Sea, in that these ministries focus overly on their own agendas (Lai and Su 2014). Besides, the PLA also wields influence over foreign and security policies, even though it was not allowed to participate directly in these issues according to the 'civilian control, military subordination' doctrine (Swaine 2012; Ji 2014). At lower levels of significance, the PLA generals have leeway in deciding the external issues closely related to their interests. The state-owned enterprises (SOEs) can also become 
international players, shaping China's international relations both positively and negatively (Haglund 2008).

In addition to these actors, a group of influential individuals have also had the ear of state leaders about foreign policymaking. These individuals include local officials, some military soldiers, leading intellectuals, and journalists. For Robert Ross (2013), China's new assertiveness, as of 2010, was driven neither by the regional situation nor the country's military strength; instead, it was attributed to growing nationalist sentiments among Chinese grassroots groups who pressured policymakers to toughen up their handling of national security issues. By examining the role of Chinese netizens in framing China's response to the Belgrade embassy bombing, the Sino-American spy plane collision, the 9/11 terrorist incident, and the 2001 Afghanistan War, Simon Shen (2007) found that, while the power to formulate China's foreign policy was in the hands of the Party and state organs, netizens could, by expressing opinions or calling for demonstrations, shape the country's foreign policymaking. Moreover, the influence of Chinese returnees from abroad on the country's foreign policy should not be underestimated. Over the past decade, a growing number of returnees who worked for Chinese governments at various levels, wellconnected research institutes, and the media, have enthusiastically articulated their opinions on major international relations issues, especially Sino-American relations (Li 2010).

More to the point, during the reform period, the influence of provincial governments on China's international relations was elevated, especially on issues of 'low politics'. This began with external activism in the coastal regions, with the rest of the country, including Yunnan and other border provinces, catching up (Chen 2005; Li 2017). Apart from continuing to receive foreign guests, build friendship or sister province relationships with foreign counterparts, organize international events under the directive of the central government, provinces have also been more concerned with attracting foreign investment, stimulating exports, and launching foreign-invested companies (Cheung and Tang 2001). The following sections are concerned with the specific domestic developments that have driven Yunnan to become an international relations actor. 


\subsection{Domestic Developments}

This section sheds light on the domestic environment in which Yunnan's interest in external affairs has been catalyzed. It has to note that the external powers of Chinese provinces have not been enshrined in the Chinese constitution, but can only be detected in the policies and behaviours of the central and provincial governments. As a matter of fact, only a few subnational governments in the world have constitutionally explicit foreign affairs powers. Therefore, a mere reading of a country's constitution rarely reveals whether a country is decentralized or centralized in foreign affairs. For Brian Hocking (1999: 18), constitutions are "no longer reliable guides to the role and place in world politics of the various levels of national political authority." For many subnational governments, while their national authorities claim to have the exclusive power to direct international relations from a constitutional point of view, they are still allowed to undertake extraconstitutional activities and project overseas (Michelmann 2009). Like most countries in the world, the PRC does not constitutionally motivate its provincial governments to engage in international relations. As originally written in 1954, for instance, the Chinese constitution (NPC 1954) did not mention the functions of provincial governments in both domestic and foreign issues. It was not until the early 1980s that the constitution (NPC 1982) finally added the administrative prerogatives of local (provincial) governments:

Local people's governments at or above the county level, within the limits of their authority as prescribed by law, conduct administrative work concerning the economy, education, science, culture, public health, physical culture, urban and rural development, finance, civil affairs, public security, nationalities affairs, judicial administration, supervision and family planning in their respective administrative areas; issue decisions and orders; appoint or remove administrative functionaries, train them, appraise their performance and reward or punish them.

Even so, the 1982 constitution did not touch on the handling of international relations by provincial governments. However, as elsewhere, it is inadequate to judge whether Chinese provincial governments play any role in international relations by merely looking at constitutions. For one thing, static legal codes cannot thoroughly reflect the most updated central-local interactions (Zheng 2007; Yang 2014). For another, China is perhaps subject to the problem of 'fake constitutionalism' (Kuznetsov 2014). This means its political process is 
mainly decided by non-constitutional mechanisms rather than by the constitution, and its constitution, rather than being prescriptive, has tended to reflect realities after the fact. Essentially, any attempt to check whether Chinese provinces have the capacity and access to build their own foreign connections should be made through close observation of the interactions between central and provincial governments.

\subsubsection{Opening up of the Border}

Chinese provinces have been incentivized to participate in international economic relations since 1978 (the third plenum of the CCP's Eleventh Congress), when Deng Xiaoping announced the opening up of coastal regions (Chen 2005; Yang 2014). Three decades into the reform, China had become a 'voluntary regulatory state', with provincial governments capable of deciding whether to implement policy enacted by the central government (Breslin 2013). China was also considered to have adopted "fiscal federalism under a unitary system" (Yang 2014: 255), if not 'de facto federalism' (Zheng 2007) or 'restorative federalism" (He 2007). Some commentators have even explicitly labelled China as "one of the most decentralized countries in the world, if not the most" (Landry 2008: 3). In foreign affairs, whereas some paradiplomacy scholars have dismissed the empowerment of provincial governments as a tactical arrangement, more have come to believe that this trend would gain momentum over the long haul (Soldatos 1990; Segal 1994; Cornago 2000). This view accords with Li Mingjiang (2014), who argued that 'local liberalism' has been adopted by Beijing, since provinces can collaborate transnationally across many fields, albeit within the parameters stipulated by the central authorities.

Still, this is not to say that the provincial governments were capable of conducting extneral affairs as soon as the 'opening up' and reform was launched; instead, in the early years of reform, the central government still remained the predominant decision-maker in foreign relations, monopolizing the management of land and mineral resources and large investment projects (Yang 2014). It was only later, after the setting up of the Special Economic Zones (SEZs) and 'open cities', that provinces, especially in the coastal regions, were given the policy space to pursue external interests by forging external connections (Li 2017). The economic returns from this round of decentralization made Beijing more willing to broaden provincial autonomy in foreign economic relations. 
As for Yunnan in particular, in the early 1980s, the provincial government released two documents, the Temporary Measures for the Administration of Sino-Burmese and the SinoLao Border Trade and the Regulations of the Administration of Small-Volume Trade in SinoBurmese Border Region, with the aim of freeing up cross-border trade, which was almost totally suspended during the Cultural Revolution (1966-1976). Nonetheless, the practical effect of these documents was minimal: they merely managed to restore the level of Yunnan's border trade to the level of the 1950s, and there were no new moves in enlarging the scope of the open area (Yang 2001). Subsequently, in 1984, the State Council rolled out the Measures for the Administration of Small-Volume Border Trade, in which it was approved for Yunnan to look for external markets, negotiate with foreign partners, and balance the profits and losses of their trade. Stimulated by this policy, the Yunnan provincial government relaxed a series of regulations ranging from trade volume and investment to tax collection and the choice of currency, while setting up twenty-seven border trade zones and allowing border residents to engage in border trade beyond 20 kilometres of the frontier.

Still, it was not until the completion of Deng Xiaoping's southern tour in 1992 that Yunnan was fully incentivized to engage in cross-border cooperation (Cheung and Tang 2001; Vogel 2011). In the wake of the tour, two landmark policies were released at the national level to further incentivize border provinces to cooperate with neighbouring countries. The first was drafted by the Central Committee of CCP to open five inland cities along the Yangtze River and grant the same favourable conditions to thirty provincial capitals as to the coastal economic special zones. Another was issued by the State Council in which Kunming and other non-coastal capital cities were provided with the autonomy akin to their coastal counterparts and were encouraged to further devolve power downwards to border towns. Thanks to these policies, Yunnan started to contextualize its development within the greater vision of regional cooperation, as was reflected in its Eighth Five-Year Plan, vowing to walk away from decades of isolation and upgrade its connectivity through the Mekong subregion all the way to the Indian and Pacific Oceans (通边达海) (Zhu 1992; Li 2014).

Yunnan was even encouraged by the central government to take an active role in the Greater Mekong Subregion (GMS) economic mechanism. Given that the GMS is a regional grouping of nation states, it may be considered surprising for Beijing to allow Yunnan to be 
the primary Chinese participant. Since then, Yunnan's external affairs powers have been enlarged accordingly. For example, before joining the GMS in 1992, Yunnan was simply supposed to report to Beijing if it sought to launch any external projects (一事一报). In the first decade of the GMS, however, a host of large-scale projects, like the Lancing-Mekong shipway, the Kunming-Bangkok Highway, and the customs clearance facilitation, were initiated by Yunnan without reporting to Beijing in advance ${ }^{4}$. One interviewee cited an Indian official as saying: "It is unbelievable that the officials from the Ministry of Foreign Affairs (MOFA) and the Ministry of Finance (MOF) were taken into Yunnan's delegation as regular members, but when my colleagues from West Bengal wished to cooperate with Yunnan, they were given little power in foreign affairs from New Delhi ${ }^{5} . "$

Furthermore, not unlike other provinces, the external interest of Yunnan provincial officials has not diminished after the Eighteenth Party Congress ${ }^{6}$. Soon after President Xi Jinping took office, Yunnanese officials, academics, and policy advisers were required to go through more complicated procedures for travelling abroad. In the end these rules turned out to be part of a crackdown on extravagance and corruption rather than constraining provincial external interactions ${ }^{7}$. Subsequently, even these rules were somehow relaxed, clearing the way for Yunnan to interact with neighbouring countries under the Belt and Road Initiative ${ }^{8}$.

\subsubsection{Inefficiency of the Central Government}

This subsection suggests that Yunnan has been motivated to consolidate its foreign linkages in response to the ineffectiveness of the central government in bridging regional economic disparities and tackling certain border-related issues. Within the paradiplomacy literature, the activeness of subnational governments in foreign affairs has usually been seen as a natural corollary of the relative declining state capacity (Balthazar 1999). The underlying cause is threefold. First, advancements in communications have eroded the monopoly of

\footnotetext{
${ }^{4}$ Interview with a government official, November 1, 2016, Kunming.

5 lbid.

${ }^{6}$ For discussions of the tightening of foreign affairs powers in the era of President Xi Jinping, political scientists on China have found evidence in the establishment of the Central National Security Commission (CNSC) (Hameiri and Jones 2016; Willy 2015; Shambaugh 2016). These scholars tended to cite Xi as saying that the CNSC was founded as a powerful coordinating platform to centralize the control over national security. Another example is the hosting of the Central Conference of Work Relating to Foreign Affairs in 2014. The level of this meeting, presided over by Xi himself, was higher than the previous two mekongetings, which indicates Xi's mounting attention to diplomatic works (Zhang 2014).

7 Interview with a government official, June 15, 2017, Kunming.

8 Ibid.
} 
nation states over information and brought non-state actors closer to foreign partners (Keohane and Nye 1974). Another is that the ideology of the 'embedded liberalism' has propelled both central and local governments to take more responsibility for managing social and economic chaos, generated by markets within their territory (Krasner 1982). A third is that subnational governments have perceived the urgency of directly tackling their external concerns rather than waiting for the central authorities, in that "subnational leaders and their publics often oppose the centre on the ground that it is unwieldy, big, over-bureaucratized, dehumanized, and above all, distant and unfamiliar with where the local and regional shoe pinches" (Duchacek 1984: 16).

In Yunnan, after enormous economic resources had been allocated in support of the coastal regions, Yunnan decided to benefit from more economic exchanges with neighbouring countries (Xiong and Xuan 2013; Tubilewicz and Jayasuriya 2015). Specifically speaking, during the reform, Yunnan found that its backwardness was, to a certain extent, worsened by the central government channelling a large portion of resources into the coastal provinces (King 2002). As a direct result of this uneven development strategy, the economic gap between Yunnan and its coastal counterparts became increasingly evident. For instance, Yunnan's GDP was behind Guangdong by just RMB10 billion in the pre-reform era, but their difference climbed to RMB41.42 billion in 1985. Compared with Fujian, another open province along with Guangdong, Yunnan's GDP had actually been on a par with it, only to be completely overtaken by Fujian in the early 1980s (Appendix 5). This disparity was bound to deteriorate after China's launching of the 'outward-oriented development strategy in the coastal areas' or 'coastal development strategy' in early 1988. This strategy was formulated against the background that the coastal region accounted for less than 14 per cent of China's land area, and 41.3 per cent of the population created 60 per cent of gross national industrial output and almost 80 per cent of China's foreign trade (Yang 1991: 42). The primary objectives of this strategy were for the coastal regions to fully participate in the international economy through boosting their labour-intensive processing industries, gaining more access to internal and external investment, and tapping into the already disadvantaged inland and border regions to purchase product materials at a low price. 
In the face of the widening disparity, however, Beijing delayed rolling out tangible policies to address domestic developmental imbalances effectively. Its persistence in favouring the development in the coastal regions met with substantial discontent from Yunnan. For example, days after the coastal development strategy was launched, Xiao Zujing (1988), the director of Kunming Policy Studies Office, complained that this strategy would make rich provinces richer and poor provinces poorer. The Yunnan Daily, a mouthpiece of the province's Party committee, invited a group of local policymakers and researchers to discuss ways for Yunnan to overcome the regional gap, which was likely to be widened by the 'coastal development strategy'. The old mentality for Beijing seemed to have been embodied in the remarks of the then Party General Secretary, Hu Yaobang, who had suggested that although the southwestern provinces could depend on the support and policy of the central government, they should rely more on their own hard work. When mentioning Yunnan, Hu was explicit "both Comrade Deng Xiaoping and I believe that the cooperation with Guangxi and financial support from the central government alone could not sustain Yunnan's development. More importantly, Yunnan must connect itself with the sea via Myanmar" (people.com.cn 2014).

However, even as Yunnan had to take the initiative to boost border trade and investment, sometimes the external interests of Yunnan clashed with the policies of the state. This was also evident in the disagreement between Yunnan and the Ministry of Commerce (MOFCOM), which prior to 2003 was known for many years as the Ministry of Foreign Trade and Economic Cooperation (MOFTEC). The MOFCOM, a primary agency in the formation and execution of specific trade policies under the State Council, has occasionally released policies that were not in Yunnan's interest. For instance, Yunnan was opposed to the MOFCOM's provision to the state-owned enterprises (SOEs) large quotas for importing foodstuffs from the Mekong countries. These SOEs included China National Cereals, Oils and Foodstuffs Corporation (COFCO) and China Grain Reserve Corporation (Sinograin) ${ }^{9}$. The MOFCOM also restricted access to frozen goods from the Mekong countries, two negative consequences of which were to increase import costs for Yunnan and to galvanize more cross-border smuggling ${ }^{10}$. One more policy was for the MOFCOM to slap import quotas on rice and beef from the Mekong countries in the name of anti-dumping, regardless of its

\footnotetext{
9 Interview with a government official, December 1, 2016, Kunming.

10 Ibid.
} 
adverse impact on Yunnanese enterprises ${ }^{11}$. In the face of opposition from local officials and businesspeople, Yunnan established several free trade experiment zones, in which the province could formulate its own import regulations and market access standards to facilitate its exchanges with neighbouring countries.

The lack of experience and inattention of the central government with regard to borderrelated matters have also prompted Yunnan to contend with these matters themselves. Encountered by the mounting negative sides of economic internationalization across the border, MOFA moved from making border-related decisions to providing material and political support, leaving the daily exchanges with the Mekong countries to Yunnan. The officials in Yunnan perceived that Yunnan is better able to deal with these issues than MOFA, which was far away in Beijing (Su 2013). As one interviewee put it:

As a border province, Yunnan is tasked with the issues that should have been handled by the central government. It is, therefore, no exaggeration to say much of Yunnan's foreign affairs tasks have no significant difference with MOFA. We often joke that Yunnan provincial Foreign Affairs Office (FAO) should be made a branch of MOFA so that Yunnan would no longer need to report to MOFA and other ministries. Though the central government wants to keep a grip on Yunnan's border management, MOFA is unfamiliar with the local situation and lacking in the capacity to get things done. Nor do MOFA and Yunnan have the same perceptions of urgency. That is, what Yunnan sees as pressing may not be so crucial to MOFA ${ }^{12}$.

When recalling his experience of working with the officials of the National Development and Reform Commission (NDRC) at a forum for the Bangladesh-China-India-Myanmar (BCIM) Economic Corridor, one interviewee charged NDRC officials with lacking the motivation to conduct cross-border projects and strategic vision. He was also critical of the professionalism of NDRC: although one of the deputy heads of NDRC attended the opening ceremony, he soon left to have tea outside, leaving Yunnanese officials to negotiate the deal. In sharp contrast, the deputy Foreign Ministers of India and Bangladesh remained at

\footnotetext{
11 Interview with a government official, November 2, 2016, Kunming.

12 Interview with a government official, November 2, 2016, Kunming.
} 
the convention hall, even revising and typing documents themselves ${ }^{13}$. This view was also echoed by another interviewee:

MOFA has limited staffing, and its focus now is perhaps on Donald Trump. If there is a meeting between $\mathrm{Xi}$ and Trump, MOFA will be entirely preoccupied and have no time for other matters. Our concerns are totally different. Yunnan, for example, cares more about Aung San Suu Kyi rather than Trump. Each time Aung San visits China, she stops by Kunming for a few days. The primary purpose of her latest visit to China is not to attend the Belt and Road Summit; instead, she was more concerned with talking with Yunnanese officials about the peacebuilding process in Northern Myanmar ${ }^{14}$.

\subsubsection{Response to Domestic Competition}

This subsection deals with Yunnan's efforts to consolidate its economic leverage over the Mekong subregion in face of its intensifying rivalry with Guangxi ${ }^{15}$. The competition between the two regions had not been apparent in the 1990s when they worked together on a couple of inter-provincial mechanisms to explore the foreign market and pressure Beijing to devolve economic power, such as the Economic Coordination Association for Southeast China (ECASC) and the so-called '9+2' Grouping (Yang 2001). It was not until the early 2000s that Guangxi severely challenged Yunnan's status in China's relations with the Mekong countries. In addition to the proposals of the 'One Axis, Two Wings' and the PanBeibu schemes, Nanning, Guangxi's capital city, has served as the permanent host city for the CAExpo since 2004, after the central government snubbed Kunming's bid ${ }^{16}$. Guangxi was also admitted to the GMS after 2005, with Yunnan being deprived of its status as the sole Chinese representative in this grouping ${ }^{17}$

\footnotetext{
13 Interview with a scholar, October 27, 2016, Kunming.

14 Interview with a government official, June 15, 2017, Kunming.

${ }^{15}$ For discussion of the domestic competition, oft-cited instances within the paradiplomacy literature include the rivalries between Queensland and other Australian states over opening more state offices overseas (Ravenhill 1999), among the thirty US states over hosting the Volkswagen assembly plant (Duchacek 1984), as well as among the 'Bimaru' states in India (Bihar, Madhya Pradesh, Rajasthan, and Uttar Pradesh) over more foreign investment (Jha 2014). In the case of China, political scientists have revealed two waves in the history of the PRC. The first occurred during the Great Leap Forward in the late 1950s, when provinces tussled with one another for the market, consumers, and goods in Hong Kong (Zheng 1994). Another transpired in the reform era during the late 1970s, as provinces became more proactive in the acquisition of trade, labour force, capital market, and resource allocation (Su 2008). Liaoning and Shandong also clashed with one another over building more linkages with South Korea before China established diplomatic ties with Seoul (Cheung and Tang 2001).

16 Interview with a scholar, October 27, 2016, Kunming

17 Interview with a government official, November 1, 2016, Kunming
} 
Faced with the competition with Guangxi, the government officials and experts within Yunnan chose to downplay the external role of Guangxi. For instance, one official in the Yunnan Foreign Affiars Office (FAO) suggested that Yunnan reflect upon its own problems rather than blaming Guangxi, as the latter should not have such influence over the Mekong subregion $^{18}$. Looking at it in the negative, in particular, a number of scholars attributed Guangxi's growing influence over the Mekong subregion to what the Chinese call 'going through the back door ${ }^{19}$. Some were disdainful in arguing that nearly 40 per cent of the projects proposed at the $5^{\text {th }}$ GMS Summit fell on Yunnan, while Guangxi oversaw merely 10 per cent ${ }^{20}$. One interviewee explicitly linked Guangxi's successful bid for the hosting of the CAExpo to the personal influence of its then deputy Governor Gao Hucheng, who was said to maintain a long-term contact with the Ministry of Commerce and even became the Minister of Commerce afterwards (MOFCOM) ${ }^{21}$. Some even went so far as to accuse Guangxi of 'talking more but acting less' in terms of the Pan-Beibu Gulf regional cooperation programme, a 2006-launched economic platform to boost the influence of Guangxi and deepen cooperation in the Gulf of Tonkin 22 .

In the meantime, Yunnan embarked on redoubling its efforts to persuade Beijing to compensate Yunnan for losing its exclusive position among the Chinese provinces with regard to China's relations with the Mekong countries. In part to de-escalate the competition between the two regions, the central government gave Yunnan a chance to organize the 2005 GMS Leaders' Summit and allowed it to claim to be the primary Chinese representative in the GMS. Kunming, the capital of Yunnan, was also made the permanent venue for the South Asia Expo, even though this expo has failed to match the CAExpo in terms of scale and the level of attendance ${ }^{23}$. One more move made by the central government to 'comfort' Yunnan was to resurrect the province's proposal to build the Third Eurasian Bridge via Kunming (Li 2015).

Yunnan has even been stimulated to take the initiative to "transform" certain national initiatives by interpreting them for its own sake. This found expression in the province's

\footnotetext{
18 Interview with a government official, November 1, 2016, Kunming

19 Interview with a scholar, December 1, 2016, Kunming

20 Interview with a scholar, October 2016, Kunming

21 Interview with a scholar, 1 December 2016, Kunming

22 Interview with a scholar, 31 October 2016, Kunming

23 Interview with a scholar, October 27, 2016, Kunming
} 
elaboration of the decision of Beijing to reposition Yunnan's strategic position in Sino-ASEAN relations, which came after the previous failures of Beijing's effort to improve Yunnan's geographic conditions (Su 2013) ${ }^{24}$. President Hu Jintao's visit in 2009 is considered as a turning point as Yunnan's position as a gateway (桥头堡) between China and Southeast Asia was finally confirmed by the central authorities (People's Daily Overseas Edition 2011). The primary objective of this repositioning was for Beijing to seek external outlets to relieve the mounting pressure stemming from the surplus capital accumulated over the last three decades of development (Harvey 2003, 2007; Su 2013). However, Yunnanese officials elaborated the Gateway scheme from their local viewpoint, viewing it as a critical opportunity for "developing the poor border minority areas, improving the outward orientation of the economy and helping with economic development and the construction of a moderately well-off society" (Summers 2013: 77). In the following years, Yunnan even linked almost all its external projects to this scheme and attempted to grasp each opportunity to advertise its new geopolitical position to overseas investors (Yunnan Daily 2010).

Yunnan's power to exploit the national policy to leverage its geographic location remains in the era of President Xi Jinping, who has claimed to turn the province into a pivot of China's opening-up to South and Southeast Asia (辐射中心) (Yunnan Daily 2015). On the sidelines of the 2015 provincial Congress, for example, Governor Chen Hao called on the province to realize the repositioning by $\mathrm{Xi}$ through the stepping up of high-level exchanges between Yunnan and neighbouring countries, making good use of existing bilateral mechanisms, such as the Yunnan-Northern Thailand Working Team, and enhancing the intensity of the peopleto-people interactions across the border (Yunnan Daily 2016). The GMS Research Centre of Yunnan University explicitly called on the province to take advantage of Xi's proposal to improve its position in China's relations with neighbouring countries across the fields of connectivity, environment, education, sanitation, and non-traditional security (Liu 2015).

\footnotetext{
${ }^{24}$ For example, one year before President Hu Jintao's repositioning of Yunnan as the Gateway between China and Southeast Asia, the gross domestic product (GDP) of Yunnan was merely RMB3570 billion, ranking $25^{\text {th }}$ among 34 Chinese provincial entities, with its poor population in this year accounting for 13.9 per cent of China's total poor (Yunnan Provincial Government 2009).
} 
As some interviewees asserted, such competition between Yunnan and Guangxi has apparently resulted in many repetitive policies and initiatives from both of them, thereby violating the original plan of Beijing to enhance its general interests in Southeast Asia by taking advantage of Yunnan and Guangxi where should have maximized their comparative strengths to propose more nuanced policies ${ }^{25}$. In the era of Xi Jinping, their competition is nowhere near de-escalated. For instance, all have explicitly proposed to become the transportation centre connecting the rest of China with Southeast Asian countries: Yunnan had prepared to complete the construction of transboundary highway, railway, electricity, and telecommunication systems by 2020 (State Council 2011), while Guangxi claimed to be a portal in the new western land-sea channel, which is designed to link China's southwest to Singapore and beyond (NDRC 2019). Moreover, all were determined to develop themselves into a regional financial centre: merely two years after Yunnan had put forward measures in relation to improving Yunnan's agglomeration of variegated financial service industries and promoting Yunnan's financial institutions to launch branches across the border (Yunnan Provincial Government 2016), Guangxi was approved to facilitate the cross-border exchange of the renminbi to further open its financial market for Southeast Asia (People's Bank of China et al 2018).

The latest policy catalyst provided by the central government to Yunnan's external activism is its approval of the latter's application to construct the so-called pilot free trade zone. China's pilot FTZs strategy was initiated in August 2013, with the first FTZ established in Shanghai. So far, 18 pilot FTZs have been established over the country, and they serve as pioneers of Beijing's reform and opening up. All these pilot FTZs are tasked with testing new styles of foreign investment management and trade facilitation, and with transforming government functions to better serve the economy in line with international practices. As detailed in the plan released by the State Council (2019), Yunnan is encouraged to become a crucial link connecting major corridors in South Asia and Southeast Asia, while turning two border prefectures, Dehong and Honghe (which border Myanmar and Vietnam, respectively), into key areas of this pilot FTZ. Within the pilot FTZ, Yunnan is specifically requested to facilitate foreign investment and trade, to establish warehouses in border areas for the purpose of boosting the cross-border e-commerce market, and to build

\footnotetext{
25 interview with a government official, November 1, 2016, Kunming
} 
incubators for tech start-ups on both sides of the border with the provision of investment funds. However, it has to be pointed out that the central government is very likely deliberately to balance the distribution of external interests between Yunnan and Guangxi, as the latter was authorised to set up its own pilot PTZ at the same time. After analysing the official plans of the two regions, it emerges that there are not many variations in terms of their international objectives, as the State Council also supports Guangxi to develop into a gateway between Southeast Asia and China's southwest, upgrade international transport routes, and become a pioneering pilot zone for China-ASEAN cooperation (State Council 2019).

\subsection{Limits of External Affairs Powers}

As previously mentioned, Yunnan has been motivated to expand its external interests, notably since the early 1990s. Not to be ignored is a crucial reality that such motivation was not unlimited, but controlled by the central government mainly through providing 'guidance' to some of Yunnan's foreign affairs agencies. Take, for example, the Yunnan provincial Foreign Affairs Office (FAO), the most specialized organ within the province for formulating and implementing foreign agendas. Despite the fact that its funding and key personnel were provided and decided on by Yunnan provincial authorities, the provincial FAO is under 'dual leadership', which means that it should answer to both provincial government and the Foreign Ministry (Chen, Jian and Chen 2010). The specific tasks designated to the provincial FAO by the Foreign Ministry include ensuring national foreign policies are strictly honoured within the province, conducting field research for state leaders, supervising national boundaries, and providing consular protection to foreign diplomatic missions ${ }^{26}$. After the Kokang incident, a series of conflicts breaking out in August 2009 between Burmese military junta forces and ethnic minorities in Kokang in Myanmar's northern Shan State bordering Yunnan's Lincang city, it was widely believed that Foreign Minister Wang Yi flew to Kunming to brief provincial officials about the sensitivity of this issue and instruct them how to manage $i^{27}$.

In addition to the FAO, the provincial National Security Department (NSD) is also under 'dual leadership'. Co-supervised by the Yunnan provincial government and the Ministry of

26 Interview with a Yunnan official, October 25, 2016, Kunming.

27 Interview with a Yunnan official, 4 November 2016. 
National Security (MONS), the provincial NSD has been responsible for monitoring the activities carried out by foreigners and foreign organizations within Yunnan (Li 2017). Although not formally stipulated, such 'dual leadership' can be found between the Ministry of Commerce and the provincial DOC, and between the NDRC and the provincial DRC (Chen, Jian and Chen 2010). Moreover, in order for the central government to ensure its Mekong policy is well executed in Yunnan, the Governor of Yunnan has been included as a deputy group head in the State Council-steered Lancang-Mekong Regional Development Preliminary Research and Cooperation Group (Tubilewicz 2016). This group also involved all relevant ministries, such the NDRC, the MOFA, and the MOF (Xiong and Wen 2009).

Furthermore, given that almost all provincial departments and local governments have their external interests to pursue, the provincial government has built up a number of superagencies to coordinate their own external activities, and to ensure that national and provincial policies are appropriately conducted. Specifically, the Yunnan provincial government has designated the provincial FAO as the secretariat of the provincial Small Leading Group on Foreign Affairs (SLGFA), chaired by the provincial Party secretary or Governor. This powerful body would convene meetings regularly, leaving its decisions to be executed by the FAO, especially its Division for Policy Research. As an executor of the SLGFA, the FAO has been obligated to coordinate the external interests of the administrative agencies and local governments within Yunnan. The FAO was also empowered by the provincial authority to scrutinize the external activities of provincial-owned enterprises.

The second superagency is the Yunnan provincial Commission for Investment (CFI). The provincial CFI has been a prominent body led by the Governor or Vice Governor responsible for foreign trade and investment. It was tasked with collecting opinions from administrative agencies, local governments, enterprises, and academics within the province for the purpose of drafting laws and regulations on the standardization of the investment environment. Principally for participation in the cooperation under the GMS, the provincial government established a small leading group, led by the Governor and composed of over thirty provincial departments, universities, and research institutes (Su 2012). Its day-to-day operations are managed from an office in Yunnan provincial DRC. Its specific tasks are coordinating the GMS-related activities within the province, drafting mid-term and longterm plans for involvement in the GMS, strengthening bilateral and multilateral cooperation 
with the GMS members, and soliciting support from state ministries (Chen, Jian and Chen 2010).

\subsection{Conclusion}

In this chapter, the author has examined the first dimension of the actorness of Yunnan province: its motivation. Yunnan has been incentivized to carry out cross-border interactions by the opening-up of border regions, the ineffectiveness of the central government in managing certain macroeconomic and border-related issues, and the competition with Guangxi over the Mekong region. This chapter further revealed that Yunnan's external interests were constrained by the central government through the configuration of provincial foreign affairs agencies. Nevertheless, while the motivation for Yunnan to become an international relations actor has been explored, this chapter did not dewell on the influence of the external environment beyond China on the improvement of Yunnan's foothold in cross-border cooperation, such as globalization and new changes in the regional situation. These questions will be discussed in the next chapter. 


\section{Chapter 5}

\section{Dimensions of Yunnan's Actorness: Opportunity}

\subsection{Introduction}

The previous chapter identified three developments in the broad domestic political and economic context that directly motivated Yunnan to become an international relations actor. These developments include the opening up of the border regions, the ineffectiveness of the central government in managing macroeconomic and some border-related issues, and the competition between Yunnan and Guangxi over economic influence in the Mekong subregion. This chapter turns to the second dimension of actorness, opportunity, with a focus on the external environment, covering improvement in the regional situation, the pressure of international institutions, and competition with extra-regional powers. Combined, these two chapters demonstrate how, through profound internal change, while facing a complex external environment, Yunnan has become more proactive in cross-border cooperation.

The chapter begins with a discussion of the regional and international stages on which Yunnan's external activism has been unfolding. It would be unlikely for the Chinese central government to open its border and allow its provinces to become deeply involve in crossborder affairs, should the regional environment be tumultuous. Therefore, it was not until China's relations with the Mekong countries gradually improved that Beijing decided to elevate the external role of Yunnan in dealing with these countries. Although, in the current decade, China's heightened economic influence and diplomatic assertiveness has adversely affected its cooperation with some these countries, the general picture of their relationship has remained favourable to Yunnan's pursuit of external interests.

Related to this point, the burgeoning transnational regionalism in Southeast Asia has proved to be useful to the upgrade of external cooperation among participant countries. This prospect has lured China to follow suit by engaging in regional economic mechanisms, especially some subnational ones. Its engagement in the Greater Mekong Subregion (GMS) economic cooperation is part of China's reaction to this trend. In order to exploit the 
geographic and cultural connection between Yunnan and the GMS members, the central government decided to make Yunnan the primary Chinese participant in this regional bloc. At the same time, the potential benefits of joining transnational cooperation has directly aroused the interest of Yunnanese officials in the involvement of subregional institutions. The chapter also points out that the conclusion of the China-ASEAN Free Trade Agreement (CAFTA) has further driven Yunnan to underpin its engagement in cross-border cooperation by vowing to play an important role in both CAFTA and GMS.

This chapter further reveals that, with respect to its external affairs powers, Yunnan benefited from the outcome of the Uruguay round of the General Agreement on Tariffs and Trade (GATT), and its more recent successor, the World Trade Organization (WTO), which motivated Beijing to close the domestic developmental gap. One of the most pressing conditions that China was required to fulfil in order to be admitted to this organization was to give up on its imbalanced development strategy, which was inconsistent with the principle of fair competition, and to pre-empt potential widened regional disparity after joining this institution. It was against this backdrop that the central authorities proposed the Western Development Programme. Under this programme, the central government embarked on a plan to turn Yunnan into a strong province in relation to ethnic cultures, the green economy, and connecting the rest of China to Southeast Asia. At the same time, the Yunnan provincial government purposely took advantage of the commitment of the central government to the GATT/WTO in terms of narrowing regional disparity, in order to press for more leeway in cross-border cooperation.

Yunnan has also indirectly benefited from the strategic rivalry between China and extraregional powers over the economic and diplomatic influence in the Mekong subregion. These extra-regional powers are the United States, India, and Japan. Among these, Japan has been the most proactive, not just involving itself in the Mekong subregion through the Asian Development Bank (ADB)-led GMS, but also initiating several moderate-scale platforms to boost its communication with the leaders of the Mekong countries. As shown in the chapter, Beijing found that the growing activism of these outside powers threatens its interests in politics, economy, and security. One of the unique advantages possessed by Beijing in the face of competition in the subregion is that it can benefit from the geographic and cultural connections between Yunnan and the Mekong countries, so it is hardly 
surprising that China would encourage more external interactions by Yunnan, to gain the upper hand in this rivalry.

This chapter is organized as follows. In Section 5.2, China's relations with the Mekong countries before and after the Cold War are briefly compared. Through a review of the developments in Sino-Mekong cooperation since the mid-1990s, this section demonstrates how the new external activism of Yunnan was related to the improvement in the situation in the Mekong subregion. Section 5.3 offers an in-depth examination of how the emergence of transnational regionalism has driven the central government to engage more closely with the GMS through Yunnan. It is followed by a discussion, in Section 5.4, on the question of how the growing external activism of Yunnan has relevance to the pressure the GATT/WTO exerted on China to close the domestic gap. Section 5.5 turns to explaining how Yunnan has indirectly benefited from competition over the economic and diplomatic influences between Beijing and extra-regional powers, such as the United States (Subsection 5.5.1), India (Subsection 5.5.2), and notably Japan (Subsection 5.5.3). A brief conclusion to this chapter is provided in Section 5.6.

\subsection{Improved Regional Situation}

This section advances an argument that China has gradually normalized its relations with the countries in mainland Southeast Asia since the 1980s, which has contributed to a stable regional environment in which Yunnan could engage with neighbouring countries more comfortably. During much of the Cold War era, China's relationship with North Vietnam largely determined the attitudes of the rest of the Mekong countries toward its giant northern neighbour (Cho and Park 2013). When China allied with North Vietnam during the Vietnam War (1954-1975) against South Vietnam and the United States, Chairman Mao Zedong allowed the local Communist forces in the Mekong countries to throw China's weight behind their rebellions (Ott and Hao 2018). Therefore, relations between China and these countries were in a state of high tension at the time. As a result, Yunnan was not able to take advantage of its long-standing access to the sea via Hai Phong in Vietnam and Yangon in Myanmar (Li 2014).

The end of the Vietnam War and the subsequent Vietnamese invasion and occupation of Cambodia caused Beijing to reverse relations with Hanoi, and paved a way for the improved 
image of China elsewhere on the Indochinese peninsula. This change also occurred because, in the era of reform, "the leadership in Beijing needed a peaceful international environment within which to concentrate on its economic development" (Kuik 2013: 314). Instead of supporting local insurgencies, China replaced its Indochinese policy with expanding political and military support to the existing regimes in those countries (Acharya 1994; Zhao 2008). In the following years, China adopted a more active approach in vying for the support of the Mekong countries. It came up with the Asian Debt Relief scheme, to write off old debts and provide new foreign aid to these countries (Suehiro 2017). Over the same period, China redoubled its contribution to projects under the GMS. In the early years of this programme, China accounted for only 27 per cent of the total investment value, with 35 per cent coming from $A D B$; however, China would later overtake $A D B$ as the primary investor and is now responsible for more than 60 per cent of the GMS investment in 2016 (Suehiro 2017).

Along with China's policy adjustment, not to be neglected was a series of developments within some Mekong countries which helped bring the regional situation back to normal. In 1986, Vietnam and Laos, two Communist countries, devised the Doi Moi Policy and the Chintanakan Mai Policy, respectively, to springboard their transitions to market economies; in 1988, Thailand promised to step up its trade and investment across the border under the slogan 'take Indochina from the battlefield to the market'; in 1989, Vietnam eventually withdrew its military forces from Cambodia ahead of the normalization of its diplomatic relationship with China; and, in 1991, the Cambodian Civil War came to an end with the Paris Peace Agreement (Suehiro 2017).

The improvement of the situation on the Indochinese peninsula has directly led to the Chinese central authorities devolving more powers to Yunnan in relation to the forging of closer cooperation with neighbouring countries. In the early 1980s, after China began improving its relations with its southern neighbours, the central government turned a few border regions within Yunnan into trading points with neighbouring countries (Yang 2001). In 1992, two years after the end of the Cold War, the central government approved Yunnan to set up five national-level and twelve provincial-level border towns (Masviriyakul 2004). Yunnan was also authorized by the central government to join the GMS on its behalf, and inaugurated the Kunming Import \& Export Fair (KIEF). The new developments in the Mekong countries have also consolidated the momentum of the opening up of Yunnan. Apart from 
Thailand, which had already established a market economy, other the Mekong countries had only recently opened up their domestic markets. Yunnan was one of the biggest Chinese beneficiaries from these markets, with huge potential demand. For instance, when Vietnam was in urgent need of steel, phosphoric products, and electricity, in the 2000s, Yunnan became the primary provider of these goods to Hanoi, and even saw its biggest buyer changing from Myanmar to Vietnam, in 2009 (Qu 2009). When Myanmar loosened its trade policy, Yunnan's export to the Mekong countries surged by 67.2 per cent and its imports by 99.2 per cent (Wang 2014).

Nonetheless, while China has been proactively turning its economic influence into diplomatic weight, a question has naturally arisen: will the intensifying apprehension in the Mekong countries about China's assertiveness adversely affect Yunnan's cross-border cooperation? Specifically, China's efforts to turn economic influence into diplomatic clout can be seen from its calling for joint patrol of the Mekong River, and the repositioning of Yunnan as a gateway for China's strategic engagement in the Indian Ocean (Sun 2012). It is also evident in China capitalizing on its investment and foreign aid to pressure Cambodia into expelling Uighur asylum seekers, and standing with Beijing on the issue of the South China Sea (Reilly 2012; Touch 2018; Chandran 2018).

As Myanmar, Cambodia, and Laos have become China's de facto client states, and Vietnam and Thailand have been economically beholden to China (Wade 2011), a backlash against China's influence was to be expected (Yoshimatsu 2015). For example, Vientiane started pushing back against China's investment in railways, mining, hydropower, and gambling (Reeves 2013). Similar resistance could be found in Myanmar, which suspended China's construction of the Myitsone dam and expedited its engagement with Western countries (Sun 2012). More interestingly, the Mekong countries turned to extra-regional powers to hedge against China's burgeoning leverage. For instance, as China sought to legitimize its claim over the South China Sea and militarized some islets there, Vietnam redoubled its cooperation with the United States, to win US support for its territorial claims (Yoshimatsu 2015). When China upgraded its presence in Myanmar, Naypyidaw took advantage of the concern of India about China's threat in the Indian Ocean to exhort New Delhi to replace its opposition to Myanmar's military junta with a pragmatic, non-interventionist policy (Lall 2006; Shee 2008; Zhao 2008). In the face of China's pervasive economic and diplomatic 
pressure, Cambodia was performing an intricate balancing act (Dalpino 2017). For instance, Prime Minister Hun Sen not only solicited Japanese investment, but also invited Japan to observe the latest national election (Nachemson 2018; Touch 2018).

Despite the fluctuations in China's relations with the Mekong countries, Yunnan's already intensive engagement with these countries would be unlikely to be heavily influenced by these. The Mekong countries were aware that China's economic support, especially in infrastructure construction, is vital to their countries' growth. For example, these countries benefited substantially from trade with China, with their trade scale expanding 5.3 times from approximately USD 11 billion to more than USD 60 billion between 2006 and 2013 (Yoshimatsu 2015). China-funded infrastructure projects further enabled these countries to connect with Yunnan via complicated highway and railway systems. The establishment of a network of hydropower stations, power transmission grids, and oil and gas pipelines, despite controversies, increased the interdependence between China and the Mekong countries. These substantial benefits have provided these countries with strong incentives to continue their engagement with China. In particular, as one interviewee pointed out, the possibility of Vietnam, China's biggest adversary on the Indochinese peninsula, coming into conflict with China and halt its exchanges with Yunnan is close to zero. This is because of their profound economic interdependence; for instance, the Vietnamese border town of Lao Cai opened a four billion RMB account in the Hekou subbranch of China Agricultural Bank three years ago, which has now reached more than ten billion ${ }^{28}$.

\subsection{Development of Transnational Regionalism}

The preceding section argued that the improved Sino-Mekong relationship has enabled Beijing to propel Yunnan to reinforce its cooperation with neighbouring countries. Related to this point, this section further points out that improved relations among the Southeast Asian countries have advanced transnational regionalism, which has provided an opportunity for the Chinese central government and Yunnan to engage more intensely in cross-border cooperation. The following section will discuss the emergence of transnational regionalism in Southeast Asia, in the late 1980s and early 1990s, followed by a discussion of the impact of this development on Yunnan's participation in subregional cooperation. Also

\footnotetext{
28 Interview with a government official, November 13, 2016, Kunming.
} 
explored is the reaction of Yunnan to the conclusion of the China-ASEAN Free Trade Agreement (CAFTA).

Regionalism was initially conceptualized in Europe, establishing norms and expectations for other regions to emulate. In the late 1980s, the theories of new regionalism were produced, and drew inspiration from the development of regional integration processes across Southern Africa, North America, East Asia, among others (Palmer 1991; Gamble et al. 1996; Bowles 1997). In Southeast Asia, regional cooperation has been driven by the new developments of globalization and improved interactions among the countries there, operating according to the logic of open regionalism achieved through informal networks rather than a legalistic integration process (Breslin and Higgott 2000). In general, there are four levels of regional cooperation in Southeast Asia. The first is the pan-regional cooperation, represented by the Asia-Pacific Economic Cooperation (APEC). Below this level is the ASEAN Plus Three (APT) cooperation, covering the entire area of Northeast Asia and Southeast Asia and participated in by the ASEAN states and China, Japan and South Korea. The third involves the ASEAN Free Trade Area (AFTA) and the free trade areas designed to involve China, Japan, and South Korea. The Greater Mekong Subregion (GMS) economic cooperation is one of the typical regional mechanisms on the fourth level, in which Yunnan has been made the primary Chinese participant up to the mid-2000s.

The preliminary development of transnational regionalism has benefited participant countries in having access to more foreign investment, enhancing competitiveness in the world market, intensifying domestic economic reform, and reducing negative competition with foreign neighbours (Sotharith 2007). In particular, subregional economic cooperation, although easily constrained by backward infrastructure and inadequate economic development, has rules and developmental objectives that are more flexible than other forms of regional integration. This would effectively prevent it from directly clashing with existing free trade arrangements (Liu 2005). Buoyed by these pull factors of transnational regionalism, Beijing has started to engage in the building and operation of regional cooperation initiatives, especially at the subregional level. Over the past few decades, the Chinese central authorities have extended their support to the development of numerous subregional economic cooperation projects, through which the border provinces could have 
access to preferential foreign economic policies (Chen, Jian, Chen 2010). The Tumen River Area Development Programme (TARDP) was founded by the United Nations Development Programme (UNDP), with the support of China, South Korea, Mongolia, and Russia. Within this programme, Jilin province has been selected as the main Chinese participant, along with other northeastern provinces. Xinjiang was chosen to take part in the Central Asia Regional Economic Cooperation Programme (CAREC), since 1997, to cooperate with the Central Asian countries to boost regional economic growth. The latest example is the Pan-Beibu Gulf Economic Cooperation (PBGEC), a regular intergovernmental forum with the involvement of Guangxi and six ASEAN member states. However, the most influential and well-established is the ADB-steered GMS.

As with many other subregional economic cooperation projects based on resource integration, if the GMS is to pay off, the participation of governments will be indispensable. This is because this type of cooperation requires participants to invest substantially at the early stages and wait a long time to see returns, and the success of their investment depends on the geopolitical situation (Zhou 2007). Chinese private investors feared pouring substantial amounts of money into the GMS, unless the government provided a guarantee by taking the lead in investing in infrastructure and fundamental industries in the subregion. Therefore, in order to encourage more public and private investors, the central government has carried out a series of initiatives, which was compared to "state rescaling" by Su Xiaobo (2012: 1329). The main purpose of the rescaling process is to deemphasize a centralized power structure, with specific tasks involving cooperation with the GMS states to achieve necessary agreements and policy initiatives, the establishment of the National Coordination Group for the GMS Preparatory Research and Development to coordinate the efforts of various domestic ministries and the Yunnan provincial government, and the granting to Yunnan of greater authority in creating institutions and proposing local initiatives for engagement in the GMS.

The decision of the central government to designate Yunnan as the primary participant in the GMS has been largely dependent on the province's geographical proximity to and cultural affinity with the Mekong countries (He 2007). To be precise, although Beijing has to consult with other member states on the direction of GMS cooperation and the operation of 
some major projects, specific tasks have fallen on Yunnanese officials. The central government has required Yunnan to collect information on the progress of the GMS projects, analyse contradictions stemming from cooperation, offer suggestions on state-level negotiation and cooperation, and communicate with other members to coordinate their domestic laws and management. That said, Yunnan could not perform these responsibilities without correspondent external affairs powers. On the one hand, given that Yunnan is not constitutionally on a par with other members of the GMS, all nation states, it would be difficult for the province to negotiate and cooperate with these. On the other hand, owing to the demand for investment in the building of the GMS, and Yunnan's underdeveloped status, the expansion of Yunnan's leverage in the GMS has been dependent on the active support of the Chinese central government (He 2007).

In addition to becoming a part of Beijing-led "state rescaling" process, interest in the subregional cooperation of Yunnan has directly stemmed from the pull of the development of transnational regionalism in Southeast Asia. Huang Huikun (1992), a Kunming-based scholar, was the first to suggest building the Golden Quadrangle in Southeast Asia, composed of Yunnan, Myanmar, Thailand, and Vietnam. He predicted that the opening up of Yunnan would be constrained, should the province fail to play a critical role in regional cooperation. Another commentator from Yunnan, Ma Shuhong (1995) was even more explicit, arguing that, in the face of the flourishing of the ASEAN Free Trade Agreement (AFTA), the North Growth Triangle, and the South Growth Triangle, if Yunnan could not further its economic influence southward, it would be placed at a disadvantage in regional competition. In 1991, Yunnan provincial Foreign Affairs Office advised the provincial authorities to assess the blessings and curses of existing regional mechanisms in the AsiaPacific region to bolster the province's cooperation with Southeast Asian countries, especially neighbouring countries. Yunnan's enthusiasm about subregional cooperation is further reflected in its preliminary work ahead of the first GMS meeting in 1992. Due to its long-term research, Yunnan was able to suggest prioritizing the improvement of transportation connectivity over other objectives under the GMS framework, while highlighting that regional cooperation would not only benefit the opening up and economic development of Yunnan, but would also enhance economic and cultural exchanges in the entire subregion (Yang 2001). 
The positive reaction of Yunnan to subregional cooperation is further indicative of its efforts to connect its involvement in the GMS with CAFTA. Under CAFTA, although Yunnan was neither a primary Chinese participant (as in the GMS) nor a proponent (as in the Bangladesh-China-India-Myanmar economic corridor), Yunnanese officials were encouraged by the conclusion of this agreement to call on the central government to position it as a starting point in the linkage between China and Southeast Asia, a primary Chinese participant in the GMS, and a front-runner in the newly-established CAFTA (Li 2013). In 2002, Vice Governor Shao Qiwei expressed the willingness of Yunnan to provide services and training for CAFTA and to further develop the GMS and other existing cooperative mechanisms with neighbouring countries (Yunnan provincial government 2003). In the same year, former Governor Xu Rongkai chaired the first full meeting of the provincial GMS Cooperation Coordination Small Group. Since then, this group has regularly convened to hear the reports as to Yunnan's participation in CAFTA (Summers 2013). The provincial Planning Commission has further suggested that Yunnan capitalizes on its locational advantages to turn itself into the experimental area of CAFTA and to elevate its role in both CAFTA and the GMS (Yunnan provincial government 2003). Since 2002, the official Yunnan Economic Almanac has begun to feature annual reports on the provincial participation in the GMS, with a particular focus on the conduct of cross-border projects under CAFTA and the GMS and the attendance of provincial leaders at activities organized by these mechanisms.

\subsection{Pressure of GATT/WTO}

This section sheds light on how Yunnan has benefited from the pressure exerted by the General Agreement on Tariffs and Trade (GATT) and its successor, the World Trade Organization (WTO), on China to close its domestic development gap. China's application for membership of the GATT/WTO was lodged in 1986, when the country started to accept transnational mechanisms. China's seeking of technical assistance from the United Nations Development Programme (UNDP), in 1978, marked the start of its conciliatory attitude towards international financial institutions. Although China was still reluctant to join Group 77, comprised of developing countries, it extended support to the group's advocacy for addressing the developmental inequality between the Global South and the Global North (Jacobson and Oksenberg 1990). Its accession to the International Monetary Fund (IMF) and 
the World Bank (WB) had already marked China's return to the world economic community (Jacobson and Oksenberg 1990).

China's bid for the GATT/WTO membership proved more challenging, because of a dispute within this institution over whether it was acceptable for an organization dedicated to free trade to include a member which had just commenced its trade and market reform (Lanteigne 2005). A variety of suggestions were proposed by the working party organized by a few contracting parties, such as the United States, Japan, and the European Community (EC), which required Beijing to propose practical measures ahead of its accession being approved. Among these suggestions, tackling the imbalanced development at home has been favourable to Yunnan's external activism. The developmental disparity has largely been caused by a Chinese version of 'trickle down' economic policy (Holbig 2004). As these preferential policies granted the coastal region excessive autonomy and resources, with a lack of fair competition, the coastal region would wield power disproportionate to their status, formulating their local trade, investment, fiscal, and currency policies, provoking discontent among both foreign and Chinese businesspeople (Zhang 2003; Wang 2007; Su 2008). Ten years after the onset of reform, the trade volume of the provinces in the western and central regions accounted for a little more than 10 per cent of total foreign trade between 1986 and 1998. As for Yunnan, in 1998, it generated merely 0.87 per cent of foreign trade volume that further declined to 0.74 per cent. Its performance in attracting FDI was even weaker, and it ranked close to the bottom among provinces.

Moreover, Beijing was aware that if it did not tackle the developmental imbalance effectively, its joining of the WTO would worsen this problem and thus make it more likely that it will breach the regulation of the organization. This is because despite the fact that the membership of the WTO would bring China plenty of economic benefits, such as a rise of 1.5 per cent in its annual growth and USD 1 trillion worth of FDI, permanent mostfavoured-nation (MFN) status, and the chance to make global trade rules (Fewsmith 2001, Adhikari and Yang 2002), the coastal regions would be far better positioned to gain, drawing on their edge in infrastructure, investment environment, management know-how, and human resources (Qiao 2001). The already limited comparative advantage of the western region in terms of natural resources would be further eroded after the accession, owing to 
the reduced dependence of the coastal regions on the basic processing industry and the challenges posed by products made by other developing countries, such as Vietnam, Indonesia, India, and Pakistan (Zhang 2003).

Partly in response to the pressure of the GATT/WTO and to stem a potential widening regional gap, Beijing launched the Western Development Programme in 1999 (Glassman 2010). A small leading body responsible for the conduct of this programme was formed months later, supervised by Premier Zhu Rongji and Vice Premier Wen Jiabao, along with a dozen ministers. Unlike previous mass economic campaigns, the Western Development Programme purported to attach equal importance to the economic, social, and ecological aspects, while the central and local officials involved in the Western Development Programme were asked by the then President Jiang Zemin to pursue sustainable objectives (Lai 2002). In accordance with the regulations of the WTO, China could not rely on the provision of preferential conditions or direct subsidies to the western regions permanently; instead, after the transition period allowed by the WTO, what the Western Development Programme was allowed to offer was limited to indirectly supporting the western region with respect to tax cuts and infrastructure building, as well as the improvement of educational levels (Zhang 2003).

Under this programme, the central government designated Yunnan as "the gateway to Sichuan, Guizhou, Guangxi provinces, and the Tibet Autonomous region, with the potential for further economic integration with neighbouring countries" (Masviriyakul 2004: 306). Later, the status of Yunnan in the Western Development Programme was further confirmed by the central authorities as "a competitive province based on bio-resources, a great province with a rich ethnic culture, and an international passageway linking China to South and Southeast Asia" (UNDP 2002: 19). Accordingly, the Yunnan provincial government specifically set out a long-term strategic blueprint under this programme, which aims to protect and enrich the cultural diversity among various ethnic minorities in Yunnan, to encourage Yunnan to balance its economic development with environmental protection, and to enhance its cross-border connectivity through the upgrade of the road, railway, waterway, and telecommunications systems. 
The realization of these goals could not be achieved without engagement with neighboring countries. Yunnan, therefore, launched the Lancang-Mekong River Subnational Economic Cooperation and Trade Development Centre, to promote its cooperation with the Mekong countries in trade and investment. Moreover, it took advantage of the Western Development Programme to undertake a variety of externally-oriented infrastructure projects. These projects encompassed the enlargement of the Wujiaba International Airport in Kunming and the upgrade of the railway linkages between Kunming and various neighbouring countries (Lai 2002). Yunnan has also been tasked with transferring energy resources to other western provinces (Su 2014). This further propelled Yunnan to consolidate energy cooperation with the Mekong countries whose abundant energy resources remained underexplored due to the shortage of investment and technology. For instance, Yunnan has boosted its dam creation activity along the Mekong River, to produce more electricity (Piseth and Sophearin 2014). Hydropower became the second key product in Yunnan's trade with Vietnam, and the province supplied $18.5 \mathrm{GW}$ power to Vietnam by 2011, valued at US\$900 million (Chen 2013). In addition to water resources, Yunnan has been active in promoting cross-border cooperation in mining ${ }^{29}$.

At the same time, Yunnan has taken advantage of the commitment of the central government to the GATT/WTO in terms of narrowing regional disparity, pressing for greater authority in cross-border cooperation. Yunnan claimed to be exploiting the Western Development Programme to boost its green economy, ethnic culture, and construction of international passages between China and neighbouring countries. It also convinced the central government that the Mekong subregion, with which Yunnan had fostered close economic and cultural connections, should be identified as a starting point for the western regions to interact with the world market (Li 2000). In order to further elevate its crucial position within the programme, Yunnanese officials habitually emphasized the province's economic complementarity with neighbouring countries, arguing that Yunnan's crossborder cooperation would not only boost the exports of textile products, household electrical appliances, and other types of basic goods produced in Yunnan and other western

\footnotetext{
${ }^{29}$ For instance, Yunnan Zhongliao Mining Industry Development Investment Limited Company built a factory capable of producing 5 million tons of muriate in the early 2000s; Yunnan Metallurgical Group signed a contract with the Vietnam National Minerals Corporation (VIMICO) to build a 10 thousand-ton electrolytic zine and a 72 thousand-ton aluminum smelting factory; Kunming Steel Group expanded business across the border by constructing a steel mill in Vietnam and a 1 million-ton steel mill project in Lao Cai (Li et al. 2004).
} 
provinces, but would also provide convenience for other western provinces to purchase cheap agricultural products, lumber, jam, and marine products from the Mekong subregion (Che 2000).

\subsection{Competition with Extra-Regional Powers}

The jockeying for economic and diplomatic influence between China and extra-regional powers has been particularly evident in the Mekong subregion. These powers include the United States, India, and especially Japan. This section seeks to address the question of how these powers' competition has evolved in the subregion and concludes with a discussion of how Yunnan's role in cross-border cooperation has gained influence from this competition

\subsubsection{United States}

China's expansion of authority into the Mekong countries has been met by challenges from the United States. Even though the US is situated at a considerable distance from these countries, and has a history of enmity toward the subregion, as the greatest economic and military power in the world, the United States has been engaged with Indochinese issues since the Cold War. However, the interest of the United States in this subregion diminished after the Vietnam War in 1975, and the establishment of Communist regimes in Laos and Cambodia in the 1970s (Yoshimatsu 2015). In the first decade of the $21^{\text {st }}$ century, the Mekong subregion was still sidelined within Washington's Asia policy, as the George W. Bush administration focused more on balancing China's rise in East Asia, maintaining peace in the Taiwan Strait, and advancing partnerships with traditional allies (Banlaoi 2003). The singular focus on security issues, such as the war on terror and the nuclear threat of North Korea, further restricted the US response to the primary concerns of mainland Southeast Asian countries: economic growth and political stability (Economy 2005).

Compared with its predecessors, however, the Obama administration was the first to explicitly elevate the Asia-Pacific region to be the primary strategic priority (Shambaugh 2013). Formally announced by President Barack Obama during his 2011 visit to Australia, the Pivot to Asia policy (hereafter the Pivot) was premised on the recognition that the United States should "focus more heavily on the strategically important and economically vibrant Asia-Pacific" (Murphy 2017: 58). As Southeast Asia was a central geographic focus of 
the Pivot, this policy, unsurprisingly, intensified the competition between China and the United States in Southeast Asia, notably in the Mekong countries (Shambaugh 2018).

The new US commitments to the Mekong countries have had a geopolitical orientation, in that the aim of the Pivot was widely believed to be balancing China's growing influence (Yoshimatsu 2015). The former US Secretary of State Hillary Clinton revealed a plan to advance US engagement in the Mekong subregion at the first US-Lower Mekong Ministerial Meeting in July 2009. The meeting also witnessed Clinton and her counterparts from Thailand, Vietnam, Cambodia, and Laos agreeing to institutionalize their cooperation under the title of the Lower Mekong Initiative (LMI). Myanmar, one of the closest Beijing's allies in the subregion, was admitted to the LMI only at its sixth ministerial meeting in 2013. Under the LMI, the US sought to counter Chinese influence in the Mekong countries by extending its scope of cooperation with these countries in areas such as the environment and water, in response to the concerns of these countries about China's dam creation activity (Giang 2018). The US also attempted to eclipse China by exploiting ideological tools. Since China has been reluctant to make a consistent commitment to transparency, openness, and human rights protection to the Mekong countries, the US stepped in and promised to abide by these values during their cooperation (Economy 2005).

\subsubsection{India}

The competition between India and China has long been a feature of the Asian region, with India seeing itself threatened economically and militarily by China ever since the 1962 border war (Zhao 2008). The specific measures China adopted in constraining the overspill of India's influence involved enhancing its military presence on its border with India, building strategic and economic links with India's neighbours, and also solidifying its maritime presence in the Indian Ocean. Specifically, India has been irked by China's moves around the Indian Ocean under the 'String of Pearls' policy ${ }^{30}$, such as the establishment of a base in the Sittwe Port (Myanmar), the proposal to build a canal through the Kra Isthmus (Thailand), the funding of the development of Gwadar (Pakistan), and the construction of

\footnotetext{
${ }^{30}$ The "String of Pearl" is a geopolitical theory concerning China's possible economic and military expansion in the Indian Ocean region. The specific approaches to achieve this objective include gaining access to ports and airfields, modernizing military forces, and undergirding diplomatic relationships with trading partners in the region (Pehrson 2006). This term was initially coined by the US consulting firm Booz Allen Hamilton in 2008, and later featured frequently in India's geopolitical and foreign policy narratives.
} 
container ports in Chittagong (Bangladesh) and Hambantota (Sri Lanka). These moves would undoubtedly bring China closer to the Bay of Bengal and threaten India's maritime route (Blumenthal and Lin 2006). For many Indian foreign policy observers, Chinese activities around the territory of India amounted to strategic encirclement (Kanwal 1999).

Considered as the cornerstone of India's post-Cold War foreign policy orientation, in 1991, the Look East policy had been devised to advance cultural and economic linkages between India and Southeast Asia, while counterbalancing China's increasing leverage (Yahya 2003). The policy was reinvigorated when India became increasingly concerned about China's expansionism and dam creation (Talbot 2017). Like China, the Mekong subregion has been of strategic importance to India, in that it is directly linked to the Indian Ocean, which New Delhi sees as its maritime backyard. The subregion also has close cultural linkages with India. Most of the Mekong countries have also maintained cultural affinity with India. The name 'Indochina' has historically evolved to refer to a buffer region between China and India, with both being concerned by each other's expansionism (Singh 2018). Myanmar, Thailand, Laos, and Cambodia were called 'Indianized' states on the Indochinese peninsula, in that their Theravada Buddhism, Hindu architecture, and Brahmin monarchies differentiated them from Chinese-influenced Vietnam (Dalpino 2017).

Under the Look East policy (renamed the Act East Policy since 2014), India has improved communication between its northeast region and Southeast Asia through multiple projects. These projects include the Kaladan Multi Modal Plan, linking Kolkata with Myanmar's Sittwe by sea, and the Trilateral Highway Project, connecting India's Manipur state to Thailand through Myanmar (Talbot 2017). The sense of competition between New Delhi and Beijing over influence in the Mekong subregion has become more evident after the former created its first subregional economic cooperation project, BIMSTEC, the Bay of Bengal Initiative for Multi-Sectoral Technical and Economic Cooperation (Batabyal 2006). Myanmar and Thailand are members, alongside some South Asian countries. India also unveiled the Mekong-Ganga Cooperation (MGC) in 2000 as a reaffirmation of its Look East policy. The idea of the MGC originated from the ASEAN Leaders' Summit in 1999, when India welcomed the proposal to undertake regional cooperation around Buddhism and tourism with Thailand, Myanmar, Cambodia, and Laos (Deng 2010). It was eventually fleshed out following the conclusion of the Vientiane Declaration, expedited by the signing of the Agreement of Commercial 
Navigation on Lancang-Mekong River between China and Laos, Myanmar, and Thailand in April 2000 (Batabyal 2006). Like BIMSTEC, the MGC claimed to help the Mekong countries improve their economic development through infrastructure construction. Strategically, it also shared an objective with BIMSTEC in countering the increasing threat from China's expansion in the Indian Ocean (Batabyal 2006). Under the MGC, the then Indian Prime Minister, Atal Bihari Vajpayee, vowed to build a railway from New Delhi to Hanoi via Myanmar, Thailand, Laos, and Cambodia, widely seen as India's answer to the China-steered Pan-Asia Railway (Zhao 2008). Although Chinese leaders welcomed the MGC, and even occasionally expressed an interest in joining it, they have yet to lodge a formal application, due to strategic concerns (Singh 2018).

\subsubsection{Japan}

Despite the fact that Japan is located several thousand kilometres away from the Mekong subregion, it has been one of the regional heavyweights to profoundly engage with the countries there (Percival 2006; Shiraishi 2009). This subsection observes that the external status of Yunnan has been improving, along with an intensifying tug-of-war between Beijing and Tokyo over influence in the Mekong subregion. The subsection starts by reviewing the interactions between Japan and the Indochina countries during the second half of the $20^{\text {th }}$ century, followed by a comparison with their interactions in the new millennium. Also discussed is the China factor in the adjustment of Japan's Mekong policy, with a focus on the competition between the two regional powers through their institution-building in the subregion.

The first phase of Japan's relationship with the countries on the Indochinese peninsula started after the end of the Second World War and continued till the early 2000s, with developmental and liberal orientations. The new millennium witnessed a shift in the orientation of Japan's Mekong policy from economic liberalism to geopolitics. This policy shift can be attributed to a number of factors, including the evolution of a positive attitude towards China among the Southeast Asian countries following China's constructive and helpful response to the 1997-98 Asian Financial Crisis, the conclusion of the China-ASEAN Free Trade Agreement (CAFTA), and China's success in discouraging certain Southeast Asian countries from supporting Japan's bid for a permanent seat on the United Nations Security Council (UNSC) (Sudo 2009). Japanese leaders perhaps believed that although they could 
not prevent China's rapid economic rise on the Indochinese peninsula and beyond, they needed to halt the downward slide in Japan's own leverage and jockey for a leadership role (Guan 2011). For instance, in order for Japan to check China's influence in the Mekong countries, it began to hold an annual Leaders' Summit with Cambodia, Laos, and Vietnam from November 2004, which was extended to also include Thailand and Myanmar in 2009 (Bi 2016). Tokyo also held a Foreign Ministers' Meeting just two months before the third GMS summit in Vientiane in 2008, a gathering to which China paid considerable attention and which was attended by the then Premier Wen Jiabao (Shiraishi 2009).

Like the United States, Japan has employed ideological tools to contend with China in the Mekong subregion. One of the overarching goals Japan suggested in its Mekong Region Partnership Programme was the quest for universal values, democracy, and the rule of law (mofa.go.jp 2008). In what was widely believed to be a thinly-veiled snub to China, Prime Minister Shinzo Abe, during his first term, from 2006 to 2007, called for the building of an 'arch of freedom and prosperity' around the rim of the Eurasian continent through valueladen diplomacy, emphasizing that Cambodia, Laos, and Vietnam should be the first countries forming this arch (Masaki 2007). However, even though it was convenient for Japan to use ideology to counter Beijing, which does not champion these values, the practical effect of this tactic is likely to be negligible because it is unrealistic for these countries to make substantial progress toward democracy and human rights protection in a short time span. An excessive emphasis on Western values might otherwise make these countries found what China advocated like the diverse nature of culture, values, and developmental path more attended to the interests of their political and economic elites (Yoshimatsu 2010).

Sino-Japanese rivalry over influence in the Mekong subregion is also manifest in regional institution-building. The GMS was the brainchild of ADB, promoting a vision of economic integration of the Mekong countries since 1992 (Medhi 2004; Oehlers 2006). Given the fact that $A D B$ is not so much a regional investment bank as an institutional vehicle for the expansion of Japanese capital in Asia (Glassman 2010), it is hardly surprising that investment in the GMS would reflect the interests of Japan in economic expansion overseas, in order to recover from economic sluggishness at home (Wan 1995). In other words, the decision by ADB to channel money into the GMS projects was inevitably influenced by Tokyo's interest 
in the reinvestment of its economic surplus and expansion of regional markets for Japanese commodities and capital (Amin 2004).

After decades of active involvement in the GMS, China considered this mechanism ineffective in leading regional cooperation, with little chance for it to succeed. As Lu Guangsheng (2016: 5) pointed out, after two decades of "acting as an important participant in the subregion, China has obvious flaws in its role in terms of projecting dominance, rulemaking power, and discourse capability." China therefore established the Langcang Mekong Cooperation (LMC) framework as a comprehensive mechanism to combine the agendas of the GMS. The objective of China to dominate the LMC can be seen in its exclusion of nonMekong countries, in sharp contrast with the GMS and its principal sponsor, ADB, in which both Japan and the United States have the greatest voting power. In fact, the geographical label 'Lancang-Mekong' was carefully chosen to indicate who could, or could not, be involved in the LMC (Bunyavejchewin 2016).

The Asian Infrastructure Investment Bank (AIIB) has reinforced the attempt by China to challenge the Japan-backed ADB. The specific objectives for China's launching of the AllB involve the following aspects. The first is that ADB could no longer provide enough money to meet the actual demand for investment in Asia, whose backward infrastructure has long thwarted its economic and human development (Blomfield 2015). The second is that China has been frustrated with $A D B^{\prime}$ s onerous procedures for infrastructure finance. In contrast, the AIIB imposes less strict conditions on recipient countries, by not asking them to privatize state-owned enterprises or deregulate businesses, and by allowing for a more straightforward screening process (Kikuchi and Wang 2016; asia.nikkei.com 2017). The most significant reason is that China has long complained that its decision-making power within ADB has failed to match its economic achievement (Yoshimatsu 2015). For instance, when China joined $A D B$, it was granted a voting share of merely 6.2 per cent, far behind Japan and the United States, which together controlled more than 25 per cent of voting shares (Strand 1999). However, when China accounted for an estimated 12.4 per cent of world GDP and surpassed an aging Japan in 2010, its voting share in ADB actually shrank to 5.5 per cent (Reisen 2015). It was therefore in China's best interest to enhance the institutional capacity to steer its own projects (Songwanich 2016; Biba 2018). 
Unsurprisingly, the AllB provoked a backlash from Japan and escalated the already heated Sino-Japanese competition. In hindsight, China's construction of an alternative source of multilateral finance did not immediately raise anxiety in Tokyo (Reisen 2015). It was only after the accession of Australia, South Korea, and especially the United Kingdom, that Japanese eyebrows were raised. As the AllB threatened to dilute the leading role of ADB in infrastructure development in the Mekong subregion, Japanese Prime Minister Shinzo Abe quickly responded by unveiling the programme of a 'partnership for quality infrastructure investment for Asia's future', with funding of USD 110 million, and pledged an extra USD 6 billion in ODA to the Mekong countries (Yu 2017).

In addition to Sino-Japanese rivalry at the multilateral level, China's tug-of-war with Japan for dominance on the Indochinese peninsula can also be seen at the bilateral level. In Myanmar, both China and Japan had offered massive support when the country it was under international sanctions. Japan emerged as its crucial partner as early as the 1950s. But with Japan following many Western countries in imposing economic sanctions on Myanmar's junta, for the subversion of democracy, Beijing quickly filled the vacuum left by Tokyo (Kudo 2010). However, in order for China not to cultivate unchecked sway over Myanmar, Japan still maintained contacts with Naypyidaw and kept a flexible attitude toward investments made by Japanese enterprises in Myanmar (Malik 2015). After 2010, China's influence in Myanmar was again balanced by Japan, which resumed its intensive economic engagement with Naypyidaw after the country commenced the process of democratization by holding general elections, relaxing political and economic controls, and releasing Aung San Suu Kyi, the Nobel Peace Prize laureate who had been detained under house arrest by Myanmar's military junta (Reilly 2013).

The same pattern of rivalry can be observed in Cambodia, with which both China and Japan have been deeply involved. In the post-Cold War era, Japan showed commitment to the peace process in Cambodia by sending UN peacekeepers and providing massive donations for the country's post-war construction and poverty reduction programmes (Sotharith 2010; Cook 2018). However, Japan has been growingly apprehensive about China's economic leverage in Cambodia, especially under its Belt and Road Initiative (Nachemson 2018). The two countries' involvement in the latest Cambodian general elections was a microcosm of Sino-Japanese rivalry. China donated USD 20 million worth of polling booths, computers, 
and other equipment to the National Election Committee, while Japan supplied the committee with over 10, 000 ballot boxes worth USD 7.5 million (Chandran 2018). Japan's refusal to follow the US and the EU in opposing this election after the Cambodia National Rescue Party (CNRP), the only viable opposition party, was illegally dissolved by Prime Minister Hun Sen demonstrates that Tokyo was reluctant to damage its relationship with Cambodia, lest it encouraged China to strengthen its stranglehold over Cambodia further.

It is worth mentioning here that China and Japan have attempted to de-escalate their competition on the Indochinese peninsula and coordinate their projects through a bilateral mechanism known as the Japan-China Policy Dialogue on Mekong Region (JCPDMR). However, this mechanism has proven to be rather ineffectual. The attending representatives of both sides were junior officials, with Japan sending its Deputy DirectorGeneral of the Southeast and Southwest Asian Affairs Department of the Ministry of Foreign Affairs to attend the dialogue, while China was represented by the Deputy Director-General of the Department of International Organizations or the Counsellor of the Department of International Economic Affairs of the Ministry of Foreign Affairs. These officials had insufficient political influence to make any breakthrough in their cooperation in the Mekong subregion (mofa.go.jp 2008, 2009, 2010, 2014).

In addition, the different policy orientations and programme selection between China and Japan have further limited the effect of this coordinative mechanism. China's interest in the Mekong subregion chiefly consisted of expanding markets for products and securing more energy sources, whereas Japan's strategies in the subregion were more geopoliticallyoriented, especially after the 2000s (Yoshimatsu 2010). Another problem is related to different mechanisms through which Japan and China prefer to advance their interests in the Mekong subregion. While Japan preferred to work under the frameworks of the Mekong-Japan Foreign Ministers' Meetings and the Mekong-Japan Summits, China favoured the GMS, and in particular the newly-established Beijing-led LMC. More essentially, the work of the mechanism was vulnerable to the vagaries of the overall Sino-Japanese relationship. Affected by the deterioration in their relations over territorial disputes and controversy concerning historical narratives, the mechanism has been suspended since 2014, forcing the Mekong countries to proceed with cooperation with the two regional powers along parallel tracks (Bi 2017). 


\subsubsection{China's Response to Competition}

From the point of view of aid and investments, the competition among major powers is fundamentally good for the Mekong countries. Regardless of who provides the funding, these countries have access to a greater amount of investment and a variety of products and services (Wan 2016). The competition also gives these countries more choices which, in turn, forces Chinese, Japanese, Indians, and Americans to improve quality and minimize costs when awarding infrastructure projects (Soong 2016). That said, the intensive engagement and intervention of extra-regional powers in China's southern neighbourhood threatens its interests in politics, economy, and security in the eyes of Beijing (Cui 2018). First, from the Chinese perspective, the engagement between the Mekong countries and outside powers, notably Japan, takes place at the cost of China's border stability, invested projects, and protection of its 'core national interests'. This can be seen from the resistance to China's dam building along the Mekong River and expansion in the South China Sea. Second, the intensifying economic interactions between the Mekong countries and these outside powers have also reduced the dependence of these countries on Chinese funds and products. China has consequently found that the geopolitical situation for its relations with the Mekong countries is much more challenging than during the expansion of economic influence by Western imperial countries in the $18^{\text {th }}$ and $19^{\text {th }}$ centuries (Su 2012).

Given these challenges stemming from strategic competition with extra-regional powers, it makes sense for the Chinese central government to maximize its available resources to step up its influence in the Mekong subregion. Just as Beijing used the AlIB to fund its own projects in the subregion, instead of channelling money into the Japanese-steered ADB, so it seeks to maximize its geographical advantage over these outside powers: a long land border between Yunnan and the Mekong subregion. Specifically, Yunnan shares a 4,060-kilometrelong border with Myanmar to the west and Laos and Vietnam to the south, also connected to Thailand and Cambodia via the Mekong River (Tubilewicz 2016). Besides, Yunnan has a population of 43 million (He and Sheng 2005: 295), with fifteen ethnic minorities straddling across the border (Chen, Jian, and Chen 2010: 338). In order to gain the upper hand in competition, by reducing transaction costs in regional economic exchanges and taking advantage of the cross-border networks based on shared ethnicity, language, and culture, the central government has authorized Yunnan to improve its geographic, economic, and 
diplomatic leverages vis-à-vis the Mekong countries. On top of this, the decision of the central government to bolster its engagement in the GMS, both through Yunnan, and later through Yunnan and Guangxi, has partly been based on the assumption that subregional economic cooperation is unlikely to pose serious challenges to the interests of outside powers (Cheung 2012). Also, by limiting its participation to a few backward provinces, China's competitiveness in the GMS would be far less threatening for other stakeholders.

\subsection{Conclusion}

This chapter set out to explore the second dimension of Yunnan province's international actorness: opportunity. Through analysis, this chapter has argued that the opportunities stemming from the regional environment have helped in creating a favourable environment for Yunnan's cross-border paradiplomacy. The normalization of relations between China and the Mekong countries precipitated Yunnan's engagement in cross-border cooperation. Influenced by the development of transnational regionalism, China has opted to engage in various regional cooperation groupings, one of which is the GMS at the sub-regional level. Yunnan has been designated by Beijing as the primary Chinese participant in this programme. Yunnan has also benefited from the commitment of Beijing to the GATT/WTO with regard to the closing of domestic developmental gap to lobby for greater authority in expanding its economic linkages across the border. The intensifying competition between Beijing and extra-regional powers - the United States, India, and Japan - over economic and diplomatic influence on the Indochinese peninsula has further led Yunnan to engage in external interactions with neighbouring countries. 


\section{Chapter 6}

\section{Dimensions of Yunnan's International Actorness: Capability}

\subsection{Introduction}

This chapter turns to Yunnan's capability: the strengths that make it more appealing for its foreign neighbours, arguing that new external affairs powers have enabled Yunnan to leverage three broad instruments to incentivize neighbouring countries to cooperate with it: infrastructure development (such as the establishment of the Great International Passage), economic statecraft (such as border trade, investment, and manpower exchanges), and diplomatic efforts (such as bilateral meetings, sister-provincial relationships, and working with overseas Chinese). Importantly, Yunnan has not always had a 'toolkit' effective enough to enhance its attractiveness for foreign neighbours. In the early years of the PRC, the province was lacking in external affairs authority and an appropriate external environment. It is only since the reform era, especially after the normalization of diplomatic relations between China and some mainland Southeast Asian countries that Yunnan has possessed the necessary pieces to be able to play on the Mekong game board.

On the infrastructure side, Yunnan has worked on the improvement of transport connectivity, pulling the Mekong countries to forge closer cooperation with it. The problem of transportation infrastructure has long constrained the domestic development of Yunnan and its external exchanges. This could partly be attributed to the fact that Yunnan was an isolated agricultural society, lacking in the will to build more roads and bridges. This situation was greatly reversed after the central government emboldened Yunnan to maximize its geographic strength and closely engage in cross-border cooperation. The past two decades have, therefore, witnessed an investment spree by Yunnan to upgrade its transportation infrastructure.

Another instrument has been economic statecraft. With the aim of extending its external influence on the Mekong subregion, Yunnan has set out to improve the economic interdependence between it and neighbouring countries, particularly in the wake of the improvement in their transportation connectivity. Yunnan and the Mekong countries have 
long been engaged in border trade with each other. Since the 1990s in particular, the Mekong countries have relied on electric commodities produced in Yunnan, while exporting product materials to the province for it to meet its increasing demand for development. Yunnan and neighbouring countries have also heavily invested in each other, notably after the founding of the GMS, when Yunnan staged an investment spree in the fields of energy and infrastructure building in these countries. Moreover, owing to geographic proximity, a substantial number of residents from Yunnan have sought employment and business opportunities across the border.

The third section of this chapter demonstrates that external affairs powers have turned Yunnan's cross-border networks into an advantage for external cooperation. The specific measures consisted of arranging meetings between Yunnan provincial leaders and their foreign counterparts more frequently, redoubling manpower exchanges with neighbouring countries, and encouraging overseas Chinese to invest in the development of Yunnan. More opportunity for Yunnan to bolster interactions with the Mekong countries have come about as a result of the substantial numbers of overseas Chinese living in these countries. Owing to cultural and historical closeness, Yunnan has been active in encouraging these overseas Chinese to participate in the province's economic growth and the improvement of cooperation between Yunnan and their host countries. Taken together, upgraded geographic connectivity, accelerated economic cooperation, and strengthened cross-border networks have become Yunnan's essential selling points: they have boosted the interdependence between Yunnan and neighbouring countries.

Apart from identifying the three broad instruments employed by Yunnan to extend its external influence, it is worth considering whether Yunnan is likely to capitalize on such influence to raise its political position by seeking secession from the rest of China. The research findings indicate that, within the paradiplomacy literature, although quite a few subnational governments have exploited their foreign linkages in order to boost their independence objectives, this is not the case for Chinese provinces. Chinese provinces are constrained by three factors that have effectively pre-empted any local secessionism. The first is the success of the central government in turning nationalism into a new source of legitimacy, and this nationalism has been based on consensus about the unity of the state. The second is that no provincial leader in the country want to risk losing access to China's 
huge domestic market in return for the pursuit of independence. The third is related to the cadre management system of the CCP. Crucially, provincial governments have no jurisdiction over the military, which is tightly controlled by the central party leadership.

This assessment is based largely on interviews in which government officials, think- tankers, and scholars from Yunnan provided significant insights into the locational advantages of the province in carrying out cross-border interactions. Despite the limitations of subjective information, the use of primary data has provided an original, unique picture of Yunnan's exploitation of its characteristics as useful diplomatic resources. In order to substantiate the research data derived from interviews, this analysis takes into account information from historical records, including news coverage in the Yunnan Daily (1980-2000), policy papers, and yearbooks. These records were accessed either online or through visiting the provincial library in Kunming.

In addition to the Introduction, this chapter contains five parts. Section 6.2 deals with the question of how Yunnan has instrumentalized its geographical position to increase the dependence of neighbouring countries on cooperation with Yunnan. To be specific, Yunnan has taken advantage of its external affairs powers to enhance cross-border connectivity (Subsection 6.2) and economic exchanges (Subsection 6.3). Yunnan's use of external affairs powers to maximize another pull factor - cross-border networks - is discussed in Section 6.4. Specific measures adopted by Yunnan for this purpose are to arrange meetings between provincial leaders and their foreign counterparts (Subsection 6.4.1), forge sister-province relationships (Subsection 6.4.2), and work closely with overseas Chinese in the Mekong subregion (Subsection 6.4.3). Section 6.5 addresses the question of whether the increased external powers of Yunnan might motivate it to make new political demands. A summary of the findings is provided in Section 6.6.

\subsection{Infrastructure Development}

This section sets out the endeavours of Yunnan to incentivize the Mekong countries to cooperate with it through improving their transportation connectivity. Some scholars, such as Su Xiaobo (2014), believe that Yunnan's geographic importance is self-evident, as it is situated at the conjunction between the resourceful Mekong subregion and the eastern coast of China, one of the most dynamic manufacturing centres in the world. This chapter, 
however, claims that the geographic position of Yunnan has become more vital because the province has purposely leveraged its infrastructure tool.

Transport connectivity is hardly a new problem. As early as the 1940s, Owen Lattimore (1943: 487) identified the problem by explaining that:

As each well-populated area was homogeneous in occupation and production with almost all other areas, there was no need for bulk traffic between them. Because of the mountains dividing them, it would have been economically wasteful to bring surplus rice from one region for storage in another region, even for political and strategic purposes, because of the small loads that carts could carry over steep roads, the extra animals needed for uphill hauls, and the expense of feeding them. (Chinese agriculture was never, in any region, geared to the growing of grains for the feeding of cart-hauling animals.) Consequently, Yunnan was a land largely without even roads for wheeled traffic; a land of narrow mountain trails on which packmules carried handicraft.

In the 1950s, more than 60 per cent of transportation within Yunnan still depended on muscle power (Summers 2013). Before the inception of the GMS in 1992, Yunnan's transportation system could handle only 10 million tons of materials a year, but actual demand was up to 25 million tons (d'Hooghe 1994). At the time, no reliable road routes existed between Yunnan and the towns located on the other side of the border. The Yunnan-Burma Road, for instance, was completed in the late 1930s, but was suspended shortly afterwards. More surprisingly, no railways existed to connect Yunnan to the Mekong subregion, except a dilapidated track linking to Vietnam (Che and Luo 2004).

Poor transport facilitates in Yunnan had constrained its economic development and external influence. This generated a need for the province to "build (a) communication network linking with Southeast Asia, get rid of (the) communication 'bottleneck' and open access to the sea" (Zhu 2010: 11). The years after the founding of the GMS saw an uninterrupted investment spree staged by Yunnan in transportation infrastructure. This had been initially stimulated by the decision of the Ministry of Transport to include the road system of Yunnan within a national highway system and to call on the province to construct more crossprovincial and cross-border highways (Donaldson 2009). In response, the Yunnan provincial government rolled out a plan to build the Great International Passages. Encompassing 
highways and railways as well as water routes and telecommunications, the project has been designed to connect East, South, and Southeast Asia to the Pacific and Indian Oceans.

\subsubsection{Highways}

The determination of Yunnan to improve its road system is manifest in two local accounts that predate the inception of the GMS. The first account was the 1992 report on Yunnan's economy and social development for the next decade. The then Governor He Zhiqiang vowed to continue attaching importance to road construction linking Yunnan to the Mekong subregion, and to turn Kunming into a pivot within the regional highway network. Another account was drafted by provincial advisor Che Zhiming in the same year, but was made public only years later. Che advised provincial leaders to improve road connections to neighbouring countries, especially Thailand. According to his explanation, Thailand would grow to be the fifth 'Little Dragon', after Hong Kong, Singapore, South Korea, and Taiwan, the four economies going through industrialization and high-speed growth. Thus, for the purpose of tapping into Thailand's economic potential, Yunnan should build a road passage through the main part of the Indochinese peninsula and all the way to Bangkok.

Yunnan's decision to upgrade its cross-border road system has tallied with the objectives of the GMS, demonstrated by its efforts to establish the Economic Corridors (Figure 6.1). The Economic Corridors proposal was a concept raised at the eighth GMS Ministerial Meeting in 1998 amidst the aftershocks of the Asian Financial Crisis. This plan was reconfirmed in the Kunming Declaration, released at the second GMS Leaders' Meeting in July 2005. For Siriluk Masviriyakul (2004: 304), the establishment of the Economic Corridors indicates a comprehensive approach by the GMS "to construct transportation network system links, to encourage effective private investment in trade, production, tourism and other services as well as to tangibly solve poverty and environmental management problems of the local people." In other words, such projects would generate more business opportunities and social contacts across the border. Among a wealth of projects relevant to the Economic Corridors, Yunnan has played a magnificent role in the road construction of the West Line of the North-South Economic Corridor. 


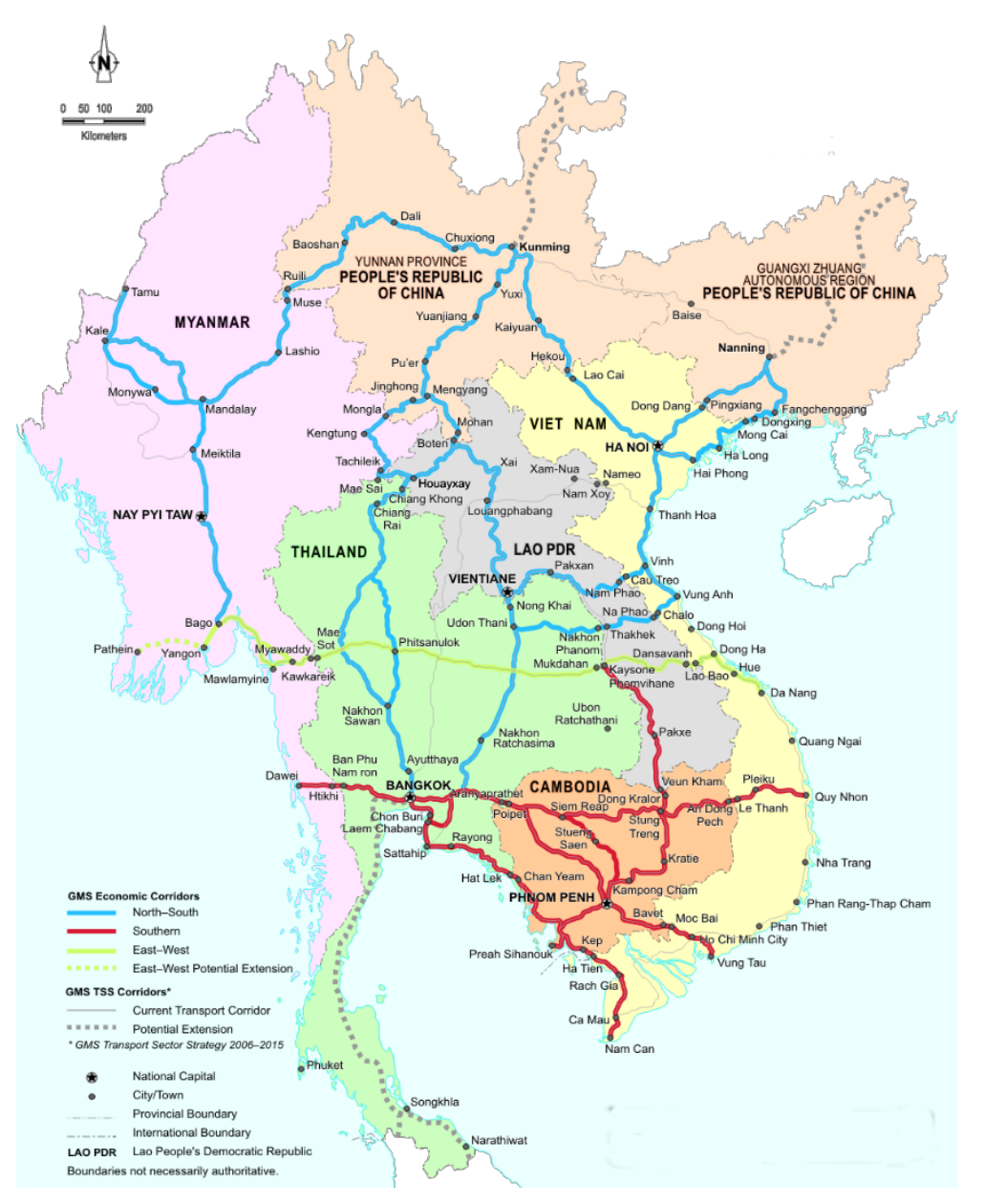

Figure 6.1 Map of the GMS Economic Corridors

Parallel to this, Yunnan cooperated with Thailand to build the Kunming-Bangkok Highway. The length of this highway is approximately $1,250 \mathrm{~km}, 831 \mathrm{~km}$ of which runs from Kunming to Mohan, the Chinese city on the border with Laos. The Asian Development Bank (ADB) provided Yunnan with a loan of USD 250 million to improve the condition of the section within its territory, while the Chinese central government followed suit, investing USD 520 million (Masviriyakul 2004). The section from Kunming to Mohei via Yunjiang was completed in 2003, and the section between Xiaokanyang and Mohan was completed in 2004 ( Li et al. 2004). An upgrade of the road between Kunming and Mohan commenced in 2004 and was finished a few years later. Beyond Yunnan, the highway stretches $263 \mathrm{~km}$ within Laos's territory. Yunnan has worked closely with Thailand and ADB to provide financial assistance to Laos to facilitate the smooth completion of the construction. According to their agreements, the section between Boten and Houei Sai, two Laotian towns, was sponsored by the sides of China and Thailand, with Laos responsible for merely one-third of the costs of 
ADB's loan. After years of effort, the Kunming-Bangkok Highway opened in 2007, laying a solid foundation for commodity transfer and transportation between Yunnan, Laos, Myanmar, and Thailand (Xiong and Wen 2009).

Apart from the Kunming-Bangkok Highway, Yunnan also established the Kunming-Hanoi Highway. A section of this highway within Vietnam starts from Lao Cai in Vietnam - a border city facing Yunnan - and ends at the Noi Bai Airport in Hanoi, stretching for $240 \mathrm{~km}$ and reducing driving time from 11 hours to 3 hours (MOT 2014). Yunnan's section of the Kunming-Hanoi Highway spans 405 km, and has already been finished after Yunnan upgraded the sections between Shilin and Mengzi and between Mengzi and Hekou from second- and third-class roads to highways (Li et al. 2004). The opening of this highway in 2014, has stimulated the development of the northwest of Vietnam, providing a convenient channel for Vietnamese agricultural and marine products to be sold in China, and facilitating the export of Yunnan's commodities to Southeast Asia.

One more important passage is the Kunming-Yangon Highway. This was built along the same route as the historical Yunnan-Burma Road, with terminals at Kunming and Lashio in Myanmar. In fact, the original Burma-Yunnan road was built in 1910 by Chinese and Burmese labourers. After Japan occupied Burma, the supply route to China was cut off. The British and American forces under Joseph Stillwell later built the section from Ledo in Assam in India to connect to the older Yunnan-Burma Road. The construction of the current Kunming-Yangon Highway has gone through four phases. The first phase marked the upgrade of the second-class Anning-Chuxiong road into a highway in 2005. The second phase witnessed a total of RMB4.75 billion spent by Yunnan to turn the Baoshan-Longling road into a high-level one. Yunnan later cooperated with Myanmar in the third phase to improve the status of the road between Heinitang in Yunnan and Myitkyina in Myanmar (Li et al. 2004).

It should be noted that the construction of highways cannot guarantee the effective use of Yunnan's geographic asset for extending external influence, should Yunnan fail to cooperate with neighbouring countries to simplify entry and exit regulations. For a long time, customs clearance procedures between Yunnan and neighbouring countries remained cumbersome, compared with those among the Mekong countries. The reasons were twofold. First were the strict regulations imposed by Yunnan, as the province was worried that vehicles from 
neighbouring countries might fail to comply with Chinese security rules, and it found it difficult to punish foreign drivers when they breached Chinese traffic regulations. Yunnan therefore only allowed foreign tour buses and private cars to drive within the province, and they had to enter and leave the province as a group. Should these drivers expect to go beyond the province, they had to apply for permission from the Traffic Management Bureau of the Public Security Ministry in Beijing ${ }^{31}$. Foreign-registered trucks were not even allowed to go outside the border towns ${ }^{32}$.

Nor did vehicles from Yunnan find it easy to access neighbouring countries. In order to attract more Chinese travellers, Thailand had allowed vehicles from Yunnan to conditionally enter as long as drivers paid a premium toll and other fees (almost RMB 1700 in total). But Thailand soon repealed this policy because of traffic accidents caused by some Chinese drivers. Given that there are no big towns in the Laos section of the Kunming-Bangkok Highway, Vientiane was fearful of ending up as just a conduit for products or passengers, with little local capture. Laos therefore started to charge more for approving transit and to ask foreign drivers to discharge the cargo before handing them over to Laos companies in order to charge more taxes. While Yunnanese companies were not afraid of paying more money, they were worried that transported agricultural products would perish due to delay ${ }^{33}$.

\subsubsection{Railways}

Among the various kinds of transport linkages, railway projects are the most expensive (Masviriyakul 2004). Yunnan has been designated by the central government as a main Chinese participant in the establishment of the Pan-Asian Railway Network (PARN) (Figure 6.2). The idea of the PARN was inspired by the plan to build a transcontinental railroad across Europe and America that linked Russia to western European countries and New York City (NYC) to San Francisco, in the 1960s. The objective of PARN is to serve as a linkage to the Third Eurasian Land Bridge, which starts from the south of China, crosses maritime South East Asian countries and the Mekong subregion, and continues westward via South Asia and the Middle East, before crossing the Mediterranean Sea and proceeding all the way

\footnotetext{
31 Interview with a Yunnan scholar on November 2, 2016

32 lbid.

33 Ibid.
} 
towards Rotterdam. Due to the Cold War, the idea of the PARN had been suspended. This idea was only revived in 1995, when the Malaysian Prime Minister, Mahathir bin Mohamed, during his first term, proposed the development of the PARN from Kunming to Singapore, but it took another ten years for an intergovernmental agreement on the PARN to be produced for all involved countries (Chan 2018).

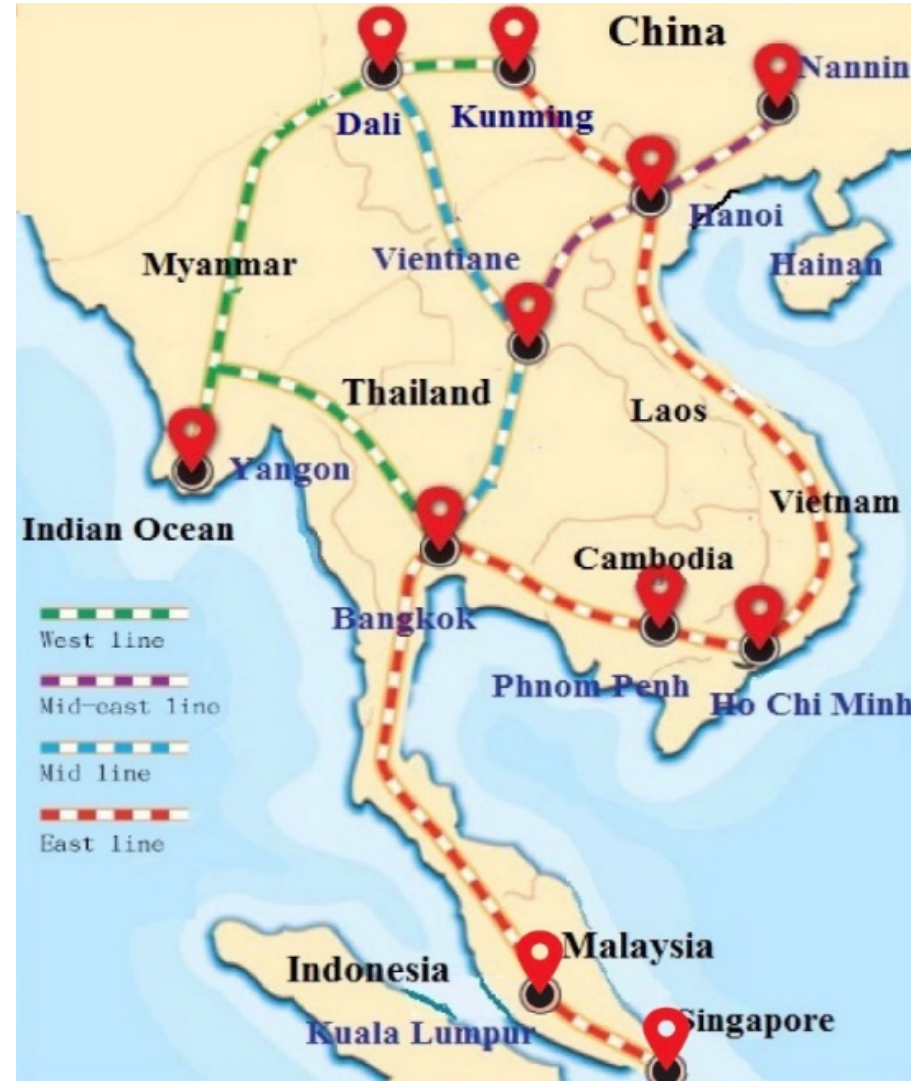

Figure 6.2 Map of the Pan-Asian Railway System (PARN)

In order to ensure the smooth implementation of this project, with the support of the central authorities, the Yunnan provincial government has upgraded its existing railroads, built more tracks connecting with the other side of the border, and integrated its own rail systems with those of neighbouring countries. Thus far, Yunnan has completed the East PARN within its territory after the opening of the stretch between Mengzi and Hekou (Yunnan provincial government 2016). Yunnan has also indicated its interest in the establishment of the China-Thailand Railway - a segment of the PARN Central Line - to further consolidate its role as a centre within the rail system in the whole of Southeast Asia (yunnan.cn 2015). For Yunnanese officials, the PARN would reduce cost and time in its transport of goods and production materials, while boosting the development of its south 
and southwestern regions (Kong 2001). To further substantiate this argument, one interviewee was explicit that: ${ }^{34}$

After the completion of the PARN, Yunnan would see an apparent growth in its export of tobacco, traditional Chinese medicine, and biologicals. Energy security in the province would be strengthened too, in that it could more easily import more crude oil and natural gas from Southeast Asia. Along with the increased intensity of passenger travel brought by the PARN, the border areas of Yunnan would have more hotels, restaurants, supermarkets, hospitals, and schools.

Another interviewee was very optimistic that Yunnan's geographic value will be apparently enhanced, given the likely incorporation of the section of the PARN within Yunnan and its domestic rail network ${ }^{35}$ :

Considering that high-speed trains from Yunnan to Guangxi and Shanghai are under operation, were they to be incorporated into the PARN, Yunnan's role as a logistical and transportation hub between China and Southeast Asia would be confirmed. This is because domestic railways would connect up in Yunnan, and this Yunnan will dominate the exchanges of resources and personnel in the GMS-steered Economic Corridors, the Yangtze River Delta Economic Corridor, the Pearl River Delta, and the BCIM Economic Corridor.

It is also worth adding that, as part of the PARN, Yunnan was keen to persuade the central government to invest in the construction of the Sino-Thailand Railway. However, during the preparation phrase, Thailand proposed to build only a part of the railway. When Yunnan was noticed, through its local informants, that this change was merely a trick by Thailand to get more economic concessions from China, the province advised the National Development Reform Commission (NDRC) to reduce construction costs for Thailand, since China would benefit more from the completion of the entire railway ${ }^{36}$. However, the NDRC dismissed Yunnan's suggestion, refused a new round of negotiations, and rushed to sign a contract. With only a segment of the railway established, the value of this project for Yunnan was compromised.

\footnotetext{
${ }^{34}$ Interview with a Kunming-based think tanker, December 12, 2016, Kunming.

35 Interview with a Yunnan official, 1 November 2016.

${ }^{36}$ Interview with a think tanker, December 1, 2016, Kunming.
} 


\subsubsection{Waterways}

In order to reduce transport costs, Yunnan has also set about the development of waterborne transportation, by improving the shipping conditions of some major cross-border rivers (Kong 2001). Related to the development of the Mekong River, Yunnan has organized a few rounds of joint surveying with riparian countries to presage an agreement on Mekong's navigation (Summers 2013). At the same time, the province cooperated with these countries to improve waterways between the location of Sino-Burmese No. 243 border tablet and Houei Sai in Laos and between Houei Sai and Vientiane, while setting up shipping facilities near the Khon Phapheng Falls in Laos (Kong 2001; Li et al. 2004). The province also invested more than RMB40 million to dredge the channel and upgrade the facilities at Simao, the first Chinese port on the Mekong River, and Chiang Roong ports (Masviriyakul 2004). The province was even permitted by the central government to send its own delegation to a Mekong-themed conference, organized by the China-Laos-Myanmar Commercial Ships Navigation Coordination Committee, at which the representative of Yunnan actively engaged in discussion on the feasibility of common navigation charging standards, routes for oil shipping, the enaction of Mekong safety regulations, and the reduction of negative impacts caused by the Laos-built hydropower station (Yunnan provincial government 2010).

Apart from the Mekong River, in recent decades, Yunnan has worked on improvements to the shipping capacities of the Red River and the Irrawaddy River. Although the Red River was renovated in the 1960s, it later went out of service (Che 1992). Along with its growing intensive economic cooperation with Vietnam, Yunnan was eager to tap into the potential value of the river ${ }^{37}$. In order to raise the Red River's carrying capacity from 0.53 million tons to 0.93 million tons, and improve its volume of passenger transport to 0.3 million persons, Yunnan has conducted, jointly with Vietnam, a survey of the Hekou-Haiphong Waterway, extended the navigation distance and scale, and spent RMB 50 million to build ferry and freight terminals in Hekou (Li et al. 2004). In addition, with an effort by Yunnan to connect directly to the Indian Ocean, the province has commenced upgrading the land and water transport in the Irrawaddy valley with support from Myanmar (Li et al. 2004). Both sides have agreed to stage a joint inspection of the roads between Dehong, Bhamo and Myitkyina,

\footnotetext{
37 Interview with a Yunnan scholar at Yunnan University, October 25, 2016, Kunming.
} 
and the waterway between Bhamo and Yangon Port, preparing to construct the Bhamo Port and the Ruili-Bhamo Class III Roadway (Fan 2011). In 2016, Yunnan's Ruili government invested RMB 0.3 billion in the renovation of the Ruili-Bhamo road to further facilitate trade, investment, and cultural exchanges between Yunnan and Myanmar (Lan 2016).

\subsubsection{Telecommunications}

At a time when developments in telecommunications technology have led to the unprecedentedly swift exchange of information and improvement in production and commercial interactions, the Mekong subregion, however, has failed to catch up with other regions in terms of the development of telecommunication. In the first half of the 2000s, of all the GMS members, the telecommunications applications of Yunnan and Thailand had reached only a developing stage ( $\mathrm{Li}$ et al. 2004). Like its problems with the traditional modes of transport, a digital divide has made it harder for the subregion to grasp firsthand market information in a timely fashion and make good use of various online services.

It was against this backdrop that ADB launched the Regional Technical Assistance (RTA) and the GMS Subregional Telecommunications Forum (STCF), in which Yunnan has played an active role. To save the cost of telecommunication, two 'backbone' projects were then proposed by the STCF to apply digital technology, alleviate congestion, and increase intraregional capability, and service quality (ADB 2014). The first project was to establish the East Loop, a modern network based on the optical fibre transmission system. Configured in a ring topology, the ten-year East Loop project was implemented in 13 transmission lines in the Mekong subregion, 5 of which were in Yunnan. Another project was developed from the East Loop, with Yunnan participating in setting up the fourth loop to connect all the GMS countries.

Along with implementing these 'backbone' projects, Yunnan has attempted to turn itself into a regional hub of information dissemination. In a report to provincial policymakers, $\mathrm{Li}$ Yigan et al. (2004) suggested that Yunnan should be transformed into an international information channel by integrating its domestic information network with South and Southeast Asia. The specific measures recommended by Li included joining up optical cables in Hekou, Mengla, Jinghong, and Ruili with those in Vietnam, Laos, Myanmar and Thailand, and expanding the coverage of the transmission system to cities in the middle of 
neighbouring countries. In practical terms, Yunnan assisted Myanmar, Laos and Vietnam in setting up high-capacity optical cables, while opening cross-border electric circuits to Laos and Myanmar by 2009. China Telecom's Yunnan branch began providing telecommunications services to Laos' telecom service providers and setting up optical cable routers between Hekou and Lao Cai. Yunnan has also committed to the advocacy of internet technology in the subregion. It provided online platforms for exchanging information in the subregion and beyond, while creating numerous electronic databases for education, tourism and technology, for users in the subregion.

\subsection{Economic Statecraft}

The upgrade of cross-border transportation facilities has helped Yunnan to maximize its use of economic statecraft. Economic statecraft has long been discussed by international relations scholars, referring to the use of economic instruments for political or diplomatic purposes. One of the earliest instances was the Megarian decree by the Athenian Empire in $432 \mathrm{BC}$ to ban its trade with Megara, due in part to the latter's support of Corinth, an ally of Sparta in the lead-up to the Peloponnesian War (Chan and Drury 2000). Other instances include the trading empires of Venice, Portugal, and the Netherlands, who constrained the powers of their competitors through economic warfare (Drezner 1999). It is clear that economic sanctions, foreign aid, and foreign trade fall within the rubric of economic statecraft (Baldwin 1985). This section will explore how Yunnan has exploited its economic statecraft to encourage the Mekong countries to cooperate with it. Research findings show that these countries have become more economically dependent on Yunnan, as a consequence of Yunnan's deliberate use of economic statecraft, in the form of border trade (Subsection 6.3.1), investment (Subsection 6.3.2), and manpower exchanges (Subsection 6.3.3).

\subsubsection{Trade}

On the eve of the foundation of the GMS in 1992, Yunnan ranked only fourth among seven border provinces in China in terms of the volume of border trade, although the province has long engaged in such trade, even during the Cultural Revolution (1966-1976), when many Southeast Asian countries slapped sanctions on China for its support of Communist forces within their territories ( $d^{\prime}$ Hooghe 1994). The second half of the 1990s continued to see a 
fall in Yunnan's trade with neighbouring countries, especially exports. Around the turn of the century, however, the improvement in cross-border connectivity had enabled Yunnan to be more proactive in border trade.

This growth has been attributed to Yunnan's exercizing its economic influence to maximize its interdependence with the Mekong subregion. For a long time, the rich reserves of various kinds of raw materials in the subregion had largely remained unexplored because of a shortage of technology and funds (Yang 2005). At the same time, in the face of a growing population and tighter environmental protection regulations, Yunnan has found its own natural resources inadequate to meet its industrial development needs. The upgrade of transportation infrastructure across the border has reduced costs for Yunnan to import lumber, petroleum, natural gas, and coal from neighbouring countries. It is also more convenient for Yunnan to take advantage of its industrial edge to sell numerous electrical appliances on the other side of the border, which include generators, logging machinery, reapers, and tobacco machinery (Yang 2005). It should be added that although Yunnan's products were not as state-of-the-art as its counterparts made in Guangdong, Zhejiang, and other Chinese industrial powerhouses, they fitted in adequately with the demands of the markets in the Mekong countries.

In terms of value, Yunnan's total trade reached USD 280 million in 2018, 46 per cent of which was earned through trade with Southeast Asian countries (Yunnan Daily 2019). However, on the eve of Deng's southern tour, the total value of Yunnan's combined export and import trade was merely USD 6.71 million. Trade with the province has largely maintained an upward trend except for in 1999 and 2015 (Yunnan provincial government 2018). In the first period, Yunnan was affected by the repercussions of the Asian Financial Crisis. The second period, moreover, saw China's decision to restructure its industry system to climb up the value ladder, to enforce environmental and labour costs, and to appreciate on the renminbi. All of these moves weighed on Yunnan's external trade. Myanmar, Vietnam, and Thailand have long been three of Yunnan's top five trading partners. In 2015, Myanmar (USD 25.02 million) even surpassed Hong Kong (USD 18.79 million) as the province's top trading partner (Yunnan provincial government 2015). Within Yunnan, Kunming - the province's capital city - has unsurprisingly maintained an obvious advantage in doing foreign business, and the total value of its trade in 2018 was USD 131.2 million, 
67.6 per cent higher than the previous year (swj.km.gov.cn 2019). Among six cities whose value of trade exceeded 10 million in 2017, four are located in border areas, with Honghe (USD 33.66 million) sharing a border with Vietnam, Pu'er (USD 12.46 million) and Xishuangbanna (USD 10.45 million) sharing a border with Laos and Myanmar, and Degong (USD 42.15 million) sharing a border with Myanmar (Yunnan provincial government 2018).

Yunnan has also taken a series of steps towards the expansion of the use of the yuan in border trade since the early 1990s. These steps were adopted against the backdrop that, since the normalization of the relations between China and Southeast Asian countries, the Mekong subregion has become one of the top trading partners for Yunnan (Liu 2012). Related to this point, the renminbi has become widely used and accepted in Vietnam, Myanmar, and Laos, and has even become the most welcome currency after US dollars and euros in the whole of Southeast Asia (Liu 2012). All of these factors have contributed to the huge demands of freer exchange of renminbi across the border.

In 1994, the Yunnan provincial authorities ordered the provincial branches of state-owned commercial banks to facilitate the use of the yuan in Yunnan's border trade. In 2003, the branches of the Agricultural Bank of China $(A B C)$ in Hekou and Masupo within Yunnan were approved to transfer renminbi in cash across the border. Hekou's branch further also created mutual accounts with the $A B C^{\prime}$ 's branch in Lao Cao of Vietnam for the trade settlement in renminbi. In 2018, such commercial banks within Yunnan as the Industrial and Commercial Bank of China (ICBC), the China Construction Bank (CCB), the $A B C$, and the Fudian Bank reached agreements with the financial institutions in Myanmar, Laos, Vietnam, Thailand, Singapore and others on the settlement of renminbi.

The role of Yunnan in the internationalization of renminbi was further elevated in 2010, when the State Council decided to turn Yunnan into a regional financial centre in South and Southeast Asia, and to increase the number of Yunnan's companies capable of conducting foreign trade using the renminbi. From 2010 to 2017, Yunnan's trade settled through renminbi amounted to RMB 100 billion, with the provincial-steered banks establishing renminbi settlement channels with 84 countries and regions (Chen 2018). In 2017, 31.26 per cent of Yunnan's trade was settled in renminbi - 5.7 times more than in 2010 - with Myanmar replacing Hong Kong as Yunnan's biggest offshore market for renminbi settlement. In August 2019, Yunnan approved the issuance of renminbi bonds by overseas enterprises 
within the province - provided that their parent companies are within China. The province is also committed to expanding the use of renminbi in various forms to support enterprises' overseas investment (State Council 2019). In a nutshell, the two-decade development of remminbi settlement has further boosted economic interactions between Yunnan and neighbouring countries, and beyond, and this in turn has benefited them through reducing their reliance on US dollars, currency exchange costs, and the risks stemming from turbulence in the currency rate.

\subsubsection{Investment Relations}

Another form of economic statecraft has been Yunnan's investment activities across the Mekong subregion. In the 1990s, Yunnan was the top recipient of investment from the subregion. One year after the establishment of the GMS, the actual investment to Yunnan from the subregion surged to US\$165 million, twice the total actual investment it received over the previous 9 years, representing almost two thirds of the total foreign investment in Yunnan, which then amounted to USD 509 million (Yunnan provincial government 1994). In subsequent years, the subregion continued to be the biggest source of overseas investment in Yunnan, except for Hong Kong in its pre-handover era. Of the 34 Yunnan-located projects funded by the Southeast Asian countries during 2001 and 2002, for instance, 21 were from the Mekong countries (Yunnan provincial government 2002, 2003).

Economic interdependence between Yunnan and the Mekong countries has continued to grow after these countries started receiving more investment from Yunnan than the other way round. Together, the subregion held 84 per cent of Yunnan's overall investment, while 77 per cent of the new overseas enterprises within the province were in the Mekong countries (Yunnan provincial government 2010). Of these countries, Laos was the single biggest recipient of Yunnan's investment. During 2000 and 2006, the province invested USD 72.56 to Laos for the development of rubber plantations (Yunnan provincial government 2001-2006). Although the biggest outward foreign direct investment (OFDI) project of Yunnan was the development of the Boeung Lake in Cambodia, the province showered a large sum of money on Laos for the redevelopment of the That Luang Lake, a mega project in the centre of Vientiane in 2010 (Qu 2008). 
Amid the 2008 economic crisis, the upward tendency of Yunnan's OFDI in mainland Southeast Asia was sustained, and its actual OFDI to this subregion even climbed to US\$270 million in 2009, a tenfold increase compared with 2005 (Yunnan provincial government 2006-2010). Amid the 2008 economic crisis, the upward tendency of Yunnan's OFDI in mainland Southeast Asia was sustained, and its actual OFDI to this subregion even climbed to US\$270 million in 2009, a tenfold increase compared with 2005 (Yunnan provincial government 2006-2010). In August 2019, under the programme of establishing a pilot free trade zone within Yunnan, the province adopted various measures to boost investment from neighboring countries and beyond. These measures involved strictly allowing foreigners to invest in Yunnan on terms no less favorable than those that apply to domestic investors; continuously shortening the negative list to open more sectors that can be invested by foreigners; and apparently improving the mechanisms for taking care of the interests of foreign investors, especially in the protection of their intellectual property rights (State Council 2019).

To a great extent, Yunnan's growing investment in the GMS countries at the time was contributed by the state-owned enterprises (SOEs) managed by various ministries in Beijing, in contrast with the provincial SOEs answerable to local authorities. In order to take advantage of Yunnan's geographical position and preferential conditions for OFDI, a number of the SOEs, i.e. State Power Investment Corporation (SPIC), China Datang Corporation, and Huaneng Power International (HNP), have created subsidiaries in Yunnan (Chen 2011). For instance, the HNP (50\%) set up the Yunnan United Power Development Company in August 2006, along with support from two Yunnanese enterprises: the Yunnan Hexing Investment and Development Company (34\%) and the Yunnan Union Resources \& Engineering Company (16\%) (chng.com.cn 2010). This company was to facilitate electricity exchanges between Yunnan and the Mekong countries, which has hitherto invested US\$475 million in Myanmar for constructing a class I hydropower station on the Ruili River (Chen 2013). Yunnan's preferential policies enacted for local enterprises also served as a catalyst for external investment, one of which is the aforementioned facilitation of the use of the yuan across the border. At the same time, the provincial government provided Yunnan-based companies involved in investing in an opium substitution programme overseas with tax waivers and easy access to loans. 


\subsubsection{Manpower Exchanges}

Meanwhile, Yunnan has conducted intensive manpower exchanges with the Mekong subregion. Owing largely to improved infrastructure connectivity and cross-border exchanges, the past two decades have witnessed a phenomenal rise in the migration of Yunnanese into neighbouring countries. As many Yunnanese residents found economic opportunities on the other side of the border, some of those with successful experiences would like to encourage more people, especially those from Yunnan's villages, to follow suit. It should be noted that the increasing flow of Yunnanese migrants has been both the causation and the outcome of the trade and investment boom between Yunnan and neighbouring countries ${ }^{38}$. The presence of a substantial number of Yunnanese migrants has galvanized the export of Chinese commodities to the subregion and attracted more Chinese investment in local hospitals, Chinese language schools, restaurants, and so forth. This investment has brought about more Yunnanese migration.

Yunnanese migrants in the post-reform era can be categorized into three groups according to the nature of their work. The first is the traders, who managed either street businesses or small stores hiring just a few employees. The second is those who came to neighbouring countries along with the inflow of Chinese investment in resource exploitation and infrastructure building. This group constitutes technicians, skilled workers, and labourers with basic skills. The third was composed of people engaged in cross-border agribusiness, mainly in the Yunnan-led opium substitution programme in northern Myanmar and Laos (Sung 2015). Still, it has be admitted that the migration of Yunnan's workers has become increasingly controversial within the local communities in the Mekong countries. Some workers hailed from other Chinese provinces, such as Sichuan province, but they served in Yunnan-owned companies or were sent overseas via Yunnan's agencies. This fact made Yunnan a scapegoat when some conflicts took place ${ }^{39}$. According to two Burmese interviewees,

In the past, we did not have any issues with the Chinese, because a lot of Chinese people have long lived in Myanmar. We could not even differentiate who is Chinese and who is Burmese. But new migrants from Yunnan have issues with local people, especially in Mandalay. Local people in Mandalay are quite

\footnotetext{
38 Interview with a government official, November 7, 2016, Kunming.

39 Interview with a scholar, October 31, 2016, Kunming.
} 
nationalistic... These migrants from Yunnan never tried to mix with local people; instead, they isolated themselves... Some even participated in illegal trade, drugs, gems and casinos. Local people are not happy with them, especially considering that the migrants' purchasing power and speculation in real estate ratchet up living costs in Mandalay ${ }^{40}$.

We now have disputes with Yunnan over labour issues. If you had come here one week earlier, you could have seen a group of Chinese workers in the next building. You can imagine that. I guess they came from Yunnan and were illegal, because we do not allow the bringing in of Chinese manual labour. It is a big problem in Yangon. The official number is around 2000-3000, the real number may be bigger, in that official statistics were produced two to three years ago. Since some companies are owned by the Chinese, they only hire Chinese workers; our own labourers were angry ${ }^{41}$.

\subsection{Diplomatic Efforts}

This section sets out the efforts of Yunnan to use a range of diplomatic means to make it more appealing for neighbouring countries. In retrospect, Yunnan has been engaged with these countries since the start of the Southern Silk Road (Wu and Jiang 1990). Although an isolationist foreign policy was overriding during the Qing Dynasty, Yunnan's external interactions did not come to an end (Wu 1997). In the early twentieth century, British and French colonialists turned Yunnan into a profitable hinterland on the Indochinese peninsula to link with Chinese markets (Giersch 2006). The flow of commodities and individuals between Yunnan and the subregion became more intensive after the completion of Yunnan's Burma Road and the France-invested Kunming-Hanoi Railway (d'Hooghe 1994; Spence 1999; Glassman 2010).

The exodus of Yunnanese residents into Myanmar was on an unprecedented scale after the Second World War and the founding of Communist China in 1949 (Chang 2014). A group of ex-Kuomintang (KMT) soldiers from Yunnan sneaked into Myanmar and rearmed themselves as guerrilla forces in preparation for a counterattack against mainland China. Later, a section of the KMT forces dispersed into northern Thailand, although many remained in northern Myanmar where they received more newcomers from Yunnan amidst political and economic disasters in China under Mao Zedong. The 1990s onwards further

\footnotetext{
40 Interview with a Myanmar government official, November 15, 2016, Yangon.

${ }^{41}$ Interview with a government official, November 17, 2016, Kunming.
} 
witnessed a rise in the migrations of Yunnanese residents into neighbouring countries in order to seek economic opportunities, while the successful experiences of the previous waves of Yunnanese migrants attracted more, especially those who came from rural Yunnan, to follow suit.

This said, the long-term migration of Yunnanese people to the subregion failed to result in enhanced influence over the subregion. Not only did restrictive policies in foreign affairs prevent Yunnan from undertaking large-scale external economic activities, but people-topeople exchanges between Yunnan and neighbouring countries were also seriously damaged. It was only in the reform era that Yunnan turned its transboundary "human resources' into a useful diplomatic tool. With their new external affairs powers, Yunnan authorities have improved the province's external influence through more external visits and receptions (Subsection 6.3.1), sister-province relationships (Subsection 6.3.2), and overseas Chinese living on the other side of the border (Subsection 6.3.3).

\subsubsection{Visits \& Receptions}

The new external affairs powers have authorized Yunnanese officials to undertake more visits to the Mekong countries and to receive more political and economic heavyweights from these countries ${ }^{42}$. This move has been conducive to the building of trust between Yunnan and neighbouring countries. Given that the visits and receptions mentioned here are chiefly limited to those conducted by the provincial Party secretary and Governor, there were fifteen high-level visits by Yunnan's leaders to the subregion from 1992 to 2015 . When visiting the subregion, these leaders were required to perform dual duties. On the one hand, they were asked to assist the central government in stabilizing relations with neighbouring countries and in advancing Beijing's neighbourhood policies (Zheng and Zhang 2007). On the other hand, the provincial leaders were responsible for promoting economic exchanges between Yunnan and its foreign neighbours, strengthening connections with overseas Yunnan's communities, publicizing Yunnan's socioeconomic achievement and investment environment, and responding to the concerns of overseas Yunnanese enterprises (Zheng and Zhang 2007).

\footnotetext{
42 Paradiplomatic activities, such as visits abroad and the receiving of foreign guests, are considered essential to improving the international profile of regions and establishing personal relations directly with foreign political or economic heavyweights. However, the quality of such interactions greatly varies in terms of the intensity and the bureaucratic level of visiting leaders (Kuznetsov 2014).
} 
Over the past few decades, through multiple visits and receptions, the senior leaders of Yunnan have not only forged intensive connections with their counterparts across the border, but have also developed good working relationships with the state leaders of neighbouring countries, in something of a break from diplomatic protocol. Specifically, Governor He Zhiqiang paid a courtesy call on King Norodom Sihanouk in Cambodia in 1994 (Yunnan provincial government 1994). Since then, although Yunnan's top leaders were not received by Sihanouk and his son, the new King of Cambodia, Norodom Sihamoni after the former's death in October 2012, they had opportunities to meet Prime Minister Hun Sen, the de facto Cambodian state leader, almost every time they visited Cambodia (Yunnan provincial government 2018). In the past two decades, Yunnan's Party secretaries and Governors were received by Thai Prime Ministers four times, but failed to call on the General Secretary of the Communist Party of Vietnam during their visits to Hanoi (Yunnan provincial government 2002, 2004).

Additionally, Yunnan has grasped the opportunity of receiving foreign leaders to promote its influence over decision-makers in neighbouring countries. After the decision by the central government to encourage the border regions to undertake more external economic activities, Yunnan has apparently improved the frequency of extending invitations to the leaders of the Mekong countries. For instance, Laotian leaders have travelled to Yunnan thirty-five times since the early 1990s. Just between 2007 and 2008, nine visits were conducted by Laotian leaders, including President Choummaly Sayasone, Prime Minister Bouasone Bouphavanh, Deputy Prime Ministers Somsavat Lengsavad and Thongloum Sisoulith (Yunnan provincial government 2007, 2008). Furthermore, Yunnan has paid considerable attention to protocol during such receptions. State leaders from these countries were received by the Yunnan provincial Party secretary or Governor. Sometimes, both held a meeting for these visiting leaders (Yunnan provincial government 2001, 2006). The representatives of political parties or influential social organizations in these countries were often met by the provincial Party secretary or the chairman of the Yunnan Committee of Chinese People's Political Consultative Conference (CPPCC). Receptions were held by the provincial Party Secretary, Li Jiheng, for the Chairmen of Myanmar Union Solidarity and Development Party (MUSDP), Aung San Suu Kyi, and by the Chairman of Yunnan's CPPCC, 
Luo Zhengfu, for the Vice President of the Lao Front for National Construction (LFNC), Phanduangchit Vongs (Yunnan provincial government 2013, 2015).

Yunnan dismissed criticism about the spending of large sums of money for visits by VIPS from neighbouring countries, especially for private purposes. Two typical instances are the arrangement by Yunnan of a medical check-up for Laotian Deputy Prime Minister Somsavat Lengsavad and a family holiday for Vietnamese President Tran Duc Luong (Yunnan provincial government 2003, 2007). However, as one interviewee argued, although in the short term it may not be economically wise for Yunnan to pay for visiting leaders and guests, Yunnan should care more about its "political account" rather than its "economic account" 43 . Moreover, given that China held the third largest proportion of ADB's shares (6.5\%), and the rest of the GMS members together accounted for less than 1\%, projects proposed by Yunnan were easily approved at the GMS meetings. This has led neighbouring countries to complain. In order to protect the relationship between Yunnan and neighbouring countries from being affected by this, it is not a waste if Yunnan spent some money on building good working relationships with the senior leaders from these countries ${ }^{44}$.

The contribution of improved exchanges between leaders from Yunnan and neighbouring countries was clearly reflected in the following two cases. The first was the manner in which Yunnan responded to the inflow of refugees in the wake of the 2009 Kokang incident, a violent series of conflicts between the Burmese military junta and ethnic minorities in Myanmar's northern Shan State. Drawing on their intelligence from Myanmar, officials in Lincang of Yunnan effectively responded by making appropriate arrangements for the refugees. Another case is related to the arrest of a group of Yunnanese residents by Burmese soldiers. This issue was swiftly resolved through the intervention of representatives in Ruili of Yunnan who had good personal contacts with their counterparts in Muse in Myanmar. As one interviewee remarked, this issue might not have been easily solved, had it been handled by the Foreign Ministry, in that the Foreign Ministry has weak contacts with local governments and communities in these countries ${ }^{45}$. This kind of strength of Yunnan was generously acknowledged by Chinese State Councillor Yang Jiechi,

\footnotetext{
${ }^{43}$ Interview with a Yunnan expert, October 27, 2016, Kunming.

$44 \mathrm{lbid}$.

45 Interview with a Yunnan official, October 2, 2016, Kunming.
} 
who is believed to have joked that he was jealous of Yunnan's leaders, in that they were often invited to visit the homes of state leaders of the Mekong countries, but he was not ${ }^{46}$.

\subsubsection{Sister-Province Relationship}

The following section sheds light on how Yunnanese officials have sought to incentivize neighbouring countries to work with Yunnan by forging sister-province relationships with provinces in these countries ${ }^{47}$. Despite the fact that there were only six such relationships built by all Chinese provinces on the eve of the reform, twinning activities have rapidly increased since then, stimulated by the decision of the central government to launch China International Friendship Cities Association (CIFCA) (cifca.org.cn 2014). The CIFCA is not intended to interfere in provinces' selection for twinning partners and signing pacts; instead, it aims to provide guidance for the establishment of sister relations between Chinese local governments and their foreign counterparts on a voluntary basis of equality and mutual benefit.

As with other provinces, Yunnan has enthusiastically embraced sister relations with foreign provinces and followed the central government in establishing the provincial IFCA. Although the provincial IFCA would be obligated to seek approval from the CIFCA, should it seek to build a sister-province relationship, it has enjoyed substantial autonomy. This is because the CIFCA seldom rejects applications from provincial IFCAs, as the former would like to take credit for the growing number of provincial-level sister relationships (Li 2017). With the efforts of the provincial IFCA, Yunnan has formed seventeen partnerships with foreign provinces (cifca.org.cn 2018). Although the province's partnering efforts quantitatively lagged nationally, sister-province relationships have contributed to the enhancement of connections between Yunnan and neighbouring partners by making it more convenient for the province to arrange official visits, carry out socioeconomic projects, and maintain contacts on a regular basis (Cheung and Tang 2001).

Yunnan's first twinning partner is Chiang Rai, the northernmost province of Thailand. Since entering into this relationship, the two provinces have strengthened their connections

\footnotetext{
46 Interview with a Yunnan official, December 4, 2016, Kunming.

47 Paradiplomacy scholars find this type of interactions to be epidemic. For instance, most American states have fostered sister-state relationships with their counterparts across Europe, Asia, South America, and the Caribbean in the fields of economy, culture, and tourism (Fry 1990). Many progressive governors in Japan have also chosen to build sister-state relationships with their Chinese provinces to redirect Japan's focus from Washington and the West (Jain 2006).
} 
among policymakers, businessmen, and academics (yfao.gov.cn 2015). In recent years, the President of Chiang Rai Rajabhat University conducted an academic tour of Yunnan University of Finance \& Economics (ynnu.edu.cn 2017), while a youth delegation from Chiang Rai called on Yunnan Nationalities University (gx211.com 2017). The officials from Chiang Rai even directly organized a promotional event in Kunming to attract more investment for Chiang Rai's economic zone (sohu.com 2016). The same is true for the connections between Yunnan and Siem Reap of Cambodia. Since they forged a twinning relationship, opportunities for people from both sides to work together have multiplied in the fields of agriculture, culture, and people-to-people exchange (yunnan.cn 2012). For instance, they cooperated to build an agricultural demonstration park in Siem Reap and a new airport for the world-class historical site Angkor Wat, two of the best-known joint projects. The artists from both sides also worked together to organize a music and dance show to demonstrate their friendship, sponsored by the Yunnan Cultural Investment Group and the Cambodian Soma Company (yfao.gov.cn 2015).

Another twinning partner of Yunnan in the subregion is Banteay Meanchey, a north-western province of Cambodia. Under the framework of this relationship, the two provinces have redoubled their communications in various fields, especially agriculture. One typical instance is their joint construction of the Friendship Park of Agricultural Science and Techniques in Banteay Meanchey (chinanew.com 2011; yfao.gov.cn 2015). In addition, Yunnan has assisted Banteay Meanchey in cultivating new types of agricultural products and increasing output to improve the wellbeing of local farmers (yunnan.cn 2012). This sort of relationship also improved Yunnan's profile in the local community of Banteay Meanchey. After 1.7 million people were affected and thousands of rice paddy fields were destroyed by floods in Banteay Meanchey, for instance, Yunnan responded quickly by providing 200 agricultural engineers to relieve the difficulties of local farmers and actively participate in its partner's post-disaster rehabilitation (xinhuanet.com 2013).

In addition to the friendship relationships it established at the provincial level, Kunming, the capital city of Yunnan, has since 1981 had sister-city bonds with 22 cities around the globe. Kunming has been hailed as "a city of blossoms", and thus some of the connections it has established are centred on the theme of flowers. For instance, Kunming and Chiang Mai have formed an enduring bond since 1999, the latter also being famous for flowers and 
hosting an annual flower festival (Nieuwenhof 2019). Among Kunming's 22 sister cities, six are in the Mekong countries, namely Chiang Mai, Mandalay, Yangon, Phnom Penh, Vientiane, Da Nang. In order to further boost tourism, trade, and exchange of culture, Kunming has organized two international events around the theme of friendship. At the Dialogue for Sister City Cooperation and Development in June 2017, which was attended by the representatives of Kunming's friendship cities in the Mekong subregion and beyond, the Mayor of Kunming, Wang Xiliang, promised to expand the scope of trade, to increase outbound investment, and to create sound business environment, calling on these cities to team up with Kunming to pursue more business opportunities in the countries covered by the Belt and Road Initiative. In November 2017, the authorities of Kunming hosted the Kunming International Friendship Cities Tourism Cooperation Conference, after which a friendship city tourism alliance was created. With its secretariat based in Kunming, this alliance was set up to allow Kunming to cooperate with its friendship cities, especially in the neighbouring countries, to carry out tourism policies, develop routes, improve facilities, and share tourism information.

\subsubsection{Overseas Chinese}

This subsection discusses how overseas Chinese in the Mekong countries have become a pull factor in helping these countries to foster close partnership with Yunnan. In the postreform period, overseas Chinese have been enthusiastic about China's embrace of the global market and have played a significant role in China's growing international interdependence (Suryadinata 2007). For many coastal provinces in China, overseas Chinese from Hong Kong, Taiwan, and Southeast Asia have been identified as one of the critical factors in their economic growth (Segal 1994).

It is also the case for Yunnan. For overseas Chinese from Yunnan living in the Mekong subregion, their migration history can be traced back to the time when groups of Yunnan natives sought political asylum in the subregion (Dong and Chen 1984). Meanwhile, a certain number of ambitious Yunnan natives crossed the border to seek financial opportunities (Hill 1998). Such migration increased after the Communist takeover of China and subsequent man-made disasters, such as the Great Leap Forward (1958-1962) and the Cultural Revolution (1966-1976) (Chang 2014). 
Years into the reform, Yunnan has been more active in encouraging overseas Chinese in the subregion to participate in its economic growth and its cooperation with their host countries $^{48}$. The Ministry of Human Resources and Social Security (MHRSS) concluded an agreement with Yunnan provincial authorities to grant the latter tangible support regarding the attraction of overseas Chinese in the subregion with expertise in technology and management. Subsequently, 80 per cent of Yunnan's actually utilized foreign capital was derived from overseas Chinese in the Mekong countries, and 70 per cent of foreign companies in Yunnan are run by overseas Chinese with ancestral connections to Yunnan. Overseas Chinese have also helped Yunnanese enterprises to become familiar with local markets and regulations in neighbouring countries before setting up their operations there ${ }^{49}$. Yunnan also established a few provincial agencies to deal with overseas Chinese, one of which is the provincial United Front Work Department (UFWD). The crucial role of this agency is reflected in the fact that its director often doubles as a member of the provincial party standing committee, the most powerful decision-making body within Yunnan (swtzb.yn.gon.cn 2015). The UFWD is also tasked with supervising the provincial Overseas Chinese Affairs Office (OCAO) (swtzb.yn.gon.cn 2015). As a provincial department-level agency, the OCAO is partly obligated to contact Yunnan natives residing in neighbouring countries, while conducting research and formulating Yunnan's overseas Chinese policy (ynqb.net.cn 2018). Contacting and mobilising returned overseas Yunnan natives is also one of the responsibilities of the provincial OCAO; for instance, its leaders habitually visit their families ahead of the Chinese Lunar New Year (ynqb.net.cn 2017).

\subsection{Raising New Political Stakes?}

Thus far, this chapter has demonstrated that, with its new external affairs powers, Yunnan has succeeded in incentivizing its foreign neighbours to engage in intensive cross-border cooperation. The specific ways have been for Yunnan to effectively exploit a mix of instruments, such as infrastructure development, trade and investment relations, and diplomatic efforts. For one interviewee, the paradiplomacy of Yunnan has been more complicated than that of its inland and coastal counterparts, since Yunnan, as a border region, has taken responsibility for some issues that should have usually been handled by

\footnotetext{
48 Interview with a Yunnan official, December 5, 2016, Kunming.

49 Interview with a Yunnan official, October 2, 2016, Kunming.
} 
the central authorities; therefore, he continued, it is not an exaggeration to say that Yunnan's foreign relations are equal to state-level diplomacy, to a large extent ${ }^{50}$. Given this statement, a question arises about the likelihood of Yunnan capitalizing on its heightened external influence to potentially raise some political demands, such as secession from the rest of China. Prior to addressing this question, a brief review of how this phenomenon is depicted in the broader paradiplomacy literature is in order.

Paradiplomacy researchers have identified nation-building as a common political driver for subnational governments to promote external linkages (Soldatos 1990; Balthazar 1999). For a subnational entity, this type of paradiplomatic activity is to "graft a more or less separatist message on to its economic, social, and cultural links with foreign nations" (Duchacek 1990: 27). Often, separatist movements are more likely to take root in regions overwhelmingly inhabited by national minorities (Lecours and Moreno 2001). The attempt by Catalonia to propagate its independent enterprise during the 1992 Summer Olympic Games is a notable instance (Keating 1999). The most-cited instance is provided by Quebec, especially under the rule of the Parti Québécois (PQ) (Fry 1990). In addition to Western cases, Iraqi Kurdistan used international connections for this propose. Through the decades, the Kurdistan Regional Government (KRG) has courted the favours of the United States and Iran in exchange for their support for its rebel movements, especially while taking part in the USled invasion to topple the Saddam Hussein regime (el-Dessouki 2012; Mohammed and Owtram 2014; Akreyi 2017). Focusing on Russia's Tatarstan, Elena Albina (2010) has argued that whereas this region attempted to press for greater tax transfer from the federal government, it pressed for this goal by taking advantage of its foreign linkages to seek independence.

In the case of Yunnan, there were indeed occasional separatist movements before the establishment of the PRC. This was due mainly to the existence of influential local forces and complicated ethnic tensions. During the Tang and Song dynasties, Yunnan was comprised of two states, Nanzhao (738-937) and Dali Kingdom (937-1253), which were not subordinate to the Chinese authorities (Ma 1983; You 1994). The rebellion launched by the Yunnan General Wu Sangui took the Kangxi Emperor eight years to suppress (1673-1681) (Ma 1983). In the same Qing dynasty, Yunnan's Muslims established a separatist regime in Dali and assisted

\footnotetext{
50 Interview with a government official, October 19, 2016, Kunming.
} 
British soldiers in attacking the central authorities in the 1860s (Huang 1976). Separatist movements continued in the era of the Republic of China (ROC) (1912-1949). On Yuan Shikai's proclamation as an emperor, Yunnan Governor Tang Jiyao declared independence and cooperated with his predecessor Cai E to resist Yuan in November 1915 (Xie 1993). In the last days of the ROC, Yunnan Chairman Lu Han staged an uprising and defected to the newly-established PRC in 1949 (Xie 1993). After the foundation of the PRC in October 1949, however, there has been no any significant separatist movement in Yunnan. The closest to such an event was the rebellion to break Shadian Town away from the PRC during July 1975 and August 1975, staged by local Muslims but not the provincial officials (Raphael 2002). However, will Yunnan be constrained from capitalising on its external influence to seek independence in the future? For four reasons, this question seems best answered in the negative.

First, China has succeeded in turning growing Chinese nationalism into a source of legitimacy in the reform era (Huang 1995). Conceived as a civilization rather than a nationstate, the concept of 'China' was based on cultural considerations, and thus there was vulnerability to fragmentation into separate political entities (Pye 1990). However, this phenomenon has incentivized the PRC to cultivate "waves of nationalist education movements aimed at cultivating or reinforcing the Chinese national identity" (Zheng 1999, 2007). This newly-cultivated, though not contested, national identity reinforces a timehonoured political value of China that treasures unity of state (Bockman 1998). Another factor is that Yunnan, like all provinces, shares mutual economic interests with Beijing. Put differently, China's domestic market is so huge and prosperous as to make any separation attempts tantamount to "cut (ing) oneself off from the one-fifth of the world's population" (Womack and Zhao 1994: 173). It is therefore safe to predict that, except Xinjiang and Tibet, which face more complicated historical, geopolitical, and religious situations, secessionist movements would not take place in the rest of the Chinese provinces, as long as the country's economy maintains a stable growth rate (Yang 1994).

A third factor is related to China's cadre management system. Under its nomenklatura (personnel) system, not only have local leaders been subject to cadre transfer and exchange regulations (Zheng 2007), but they have also been constrained by the non-native principle 
(Yang 2014). These regulations have been aimed at preventing local leaders producing great regional influence. In addition, the central authorities have monopolized a final say in deciding all crucial appointments and removals (Landry 2008). If subnational leaders expect to climb the ladder of their career within the CCP's bureaucratic system, they will not stick their necks out against Beijing. Beijing has often staged anti-corruption campaigns to 'remind' local leaders of who calls the shots (Hameiri and Jones 2016). Above all else, provincial governments do not gain access to military power to seek independence. Although there were huge field armies tightly linked to specific geographic areas in the early years of the PRC, a series of military reforms have taken place to prevent local leaders from colluding with the PLA stationed in their regions. The first was the disengagement between military and civilian officials. The second was for military officers to be trained to be more professional and disciplined so that they become less interested in local politics (Swaine 1994). The third was for the army to be informed by nationalism, to unconditionally uphold national unity and the Party leadership (Joffe 1994). The last was for the Party to use anticorruption campaigns to ensure the loyalty of the top brass, especially under Xi Jinping (Lam 2015).

Despite the lack of impulse to raise secessionist demands, this is not to say that Yunnan could not leverage its external influence to press for more economic benefits from the central government. One of the typical instances is for Yunnan to take advantage of the Asian Development Bank (ADB) to derive more preferential policies from Beijing. ADB requested that should the bank be invited to underwrite a GMS project, the national government of the recipient country has to spend the same amount of money to guarantee the smooth completion of this project. Knowing that Beijing would not like to tarnish its reputation as a primary promoter of the GMS by violating the regulation of ADB, Yunnan officials often deliberately strove for more ADB-sponsored projects, in order to induce Beijing to loosen its purse strings for the cross-border projects concerning Yunnan ${ }^{51}$. Another case is related to Yunnan's paying for visiting VIPs from neighbouring countries. Despite some complaints that it is not economically-wise for Yunnan to receive these guests, the real motivation for the province is to draw the attention of Beijing by highlighting its salience in China's cooperation in the GMS, and to urge Beijing to award more policy spaces

\footnotetext{
51 Interview with a scholar, October 27, 2016, Kunming.
} 
and resources to the province in dealing with cross-border issues ${ }^{52}$. However, it should be added that the decision by Yunnan to leverage its external linkages to struggle for greater economic support from Beijing could be the result of the lack of a direct, established channel for provincial officials to have the ear of national leaders. The existing channels involve communicating with the ministries under the State Council, submitting motions at the annual National People's Congress session, reporting to state leaders during their inspection tours to Yunnan, and taking advantage of their private contacts with state leaders (Yang 2014). However, these paths have often proven to be either ineffective or opportunistic.

\subsection{Conclusion}

Following the last two chapters, which dealt with the first two dimensions of the actorness of Yunnan in international relations, this chapter aimed at exploring the third component: capability. It has identified the means by which Yunnan exerted its external capability to make the province more appealing for neighbouring countries to cooperate with it. This chapter has argued that Yunnan has relied on three broad instruments to achieve this goal: infrastructure development, economic statecraft, and diplomatic efforts. These instruments have been based on some locational advantages, such as geographic proximity and crossborder networks. However, it is the new external affairs powers that have enabled Yunnan to develop these advantages into useful diplomatic instruments. The findings of this chapter were chiefly derived from interview materials in which Yunnanese officials, think-tankers, and scholars who have been deeply involved in or specialized in the paradiplomatic activities of the province provided their insights on the diplomatic resources developed by Yunnan in advancing its external interactions.

52 Interview with a governmental official, November 1, 2016, Kunming. 


\section{Chapter 7}

\section{Dimensions of Yunnan's Actorness: Presence}

\subsection{Introduction}

As introduced in Chapter 2, presence refers to the recognition of the international actorness of a subnational entity by other parties. This chapter reveals that Yunnan's international actorness has clearly been recognized by neighbouring countries. This recognition can be deduced in a number of ways, from the behaviour of the countries in the subregion. The first way was for these countries to allow Yunnan to sign non-treaty agreements. The second route to recognition for Yunnan was for these countries to accept the presence of permanent official representatives from Yunnan in their territories, in the form of Yunnan's Overseas Representative Offices (OROs). This recognition was also manifest in the approval by neighbouring countries to permit Yunnan to engage in various bilateral and multilateral institutions, the most influential being the Greater Mekong Subregion (GMS) economic cooperation.

Yunnan's international actorness has also been acknowledged by the central government, as can be seen from the attitude and policies of Beijing as to Yunnan's engagement in crossborder cooperation. First, it can be seen in the fact that the central government has allowed Yunnanese representatives to participate in national delegations at various international events and visits. Second, recognition by the central government is also evident in its selection of Yunnan to manage a few external events, which include not only commercial and cultural ones, but also certain security-themed summits. Third, it can also be reflected in decisions by the central government to give precedence to Yunnan in the face of some controversial border affairsLast, one more substantiation is provided by the central government encouraging Yunnan to cooperate with neighbouring countries to establish various types of economic zones.

The findings in this chapter are based mainly on historical records, policy papers, and news reports from portal media. Yunnan Almanacs (1984-2015) were exceptionally helpful, in that they comprehensively recorded major events concerning the socioeconomic progress of 
Yunnan and the province's critical external interactions. In order to substantiate the findings from desk research and online searches, interviews were undertaken in Kunming, Yangon in Myanmar, and Khon Kaen in Thailand. In light of the fact that this chapter deals with detailed cooperation between Yunnan and neighbouring countries, some officials and experts from the Mekong countries were also interviewed. Following the Introduction, the question of how Yunnan's role as an international relations actor has been recognized by neighbouring countries is addressed in Section 7.2. Section 7.3 then discusses the recognition by the central government of Yunnan's international actorness. This chapter concludes with the generalization of findings (Section 7.4).

\subsection{External Recognition}

This section deals with the recognition of Yunnan as an international relations actor by neighbouring countries. As their recognition of Yunnan can be inferred from the interactions between Yunnan and these countries, the section explores how these countries have treated Yunnan as an authorized signatory of non-treaty agreements, which lack binding force and do not require complicated domestic approval procedures (7.2.1). They also allowed Yunnan to dispatch representatives to their territories in the form of the Overseas Representatives Office (OROs) (7.2.2), and to engage with a range of bilateral and multilateral regional institutions (7.2.3).

\subsubsection{Signing Non-Treaty Agreements}

This section argues that the Mekong countries have recognized Yunnan's international actorness by accepting the province as an authorized signatory of non-treaty agreements. According to the Chinese constitution (NPC 1982), the formulation, approval, and repeal of external treaties are within the jurisdiction of the President of the PRC, the National People's Congress (NPC), and the State Council. However, Yunnan has entered into a variety of non-treaty agreements which technically lack legal binding force and do not require complicated domestic approval procedures (Hillgenberg 1999). The types of agreements signed by Yunnan constituted cooperation framework agreements, memorandums of understanding (MOUs), letters of intent (LOTs), trade agreements, and meeting summaries across the fields of economy trade, technology, transportation, and tourism (Colin 2014). 
Theoretically, owing to diplomatic protocol, the agencies of the Yunnan should only conclude agreements with foreign subnational authorities. For instance, Yunnan provincial authorities signed an agreement with Banteay Meahchey to jointly construct an agricultural and technological demonstration zone, and with Lao Cai in Vietnam to create a cross-border economic cooperation zone CEZ (Yunnan Daily 2012). The Department of Agriculture and Forestry of Luang Namtha in Laos signed an MOU with Yunnan Entry-Exit Inspection and Quarantine Bureau on detecting guava fruit fly (Yunnan Daily 2010). However, the role of Yunnan as an interlocutor is recognized not only by local governments but also by some national agencies in the Mekong subregion. The latest instances include the agreements signed in the $2^{\text {nd }}$ China-Southeast Asia Business Forum in June 2018. During the forum, the Yunnanbranch of China Council for Promotion of International Trade concluded with the national commerce chambers of Vietnam and Laos, respectively. Through the agreements, Yunnan demonstrated its commitment to cooperating with the two countries in the development of energy resource and other new industries, drawing on its relative edge in the areas of technology, strict environmental protection regulations, and capital. To encourage a large number of tourists within Yunnan and the Mekong subregion to visit each other region, the Yunnan Tourism Administration (YTA) concluded a series of agreements or MOUs with the national tourism agencies of the neighbouring countries, highlighting their proximity, dramatic landscape, and breath-taking views, and teaming up with these countries to facilitate travel into and within the regions, to upgrade travel facilitates and services, and to enhance mutual assistance in human resources development (Chen 2014).

\subsubsection{Accepting Provincial Representatives}

The Mekong countries have recognized the international actorness of Yunnan through allowing for the de facto diplomatic presence of Yunnan in their territories. The provincial representation has taken the form of Overseas Representative Offices (OROs). To begin with, these OROs were established in the capital cities of Laos, Vietnam, and Myanmar, but they were later extended to cover 26 countries, including all the Mekong countries (ceh.com.cn 2017). Under the authority of the provincial government, the OROs are guided by the provincial Department of Commerce (DOC) and Foreign Affairs Office (FAO) in performing their daily duties. Their use of money is supervised by the provincial finance authority. The daily operations of all the OROs on the Indochinese peninsula are managed by Yunnan- 
owned enterprises operating businesses in foreign countries. According to one interviewee, the reason why Yunnan's OROs are associated with provincial enterprises is mainly because it would be more cost-effective and convenient for the OROs to tap into the social resources and funds of these enterprises ${ }^{53}$. The enterprises were permitted to select their own employees to take charge of the OROs. For instance, Li Shaoquan, the General Manager of the Cambodian branch of Yunnan Construction and Investment Holding Group (YCIH), doubled as the director of the ORO in Phnom Penh.

The OROs are tasked with assisting the provincial government in collecting information, building databases, analysing local socioeconomic situations, and arranging visits by provincial leaders ${ }^{54}$. They organize trade fairs, inspections, and face-to-face negotiations for local and foreign investors and government officials. The OROs also assist Yunnan's corporations in familiarizing themselves with local customs, regulations, and laws. A notable instance was provided by the ORO in Vientiane, who delivered lectures to Yunnanese investors on local environment protection and industrial regulations (sohu.com 2017). Another example is that of the ORO in Naypyidaw who invited Yunnanese entrepreneurs to share their experience of dealing with local partners (yunnan.cn 2017). These OROs in the Mekong countries are further responsible for improving Yunnan's popularity overseas. The hosting of a car rally on the fringes of a trade fair by the ORO in Phnom Penh in 2017 is one instance (Yunnan Daily 2017).

\subsubsection{Engaging Regional Institutions}

Recognition of Yunnan's role as an international actor by neighbouring countries is also manifested in the fact that these countries agreed for Yunnan to engage with many bilateral and multilateral institutions. Through these institutions, Yunnanese officials could directly negotiate with the representatives of neighbouring countries and better integrate the province's projects into a broader picture of regional development.

Yunnan started to leverage its locational advantages to join a few cross-border working teams (WTs). Ostensibly, the jurisdictions of these WTs were limited to cooperation between Yunnan and the northern parts of neighbouring countries, because Yunnan is not

\footnotetext{
53 Interview with a government official, December 14, 2016, Kunming.

$54 \mathrm{lbid}$.
} 
politically on a par with these countries. But in reality, the WTs are responsible for Yunnan's economic exchanges with the totality of each neighbouring country ${ }^{55}$. Specifically, Yunnan has joined a WT with Northern Thailand since 2004 to expedite the flow of information and resources. The first conference of this WT was co-chaired by Yunnan Governor Xu Rongkai and the then Thai Foreign Minister, Surakiart Sathirathai, with both vowing to work together to address the problems stemming from their cooperation under this WT (Yunnan Daily 2004). During this meeting, Yunnan concluded a variety of agreements with Thailand in general, concerning the construction of an economic experimental area in northwestern Thailand and a tobacco factory in Chiang Mai, the promotion of tourism on the Mekong River, and the improvement of the condition of the Mekong River (Yunnan Daily 2004). At the $6^{\text {th }}$ meeting of this WT in July 2017, both sides expanded the scope of their mutual interests to 14 fields, including transporation and security (Chen 2018).

Yunnan-Northern Laos working team was inaugurated in the same year. The Yunnan provincial Development and Reform Commission (DRC) and the Lao-China Cooperation Department of the Ministry of Planning and Investment were designated as liaison offices for each side (yunnan.cn 2009). Over the last decade, the Yunnan-Northern Laos WT has convened eight high-level meetings, initiated several joint projects, and contributed to the elevation of Laos as Yunnan's second-biggest trade partner in Southeast Asia. At its $8^{\text {th }}$ conference in September 2017, for instance, both sides agreed to redouble their cooperation under this WT, to improve mutual understanding and high-level exchanges, to facilitate customs clearance, and to cooperate further in education and human resource development (whyn.gov.cn 2017). The two sides also agreed at this meeting that China's Belt and Road Initiative and Laos' strategy of "turning itself from a land-locked country into a land-linked country" can undergird each other through jointly developing such flagship projects as the Saysettha Development Zone and Mohan-Botan Economic Zone (Chen 2018).

The Yunnan-Myanmar Cooperation Business Forum was set up against the backdrop of Yunnan becoming Myanmar's biggest trade partner (mofcom.gov.cn 2013). The missions of this forum were promoting the establishment of the Ruili-Muse Cross-border Economic Cooperation Zone, regulating border trade, strengthening control over the border, cracking down on border-related crimes, stepping up efforts in the opium substitution programme,

\footnotetext{
55 Interview with a government official, November 2, 2016, Kunming.
} 
and coordinating works related to the construction of the Bangladesh-India-China-Myanmar (BCIM) economic corridor (yunnan.cn 2014). Thus far, the conferences of this forum have been successfully held for five consecutive years, serving as an important platform for Myanmar to directly engage with Yunnan across the areas of trade, tourism, and border security (yunnan.cn 2018).

Additionally, Yunnan has participated in two bilateral mechanisms with the northern provinces of Vietnam. One is an economic conference between Yunnan and Northern Vietnam, joined by four Vietnamese provinces: Lao Cai, Hanoi, Haiphong, and Quang Ning (Yunnan Daily 2017). This conference is aimed at coordinating works relevant to the SinoVietnam Economic Corridor (Nhan Dan 2017; xinhuanet.com 2017). At the latest round of the conference in Vietnam's port city of Hai Phong in November 2017, both sides vowed to advance cooperation in building the economic corridor into a model of effectiveness (xinhuanet.com 2017). Another is the Yunnan-Northern Vietnam WT, established to facilitate economic growth and border stability in Yunnan and its adjacent regions in Vietnam (xinhuanet.com 2016). This WT includes four Vietnamese provinces Lao Cai, Ha Giang, Lai Chau, and Dien Bien, with Lao Cai being the only Vietnamese province occupying a seat in both WTs (kunming.cn 2016). The specific tasks of the Yunnan-Northern Vietnam WT involve matters relevant to border management, port construction, and commercial promotion (yunnan.cn 2012). At its $6^{\text {th }}$ meeting in January 2017, for instance, all sides reached an agreement in Kunming on a series of non-traditional security affairs. They were committed to establishing a regime for forestry cooperation, preserving wildlife, monitoring wildlife diseases, preventing forest fires, and managing illegal cross-border trade (xinhuanet.com 2017).

The Mekong countries have further allowed Yunnan to be a member of multilateral institutions, the most influential of which was the GMS economic cooperation programme. Since its inception, in 1992, Yunnan has joined with Thailand, Laos, Cambodia, and Vietnam. This was by no means a nominal representation. Yunnan was authorized to address all China-related issues within the GMS on border trade, investment, connectivity, energy, and non-conventional security (Li 2014). The degree to which Yunnan was involved in the GMS can be divided into four phases. The first phase actually predated the establishment of this programme. At the time, Yunnan shared the problem of severe economic imbalance within 
its territory with most of the Mekong countries. Yunnan scholar, Huang Huikun, had called for what would amount to a growth quadrangle, involving Laos, Thailand, Myanmar, and Yunnan (Yang 2001; King 2002). Yunnan's FAO responded positively to Huang's proposal and suggested that the province should learn from the experiences of the existing Growth Triangles in Asia (Appendix 6). Therefore, in August 1992, when ADB officials conducted a trip to Yunnan to study the feasibility of building the GMS, they were impressed by Yunnan's strong interest in this initiative and effective preparation (Chen, Jian and Chen 2010). Thanks to its preliminary studies, Yunnan proposed that transport infrastructure should be labelled as the most fund-needy field in future GMS cooperation, and put forward an ambitious road development plan accordingly (Chen, Jian and Chen 2010).

The next phase was from 1992 to the late 1990s, when Yunnan was granted substantial leeway in contending with the issues concerned with its interests in the GMS. This was in part attributed to Beijing's lukewarm interest in this regional grouping and lack of experience of dealing with the countries in the Mekong subregion (Yang 2001; Swain 2002; Tubilewicz and Jayasuriya 2015). This has propelled other GMS members to turn more closely to Yunnan. The indifference of Beijing within the GMS was manifest in its selection of officials for the Ministerial Conferences. In the early years of the GMS, the Foreign Ministry did not dispatch any officials, and the only representative of Beijing was a junior official from the People's Bank (xinhuanet.com 2008). In contrast, Wu Guangfan, the general secretary of the provincial government, was sent by the Yunnan provincial government to the GMS conferences for four straight years, and considered as the de-facto leader of the Chinese delegation because of his seniority and experience ${ }^{56}$.

The next phase was from the late 1990s to the 2000s, when Beijing became more enthusiastic about the GMS (Tubilewicz and Jayasuriya 2015). The change in attitude can be seen from its dispatching of deputy-ministerial officials to the GMS Ministerial Conferences, calling for a GMS leaders' summit, and moving up some Yunnan-led GMS projects to the national level${ }^{57}$. It is also identifiable in state reports on China's participation in the GMS in 2002, 2005, and 2008, co-authored by the National Development and Reform Commission (NDRC), the Ministry of Foreign Affairs (MOFA), and the Ministry of Finance (MOF) (Colin

\footnotetext{
56 Interview with a Yunnan-based think-tanker, December 1, 2016, Kunming.

57 Interview with a Yunnan scholar, October 27, 2016, Kunming.
} 
2014). It should to be noted that, from the perspective of Yunnanese officials, the growing attention of the central government to the GMS was a double-edged sword. On the one hand, it meant that Yunnan's hard work within the GMS had been acknowledged by the central authorities. On the other hand, the interest of other GMS members in Yunnan stood to diminish once Beijing was directly involved in discussions. Yunnanese officials and scholars owed its deprivation of the role of the sole Chinese representative to concern from the central government over Yunnan's intensifying activism within the GMS ${ }^{58}$.

The fourth phase saw engagement between the Mekong countries and Yunnan rekindled in the wake of the signing of the China-ASEAN Free Trade Agreement (CAFTA) (Yang 2001). Just as former Governor Xu Rongkai asserted in his annual report to the provincial People's Congress, CAFTA has brought many opportunities to Yunnan, and the province should consolidate its cooperation with GMS members in order to extend its influence over the whole of Southeast Asia. The Yunnan Academy of Social Science (YASS) further called on the province to deepen its participation in the GMS to lay a foundation for its role as a coordinator between China and the ASEAN, under CAFTA. At the same time, unlike the preceding phase when the central government attempted to downplay the influence of Yunnan in the GMS, it now began to rely on Yunnan to channel excessive foreign exchange reserves, accumulated from China's long-term trade profits and holding of U.S. debt, into GMS infrastructure projects (Tubilewicz and Jayasuriya 2015).

Apart from the GMS, the Mekong countries have also welcomed Yunnan as a permanent member of the Mekong Institute (MI) (Figure 7.1). The $\mathrm{MI}$ is an intergovernmental organization providing high-quality human resource development over the Mekong subregion. It was initiated by New Zealand and Thailand, in association with Thailand's Khon Kaen University (mekonginstitute.org 2018). Since its establishment, the members of the MI have engaged with Yunnan. Yunnan has been involved in the management of the MI. Despite the fact that the Chinese Foreign Ministry asked the Permanent Representative of the Permanent Mission of China to the Economic and Social Commission for Asia and the Pacific (ESCAP) to represent China on the Steering Committee of the MI, the only Chinese seat in the Council, the supreme decision-making body of the $\mathrm{MI}$, has been taken up by the Deputy Governor of Yunnan (mekonginstitute.org 2018). The Scientific Development

\footnotetext{
58 Interview with a Yunnan scholar, October 31, 2016, Kunming.
} 
Research Centre under Yunnan provincial Science and Technology Department was also chosen as the only Chinese representative within the Ml's Coordinating Agency (mekonginstitute.org 2018).

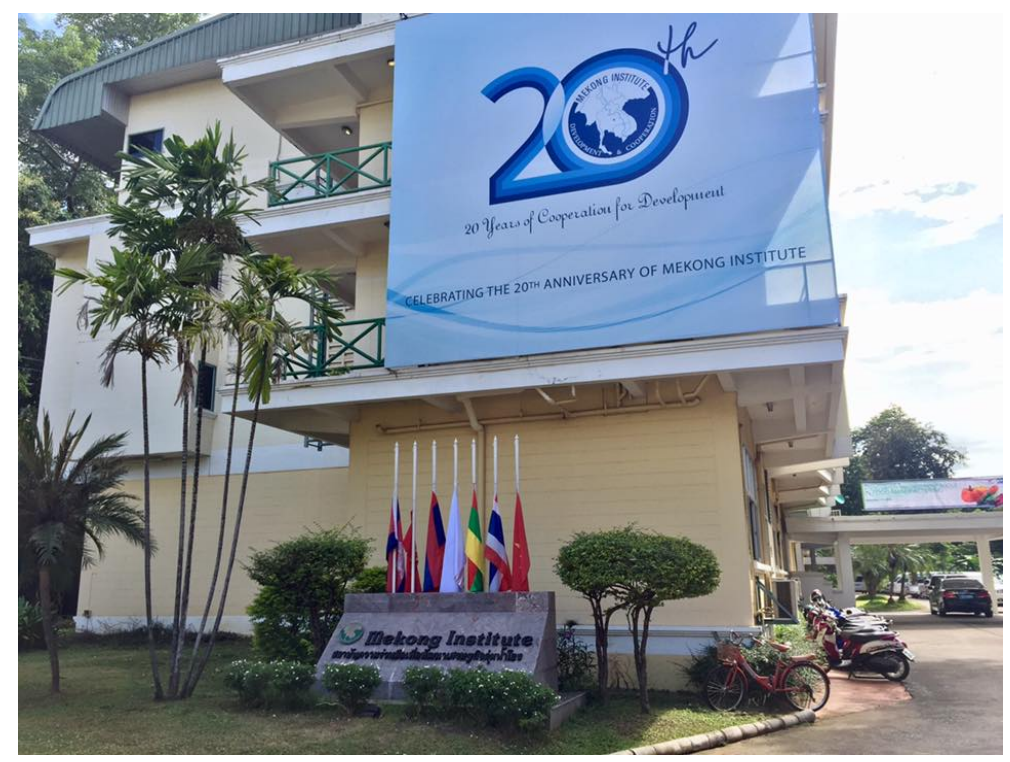

Figure 7.1 The Mekong Institute (MI) in Khon Kaen, Thailand

The MI has also worked with Yunnan to undertake various projects, especially in the fields of human resources and technological support. Most of the time, when projects were sponsored by Yunnan, the $\mathrm{MI}$ and the provincial FAO needed only to symbolically report to the Permanent Mission of China of ESCAP, and then make them into practices, as long as the Permanent Mission approved. When projects were under Beijing's auspices, however, the MI was obliged to report to the Permanent Mission, which had the right to decide whether to inform Yunnan provincial FAO or not. Over the past decade, for example, the MI has signed a cooperation framework agreement with Yunnan's Scientific Development Research Centre to establish the GMS Strategic Resources Base and the GMS Scientific and Technological Innovation and Technology Transfer Base, and worked with the provincial Technology Department on the provision of training sessions on biopharmaceutical and technology and the construction of a GMS scientific and technological forum ${ }^{59}$.

The involvement of Yunnan can also be manifested in the sharing of the MI-related budget with the Chinese central government. As Beijing was reluctant to take the lead in the MI, by pouring in more investment than Thailand (the host country of the MI), its investment of

59 Interview with an MI staff member, November 10, 2016, Khon Kaen. 
USD 200,000 annually in the MI has been modest, with another USD 150,000 being paid through various projects ${ }^{60}$. For instance, the Development Research Centre, affiliated with China's State Council, negotiated with MI regarding the construction of a knowledge-sharing centre, through which the MI could secure extra funds. Meanwhile, the MI acquired financial support from organizing training sessions for the Yunnan Power Grid Company across a wide range of topics, from infrastructure building to communication skills. It should be added that, despite various opinions within Yunnan, it is widely believed that the financial support given to the $\mathrm{Ml}$ is worthwhile, especially considering that trainees from Yunnan can take advantage of this platform to engage with their foreign counterparts, implanting a better understanding of Yunnan in the latter ${ }^{61}$.

\subsection{Internal Recognition}

This section reveals that the increased power capability of Yunnan has driven the central government to acknowledge its value in Beijing's cooperation with the Mekong subregion, thereby recognizing the province as an international actor, chiefly in cross-border cooperation. As with external recognition, the internal recognition of Yunnan can be inferred from the attitude and behaviour of the central government. This section proves such recognition, from the fact that the central government has permitted Yunnan to send its representatives to some national delegations (7.3.1), to manage a few external events (7.3.2), to become involved in certain sensitive border issues (7.3.3), and to establish external trade cooperation zones (7.3.4

\subsubsection{Participation in National Delegations}

The first piece of evidence indicating the recognition of Yunnan's international actorness by the central government is the participation by Yunnanese representatives in national delegations on various international occasions. The roles that Yunnanese representatives play in these delegations are varied. One approach is for Yunnanese representatives to take an advisory position within national-level delegations. However, this is not to say that Yunnanese representatives play only a minimal role in such cases. For instance, Yunnan Governor Qin Guangrong once joined a delegation led by Premier Wen Jiabao to the GMS leaders' summit in March 2008. Even though he was ostensibly an ordinary member, Qin

\footnotetext{
$60 \mathrm{lbid}$.

61 Interview with a Yunnan-based think tanker, December 1, 2016, Kunming.
} 
stuck his neck out to express strong confidence about the prospect of Yunnan's cooperation in the GMS during his meetings with the Laotian and Cambodian leaders on the sidelines of the summit (Yunnan provincial government 2008; Su 2014). Another instance includes the attendance of Vice Governor, Chen Shun, at the $11^{\text {th }}$ meeting of China-Vietnam Steering Committee in April 2017 in Beijing. Chen was one of the members of the Chinese delegation, which was led by State Councilor, Yang Jiechi. On the sidelines of the meeting, which was aimed at mapping out a plan for bilateral cooperation and narrowing differences between the two countries, Chen exchanged opinions with his Vietnamese counterpart from Lao Cai Province regarding the construction of the Hekou-Lao Cai Cross-Border Economic Zone (yfao.gov.cn 2018). As these examples show, the attendance of Yunnan representatives provided a hint as to the attitude of the central government towards the economic development of the province, which was closely observed by potential investors and others at home and abroad. Consequently, after the Foreign Ministry declined to include Yunnan's representative in the state-level delegation to the 2016 Leaders' Meeting of the LancangMekong Cooperation (LMC) in Hainan, an intensifying discussion was sparked among Yunnanese officials and scholars as to whether the central government was still supportive of Yunnan's expansion of its economic influence across the border.

Another approach is for Yunnan representatives to carry heavier weight in state-level delegations under the leadership of national representatives. This is either because the province is more specialized in the topic to be discussed at the meeting, or because the central authorities do not pay enough attention to the meeting. One salient example is the participation by Yunnanese representative at the GMS ministerial conferences. In the initial years of the GMS, Chinese delegations were headed by the acting director of the International Department of the People's Bank of China, but the position of deputy head was taken by the General Secretary of the Yunnan provincial government (Summers 2008). As Yunnan's representative enjoyed the highest seniority in the delegation, it was he who served as the de facto leader of the delegation, responsible for coordination within the delegation and the draft plans to be submitted ahead of the leaders' summit (Su 2015). One oft-cited scenario is that after the exchange of pleasantries by the head of the state-level delegation at the opening ceremony of one GMS Ministerial Conference, Yunnan's 
representative, Wu Guangfan, spent an entire hour elaborating on the province's vision for the GMS cooperation (Chen, Jian and Chen 2010).

The third approach is for Yunnanese representatives to represent China. One of the instances is the annual conferences organized by the Council of the Mekong Institute (MI). As Yunnan is the only Chinese member of this Council, the deputy Governor of Yunnan with responsibility for foreign issues is tasked with leading the whole Chinese delegation (Mekonginstitute.org 2018). During the 2015 conference, for instance, Vice Governor Gao Shuxun not only expressed Yunnan's support for the projects initiated by the MI, but, more importantly, called, as the head of the Chinese delegation, on relevant national agencies to redouble their commitment to the projects led by the MI (ynstc.gov.cn 2015).

\subsubsection{Becoming a Host for Major External Events}

Yunnan has sought recognition from the central government through persuading Beijing to agree for it to host some external events. More than a decade of managing such events has given the province more opportunities to showcase its local development and lure foreign investments through these occasions. The selection of Yunnan to be the host of various cross-border events was also in the interest of the central government, in that Yunnan was endowed with unique geographical and social connections with the Mekong countries. These locational advantages enabled the province to attract numerous visitors from neighbouring countries to take part in a variety of official and semi-official activities, such as cultural festivals, sporting events for college students in the subregion, and forums for the heads of villages of neighbouring countries. During 1999's Kunming World Horticulture Expo, for instance, more than 9 million Chinese and overseas tourists travelled to Yunnan within half a year and generated RMB 16 billion (Yunnan provincial government 2000). At the same time, these locational advantages have also helped Yunnan to attract a large amount of investment: Yunnan signed contracts worth USD 87 million during the first Kunming Import \& Export Fair (KIEF), while reaching agreements totalling USD 908 million at the 2014's KIEF (d’Hooghe 1994; Yunnan provincial government 2014).

As a sign of the recognition of the central government, Yunnan has been allowed to improve the scale of existing expositions. One example is that, since 2007, Yunnan has juxtaposed the KIEF with the higher-level China-South Asia Exposition (CSAE). Yunnan also established 
forums for governors from the GMS countries to interact with each other and with Chinese officials and businessmen on the sidelines of the CSAE (People's Daily Overseas Edition 2015). In the 2016 forum, more than a dozen Governors from the GMS countries exchanged opinions concerning stepping up regional connectivity, optimizing production capability, and building a region with a common destiny (people.com.cn 2016). Although the central government asked for the CSAE and the KIEF to be held in alternate years after 2017, it still gave special permission to Yunnan to host the provincial-level South \& Southeast Asia Commodity Exposition and Investment Fair (SSACEIF) (Figure 7.2) in the year without these two expositions ${ }^{62}$.

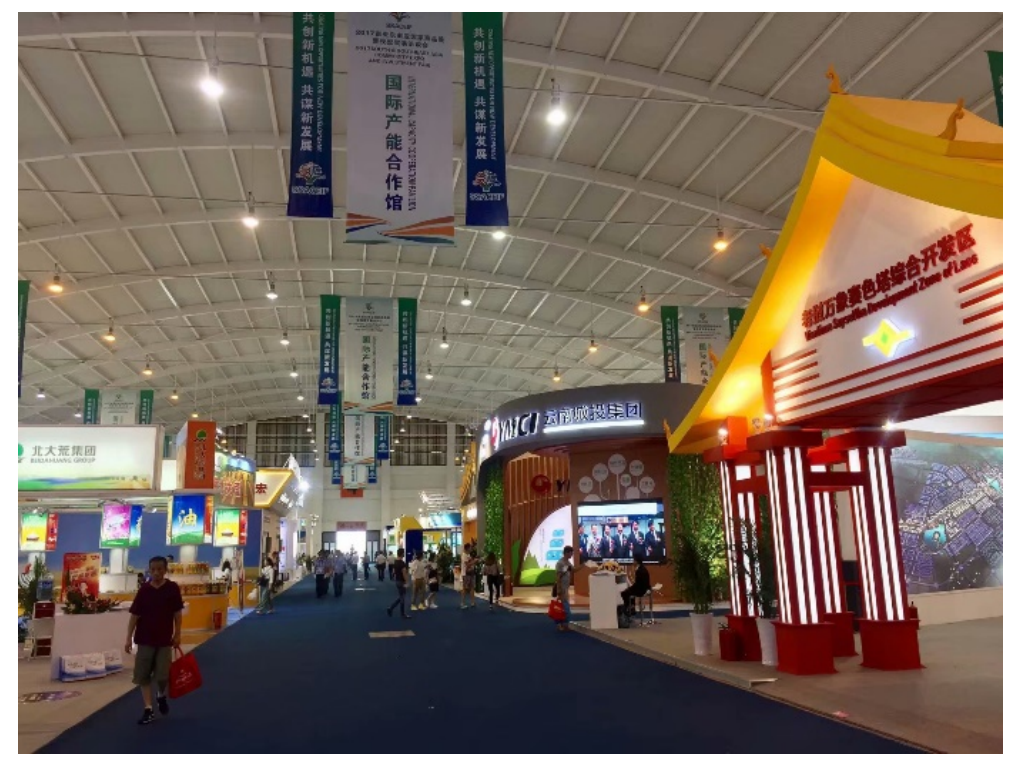

Figure 7.2 The pavilion of the South \& Southeast Asia Commodity Exposition and Investment Fair (SSACEIF)

The central government has also authorized Yunnan to hold annual border trade expositions. Although these expositions were initiated by Yunnan provincial authorities, the prefecture authorities of Ruili, Jinghong, Hekou, and Wenshan were the main implementers. These expositions were held on either side of the border, annually. Since the 1990s, these expositions have contributed to collaboration between Yunnanese enterprises and their counterparts in the Mekong countries across fields as diverse as commodities trade, services trade, investment, tourism, and cultural exchanges, while providing a chance for senior officials and businessmen from both sides to communicate with each other.

62 Interview with a government official, June 14, 2016, Kunming. 
Since 2017, in particular, Yunnan has been authorized to provide hospitality for a variety of political, economic, and cultural events under the newly established Lancang-Mekong Cooperation (LMC). Unlike the GMS which is influenced by Japan through ADB, the LMC was a China-led regional cooperation mechanism only exclusive to China and five countries on the Indochinese Peninsula. Officially established in December 2015, the LMC has focused not only on economic development, but also on the promotion of cooperation across the fields of political security and society. The salience of Yunnan in the LMC was not clearly proclaimed by the central government, which had officially designated Yunnan to represent China in the GMS, at least during the first decade of this programme. Many scholars from Yunnan even claimed that the central government had deliberately played down the international role of Yunnan by citing the example that senior Yunnanese officials were not invited to participate in the national delegation to the first LMC Leaders' Meeting on March 2016 in Sanya of Hainan province. However, this argument seems not to be beyond doubt. Some officials interviewed explained that the absence of Yunnanese leaders at the conference was due to the fact that it was held at the same time as the 2016 Boao Forum for Asia, at which forum the Chinese delegation normally does not include provincial officials, except for those from Hainan ${ }^{63}$.

Another reason is that Yunnan has been awarded opportunities to line up a host of other major events relevant to the LMC, which demonstrates that the international influence of Yunnan in China's relations with the Mekong countries has not weakened. Although Yunnan missed the chance to host the first LMC Leaders' Meeting, the province collaborated the central government to organize the first LMC Foreign Ministers' Meetings in December 2015. This meeting was rather prominent in that it was considered to mark the start of the LMC (Liu 2017). Yunnan's Party secretary, Li Jiheng, and Governor Chen Hao specially flew from Kunming to Xishuangbanna (Sipsong Paana), an autonomous prefecture in the extreme south of Yunnan, to host a welcoming banquet for the delegations of all the LMC countries and to deliver speeches highlighting Yunnan's economic growth, while expressing the province's willingness to deepen cooperation with neighbouring countries (Yunnan Daily 2016). In December 2017, the Foreign Ministers of the LMC countries convened once again in Yunnan. At the meeting, the central government approved to set up a liaison office of the

\footnotetext{
63 Interview with a governmental official, 1 November 2016, Kunming.
} 
LMC China Secretariats in Kunming. This liaison office, which is subordinate to the Yunnan provincial Foreign Affairs Office (FAO), is the first local coordinating office of the six LMC countries, and it works as a coordinating organ for Yunnan to participate in the LMC. Yunnan was also chosen by Beijing as a host city for the LMC Roundtable Dialogue on Water Environment Management in the late 2018. The Kunming Initiative was issued during the dialogue, in an effort to improve the transboundary water resources management and to assist LMC countries in minimizing the adverse effects of climate change (Xinhuatnet.com 2018).

\subsubsection{Managing Border-Related Controversies}

Recognition by the central government of Yunnan's international actorness can also be perceived from the phenomenon that Yunnan has always been highlighted by Beijing in the face of politically-sensitive border issues. The first set of examples is provided by the participation by Yunnan in dam building. The Mekong River provides shared resources, such as drinking water, wild freshwater fish, transport, and irrigation water, with more than 80 million people depending on the river for survival (Goh 2017). Nonetheless, recent decades have seen China intensifying dam construction along the river, arousing resistance from local communities in riparian countries, due in part to the lack of effective communication channels between China and these countries (Goh 2004). Most of the preliminary studies regarding the construction of dams on the Mekong River were conducted by China during the 1980s, when Beijing had yet to normalize its relations with some riparian countries. Nor did it count on Yunnan to collect relevant intelligence, because the province had yet to engage in large-scale cross-border cooperation at that time. It was under these circumstances that the national Mekong plan had been enacted, without seriously considering environmental costs.

In contrast, Yunnan has built a wealth of area-specific expertise, and its well-established connections and enduring personal connections with the subregion have helped in breaking down the barrier of misperception. This is why the central government started to authorize Yunnan to engage closely in dam building. Indeed, thanks to various channels through which political and business leaders from Yunnan can effectively communicate with their counterparts in neighbouring countries, Yunnan captured timely and accurate information as to the concerns in riparian countries that are disproportionately vulnerable to the side 
effects of dam programmes. This advantage has enabled Yunnan to form a subregion-wide view when making its dam plans, focusing not only on the impact within its own territory, but also on potential collateral risks to downstream countries.

This subregion-wide view was further embodied in the measures taken by Yunnan. For instance, it imposed a ban on logging in Sipsong Panna Prefecture after the 1998 flood in the Mekong subregion, and released the Green Mountain and Clean Water Trans-Century Green Engineering Plan to control industrial pollution across the border (Goh 2004). Costs stemming from the neglect by Beijing of the suggestion of Yunnanese officials and experts were paid in Myitsone Dam project. According to one interviewee, officials and experts from Yunnan advised the China Power Investment Corporation (CPI), the sponsor of Myitsone Dam, to scale back this project to avoid provoking anti-dam campaigners and international NGOs in Myanmar ${ }^{64}$. Disregarding Yunnan's advice, the CPI persisted in making the Myitsone Dam a gigantic project, without enough concern for the local environment and the impact of local resistance.

The fact that the central government has encouraged Yunnan to take a more active role in dam building along the Mekong River could also be attributed to the province's status as a sovereignty-free and a sovereignty-bound actor simultaneously ${ }^{65}$. On the one hand, Yunnan is regarded as a sovereignty-free actor, since it has no command over military forces, nor does it access the right to dispatch and receive ambassador-level missions. On the other hand, Yunnan is bounded by sovereignty which differentiates it from other non-state actors, in that "they are governmentally- and territorially-based actors, having legitimate power to extract resources, to regulate and police local affairs within a clearly demarcated area" (Chen 2005: 188). In the case of dam building, unlike the central government, projects undertaken by Yunnan would not need to encounter excessive nationalist pressure at home. This is why, during negotiations with riparian countries, Yunnan was able to avoid touching

\footnotetext{
64 Interview with a scholar, October 30, 2016, Kunming.

65 In the discussions on "sovereignty ambiguity", paradiplomacy scholars often cite instances related to US states adopting tough stances against those countries with poor labour standards. Understandably, such measures are more easily taken by subnational governments rather than the federal government, since the latter has to take into account the general foreign relations. Another instance is related to the Spanish sub-regions, including the Basque Country, Catalonia, and Andalucía, forging close cooperation with the Republic of Sahara, which was not acknowledged by Madrid (Cornago 2000). During the Cold War, the Social Democratic Party (SPD)-dominated Länder in West Germany tended to focus their paradiplomatic efforts on their foreign left-wing counterparts, which contrasts with the conservatively governed Länder. This allowed Bonn to create a bond with the countries that Bonn would find it difficult to build up relationships with. In East Asia, the subnational governments of Japan and China redoubled their commercial and cultural exchanges to improve the relationship between two countries enmeshed in historical disputes (Jain 2006).
} 
upon water disputes on the Mekong River, but focused overly on the possibility of joint exploration ${ }^{66}$.

When disputes over China's dam building became unavoidable, sovereignty ambiguity made Yunnan more flexible in its selection of reactions. When Vietnam charged Yunnan with altering the natural regime of the river, increasing downstream dry-season flows, and reducing the normal flow of nutritious sediments, Yunnan dismissed this accusation and blamed Vietnam instead for the shortage of flow on the Mekong, citing evidence that Vietnam's rice cultivation had increased by 30 per cent during the past three decades and its water usage in 2014 even amounted to 12 per cent of Yunnan's water yield ${ }^{67}$. Yunnan was also more likely to make bold concessions. Unlike the central government, embattled in the South China Sea disputes, Yunnan, in the face of opposition from riparian countries in its use of the Mekong River, has taken a series of deescalating measures, which could not have been easily taken by Beijing. These measures included declassifying hydrological information and allowing foreign journalists to inspect on spot, both of which were considered as breakthroughs, since hydrological information was treated as a state secret, in particular during the Cold Warr8.

In addition to dam building, the central government has confirmed a role for Yunnan in cooperation with Myanmar as to the construction of the Sino-Myanmar oil and gas pipelines, another testament to the recognition by Beijing of Yunnan's international actorness. The natural gas pipeline was completed in July 2013, funded and constructed by the China National Petroleum Corporation (CNPC). A pipeline for crude oil was established two years later, with the CNPC as its biggest sponsor and stakeholder (Kong 2010). The idea of this project was raised in 2004 by professor Yang Xiaohui from Yunnan University, in the name of promoting the energy security of the whole country (Leung 2011). Subsequently, the former Yunnan Governor, Xu Rongkai, persuaded President Hu Jintao to approve this project during Hu's 2006 visit to Yunnan, while briefing Hu about the situation in northern Myanmar and the history of the pipeline built by US General Joseph Stilwell during the Second World War. After Xu, Governor Qing Guangrong even made the Sino-Myanmar oil and gas pipelines the topic of his PhD dissertation at the Party School of the Central Committee of

\footnotetext{
66 Interview with a governmental official, 2 November 2016, Kunming.

67 Ibid.

68 Interview with a governmental official, 6 November 2016, Kunming.
} 
CCP (Zhang 2017). For Yunnanese officials, "Direct energy supply after the construction of these pipelines would alleviate high prices and shortages, diversify Yunnan's economy, secure greater investment and increase its strategic and political significance to Beijing" (Wong 2018: 739).

Yunnan's proposal for this project received positive responses from Myanmar. In July 2005, the NDRC and Myanmar's Ministry of Energy signed a cooperation framework agreement, in which the two sides agreed on conducting preliminary works for this project (Zhang 2017). However, China's three big oil companies initially hesitated to formally submit a proposal for this project, due to concerns about Myanmar's political instability, Western countries' sanctions against Naypyidaw, and potential wrangling with India. In addition to a strong commitment to this project expressed by Myanmar's Premier Soe Win during his 2006's visit to China, the decision of the central government to call for Yunnan to capitalize on its networked connections with Myanmar to ensure the success of this project has also boosted the confidence of these oil companies. After the CNPC finally won the bid, the Yunnan provincial government concluded a strategic cooperation agreement with the CNPC. At a meeting with the CNPC, the former Yunnan Governor Li Jiheng suggested that:

The Sino-Myanmar pipelines project and the petrochemical industry are important components of Yunnan's bridgehead construction. The CNPC and the Yunnan provincial government both pay high attention to them and collaborate with each other. It is our wish as well as our responsibility to complete these two projects. The provincial government and its agencies will give the green light to these projects and fully support CNPC (yunnan.cn 2012).

Yunnan continued to conclude a strategic cooperation agreement with the CNPC (Yunnan Daily 2010), which was followed by the setting up of a governor-led steering group to assist the CNPC in the course of land acquisition, village relocation, and infrastructure upgrading (Su 2014). It needs to be added that, for the CNPC, its smooth cooperation with Yunnan provincial authorities throughout the construction of the pipelines can perhaps also be attributed to the close personal relationship between former President Jiang Jiemin and the former Party Secretary of Yunnan Bai Enpei, both of whom worked together in Qinghai province (1997-2001) (Wong 2018). 
Apart from infrastructure building, the central government has relied on the international role of Yunnan to implement anti-drug initiatives. Due in part to geography, Yunnan has been the most effective passage between China and the Golden Triangle (an era where the borders of Thailand, Laos, and Myanmar meet) (Figure 7.3), with Kunming being a regional distribution hub for trafficked drugs (Su 2015). Especially with the anti-drug campaigns in neighbouring countries, which hamstrung the southward transmission lines, drug crime in Yunnan, to the north of the Golden Triangle, has become rampant (Ma 1994; Chin 2009). Yunnan's drug problem was further worsened by the disintegration of Communist forces in Myanmar, resulting in the relocation of drug production to northern Myanmar and Laos, on the doorstep of Yunnan. China's suspension of financial assistance to Myanmar's Communist forces also pushed previous Marxist followers to be reliant on drug earnings (Yang 2001).

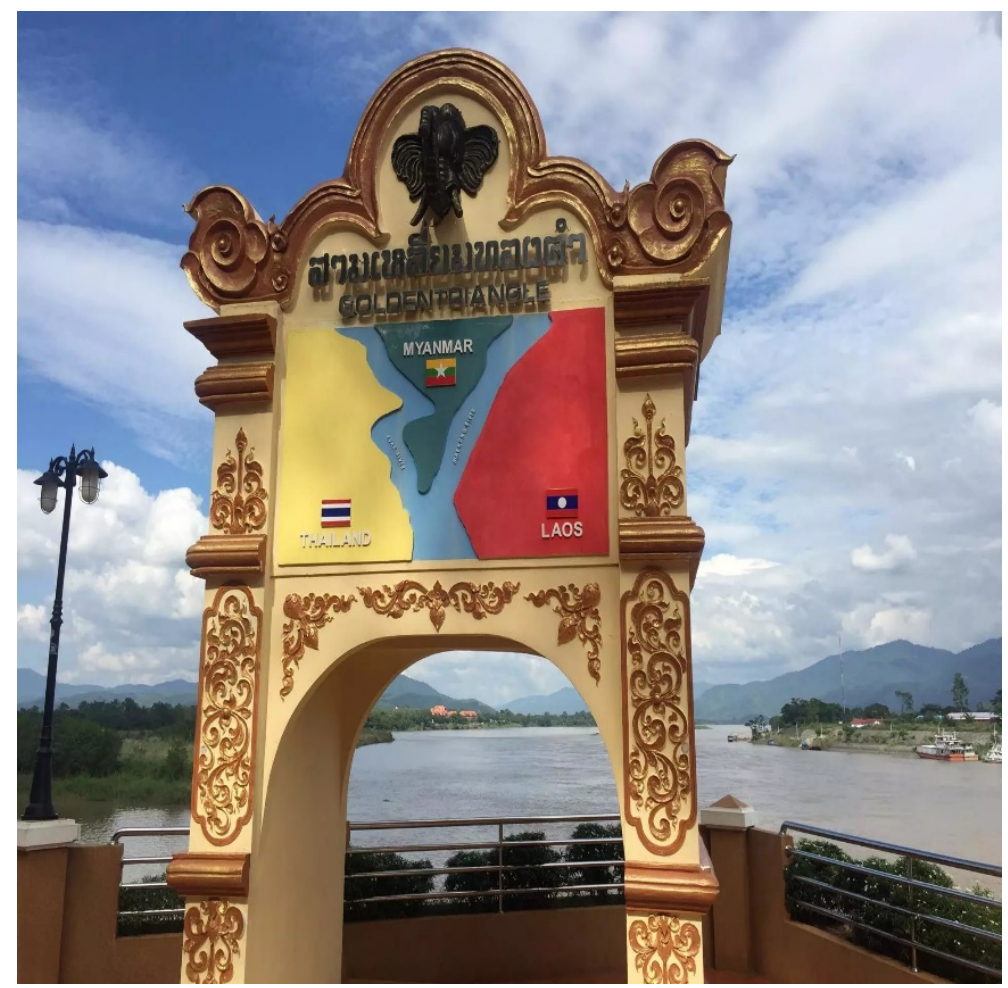

Figure 7.3 The Golden Triangle

The repercussions of drug-related crimes in Yunnan have been evident. The province has become a home to half of the registered drug addicts in China, with an apparent growth in the number of AIDS victims. The high demand for drugs has also impeded Yunnan's development in its previously advantageous fields of chemical engineering and metallurgy, 
since these industries depend on importing raw materials from neighbouring countries that are also used for drug production (Liu 2007).

In these circumstances, the central government authorized Yunnan to cooperate with neighbouring countries to investigate the drug situation across the border, to take transnational actions, to strengthen the sharing of intelligence, and to co-organize personnel training sessions with neighbouring countries (Su 2012). Yunnan first joined the regional division of labour in law enforcement: the Mekong countries were responsible for countering drug lords and multinational drug syndicates, while Yunnan mainly zeroed in on bringing ordinary traffickers to justice (Su 2015). The central government also approved Yunnan to establish overseas liaison offices in Myanmar, Laos, and Vietnam with the legal authorities of these countries. Judicial cooperation between Yunnan and neighbouring countries culminated in late 2011 after thirteen Chinese shipmen were shot to death on the Mekong River. Yunnan formed a task force (TF) with the countries involved to organize onthe-spot inspections, search victims' bodies, and escort the remaining Chinese sailors home (Su 2012). This TF was later transformed into a law enforcement agency, participated in through Yunnan's maritime policies and alongside their counterparts from these countries, launching joint patrols along the Mekong shipping lanes (Wang 2012; Parameswaran 2017).

Through a guiding document issued in April 2006, the State Council encouraged Yunnan's government and enterprises to participate more actively in developing alternatives to opium poppy cultivation in northern Myanmar and Laos. In retrospect, Yunnan has been involved in this programme since the 1990s with the backing of the National Narcotics Control Commission (NNCC). Both province-owned and private enterprises within Yunnan were led by the provincial government to cooperate with the authorities and companies in the Golden Triangle, assisting the latter in developing and implementing opium substitution policies and programmes (Fang 2010). The importance of Yunnan in the opium substitution programme has been further elevated along with the new challenges facing this programme. At the turn of the $21^{\text {st }}$ century, a new situation emerged in which it became possible to produce heroin from synthetic chemicals rather than natural ingredients. ${ }^{69}$ Given this

\footnotetext{
69 In the past, heroin manufacturers must extract morphine from opium before converting morphine to heroin. The extraction is a rather simple process, requiring merely a few chemicals and a supply of water. The production of synthetic drugs, such as Ecstasy, LSD, and methamphetamine, reduces the cost of making drugs and makes the processing more clandestine.
} 
situation, the opium substitution programme alone was no longer enough to wipe out the production and use of narcostics in the Golden Triangle. It is only through the eradication of poverty among the region that the drug-related crimes could be effectively controlled. Yunnan's involvement in China's cooperation with the Mekong countries in the area of drug control was thus given more attention by the central government, since Beijing not only counted on Yunnan assisting the Mekong farmers in replacing opium poppies with other grain and cash crops, such as sugar cane, coffee, and avocados, but also on the province boosting the development of northern Myanmar and Laos through transferring cultivation and processing technology, constructing factories, schools, and hospitals, as well as enhancing transportation infrastructure (Chen 2011; Zhou 2014).

After the central government launched the "122 Task Force" under the Ministry of Commerce (MOFCOM) to guide the opium alternative programme, Yunnan established its own task force to strengthen its cooperation with the Mekong countries in this field, primarily through conducting joint research and making medium- and long-term plans. Beijing's recognition of Yunnan's leading role in this programme also emboldened the provincial officials to fly to Beijing to ask for more funds and preferential policies from the Ministry of Finance (MOF), the MOFCOM, and the NNCC, in support of Yunnan enterprises conducting relevant business across the border (Fang 2010). The provincial government was also allowed to set up the Alternative Development Association in May 2008, in order to coordinate the cooperation between Yunnan provincial government, the involved enterprises, and the authorities of Mekong countries (ynada.org 2011). It must be added that Yunnan has claimed that, since the start of the opium substitution programme, heroin production in the Golden Triangle has been reduced by nearly 300 tons, with millions of farmers in northern Myanmar and Laos no longer subsisting on growing poppies (Liu 2007). However, the actual achievements of this programme might not be as substantial as Yunnan has proclaimed, given that many local farmers in the Mekong countries who had previously been persuaded to switch to other profitable crops have ended up returning to growing poppies (Angeles 2016). Worse, a few participating companies from Yunnan tarnished the 
province's reputation by faking their actual demand for land in order to undertake illegal crop planting ${ }^{70}$.

The recognition of Yunnan's role in international relations by the central government can also be identified in the decision of Beijing to authorize Yunnan to handle conflicts between Myanmar's military and ethnic minority armed groups. As a Han Chinese community adjacent to Yunnan's Lincang city, Kokang, in the north-west of Myanmar, is dependent on electricity from Yunnan, even sharing the same phone area code as the area north of the border (Chao 2015). It is now a self-administered region ruled by a man of Chinese descent, Pheung Kya-shin, and his Myanmar Nationalities Democratic Alliance Army (MNDAA). Conflicts between the MNDAA and Tatmadaw, the Myanmar Armed Forces (MAF), have existed for decades (Kim 2017). The reason for Beijing designating Yunnan to deal with these conflicts is that these armed groups largely originated from previous Myanmar Communist forces. Given that Myanmar had normalized its relations with China only in the 1980s, after China withdrew its support from the Burmese Communist Party (BCP), any new signs of close contacts between China and ethnic minority insurgents would provoke Naypyidaw, which already suspected that China sent ex-soldiers from the People's Liberation Army (PLA) and arms in support of these groups ${ }^{71}$.

Once fighting broke out, Yunnan provincial and local authorities soon extended humanitarian aid to Kokang refugees by housing them in tents, providing foodstuffs and running water, and contacting their relatives or friends in Yunnan. After stray bullets from the Kokang side led to the bombing of Yunnanese residents and properties, the director of the provincial FAO called on Myanmar's Consul-General in Kunming to deliver a stern warning. In recent years, the role of Yunnan as a broker in the peace-building process has been rising under Beijing's guidelines of 'persuading for peace and promoting dialogue (劝 和促谈)'. Provincial officials emphasized 'restraints' and 'no war' whenever they met the leaders of these ethnic minority armed groups. Yunnan even dispatched the director general of its Public Security Department (PSD) to escort these leaders to a meeting in Naypyidaw with Myanmar's authorities via Kunming (Sun 2012; Glauert 2018). It also held direct peace talks between the Myanmar government and the rebel Kachin Independence Organization

\footnotetext{
70 Interview with a governmental official, November 16, 2016, Yangon.

71 Interview with a governmental official, 4 November 2016.
} 
(KIO) in Ruili, while providing protection to participants from all sides, listening carefully to their demands, and mediating actively between their claims (Sun 2013).

\subsubsection{Establishing Economic Zones}

This subsection continues to highlight that the recognition of Yunnan's international actorness by the central government has also found expression in the decision by Beijing to press Yunnan to select cities and towns as spaces for regulatory experimentation, and as windows for external interactions. With the authorization of the central government, in 1984, Yunnan initially established twenty-seven border trade zones, comprised of 92,325 kilometres with a population of more than 4.6 million, releasing preferential policies to be implemented in these zones. Those policies consisted in scrapping the requirement that kept border residents from doing business beyond $20 \mathrm{~km}$ from the border, simplifying the procedures for application for border trade franchise, reducing import tax for nearly 200 types of commodities, and allowing border residents to sell or purchase as much as they can. Following the first batch of border trade zones, the central government allowed Yunnan to establish more special economic zones, to consolidate its geographic, commercial, and social connections to the Mekong subregion. One example is an urban cluster built upon the geographical and industrial strengths of the cities of Kunming, Qujing, Yuxi, and Chuxiong. This city cluster comprises 24.4 per cent of Yunnan's total area and 60 per cent of its GDP (Zhang et al 2014). Both central and provincial authorities expected to turn this urban cluster into an engine for growth in western China, a bridge linking China with the Indian and Pacific Oceans, and a strategic region of China in the face of the markets in South and Southeast Asia (Wang, Wu and Yang 2011; Su 2014). To realize this objective, Yunnan has released a planning report to elaborate the division of labour among these cities. In fact, Kunming has been asked to play a leading role in the urban cluster and to improve its core competency and service industry. Qujing has been encouraged to collaborate with neighbouring countries and construct more advanced industry and service bases. Yuxi has been advised to grasp opportunities stemming from the completion of the KunmingBangkok Highway, to host more international conventions, and to promote high-level education and R\&D. Chuxiong has been designated to provide comprehensive services for the construction of the BCIM economic corridor, and to become a hub for the production of organic agriculture goods and for modern logistics. 
Moreover, the central government approved Yunnan to establish various cross-border economic zones to develop far-flung townships, whose construction was expedited by two policy documents issued by the central government. In a landmark document on the Belt and Road Initiative, the central government advised Yunnan and other border provinces to explore new models of economic cooperation zone (NDRC, MOF and MOFCOM 2015). In January 2016, the State Council issued another document in support of the development of key border areas, calling in particular for the establishment of opening-up experimental zones, national border ports, border cities, and cross-border cooperation zones. Encouraged by these policy documents, Yunnan redoubled its cooperation with neighbouring countries on the construction of the Cross-border Economic Cooperation Zones (CEZs) and the Overseas Economic Cooperation Zones (OEZs). These, as explained below, would partly or fully traverse the territories of Yunnan's neighbouring countries.

For one thing, Yunnan has established a batch of CEZs, namely those between Hekou County and Vietnam's Lao Cai Province, between Ruili and Muse of Myanmar, and between Mohan and Boten of Laos (Guo and Luo 2012). These CEZs are ideally located. Situated in the south of Yunnan, Hekou shares a 193-kilometre border with Lao Cai. They are separated by two narrow, shallow rivers, with intensive cross-border exchanges making them tantamount to one city in two countries (Colin 2014). Ruili, the Yunnan city closest to the Indian Ocean, borders on Muse along a 288.9-kilometre boundary and serves as a Chinese starting point of the Sino-Myanmar communication optical cable, oil and gas pipelines, and the West PanAsian Railway. Mohan is situated in the southernmost point of Yunnan, bordering on Laos to the east and south, and facing Myanmar across the Irrawaddy River in the west. It is wellknown for its proximity to China's largest land port towards Laos, and for severing as a gateway for Southeast Asian countries to enter China via the Mekong River.

These CEZs have been created to be multifunctional. A business and trade zone would be built within the Hekou-Lao Cai CEZ to take care of industries from logistics and processing to finance and insurance (Guo and Luo 2012). Likewise, the Ruili-Mose CEZ would provide services in the fields of export processing and assembly, import resource processing, warehouse and logistics, and financial services (Li 2013). The Mohan-Boten CEZ was encouraged to be a centre for information and consulting, education, off-line experience stores, leisure, and ecological vacations (Luo 2012). In order to attract more foreign 
investment, Yunnan allowed these CEZs to provide their own sweeteners to compete with one another, albeit largely homogenous. The Lincang-Kokang CEZ exempted companies from taxes for the first three years and allowed them to pay half for the following four years. Other CEZs were more generous, exempting taxes for five straight years and exempting half for another five years. On top of that, all the CEZs provide concessions on the use of land for greening landscapes, ecological conservation, and reserving water, with the Lincang-Kokang CEZ going even further, offering foreign and overseas Chinese investors rent-free venues for three consecutive years ${ }^{72}$. Other preferential policies provided by these CEZs range from the employment of labourers and the support of new industries to easy access to loans.

The central government has further agreed to the proposal by Yunnan's local governments and enterprises to cooperate with neighbouring countries to establish the Overseas Economic Cooperation Zones (OEZs), fully within the territories of foreign countries. The creation of the OEZs is a new instrument used by Beijing to expand its economic influence over other developing countries. However, the Chinese government's rationale in encouraging the OEZs is strongly economic. As Deborah Bräutigam and Tang Xiaoyang (2012: 815) suggested, the OEZs had been designed for "providing a platform to accelerate China's own domestic restructuring", "increasing demand for Chinese-made machniary and equipment", and especially "reducing trade frictions by relocating Chinese production to third countries." In the case of Yunnan, the specific reasons for Yunnan's interest in OEZs are twofold. For one thing, the province expects to take advantage of preferential conditions in Myanmar and Laos. As these had been identified by the United Nations, the European Union, and more than forty countries as the least developed countries, Yunnan enterprises operating businesses in these the Mekong countries could benefit from the Generalized System of Preference. Yunnan commodities produced in Myanmar and Laos would enter foreign markets without tariff and quota restrictions. For another, Yunnan counted on these OEZs to extend the reach of its commodities and investment as far afield as the European and American markets ${ }^{73}$.

Thus far, Yunnan has been working on the construction of four OEZs. The initial project is the Tengchong-Mandalay OEZ, 58 kilometres from Mandalay and 11 kilometres from nearby

\footnotetext{
72 Interview with a government official, June 15, 2016, Kunming.

$73 \mathrm{lbid}$.
} 
Myotha. Designed to occupy an area of 45 square kilometres, this OEZ has developed into a comprehensive industrial city, incorporating traditional, high-tech, and service industries (baoshan.gov.cn 2017). The second is the Vientiane Saysettha Development Zone, cofunded by Yunnan Overseas Investment Company and the Vientiane municipal government (ivsdz.com 2017). Situated 17 square kilometres northeast from downtown Vientiane, this zone includes two bases for processing agricultural and light industrial commodities, one centre for logistics and modern business, and one high-level residential area (mofcom.gov.cn 2013). The third is the Xaythany Extraterritorial Economic Cooperation Zones in Vientiane. By investing US\$98 million, Yunnan seeks to create this zone as a spearhead of economic growth for Laos, a base for the subregion's advantageous industries, and a modern service centre facing the Southeast Asian market. The last is the Kyaukphyu Special Economic Zone. The Yunnan Construction and Investment Holding Group (YNIH) has a stake in the Kyaukphyu's project through its membership of the consortium led by the China International Trust and investment Corporation (CITIC), with a focus on the construction of a deep-sea port and industrial zones (straitstimes.com 2018). This zone has gained importance due to its strategic location. Along with the ports in Gwadar (Pakistan), Hambantota (Sri Lanka), and Chittagong (Bangladesh), Kyaukphyu is one of the ports constituting China's 'String of Pearls' strategy in the Indian Ocean (Madanayaka 2016). The Sino-Myanmar oil and gas pipelines, through which Yunnan imports gas from Myanmar's offshore gas field and oil from the Middle East, also start from Kyaukphyu (Brewster 2014).

\subsection{Conclusion}

The chapter discussed the question of how third parties reacted to the intensified external capability of Yunnan by informing the fourth dimension of actorness: presence. It argued that the international actorness of Yunnan has been acknowledged by the countries in the Mekong subregion and the Chinese central government. This can be deduced from their actions and attitudes toward Yunnan's role in cross-border cooperation. The international actorness of Yunnan has been recognized by the countries in the Mekong subregion, which can first be seen from the facts that these countries acknowledged Yunnan as an authorized signatory to external agreements, allowed Yunnan to dispatch provincial representatives to their territories, and accepted Yunnan as a member of some regional institutions. The central government in Beijing has also acknowledged Yunnan as an international relations 
actor. This can be seen from Beijing's efforts to grant seats for Yunnan representatives in national delegations on some international occasions and to delegate certain powers to Yunnan that would allow it to involve in some border-related issues and projects. 


\section{Chapter 8}

\section{Conclusion}

\subsection{Introduction}

This study has addressed the question of how Yunnan has become an international relations actor in the reform era, particularly since the early 1990s. It specifically argued that, first, the Chinese central government has granted Yunnan certain external affairs powers against the backdrop of several new domestic developments. Second, opportunities stemming from the external environment have indirectly helped in consolidating the newly-gained external affairs powers of Yunnan. Third, new external affairs powers have enabled Yunnan to leverage three broad instruments to raise the awareness of neighbouring countries concerning the importance of cooperation with Yunnan: infrastructure development, economic statecraft, and diplomatic efforts. Lastly, the enhanced external capability of Yunnan has resulted in its recognition as an international relations actor by neighbouring countries and the Chinese central government.

The objectives of this chapter are to offer a summary, based on the case study of Yunnan's cross-border cooperation, to accentuate the theoretical, methodological, and empirical implications of this thesis, and to make recommendations for further research. The structure of this chapter reflects these objectives. Section 8.2 sheds light on the main findings of the thesis and demonstrates how these have addressed the research question. The original contributions of this study are presented in Section 8.3, which also discusses policy implications. The chapter concludes with recommendations for further research in Section 8.4.

\subsection{Overview of Research Questions}

This section generalizes the findings of each chapter and discusses whether the research question proposed in the introduction chapter has been addressed. The introduction chapter suggested that for Yunnan to be regarded as an international actor, its paradiplomacy has to meet four dimensions: the province has access to external affairs 
powers; it is situated in an appropriate external environment within which its international interactions take place; it has the capability to incentivise foreign countries to work with it; and its international role is recognized by third parties. The introduction chapter further justified the selection of Yunnan for the study, and proposed the research question and hypotheses. Also discussed were the methods of collecting data to address the research question.

Chapter 2 indicated that the research question arose from a review of the various strands of the literature on the international relations of subnational governments. The chapter argued that the extant literature has provided invaluable knowledge of this phenomenon, but still requires more works in the following areas: first, the topic of paradiplomacy has received little attention, when compared with the international actions of other non-nation state players. Second, scant attention has been paid to paradiplomatic activities in nonWestern, centralized states. Third, some aspects of subnational participation in foreign affairs have not been studied comprehensively. Fourth, of the limited works on Chinese paradiplomacy, most focus on the central-provincial interactions in foreign affairs, rather than seeing provincial governments as somewhat autonomous actors in international relations. Lastly, there has been an apparent lack of work on the paradiplomacy conducted by the non-coastal Chinese provinces. To narrow these gaps, this thesis has provided an analytical framework, ahead of exploring the international actorness of Yunnan, one of the border provinces in China.

Chapter 3 examined the methodology for the study. To address the research question in an effective way, the thesis undertook a single instrumental case study, because of the constraints of time and resources. The case would be analysed by qualitative means, which was decided upon after considering that the research question could not realistically be addressed in a quantitative way. Also discussed was the selection of Yunnan as a study focus. For one thing, compared to other border Chinese provincial entities, Yunnan is widely believed to have broader, more institutionalized involvement in cross-border cooperation. This would be helpful to the generalizing efforts of this study. For another, the selection of Yunnan was determined by the fact that the author had a better understanding of Yunnan and more established contacts with its officials and scholars. 
With reference to data collection, the first method this study made use of was interviews, during which the author not only sought relevant information from interviewees, but also engaged in dialogues and encouraged interviewees to speak from their personal experiences. Content analysis was also undertaken, by reviewing policy papers, legal documents, provincial yearbooks, and newspapers. Online information provided on the webpages run by the Yunnan provincial government and its agencies were also employed. In addition, participant observation was undertaken, in order to acquire an overview of the daily work of officials and the operation of institutions involved in this study, and to apprehend what happens, by listening to what was said, and by questioning participants over a long time period.

Chapter 4 examined the first dimension of actorness - its motivation - in relation to Yunnan. The external interest of Yunnan has been produced, first of all, through a host of domestic developments. The first development is the decision of the central government to open up the border regions to the world market. The second domestic development was related to the inefficiency of the central government in managing some macroeconomic and borderrelated issues. The last domestic development, which resulted in the enlargement of the external interest of Yunnan, was the heightened competition versus Guangxi, another provincial-level jurisdiction in the southwest of China, over economic interests in the Mekong subregion.

Chapter 5 dealt with the second dimension of actorness - opportunity - and explored whether and how the development of Yunnan's external affairs powers had been related to opportunity in the external environment. This chapter specifically argued that the normalization of relationships between China and the countries in the Mekong subregion has precipitated Yunnan's engagement in cross-border cooperation. The research findings further indicated that Yunnan had benefited from the pressure exerted by the GATT/WTO onto China to close its domestic developmental gap. Lastly, this chapter revealed that intensifying competition between Beijing and extra-regional powers - the United States, India, and Japan - over the economic and diplomatic influence in the Mekong subregion has been beneficial to the expansion of Yunnan's external role, albeit in an indirect way.

The third dimension of actorness - capability - was explored in Chapter 6. The chapter argued that new external powers have enabled Yunnan to capitalize on three broad 
instruments to encourage neighbouring countries to cooperate more closely with Yunnan: infrastructure development, economic statecraft, and diplomatic efforts. On the infrastructure side, Yunnan has invested heavily to reduce obstacles to connectivity between Yunnan and various economic centres in the Mekong subregion. On the economic side, Yunnan has forged closer economic interdependence with the Mekong countries by redoubling their cooperation on border trade, investment, and manpower exchanges. On the diplomatic side, Yunnan has exploited its locational and social advantages to boost its cross-border networks.

Chapter 7 shed light on the last dimension of actorness - presence, arguing that, over the years, the international role of Yunnan has been recognized by third parties. On the one hand, the international actorness of Yunnan has been acknowledged by neighbouring countries. This external recognition can in part be seen in Mekong countries allowing Yunnan to dispatch provincial representatives to their territories. On the other hand, the Chinese central government has treated Yunnan as an international relations actor, which can be seen from its use of geographical and social closeness between Yunnan and the Mekong countries for the sake of national diplomacy.

\subsection{Main Research Contributions}

As stated, this research has empirical and theoretical relevance. The exploration of the research question has provided an opening to the understanding of the cross-border relations of Yunnan, made possible using an analytical framework that involved four dimensions of actorness. This section begins with the demonstration of the contributions of this thesis to paradiplomacy theory (Subsection 8.3.1) and methodology (Subsection 8.3.2), followed by a discussion of the policy implications that can be derived from the analysis of the subnational diplomacy conducted by Yunnan (Subsection 8.3.3).

\subsubsection{Contributions to Theory}

First, the study has identified external interactions undertaken by a subnational government, despite the fact that scholarly interest in paradiplomacy is not new. As Chapter 2 outlined, investigation into the role of subnational governments as international relations players has experienced three distinct phases. The first phase has marked the inception of paradiplomacy studies in the 1970s, when almost all influential publications were based on 
the cases of the United States and Canada. The 1980s saw scholarly attention that expanded to include cases from European countries, and efforts to theorize and conceptualize the engagement of subnational governments in the international arena. Since the early 2000s, while the scope of paradiplomacy studies has extended to non-Western and even unitary countries, the intensifying external activism of Chinese provinces has yet to receive sufficient attention. Of the limited number of works on this topic, the majority focus on affluent coastal provinces, rather than inland and border provinces. Furthermore, these works have been more concerned with central-provincial interactions on external affairs, without presenting the full picture of the international actorness - a set of fundamental characteristics for an international relations actor - of these provinces. Thus, it is possible to conclude that this thesis has contributed to the paradiplomacy literature by providing indepth insights into the international actorness of a largely unresearched border Chinese province.

This study has contributed to the extant paradiplomacy literature by presenting a new analytical framework. As the main objective of this thesis has been to formulate a systematic knowledge of the paradiplomacy of Yunnan, it has opted to investigate the full spectrum of the province's international actorness. Among the previous works, few analytical frameworks were able to account fully for the international actorness of subnational governments, no matter whether these were within federal or unitary states. Some of the weaknesses of these frameworks are that they pay excessive attention to one or two elements of paradiplomacy, rather than presenting a whole picture; that they have some overlapping elements within the framework; and that they are not very applicable to border external exchanges. Taking into account these limitations, this thesis has devised an analytical framework that combines the concept of paradiplomacy with the theory of actorness. The specific dimensions of international actorness in this thesis have been adapted from earlier theoretical works. These dimensions range from motivation and opportunity to capability and presence.

The thesis has further found that the engagement of Chinese provinces in external interactions can largely fit into the broader context of paradiplomacy scholarship that was based on Western cases. For many paradiplomacy scholars, external roles were seldom assumed by subnational governments in centralized countries, in that these countries were 
lacking in the democratic sharing of international relations prerogatives (Kuznetsov 2014). Although Chinese provinces have become increasingly proactive in the international arena since the reform era, the stereotype remained that the provincial governments of China could not be genuine international actors (Chen, Jian and Chen 2010). This is because China is highly centralized, Beijing monopolises the formulation and execution of foreign policies, and the provincial authorities have neither incentives nor authority to undertake foreign relations (Goldstein 2003; Hameiri and Jones 2016). Even in the limited number of scholarly works on the external interactions of Chinese provincial governments, few have answered the question of whether paradiplomacy theories that have been formulated based on Western cases could be applied to Chinese cases, or whether the Chinese provinces, at least Yunnan, is comparable to other western paradiplomatic players.

This thesis has argued that, although senior provincial leaders in China are chosen by Beijing and do not dare to go too far in their pursuit of local external interests, research findings show that Yunnan is on a par with subnational entities within federal countries in terms of satisfying the criteria of international actorness. In other words, it can be regarded as an international relations player. Furthermore, it is argued that the cultivation of external interests within Yunnan was caused by a combination of external and internal factors. This has found expression in the mainstream paradiplomacy literature. For instance, Panayotis Soldatos (1990) considered the motivations of paradiplomacy as subnational, domestic, and external. Daniel Latouche (1988: 34) was explicit that "we are operating at the margin of both the domestic and international spheres, a location where what is 'inside' and what is 'outside' becomes difficult to assess." At the turn of the new millennium, André Lecours (2002) suggested analysing structural changes at domestic, regional, and international levels.

When it comes to the specific driving forces of the paradiplomacy of Yunnan, this thesis identified that one of the factors relates to the development of the globalized economy. This was in tune with many paradiplomacy works that have considered globalization as an enabling factor for the enhanced role of subnational governments in the international arena (Requejo 2010). Besides, the thesis has demonstrated that the limitations of the central government in managing macroeconomic and border-related issues has partly motivated Yunnan to be an international relations actor.This phenomenon was not uncommon in the Western cases. Just as paradiplomacy scholars have previously argued, subnational 
governments have to "direct more resources to preferred foreign goals" (Cohn and Smith 1996: 31) and be "more functionally specific and targeted" (Keating 1999: 11). More pointedly, Ivo Duchacek (1984: 16) asserted that "subnational leaders and their publics often oppose the center on the ground that it is unwieldy, big, over-bureaucratized, dehumanized, and above all, distant and unfamiliar with where the local and regional shoe pinches".

This thesis continued to identify that Yunnan has used infrastructure development, economic statecraft, and diplomatic efforts, to incentive neighbouring countries to work more closely with it. All these instruments were mentioned in the previous paradiplomacy literature. In relation to diplomatic efforts in particular, Noé Cornago (2000) argued that they could be established by periodical meetings and other types of informal interactions that would produce clientelism between government officials on both sides of the border. As many paradiplomacy scholars have shown, most American states have fostered sisterstate relationships with their counterparts across Europe, Asia, South America, and the Caribbean in the fields of economy, culture, and tourism (Fry 1990). Many progressive subnational entities in Japan have also chosen to build sister-state relationships with Chinese provinces in order to redirect Japan's focus from Washington and the West (Jain 2006). In the case of Yunnan, this study has shown that provincial officials have concluded agreements on the establishment of sister-province relations with their foreign counterparts in various countries.

As for the dimension of presence, the international role of Yunnan has been acknowledged by neighbouring countries. One of the key ways to do this is for these countries to allow Yunnan to be an authorized signatory of non-treaty agreements. Concerning discussions of the power of making external agreements in the literature, oft-cited instances involved the constitutionally-confirmed treaty-making powers associated with the regions and communities of Belgium (Paquin 2010), agreements concluded between the contiguous regions of Austria and Italy to lower trade barriers (Pelinka 1990), and the agreementmaking powers of Swiss cantons (Wildhaber 1990). Yunnan's international actorness has also been recognized by the Chinese central government. This can be seen from various approaches, with the most apparent one being allowing Yunnan's representatives to participate in national delegations. The precedents for the involvement of provincial 
representatives in national delegations cited within the paradiplomacy literature are Canadian provinces' joining the GATT and the Canadian-U.S. free trade negotiations within Ottawa's delegation (Feldman and Feldman 1990), the attendance of Tyrol's representatives at the UN conference concerning the question of South Tyrol, along with Vienna's officials (Duchacek 1990), and the presence of state government officials within Australian delegations to the UN conference on the Law of the Sea and the International Sugar Conference (Ravenhill 1999).

However, two caveats need to be made in reference to the paradiplomacy literature as it relates to Yunnan. First, earlier paradiplomacy researchers have usually identified the seeking of political independence as a political motivation for subnational governments to foster external linkages (Soldatos 1990; Balthazar 1999). Yet, as an earlier chapter has revealed, it has not been the case in China. The second caveat is that paradiplomacy researchers have yet to theorize the phenomenon where subnational governments redouble their external interactions as a result of intensifying domestic competition. One such theoretical attempt was made by those who proposed 'me-tooism', which indicates that "some states and local governments have established foreign contacts simply to emulate other subnational successes in attracting foreign investment or manufacturing plants to their territory" (Duchacek 1984: 18). However, this theory cannot fully account for the influence of domestic competition on the generation of paradiplomacy. This thesis has demonstrated how, beginning in the early 2000s, Yunnan increased its paradiplomatic efforts to vie for greater external opportunities when it found itself being challenged by the similar efforts of Guangxi to expand its influence in the Mekong subregion.

\subsubsection{Contributions to Methodology}

This subsection reveals three findings about methodology in this research. These findings are related to the analysis in Chapter 3. First, the study found that the selection of the case study was appropriate for understanding the whole picture of paradiplomacy in a particular subnational entity. For the most research questions in the form of 'how', the use of histories, experiments, and case studies are all feasible. The case study approach was eventually chosen because this research focuses chiefly on a contemporary set of events, and exerts little control over interviewees and environment. Besides, the research suggested that the choice between doing a single case study or a multiple one depends on the purpose of the 
case study research. Admittedly, although a comparative analysis between two or more border provinces might produce broader results, it would not have been suitable for the purpose of this study, which is to comprehensively analyse autonomy, opportunity, capability, and presence in relation to Yunnan's paradiplomacy. At the same time, the problem of the single case study with generalization can partly be overcome by selecting a typical case and delving into that as deeply as possible.

The research, therefore, entails adding new thoughts on sampling to the existing paradiplomacy literature. Although random sampling reduces bias and subjectivism, purposive sampling facilitates the inferential process by enabling researchers to choose the most typical case and to derive more generalized knowledge. Furthermore, many pragmatic or logistical elements, such as location, time, and the availability of data, might shape the decisions of researchers. For this research, for instance, its selection of case was guided by the principle of 'opportunity to learn'. Worth noting is that, despite the viability of purposive sampling, more attention should be devoted to the issue of generalizability. This research found purposive sampling both generalizable and comparable. For instance, some findings are thought to challenge the established proposition within the paradiplomacy literature, while some offer new knowledge that has been barely mentioned before.

Third, when compared to the existing literature on Chinese paradiplomacy, this research has the advantage of direct access to the practitioners of Yunnan's external interactions and the local experts who have the ears of the provincial policymakers. Many critical views and original materials have been derived from these key actors, which cannot be not found through open publications. Their value is more evident, given that access to official information in China is not always reliable. In addition, few studies with regard to China's cross-border paradiplomacy have collected data from interviews with diplomats and experts in neighbouring countries and some leading regional institutions. Reaching these foreign stakeholders has helped the findings of this thesis to become more balanced and unbiased.

\subsubsection{Policy Implications}

As previously indicated, the external involvement of Yunnan assumed great importance when the central government decided to open the border to the world, which created institutional space for Yunnan to formulate foreign agendas. The central government 
encountered difficulty in balancing regional development and managing border-related issues, while having to rely on Yunnan in competing with the extra-regional powers in the Mekong subregion. As a result, external affairs power could no longer be exclusive to the central authorities and the coastal provinces. Based on this finding, the following three policy recommendations can be made, respectively, for China's border provinces, the central government, and neighbouring countries.

First, for the border provincial governments, success in their pursuit of external interests depends on cooperation with the central government. There might have been no prospects for the provinces to establish close foreign linkages had the central government been reluctant to devolve autonomy. However, this does not mean that the border provinces are only passive recipients; in fact, they can take the initiative in pushing the central authorities to grant them greater policy space. The border provinces can also use the incapacity or inability of the central government in certain aspects to exploit their own diplomatic value in dealing with cross-border issues. This not only increases the attractiveness of these provinces in external relations, but also makes the central authorities further aware of their importance in China's peripheral diplomacy.

Second, for the central government, given that it appears unlikely for the border provinces to use their external linkages to seek secession from China, the devolvement of more foreign affairs powers to these provinces is expected. The central government has to acknowledge that the border provinces might perform better in certain fields, such as boosting border trade and managing cross-border incidents, when it has limited economic resources and border-related experience. The central government should make the most of the border provinces in its quest for external interests, since the local communities of neighbouring countries have become increasingly discontent with their governments directly interacting with Beijing. It would also be in the interests of the central government to allow a degree of competition between the provinces, as long as it can maintain its status as a credible arbitrator. Such competition is likely to propel the provinces to chase after more external opportunities and to fine-tune their external interests in line with national interests in order to gain more support from the central authorities.

Lastly, China's neighbouring countries have to understand that there is growing interest from the border Chinese provinces in seeking more comprehensive cooperation with foreign 
countries. Furthermore, given that China has been determined to boost the development of the far-flung, disadvantaged provinces, through such initiatives as the Western Development programme and the Belt and Road initiative, neighbouring countries are expected to take the opportunity to improve their connectivity with their Chinese neighbours and to improve economic complementarity with them. They could also seek to strengthen their cooperation with these Chinese provinces on non-traditional security issues, since border stability is also key to the implementation of various Chinese developmental initiatives. These countries might consider working with the Chinese border provinces to conduct joint projects, thereby avoiding more controversy aroused at home from dealing directly with Beijing. At the same time, these countries could take advantage of domestic competition within China, to maximize their interests, since it has been shown that individual provinces have tended to offer better conditions for foreign investors in order to outcompete their domestic counterparts. Similarly, they will further benefit from the strategic rivalry between China and other major countries over regional influence.

\subsection{Recommendations for Further Research}

Based on the research carried out, three issues are worthy of further research. First, the analytical framework suggested in this thesis could be applied to the further study of border paradiplomacy in China and beyond. One of the potential topics where this analytical framework could be used is the comparison of the external interactions between Yunnan and Guangxi. As the two Chinese provincial jurisdictions have grabbed with one another for economic and diplomatic leverage in the Mekong subregion, it would be very interesting to explore and contrast their respective motivations, resources, and strategies in their pursuit of external interests. This would further supplement the findings of this thesis. Another interesting topic might be the paradiplomacy of Xinjiang or Tibet, two restive border entities. Their interactions with Central Asia and India are worth exploration.

Second, constrained by time and resources, this thesis sheds light only on the engagement of Yunnan with five countries proximate to the Mekong River. In reality, the scope of the external cooperation of Yunnan is by no means limited to this subregion. For instance, Yunnan has initiated and participated in the Bangladesh-China-India-Myanmar Forum for Regional Cooperation (BCIM), designed to boost the integration of trade and investment among the four countries. It has also promoted the Kunming-Kolkata cooperative forum 
(K2K), to underpin regional economic integration and cultural exchanges. Therefore, further research could explore how Yunnan has been involved in cooperation with South Asian countries, and how different Yunnan's cooperation with these countries might be, compared with the Mekong countries. Further topics might also be how Yunnan has played a role in China's relations with South Asian countries, especially India, and how Yunnan's activism in this region is linked to its Mekong agenda.

Third, as this research has suggested, the paradiplomacy of Yunnan has been premised on the authorization of the central government; to be specific, although the latter chose to decentralize certain foreign affairs powers, it does mean that its authority over domestic and foreign issues was shrinking. Given that background, further research could discuss how provinces try to affect the making of Chinese foreign policies, with the aim of advancing their own provincial interests. The existing studies revealed only the conventional channels for provincial leaders to have the ears of state leaders; these channels involve proposing motions at the annual congress session, coming up with suggestions during inspection by the state leaders, and taking advantage of their private connections with state leaders. However, in practice, the provincial inputs on foreign policymaking take more variegated forms. Thus, in-depth empirical, theoretical works on this topic could yield interesting results. At the same time, when China's international relations are no longer monopolized by the central authorities, formulating a better understanding of provincial influences is indispensable to the foreign diplomats and observers who may be vulnerable to mistaking the external initiatives of China's provinces for the country's macro foreign policies. 


\section{References}

Acharya, Amitav. 1994. An Arms Race in Post-Cold War Southeast Asia: Prospects for Control. Singapore: Institute of Southeast Asian Studies.

ADB. 2014. "Promoting Information and Commutation Technology in ADB Operation." Adb.org. Retrieved March 27, 2019 (https://www.adb.org/sites/default/files/publication/42673/promoting-ict-adboperations.pdf).

Adhikari, Ramesh and Yang Yongzheng. 2002. "What Will WTO Membership Mean for China and Its Trading Partners?" Finance and Development 39 (3): 22-25.

Aguirre, Iñaki. 1999. "Making Sense of Paradiplomacy? An Intertextual Enquiry about a Concept in Search of a Definition." Regional \& Federal Studies 9 (1): 185-209.

Akreyi, Akram. 2017. "The Iraqi Kurdistan in the Post-Saddam Era: Security, Natural Resources and Foreign Policy Activism." Iran and the Caucasus 21 (1): 92-100.

Albina, Elena. 2010. "The External Relations of Tatarstan: In Pursuit of Sovereignty, or Playing the Sub-Nationalist Card", Pp.99-124 in Regional Sub-State Diplomacy Today, edited by David Criekemans. USA: Martinus Nijhoff Publishers.

Aldecoa, Francisco and Michael Keating. 1999. "Introduction" in Paradiplomacy in Action: The Foreign Relations of Subnational Governments, edited by Francisco Aldecoa and Michael Keating.

Aldecoa, Francisco. 1999. "Toward Plurinational Diplomacy in the Deeper and Wider European Union (1985-2005)", Pp.82-94 in Paradiplomacy in Action: The Foreign Relations of Subnational Governments, edited by Francisco Aldecoa and Michael. UK: Frank Cass.

Allen, David and Michael Smith. 1990. "Western Europe's Presence in the Contemporary International Arena." Review of International Studies 16 (1): 19-37.

Amin, Samir. 2004. "US Imperialism, Europe, and the Middle East." Monthly Review 56 (6): 13-34.

Angeles, Mark. 2016. "Will Myanmar's Economy Ever Kick Its Opium Habit?" Scmp.com. Retrieved December 17, 2018 (https://www.scmp.com/weekasia/politics/article/2009572/will-myanmars-economy-ever-kick-its-opium-habit).

Aquilino, William. 1991. "Telephone versus Face-to-Face Interviewing for Household Drug Use Surveys." International Journal of the Addictions 27 (1): 71-91.

Asia.nikkei.com. 2017. "Vietnam Can Leverage the ADB and AllB to Its Advantage." Asia.nikkei.com. Retrieved August 24, 2018 (https://asia.nikkei.com/Economy/Vietnam-can-leverage-the-ADB-and-AllB-to-itsadvantage2).

Atkey, Ronald. 1970. "The Role of the Provinces in International Affairs." International 
Journal 26 (1): 249-273.

Babbie, Earl. 2013. The Practice of Social Research. UK: Cengage Learning.

Baldwin, David. 1985. Economic Statecraft. USA: Princeton University Press.

Balthazar, Louis. 1999. "The Quebec Experience: Success or Failure?”, Pp.153-169 in Paradiplomacy in Action: The Foreign Relations of Subnational Governments, edited by Francisco Aldecoa and Michael Keating. UK: Frank Cass.

Banlaoi, Rommel. 2003. "Southeast Asian Perspectives on the Rise of China: Regional Security after 9/11." Parameters: 98-107.

Baoshan.gov.cn (保山市人民政府). 2017. “The Introduction of the Tengchong-Mandalay OECZ (保山市腾冲 - 曼德勒缪达经济贸易合作区简介)." Baoshan.gov.cn (保山市 人民政府). Retrieved July 12, 2018 (http://www.tcbhq.baoshan.gov.cn/info/1159/1654.htm).

Barnett, Doak. 1967. China after Mao: With Selected Documents. USA: Princeton University Press.

Barnett, Doak. 1985. The Making of Foreign Policy in China: Structure and Process. UK: Westview Press.

Batabyal, Anindya. 2006. "Balancing China in Asia: A Realist Assessment of India's Look East Strategy." China Report 42 (2): 179-197.

Baxter, Pamela and Susan Jack. 2008. "Qualitative Case Study Methodology: Study Design and Implementation for Novice Researchers." The Qualitative Report 13 (4): 544-559.

Baylis, John, Steve Smith and Patricia Owens. 2008. The Globalization of World Politics. UK: Oxford University Press.

Becker, Howard and Blanche Geer. 1957. "Participant Observation and Interviewing: A Comparison. Human Organization 16 (3): 28-32.

Becker, Howard. 1958. "Problems of Inference and Proof in Participant Observation." American Sociological Review 23 (6): 652-660.

Becker, Howard. 1998. Tricks of the Trade: How to Think about Your Research While Doing It. USA: University of Chicago Press.

Bélanger, Claude. 2000. "The Quite Revolution." Marianopolis.edu. Retrieved May 16, 2018

(http://faculty.marianopolis.edu/c.belanger/quebechistory/events/quiet.htm).

Berelson, Bernard. 1952. Content Analysis in Communication Research. USA: Free Press.

Beveridge, William. 1951. The Art of Scientific Investigation. UK: William Heinemann.

Bi, Shihong (毕世鸿). 2016. The Relationship between Japan and the Mekong Countries in the Post-Cold War Era (冷战后日本与湄公河国家关系). China: Social Sciences Academic Pressure (社会科学文献出版社).

$\mathrm{Bi}$, Shihong. 2017. "China and Japan, in the Mekong Region: Competition and Cooperation," Pp.185-202 in China-Japan Relations in the $21^{\text {st }}$ Century: Antagonism 
despite Interdependency, edited by Lam Peng. UK: Palgrave Macmillan.

Biba, Sebastian. 2018. "China's 'Old' and 'New' Mekong River Politics: The LancangMekong Cooperation from a Comparative Benefit-Sharing Perspective." Water International: 1-20.

Bisley, Nick. 2007. Rethinking Globalization. UK: Palgrave Macmillan.

Blatter, Joachim et al. 2008. The Foreign Relations of European Regions: Competences and Strategies. West European Politics 31 (3): 464-490.

Blomfield, Alex. 2015. "The Asian Infrastructure Investment Bank-Shaping Development." Globalbankingandfinance.com. Retrieved August 22, 2018 (https://www.globalbankingandfinance.com/the-asian-infrastructure-investmentbank-shaping-development/).

Blumenthal, Dan and Joseph Lin. 2006. "Oil Obsession: Energy Appetite Fuels Beijing's Plans to Protect Vital Sea Lines." Armed Forces Journal 1: 48.

Bockman, Harald. 1998. "China Deconstructs? The Future of the Chinese Empire-State in A Historical Perspective," Pp.310-346 in Reconstructing Twentieth-Century China: State Control, Civil Society, and National Identity, edited by Kjeld Brødsgaard and David Strand. UK: Clarendon Press.

Bowles, Paul. 1997. "ASEAN, AFTA and the 'New Regionalism'." Pacific Affairs: 219-233.

Bräutigam, Deborah and Tang Xiaoyang. 2012. "Economic Statecraft in China's New Overseas Special Economic Zones: Soft power, Business or Resource Security?" International Affairs 88 (4): 799-816.

Breslin, Shaun. 2013. "China and the South: Objectives, Actors and Interactions." Development \& Change 44: 1273-94.

Breslin, Shaun and Richard Higgott. 2000. "Studying Regions: learning from the Old, Constructing the New." New Political Economy 5 (3): 333-352.

Brewster, David. 2014. "Beyond the 'String of Pearls': Is There Really a Sino-Indian Security Dilemma in the Indian Ocean?" Journal of the Indian Ocean Region 10 (2): 133-149.

Bretherton, Charlotte and John Vogler. 2006. The European Union as a Global Actor. UK: Routledge.

Brown, Seyom. 1974. New Forces in World Politics. USA: Brookings Institution Press.

Bunyavejchewin, Poowin. 2016. "The Lancang-Mekong Cooperation (LMC) Viewed in Light of the Potential Regional Leader Theory." Journal of Mekong Societies 12 (3): 49-64.

Burgess, Michael. 2006. Comparative Federalism: Theory and Practice. UK: Routledge.

Bursens, Peter and Jana Deforche. 2010. “Going Beyond Paradiplomacy? Adding Historical Institutionalism to Account for Regional Foreign Policy Competences", Pp.151-171 in Regional Sub-State Diplomacy Today, edited by David Criekemans. The United States: Martinus Nijhoff Publishers.

Cai, Wenguo. 1996. "China's Membership in the WTO: Historical and Legal Issues." 
Pp.10-32 in China and the World Trade Organization: Requirements, Realities, and Resolution, edited by Cai Wenguo, Marruay Smith and Xu Xianquan. Canada: Centre for Trade Policy and Law.

Casey, Dympna and Catherine Houghton. 2010. "Clarifying Case Study Research: Examples from Practice." Nurse Researcher 17 (3): 41-51.

Cassell, Catherine and Gillian Symon. 1994. "Qualitative Research in Work Contexts," Pp.1-13 in Qualitative Methods in Organizational Research: A Practical Guide, edited by Catherine Cassell and Gillian Symon. USA: SAGE.

Ceh.com.cn. 2017. “Yunnan's OROs to Expand External Connection (云南: 设立驻外商务 代表处扩大对外联系的点和面).” Ceh.com.cn (中国经济导报网). Retrieved September 17, 2017 (http://ceh.com.cn/epaper/uniflows/html/2017/11/03/A02A03/A02A03 73.htm)

Chan, Gerald. 2018. Understanding China's New Diplomacy: Silk Roads and Bullet Trains. UK: Edward Elgar Publishing.

Chan, Steve and Cooper Drury. 2000. "Sanctions as Economic Statecraft: An Overview," Pp.1-16 in Sanctions as Economic Statecraft: Theory and Practice, edited by Copper Drury and Steve Chan. UK: Palgrave Macmillan.

Chandran, Nyshka. 2018. "The Japan-China Rivalry is Playing out in Cambodia's Election." Cnbc.com. Retrieved August 24, 2018 (https://www.cnbc.com/2018/07/18/japanand-china-compete-for-influence-incambodia.html).

Chang, Wen-Chin. 2014. Beyond Borders: Stories of Yunnanese Chinese Migrants of Burma. USA: Cornell University Press.

Chao, Chung-chi. 2015. "The Kokang Incident and the Contradictory Relations between China and Burma." Asian Ethnicity 16 (4): 589-592.

Che, Zhimin (车志敏). 1992. Yunnan's External Passages and Port (云南对外通道及口 岸). China: Yunnan People's Publishing House (云南人民出版社).

Che, Zhimin (车志敏) and Luo Lin (罗林). 2004. China's Great International Passages Construction Connecting to the South and Southeast Asia and Financing Plan (中国 连接东南亚南亚国际大通道建设及融资方案). China: Yunnan People's Publishing House (云南人民出版社).

Che, Zhimin (车志敏). 2000. “To Speed up Yunnan's Opening up in Develop West (在西 部大开发中加快云南对外开放).” Creation (创造) 6: 7-8.

Chen, Songtai (陈松涛). 2018. “The Economic and Social Development in Yunnan and Its Engagement in the Lancang-Mekong Cooperation (2017 年云南经济社会发展及其 澜沧江-沑公河合作的参与)," Pp.125-142 in Report on the Development of the Lancang-Mekong Cooperation (澜沧江-湄公河合作发展报告), edited by Liu Zhi (刘稚). China: Social Sciences Academic Press (社会科学文献出版社).

Chen, Tiejun (陈铁军). 2011. “Catching up New Opportunity, Making New Breakthroug: The New Development in the Yunnan-ASEAN Cooperation in 2010 (抓住新机遇, 实现新跨越：2010 年云南省与东盟合作的新发展)", Pp.227-238 in Southeast Asian Report: 2010-2011 (东南亚报告：2010-2011), edited by Wang Shilu (王士 
录). China: Yunnan University Press (云南大学出版社).

Chen, Tiejun (陈铁军). 2013. “Yunnan Endeavoring to Build Border Economic Cooperation Zone (云南着力打造边境经济合作区)”, Pp.252-262 in Southeast Asian Report: 2012-2013 (东南亚报告：2012-2013), edited by Sun Jianxun (孙建 勋). China: Yunnan University Press (云南大学出版社).

Chen, Xin (陈昕). 2014. “The Past and Future of Yunnan's Participation in the GMS Tourism Cooperataion (云南省参与 GMS 旅游合作回顾与展望).” Journal of Yunnan Nationalities University (Social Sciences) (云南民族大学学报 <哲学社会科 学版>) 31 (1): 116-121.

Chen, Zhimin. 2005. "Coastal Provinces and China's Foreign Policy Making," Pp.187-207 in China's Foreign Policy Making: Societal Force and Chinese American Policy, edited by Yufan Hao and Lin Su. USA: Ashgate.

Chen, Zhimin, Jian Junbo, and Chen Diyu. 2010. "The Provinces and China's Multi-layered Diplomacy: The Cases of GMS and Africa." The Hague Journal of Diplomacy 5 (4): 331-356.

Cheung, Peter. 2012. "The Politics of Regional Cooperation in the Greater Pearl River Delta." Asia Pacific Viewpoint 53 (1): 21-37.

Cheung, Peter and James Tang. 2001. "The External Relations of China's Province," Pp.91-120 in The Making of Chinese Foreign and Security Policy in the Era of Reform, edited by David Lampton. USA: Stanford University Press.

Chin, Ko Lin. 2009. The Golden Triangle: Inside Southeast Asia's Drug Trade. USA: Cornell University Press.

Chinanew.com (中国新闻网). 2011. “Yunnan and Banteay Meanchey to Build Friendship Provinces (云南省与柬埔寨班迭棉吉省结为友好省份).” Chinanew.com (中国新 闻网). Retrieved March 16, 2018 (http://www.chinanews.com/qxcz/2011/1207/3515704.shtml).

Ching, Cheong and Hung Yee Ching. 2003. Handbook on China's WTO Accession and Its Impacts. Singapore: World Scientific.

Chng.com.cn. 2010. "Yunnan United Power Development Co., Ltd." Chng.com.cn. Retrieved March 19, 2019 (http://www.chng.com.cn/eng/n75871/n75965/n1112742/index.html).

Cho, II Hyun and Seo-Hyun Park. 2013. "The Rise of China and Varying Sentiments in Southeast Asia toward Great Powers." Strategic Studies Quarterly 7 (2): 69-92.

Chu, Yanli. 2008. Foreign-Related Activities of the Chinese Local Governments and Agents of Globalization: A Case Study of 31 Provinces in Mainland China. USA: University of Southern California.

Cifca.org.cn. (中国国际友好城市联合会).2014. “China International Friendship Cities Association." Cifca.org.cn. Retrieved February 6 (http://english.cifca.org.cn/Showarticle.aspx?id=1\&astyle=6.)

Cifca.org.cn (中国国际友好城市联合会). 2018. “Yunnan (云南).” Cifca.org.cn (中国国际 友好城市联合会). Retrieved February 6 
(http://www.cifca.org.cn/Web/SearchByPro.aspx?prolD=88\&proName=\%D4\%C6\% C4\%CF).

Clarke, Michael. 2003. “Xinjiang and China's Relations with Central Asia, 1991-2001: Across the 'Domestic-Foreign Frontier'?" Asian Ethnicity 4 (2): 207-224.

Cohn, Theodore and Patrick Smith. 1996. "Subnational Governments as International Actors: Constituent Diplomacy in British Columbia and the Pacific Northwest." BC Studies: The British Columbian Quarterly 110: 25-59.

Colin, Sébastien. 2014. "The Participation of Yunnan Province in the GMS: Chinese Strategies and Impacts on Border Cities", Pp.107-142 in Transnational Dynamics in Southeast Asia: The Greater Mekong Subregion and Malacca Straits Economic Corridors, edited by Nathalie Fau, Sirivanh Khonthapane and Christian Taillard. Singapore: Institute of Southeast Asian Studies.

Conlan, Timothy. 1988. New Federalism: Intergovernmental Reform from Nixon to Reagan. USA: Brookings Institution Press.

Cook, Erin. 2018. "Why Japan Is Wrong on Rights in Cambodia." Thediplomat.com. Retrieved August 22, 2018 (https://thediplomat.com/2018/04/why-japan-is-wrongon-rights-in-cambodia/).

Cornago, Noé. 1999. "Diplomacy and Paradiplomacy in the Redefinition of International Security: Dimensions of Conflict and Co-operation," Pp.40-57 in Paradiplomacy in Action: The Foreign Relations of Subnational Governments, edited by Francisco Aldecoa and Michael Keating.

Cornago, Noé. 2000. "Exploring the Global Dimensions of Paradiplomacy: Functional and Normative Dynamics in the Global Spreading of Subnational Involvement in International Affairs." Amazonaws.com. Retrieved January 7, 2016 (https://s3.amazonaws.com/academia.edu.documents/31982820/924-FRCU0105intcornago.pdf?AWSAccessKeyId=AKIAIWOWYYGZ2Y53UL3A\&Expires $=1540447967 \&$ S ignature $=$ GQpwmZnpZLCaoJWImxSSOYaEno8\%3D\&response-contentdisposition=inline\%3B\%20filename\%3D924 FRCU0105 int cornago.pdf).

Cornago, Noé. 2012. "Breviario del postestructuralismo para internacionalistas." Amazonaws.com. Retrieved August 15, 2015 (https://s3.amazonaws.com/academia.edu.documents/30334965/Cornago Breviar io de Postestructuralismo.pdf?AWSAccessKeyld=AKIAIWOWYYGZ2Y53UL3A\&Expir es=1540451776\&Signature=TeHWsyisqSRf72RP3OnazvEwwpM\%3D\&responsecontentdisposition=inline\%3B\%20filename\%3DBreviario de postestructuralismo para in. pdf).

Creswell, John. 1998. Research Design: Qualitative, Quantitative, and Mixed Methods Approaches. USA: SAGE.

Criekemans, David. 2010. "The Foreign Policy and Diplomatic Representation of the Belgian Regions: Flanders and Wallonia Cpmpared," Pp.43-101 in Foreign Policy of Constituents Units at the Beginning of 21st Century, edited by Ferran Requejo. Spain: Institut d'Estudis Autonòmics. 
Cui, Shengmin. 2018. China's Role and Interests in the Greater Mekong Subregion. Germany: Logos Verlag Berlin GmbH.

d'Hooghe, Ingrid. 1994. "Regional Economic Integration in Yunnan," Pp.286-321 in China Deconstructs: Politics, Trade and Regionalism, edited by David Goodman and Gerald Segal. UK: Routledge.

Dalpino, Catharin. 2017. "The Mainland Minus One: Power Dynamics in Thailand, Laos, Cambodia, and Myanmar." Pp.215-238 in China, the United States, and the Future of Southeast Asia, edited by David Denoon. USA: New York University Press.

Doidge, Mathew. 2008. "Regional Organizations as Actors in International Relations: Interregionalism and Asymmetric Dialogues," Pp. 48-70 in Asian-European Relations, edited by Jurgen Ruland et al. UK: Routledge.

Doyle, Michael. 1983. "Kant, Liberal Legacy, and Foreign Affaris." Philosophy and Public Affairs 12: 205-235 (part 1), 323-353 (part 2).

Tan, Danielle. 2014. "The Greater Mekong Subregion Programme: Reflections for a Renewed Paradigm of Regionalism." Asia Europe Journal 12 (4): 383-399.

Deng, Lan (邓蓝). 2010. “The Ten-Year Plan for the Mekong-Ganga Cooperation: The Preview of the Development and Prospect in Ten Years (湄公河-恒河十年合作倡 议: 十年发展与前景展望). Southeast Asian and South Asian Studies (东南亚南亚 研究) 4: 67-70.

de Vaus. 1991. Surveys in Social Research. UK: University College London Press.

Dexter, Anthony. 2006. Elite and Specialized Interviewing. UK: Ecpr Press.

Dillman, Don. 1978. Mail and Telephone Surveys: The Total Design Method. USA: J. Wiley and Sons.

Donaldson, John. 2009. "Why Do Similar Areas Adopt Different Developmental Strategies? A Study of Two Puzzling Chinese Provinces." Journal of Contemporary China 18 (60): 421-444.

Dong, Mengxiong (董孟雄) and Chen Qingde (陈庆德). 1984. “The Formation and Structure of the Cotemporary Overseas Chinese in Yunnan and the Function of the Capital of Overseas Chinese (云南近代华侨的形成、结构和华侨资本的作用)." The Ideological Front (思想战线) 5: 46-54.

Drezner, Daniel. 1999. The Sanctions Paradox: Economic Statecraft and International Relation. UK: Cambridge University Press.

Duchacek, Ivo. 1984. "The International Dimension of Subnational SelfGovernment." Publius: The Journal of Federalism 14 (4): 5-31.

Duchacek, Ivo. 1990. "Perforated Sovereignties: Toward a Typology of New Actors in International Relations", Pp.1-33 in Federalism and International Relations: The Role of Subnational Units, edited by Hans Michelmann and Panayotis Soldatos. UK: Oxford.

Duran, Manuel. 2011. "French Regions as Diplomatic Actors: The Case of ProvenceAlpes-Côte d'Azur." French Politics 9 (4): 339-363. 
Economy, Elizabeth. 2005. "China's Rise in Southeast Asia: Implications for the United States." Journal of Contemporary China 14 (44): 409-425.

Elazar, Daniel. 1997. "Contrasting Unitary and Federal Systems," Pp.237-251 in International Political Science Review 18 (3): 237-251.

el-Dessouki, Ayman. 2012. "Structural Contexts and Paradiplomacy of Iraqi Kurdistan." Elnahda 13 (2): 1-36.

Elliott, Robert, Constance Fischer, and David Rennie. 1999. "Evolving Guidelines for Publication of Qualitative Research Studies in Psychology and Related Fields." British Journal of Clinical Psychology 38 (3): 215-229.

Elman, Miriam. 2000. "Unpacking Democracy: Presidentialism, Parliamentarism, And Theories of Democratic Peace." Security Studies 9 (4): 91-126.

Evera, Stephen. 1999. Causes of War: Power and the Roots of Conflict. USA: Cornell University Press.

Fan, Hongwei. 2011. "China's Look South: China-Myanmar Transpor Corridor." Ritsumeikan International Affairs 10: 43-66.

Fang, Yun (方芸). 2010. “The Problem with and Reflection on Yunnan's Development of Overseas Opium Substitution (云南境外代替发展的问题和思考).” Southeast and South Asian Studies (东南亚南亚研究) 1: 58-62.

Farber, Henry and Joanne Gowa. 1995. "Polities and Peace." International Security 20 (2): 123-146.

Feldman, Elliot and Lily Feldman. 1990. "Canada," Pp.176-210 in Federalism and International Relations: The Role of Subnational Units, edited by Hans Michelmann and Panayotis Soldatos. UK: Oxford.

Fenig, Shmuel et al. 1993. "Telephone vs Face-to-Face Interviewing in a Community Psychiatric Survey." American Journal of Public Health 83 (6): 896-898.

Fewsmith, Joseph. 2001. "The Political and Social Implications of China's Accession to the WTO." The China Quarterly 167: 573-591.

Flyvbjerg, Bent. 2006. "Five Misunderstandings about Case-Study Research." Qualitative Inquiry 12 (2): 219-245.

Fontana, Andrea and James Frey. 1994. "The Art of Science," Pp.361-376 in The Handbook of Qualitative Research, edited by Norman Denzin and Yvonna Lincoln. USA: SAGE.

Fry, Earl. 1990. "The United States of America," Pp.276-298 in Federalism and International Relations: The Role of Subnational Units, edited by Hans Michelmann and Panayotis Soldatos. UK: Oxford.

Fukuyama, Francis. 1992. The End of History and the Last Man. USA: The Free Press.

Gamble, Andrew et al. 1996. Regionalism and World Order. UK: Macmillan.

Garver, John. 1993. Foreign relations of the People's Republic of China. USA: Prentice Hall. 
Giang, Nguyen. 2018. "China is Making Mekong Friends." Eastasiaforum.org. Retrieved August 17, 2018 (http://www.eastasiaforum.org/2018/05/19/china-is-makingmekong-friends/).

Gibbs, Graham. 2007. Analyzing Qualitative Data. USA: SAGE.

Giddens, Anthony. 2000. Runaway World: How Globalisation is Shaping Our Lives. UK: Routledge.

Giersch, Patterson. 2006. Asian Borderlands: The Transformation of Qing China's Yunnan Frontier. USA: Harvard University Press.

Glassman, Jim. 2010. Bounding the Mekong: The Asian Development Bank, China and Thailand. USA: University of Hawaii Press.

Glauert, Rik. 2018. "China's Myanmar Policy: Peace, Conflict - Whatever Works." Scmp.com. Retrieved March 26, 2019 (https://www.scmp.com/weekasia/geopolitics/article/2155221/chinas-myanmar-policy-peace-conflict-whateverworks).

Goh, Evelyn. 2004. "China in the Mekong River Basin: The Regional Security Implications of Resource Development on the Lancang Jiang." RSIS Working Paper 69.

Singapore: Nanyang Technological University.

Goh, Evelyn. 2017. "China in the Mekong River Basin: The Regional Security Implications of Resource Development on the Lancang Jiang," Pp.237-258 in Non-Traditional Security in Asia: Dilemmas in Securitization, edited by Ralf Emmers. UK: Routledge.

Goldstein, Avery. 2003. "An Emerging China's Emerging Grand Strategy," Pp.57-106 in International Relations Theory and the Asia-Pacific, edited by John Ikenberry et al. USA: Columbia University Press.

Goodman, David and Feng Chongyi. 1994. "Guangdong: Greater Hong Kong and the New Regionalist Future," Pp.177-201 in China Deconstructs: Politics, Trade and Regionalism, edited by David Goodman and Gerald Segal. UK: Routledge.

Gowa, Joanne. 2011. Ballots and Bullets: The Elusive Democratic Peace. USA: Princeton University Press.

Groves, Robert and Robert Kahn. 1979. Surveys by Telephone. UK: Academic Press.

Grugel, Jean. 2004. "New Regionalism and Modes of Governance: Comparing US and EU Strategies in Latin America." European Journal of International Relations 10 (4): 603-626.

Guan, The. 2011. "Japan-China Rivalry: What Role Does the East Asia Summit Play?" Asia Pacific Viewpoint 52 (3): 347-360.

Guo, Xiaonian (郭小年) and Luo Shengrong (罗圣荣). 2012. “The Construction of Yunnan's Cross-border Economic Cooperation Zone: Status Quo, Problem and Suggestion (云南省跨境经济区建设: 现状、问题与建议)," Pp.105-121 in Report on the Cooperation and Development in the Greater Mekong Subregion (20112012) (大泦公河次区域合作发展报告 <2011-2012>), edited by Liu Zhi (刘稚). China: Social Sciences Academic Press (社会科学文献出版社).

Gx211 (中国高校之窗).com. “The Official Youth Delegation from Chiangrai of Thailand 
to Yunnan Minzu University (泰国清莱政府代表团到云南民族大学访问).”

Gx211.com (中国高校之窗). Retrieved March 27, 2018

(http://www.gx211.com/news/20170526/n14957958322984.html).

Haglund, Dan. 2008. "Regulating FDI in Weak African States: A Case Study of Chinese Copper Mining in Zambia." The Journal of Modern African Studies 46 (4): 547-575.

Hameiri, Shahar and Lee Jones. 2016. "Rising Powers and State Transformation: The Case of China." European Journal of International Relations: 1-27.

Harris, Stuart. 2005. "China: Globalization and Its Diplomatic Structure and Process", Pp.114-133 in Diplomacy and Developing Nations: Post-Cold War Foreign PolicyMaking Structures and Processes, edited by Justin Robertson and Maurice A. East. UK: Routledge.

Hartley, Jean.1994. "Case Studies in Organizational Research," Pp.208-229 in Qualitative Methods in Organizational Research: A Practical Guide, edited by Catherine Cassell and Gillian Symon. USA: SAGE.

Harvey, Carol. 1988. "Telephone Survey Techniques." Canadian Home Economics Journal 38 (1): 30-35.

Harvey, David. 2003. The New Imperialism. UK: Oxford University.

Harvey, David. 2007. "In What Ways is 'the New Imperialism' Really New?" Historical Materialism 15 (3): 57-70.

$\mathrm{He}$, Baogang. 2007. "Democratization and Federalization in Asia," Pp.1-32 in Federalism in Asia, edited by He Baogang, Brian Galligan and Takashi Inoguchi. UK: Edward Elgar Publishing.

He, Shengda and Sheng Lijun. 2005. "Yunnan's Greater Mekong Sub-Region Strategy," Pp.294-315 in ASEAN-China Relations: Realities and Prospects, edited by Saw SweeHock, Sheng Lijun and Chin Kin Wah. Singapore: Institute of Southeast Asian Studies.

He, Shengda (贺圣达). 2007. “The GMS Cooperation: A Complicated Cooperational Mechanism and China's Participation (大湄公河次区域合作: 复杂的机制合作机 制和中国的参与)," Pp.3-22 in A Study on Economic Cooperation in Greater Mekong Subregion (大湄公河次区域经济合作研究), edited by Chai, Yu (柴瑜), Lu Jianren (陆建人) and Yang Xianming (杨先明). China: Social Sciences Academic Press (社会科学文献出版社).

Held, David et al. 1999. Global Transformations. USA: Stanford University Press.

Hettne, Björn. 1999. "Globalization and the New Regionalism: The Second Great Transformation," Pp.1-24 in Globalism and the New Regionalism, edited by Osvaldo Sunkel and András Inotai. UK: Palgrave Macmillan.

Hill, Ann. 1998. Merchants and Migrants: Ethnicity and Trade among Yunnanese Chinese in Southeast Asia. USA: Yale Univ Southeast Asia Studies.

Hillgenberg, Hartmut. 1999. "A Fresh Look at Soft Law." European Journal of International Law 10 (3): 499-515.

Hocking, Brian and Michael Smith. 1990. World Politics: An Introduction of International 
Relations. Australia: Pearson Education Limited.

Hocking, Brian. 1993. "Introduction," Pp.3 in Foreign Relations and Federal State, edited by Brian Hocking. UK: Leicester University Press.

Hocking, Brian. 1993. Localizing Foreign Policy: Non-Central Governments and Multilayered Diplomacy. USA: St. Martin's Press.

Hocking, Brian. 1999. "Catalytic Diplomacy: beyond 'Newness' and 'Decline'," Pp.21-42 in Innovation in Diplomatic Practice, edited by Jan Melissen. UK: Macmillan Press Ltd.

Hocking, Brian. 1999. "Patrolling the 'Frontier': Globalization, Localization and the 'Actorness' of Non-Central Governments," Pp.17-39 in Paradiplomacy in Action: The Foreign Relations of Subnational Governments, edited by Francisco Aldecoa and Michael Keating.

Holbig, Heike. 2004. "The Emergence of the Campaign to Open up the West: Ideological Formation, Central Decision-Making and the Role of the Provinces." The China Quarterly 178: 335-357.

Holsti, Jaakko and Thomas Levy. 1974. "Bilateral Institutions and Transgovernmental Relations between Canada and the United States." International Organization 28 (4): 875-901.

Holsti, Ole. 1969. Content Analysis for The Social Sciences and Humanities. USA: Reading.

Hooghe, Liesbet, Gary Marks and Arjan Schakel. 2010. The Rise of Regional Authority: A Comparative Study of 42 Democracies. UK: Routledge. Huang, Jiamo (黄嘉馍). 1976. British Relations with the Panthay Regime of Western Yunnan, 1868-1874 (滇 西回民政权的联英外交: 1868-1874). Taiwan: Institute of Modern Histoty, Academia Sinica (中央研究院近代史研究所).

Huang, Huikun (黄惠焜). 1992. “Take Effort to Internationalize Regional Economy (努力 建立国际化的区域经济).” Yunnan Daily (云南日报), June 5, A3.

Huang, Yasheng. 1995. "Why China Will Not Collapse." Foreign Policy 99: 54-68.

Huntington, Samuel. 1973. "Transnational Organizations in World Politics." World Politics 25 (3): 333-368.

Huntington, Samuel. 1996. The Clash of Civilizations and the Remaking of World Order. UK: Penguin Books.

Hurrell, Andrew. 1995. "Regionalism in Theoretical Perspective." Regionalism in World Politics: Regional Organization and International Order: 37-73.

Ivsdz.com (塞塔综合开发区). 2017. “Introduction of the Zone (园区介绍).” Ivsdz.com (塞塔综合开发区). Retrieved July 24, 2018

(http://www.lvsdz.com/list/zllhtzpc/7/481/auto/20/0.html).

Jacob, Jabin. 2016. "China's Provinces and Foreign Policy: Lessons and Implications for India and Its States", Pp.253-270 in The Agartala Doctrine: A Proactive Northeast in Indian Foreign Policy, edited by Subir Bhaumik. UK: Oxford University Press.

Jacobson, Karan and Michel Oksenberg. 1990. China's Participation in the IMF, the World 
Bank, and GATT: Toward a Global Economic Order. USA: University of Michigan Press.

Jain, Purnendra. 2006. Japan's Subnational Governments in International Affairs. USA: McGraw Hill Professional.

Jeffery, Charlie. 2010. "Scotland's European and International Policy," Pp.103-120 in Foreign Policy of Constituents Units at the Beginning of 21st Century, edited by Ferran Requejo. Spain: Institut d'Estudis Autonòmics.

Jersild, Austin. 2014. The Sino-Soviet Alliance: An International History. USA: The University of North Carolina Press.

Jha, Prakash. 2014. "Federalism, Regionalism and States Paradiplomacy in India," Pp.234260 in Federalism in India: Towards A Fresh Balance of Power, edited by Lancy Lobo and Jayesh Shah. India: Rawat Publicatio.

Ji, You. 2014. "The PLA and Diplomacy: Unravelling Myths about the Military Role in Foreign Policy Making." Journal of Contemporary China 23 (86): 236-254.

Joenniemi, Pertti and Alexander Sergunin. 2014. "Paradiplomacy as a Capability-Building Strategy: The Case of Russia's Northwestern Subnational Actors." Problems of PostCommunism 61 (6): 18-33.

Joffe, Ellis. 1994. "Regionalism in China: The Role of the PLA," Pp.43-58 in Chinese Regionalism: The Security Dimension, edited by Richard Yang et al. USA: Westview Press.

Johannson, Roff. 1978. "Provincial International Activities." International Journal 33 (2): 357-378.

Jordan, Lawrence, Alfred Marcus and Leo Reeder. 1980. "Response Styles in Telephone and Household Interviewing: A Field Experiment." Public Opinion Quarterly 44 (2): 210-222.

Jones, Randall, Robert King and Michael Klein. 1993. "L'intégration économique entre Hong-Kong, Taïwan et les provinces côtières de la Chine." Revue Economique de I'OCDE 20: 129-163.

Kanwal, Gurmeet. 1999. "China's Long March to World Power Status: Strategic Challenge for India." Strategic Analysis 22 (11): 1713-1728.

Keating, Michael. 1999. "Regions and International Affairs: Motives, Opportunities and Strategies." Regional \& Federal Studies 9 (1): 1-16.

Keating, Michael. 2000. "Paradiplomacy and Regional Networking." Forumfed.org. Retrieved August 20, 2016 (http://www.forumfed.org/libdocs/ForRelCU01/924FRCU0105-eu-keating.pdf).

Keohane, Robert and Joseph Nye. 1973. Transnational Relations and World Politics. USA: Harvard University Press.

Keohane, Robert and Joseph Nye. 1974. "Introduction: The Complex Politics of CanadianAmerican Interdependence." International Organization 28 (4): 595-607.

Keohane, Robert and Joseph Nye. 1974. "Transgovernmental Relations and International 
Organizations." World Politics 27 (1): 39-62.

Kewalram, Ravi. 2004. "WTO Dispute Settlement and Sub-National Entities in China," Pp.412-420 in China and the World Trading System: Entering the New Millennium, edited by Deborah Cass et al. UK: Cambridge University Press.

Kikuchi, Tomoo and Wang Zi. 2016. "The AllB and Shifting Economic Dynamics in Southeast Asia." Brinknews.com. Retrieved August 20, 2018

(http://www.brinknews.com/asia/the-aiib-and-shifting-economic-dynamics-insoutheast-asia/).

Kim, Nam Kyu. 2017. "Anti-Regime Uprisings and the Emergence of Electoral Authoritarianism." Political Research Quarterly 70 (1): 111-126.

Kim, Samuel. 2007. "The Two Koreas: Making Grand Strategy amid Changing Domestic Politics," Pp.113-138 in Domestic Political Change and Grand Strategy, edited by Ashley Tellis and Michael Wills. USA: The National Bureau of Asian Research.

Kincaid, John. 1990. "Constituent Diplomacy in Federal Polities and the Nation-State: Conflict and Co-operation", Pp.54-75 in Federalism and International Relations: The Role of Subnational Units, edited by Hans Michelmann and Panayotis Soldatos. UK: Oxford.

King, Roger. 2002. "Development Opportunities in the Greater Mekong Sub-Region." Aiec.idp.com. Retrieved July 27, 2018 (http://aiec.idp.com/uploads/pdf/King roger p.pdf).

Kluckhohn, Florence. 1940. "The Participant-Observer Technique in Small Communities." American Journal of Sociology 46 (3): 331-343.

Kohlbacher, Florian. 2006. "The Use of Qualitative Content Analysis in Case Study Research." Forum: Qualitative Social Research 7 (1): 1-30.

Kolbe, Richard and Melissa Burnett. 1991. "Content-Analysis Research: An Examination of Applications with Directives for Improving Research Reliability and Objectivity." Journal of Consumer Research 18 (2): 243-250.

Kong, Bo. 2010. "The Geopolitics of the Myanmar-China Oil and Gas Pipelines," Pp.55-66 in Pipeline Politics in Asia, edited by Edward Chow et al. USA: National Bureau of Asian Research.

Kong, Xianggeng (孔祥庚). 2001. China's Develop the West: Research on Yunnan's Key Strategic Projects (中国西部发开发：云南重大战略工程研究). China: Yunnan People's Publishing House (云南人民出版社).

Krasner, Stephen. 1982. "Structural Causes and Regime Consequences: Regime as Intervening Variable." International Organization 36: 185-205.

Kratochvíl, Petr. 2013. The EU as a Political Actor: The Analysis of Four Dimensions of the EU's Actorness. Germany: Nomos.

Kudo, Toshihiro. 2010. "Myanmar's Border Trade with China: Situation, Challenge and Prospects," Pp.266-294 in Economic Relations of China, Japan and Korea with the Mekong River Basin Countries, edited by Mitsuhiro Kagami. Thailand: Bangkok Research Center. 
Kuik, Cheng-Chwee. 2013. "Malaysia's US Policy under Najib: Structural and Domestic Sources of a Small State's Strategy." Asian Security 9 (3): 143-164.

Kunming.cn (昆明信息港). 2016. “The Holding of the Sixth Conference between Yunnan and Vietnamese Lao Cai, Ha Giang, Lai Chau, and Dien Bien (云南省与越南河江莱 州奠边省联合工作组第六次会议举行).” Kunming.cn (昆明信息港). Retrieved February 25, 2018 (http://xw.kunming.cn/a/2016-12/27/content 4468513.htm).

Kuznetsov, Alexander. 2014. Theory and Practice of Paradiplomacy: Subnational Governments in International Affairs. UK: Routledge.

Kvale, Steinar. 2007. Doing interviews. USA: SAGE.

Lai, Hongyi. 2002. "China's Western Development Program: Its Rationale, Implementation, and Prospects." Modern China 28 (4): 432-466.

Lai, Hongyi and Su-Jeong Kang. 2014 "Domestic Bureaucratic Politics and Chinese Foreign Policy." Journal of Contemporary China 23 (86): 294-313.

Lalande, Gilles. 1973. "Quebec and International Affairs," Pp.239-243 in Quebec Society and Politics: Views from the Inside, edited by Thomson Dale. Canada: McCelland and Stewart Limited Publishers.

Lall, Marie. 2006. "Indo-Myanmar Relations in the Era of Pipeline Diplomacy." Contemporary Southeast Asia 28 (3): 424-446.

Lampton, David. 2001. “China's Foreign and National Security Policy-Making Process: Is It Changing, and Does It Matter?", Pp.1-36 in The Making of China Foreign and Security Policy in the Era of Reform, 1978-2000, edited by David Lampton. USA: Stanford University Press.

Lam, Willy. 2015. "The General's Growing Clout in Diplomacy." Jamestown.org. Retrieved September 27, 2017 (https://jamestown.org/program/the-generals-growing-cloutin-diplomacy//).

Landry, Pierre. 2008. Decentralized Authoritarianism in China. UK: Cambridge University Press.

Lanteigne, Marc. 2005. China and International Institutions. UK: Routledge.

Lan, Yuzhi (蓝玉芝). 2016. Ruili Recently to Invest 315 Million for Ruili-Bhamo Expressway Improvement (瑞丽近期将投资 3.15 亿改造瑞丽至八莫公路).

Dh.gov.cn. Retrieved April 15, 2017 (http://www.dh.gov.cn/Web/ 20910.htm).

Latouche, Daniel. 1988. "State Building and Foreign Policy at the Subnational Level," Pp.29-42 in Perforated Sovereignties and International Relations, edited by Ivo Duchacek et al. USA: Greenwood Press.

Lattimore, Owen. 1943. "Yunnan, Pivot of Southeast Asia." Foreign Affairs 21 (3): 476493.

Leach, Richard, Donald Walker and Thomas Levy. 1973. "Province-State Trans-Border Relations: A Preliminary Assessment." Canadian Public Administration 16 (3): 468482.

Lecours, André and Luis Moreno. 2001. "Paradiplomacy and Stateless Nations: A 
Reference to the Basque Country." Unidad de Politicas Comparadas (CSIS), Working Paper: 1-6.

Lecours, André. 2002. "Paradiplomacy: Reflections on the Foreign Policy and International Relations of Regions." International Negotiation 7 (1): 91-114.

Lecours, André. 2010. "Canadian Federalism and Foreign Relations: Quebec and Alberta," Pp.29-41 in Foreign Policy of Constituents Units at the Beginning of 21st Century, edited by Ferran Requejo. Spain: Institut d'Estudis Autonòmics.

Lees, Loretta. 2003. "Urban Geography: 'New' Urban Geography and the Ethnographic Void." Progress in Human Geography 27 (1): 107-113.

Lejeune, Yves. 1990. "Belgium," Pp.142-175 in Federalism and International Relations: The Role of Subnational Units. UK: Clarendon Press.

Leung, Guy. 2011. "China's Energy Security: Perception and Reality." Energy Security 39: 1330-1337.

Lewis, John. 1963. Leadership in Communist China. USA: Cornell University Press.

Li, Cheng. 2010. "Shaping China's Foreign Policy: The Paradoxical Role of ForeignEducated Returnees." Asia Policy 10 (1): 65-85.

Li, Chenyang (李晨阳). 2015. “From Bridgehead to Radiation Centre: Exploration into Yunnan's External Opening up (从桥头堡到辐射中心-云南对外开放的探索).” World Affairs (世界知识) 10: 73-73.

Li, Mingjiang. 2014. "Local Liberalism: China's Provincial Approaches to Relations with Southeast Asia." Journal of Contemporary China 23 (86): 275-293.

Li, Mingjiang. 2017. "Central-Local Interactions in Foreign Affairs," Pp.209-228 in Assessing the Balance of Power in Central-Local Relations in China, edited by John Donaldson. UK: Routledge.

Li, Tao (李涛). 2013. “Difficulties and Breakthrough of Yunnan's Construction of CrossBorder Economic Cooperation Zone (云南省在推进跨境经济合作区建设中的难 点与突破)." Around Southeast Asia (东南亚纵横) 9: 45-49.

Li, Yigan (李义敢). 2000. “To Actively Participant in Lancang-Mekong Subregion Cooperation is A Substantial Strategy in China's Develop the West (积极参与澜沧 江 - 湄公河次区域合作是中国西部开发的重大战略).” The Annual Academic Meeting of China's Soft Science (中国软科学学术年会).

Li, Yigan (李义敢) et al. 2004. Plan and Research (2003-2005) on Yunnan's Participation in Lancang-Mekong Subregion Cooperation (云南省参与澜沧江 - 湄公河次区域 合作 2003-2005 年规划研究). China: The Nationalities Publishing House of Yunnan (云南民族出版社).

Lieberthal, Kenneth. 2007. "How Domestic Forces Shape the PRC's Grand Strategy and International Impact," Pp.29-68 in Domestic Political Change and Grand Strategy, edited by Ashley Tellis and Michael Wills. USA: The National Bureau of Asian Research.

Liu, Chuanchun (刘传春). 2017. “Identity Recognition Reflected in China's External Cooperation Mechanisms: A Case Study of the LMC (中国对外合作机制的身份认 
同功能: 以澜涺合作机制为例的分析)." International Forum (国际论坛) 19 (6): 35-40.

Liu, Junsheng (刘均胜). 2005. “The Macroeconomic Policies Coordination in the Subregional Cooperation: To Undergird the Coordination of Economic Policies in the Subregional Cooperation through the Functional Cooperation (次区域合作中 的宏观经济政策协调: 通过功能性合作加强大湄公河次区域合作中的宏观政策 协调)." Meeting Conference at the GMS International Seminar. Retrieved January 3, 2019 (http://www.doc88.com/p-977462927008.html).

Liu, Zhi (刘稚). 2007. “The Status Quo and Prospect of the Antidrug Cooperation in the Greater Mekong Subregion (大湄公河次区域国际禁毒合作的现状和前景)," Pp.251-264 in A Study on Economic Cooperation in Greater Mekong Subregion (大 湄公河次区域经济合作研究), edited by Chai, Yu (柴瑜), Lu Jianren (陆建人) and Yang Xianming (杨先明). China: Social Sciences Academic Press (社会科学文献出 版社).

Liu, Zhi (刘稚). 2015. GMS Report (大沣公河次区域合作发展报告). China: Social Sciences Academic Press (社会科学文献出版社).

Loh, Francis. 2009. “Federation of Malaysia," Pp.189-210 Pp.10-35 in Foreign Relations in Federal Countries, edited by Hans Michelmann. Canada: McGill-Queen's University Press.

Long, Simon. 1994. "Regionalism in Fujian," Pp.202-223 in China Deconstructs: Politics, Trade and Regionalism, edited by David Goodman and Gerald. UK: Routledge.

Lu, Guangsheng. 2016. "China Seeks to Improve Mekong Sub-Regional Cooperation: Causes and Policies." Think-asia.org. Retrieved October 22, 2018 (https://thinkasia.org/handle/11540/6512).

Luard Evan. 1990. The Globalization of Politics. UK: Palgrave Macmillan.

Luo, Shengrong (罗圣荣). 2012. “Analysis on the Construction of Yunnan's Cross-Border Economic Cooperation Zone (云南省跨境经济合作区建设研究).” Journal of International Economic Cooperation (国际经济合作): 81-87.

Ma, Shuhong (马树洪). 1994. “The Drug Problem in the Indochina Peninsula (中南半岛 的毒品问题).” Asia Discovery (亚洲探索) 3: 19-26.

Ma, Shuhong (马树洪). 1995. “The Emerging Southeast Asia's Economy and Its Impact on the Southwest of China (正在崛起的东南亚经济及其对中国西南的影响)." Social Sciences in Yunnan (云南社会科学) (4): 32-39.

Ma, Yao (马曜). 1983. The Brief History of Yunnan (云南简史). China: Yunnan People Publishing Housing (云南人民出版社).

Mackerras, Colin and Michael Clarke. 2009. China, Xinjiang and Central Asia: History, Transition and Crossborder Interaction into the $21^{\text {st }}$ Century. UK: Routledge.

Mackerras, Colin. 2015. "Xinjiang in China's Foreign Relations: Part of a New Silk Road or Central Asian Zone of Conflict?" East Asia 32 (1): 25-42.

Madanayaka, Shashikala. 2016. "China, India and the Balance of Power in South Asia: with Reference to Sri Lanka's Position." Felicitation Volume of Senior Professor 
Prema Podimenike, Department of Economics, University of Kelaniya: 196-199.

Madill, Anna, Abbie Jordan and Caroline Shirley. 2000. "Objectivity and Reliability in Qualitative Analysis: Realist, Contextualist and Radical Constructionist Epistemologies." British Journal of Psychology 91 (1): 1-20.

Makarychev, Andrei and Vasilii Valuev. 2001. "External Relations of Tatarstan: Neither inside, Nor outside, But alongside Russia." Isn.ethz.ch. Retrieved December 18, 2015 (http://www.isn.ethz.ch/DigitalLibrary/Publications/Detail/?ots591=0c54e3b3-1e9c-be1e-2c24a6a8c7060233\&lng=en\&id=450).

Manning, Bayless. 1977. "The Congress, the Executive and Intermestic Affairs: Three Proposals." Foreign Affairs 55 (2): 306-324.

Masaki, Hisane. 2007. "Japan Vies with China for Dominance in Indochina and ASEAN." The Asia-Pacific Journal 5 (5). Retrieved October 22, 2018 (https://apijf.org/Hisane-MASAKI/2429/article.html).

Mason, Jennifer. 2002. Qualitative Researching. USA: SAGE.

Masviriyakul, Siriluk. 2004. "Sino-Thai Strategic Economic Development in the Greater Mekong Subregion (1992-2003)." Contemporary Southeast Asia 26 (2): 302-319.

Mattoo, Amitabh and Happymon Jacob. 2009. "The Republic of India," Pp.169-187 in Foreign Relations in Federal Countries, edited by Hans Michelmann. Canada: McGill-Queen's University Press.

Mayring, Phillip. 2000. "Qualitative Content Analysis." Forum on Qualitative Social Research 1 (2). Retrieved June 2, 2018 (http://nbn-resolving.de/urn:nbn:de:0114fqs0002204).

McCracken, Grant. (1988). The Long Interview. USA: SAGE.

McDowell, Linda. 1998. "Elites in the City of London: Some Methodological Considerations." Environment and Planning 30 (12): 2133-2146.

McFaul, Michael. 2000. “One Step forward, Two Steps back." Journal of Democracy 11 (3): 1933.

McMillan, Samuel. 2012. The Involvement of State Governments in US Foreign Relations. USA: Springer.

Mearsheimer, John. 1990. "Back to the Future: Instability in Europe after the Cold War." International Security: 5-56.

Medhi Krongkaew. 2004. "The Development of the Greater Mekong Subregion: Real Hope or False Promise?" Journal of Asian Economics 15 (5): 977-998.

Megoran, Nick. 2006. "For Ethnography in Political Geography: Experiencing and ReImagining Ferghana Valley Boundary Closures." Political Geography 25 (6): 622-640.

Mekonginstitute.org. 2018. "Structure." Mekonginstitute.org. Retrieved March 2, 2018 (http://www.mekonginstitute.org/who-we-are/structure/).

Mekonginsttitute.org. 2018. "About Mekong Institute." Mekonginsttitute.org. Retrieved 
March 2, 2018 (http://www.mekonginstitute.org/who-we-are/about-mi/).

Michelmann, Hans. 2009. "Introduction," Pp.3-8 in Foreign Relations in Federal Countries, edited by Hans Michelmann. Canada: McGill-Queen's University Press.

Michelmann, Hans. 2009. "Conclusion," Pp.324-352 in Foreign Relations in Federal Countries, edited by Hans Michelmann. Canada: McGill-Queen's University Press.

Miller, Carol. 1995. "In-depth Interviewing by Telephone: Some Practical Considerations." Evaluation \& Research in Education 9 (1): 29-38.

Milner, Helen. 1997. Interests, Institutions, and Information: Domestic Politics and International Relations. USA: Princeton University Press.

Mochizuki, Mike. 2007. "The Politics of Recalibrating Grand Strategy," Pp.69-112 in Domestic Political Change and Grand Strategy, edited by Ashley Tellis and Michael Wills. USA: The National Bureau of Asian Research.

Mofa.go.jp. 2008. "The First Meeting of the Japan-China Policy Dialogue on the Mekong Region." Mofa.go.jp. Retrieved August 24, 2018 (https://www.mofa.go.jp/announce/event/2008/4/1179410_932.html).

Mofa.go.jp. 2009. "The Second Meeting of the Japan-China Policy Dialogue on the Mekong Region." Mofa.go.jp. Retrieved August 24, 2018 (https://www.mofa.go.jp/announce/event/2009/6/1193207 1160.html).

Mofa.go.jp. 2010. "The "Third Meeting of the Japan-China Policy Dialogue on the Mekong Region." Mofa.go.jp. Retrieved August 24, 2018 (https://www.mofa.go.jp/announce/announce/2010/4/0416 03.html).

Mofa.go.jp. 2014. "The Fifth Meeting of the Japan-China Policy Dialogue on the Mekong Region." Mofa.go.jp. Retrieved August 23, 2018 (https://www.mofa.go.jp/press/release/press4e 000540.html).

Mofcom.gov.cn (商务部). 2013. “The Attraction of Investment in the Laotian Vientiane Saysettha Development Zone (万象赛塞塔综合开发区招商).” Mofcom.gov.cn (商务 部). Retrieved April 12, 2018 (http://www.mofcom.gov.cn/article/i/ishz/new/201312/20131200419472.shtml).

Mofcom.gov.cn (商务部). 2013. "The Holding of the First China's Yunnan-Myanmar Cooperation Forum in Kunming (首届中国-缅甸合作论坛在昆举行).” Mofcom.gov.cn (商务部). Retrieved February 25, 2018 (http://www.mofcom.gov.cn/article/resume/n/201308/20130800257367.shtml).

Mohammed, Khali and Francis Owtram. 2014. "Paradiplomacy of Regional Governments in International Relations: The Foreign Relations of the Kurdistan Regional Government (2003-2010)." Iran and the Caucasus 18 (1): 65-84.

Mohan, Raja. 2007. "Poised for Power: The Domestic Roots of India's Slow Rise," Pp.177-210 in Domestic Political Change and Grand Strategy, edited by Ashley Tellis and Michael Wills. USA: The National Bureau of Asian Research.

MOT (交通运输部). 2014. “The 650km Expressway between Kunming and Hanoi Completed (昆明至河内全程贯通 650 公里高速公路).” 163.com. Retrieved December 17, 2018 (http://news.163.com/14/0926/11/A72K9BEP00014SEH mobile.html\#). 
Murphy, Ann. 2017. "ASEAN's External Policy," Pp.50-78 in China, The United States, and the Future of Southeast Asia: U.S.-China Relations, edited by David Denoon. USA: New York University Press.

Murphy, Elizabeth and Robert Dingwall. 2001. "The Ethics of Ethnography," Pp.339-351 in Handbook of Ethnography, edited by Paul Atkinson at al. USA: SAGE.

Nachemson, Andrew. 2018. "Japan Plays China's Game in Cambodia. Hun Sen Wins." Scmp.com. Retrieved August 25, 2018 (https://www.scmp.com/weekasia/geopolitics/article/2149397/japan-plays-chinas-game-cambodia-hun-sen-wins).

Nagel, Klaus-Jürgen. 2010. "Foreign Policy: The Case of the Germany Lander," Pp.121-142 in Foreign Policy of Constituents Units at the Beginning of 21st Century, edited by Ferran Requejo. Spain: Institut d'Estudis Autonòmics.

Nathan, Richard. 1975. "The New Federalism versus the Emerging New Structuralism." Publius 5 (3): 111-129.

NDRC (国际发改委). 2019. “Comprehensive Plan for the New Western Land-Sea Channel (西 部陆海新通道总体规划).” Ndrc.gov.cn (国家发改委网). Retrieved September 17， 2019 (http://www.ndrc.gov.cn/gzdt/201908/t20190815 944636.html).

NDRC, MOFA, MOC. 2015. "Vision and Actions on Jointly Building Silk Road Economic Belt and 21st-Century Maritime Silk Road." Ndrc.gov.cn. Retrieved November 3, 2015 (http://en.ndrc.gov.cn/newsrelease/201503/t20150330 669367.html).

Neuman, Lawrence. 1997. Social Research Methods, Qualitative and Quantitative Approaches. USA: Allyn and Bacon.

Nganje, Fritz. 2014. "Paradiplomacy and the Democratisation of Foreign Policy in South Africa. South African Journal of International Affairs, 21(1): 89-107.

Nhan Dan. 2017. "Conference Boosts Vietnam-China Economic Corridor Cooperation." Nhandan.com.vn. Retrieved March 28, 2018

(http://en.nhandan.com.vn/business/item/5662902-conference-boosts-vietnam-chinaeconomic-corridor-cooperation.html).

Palmer, Norman. 1991. The New Regionalism in Asia and the Pacific. USA: Lexington Books.

Noureddine, Dakhane and Zerrouga Ismail. 2017. "The Role of Civil Society in Foreign Policy, a Study in the Liberal Democracy-Practical Policies." Noble International Journal of Social Sciences Research 2 (1): 1-9.

NPC (全国人民代表大会). 1954. The Constitution of the PRC (中华人民共和国宪法). China: NPC (全国人民代表大会).

NPC (全国人民代表大会). 1982. The Constitution of the PRC (中华人民共和国宪法). China: NPC (全国人民代表大会).

Oehlers, Alfred. 2006. "A Critique of ADB Policies towards the Greater Mekong SubRegion." Journal of Contemporary Asia 36 (4): 464-478.

Ohmae, Kenichi. 1995. The End of the Nation-State: The Rise of Regional Economics. USA: The Free Press.

O'leary, Greg. 1980. The Shaping of Chinese Foreign Policy. Australia: Australian National 
University Press.

Opdenakker, Raymond. 2006. "Advantages and Disadvantages of Four Interview Techniques in Qualitative Research. Forum: Qualitative Social Research 7 (4). Retrieved April 20, 2018 (http://www.qualitative-research.net/index.php/fqs/article/view/175/391\%3E).

Ott, Marvin and Hao Yilin. 2018. "Chinese Strategic Assessments of Southeast Asia." Wilsoncenter.org. Retrieved October 22, 2018 (https://www.wilsoncenter.org/sites/default/files/ott haochinese strategic assessments of southeast asia.pdf).

Paquin, Stephane. 2010. "Federalism and Compliance with International Agreements: Belgium and Canada Compared", Pp.173-197 in Regional Sub-State Diplomacy Today, edited by David Criekemans. The United States: Martinus Nijhoff Publishers.

Parameswaran, Prashanth. 2017. "China Conducts Joint Patrol with ASEAN Mekong State." The Diplomat. Retrieved April 22, 2018 (https://thediplomat.com/2017/10/chinaconducts-joint-patrol-with-asean-mekong-states/).

Paul, Darel. 2002. "Re-Scaling IPE: Subnational States and the Regulation of the Global Political Economy." Review of International Political Economy 9 (3): 465-489.

PBOC (人民银行) et al. 2018. “Comprehensive Plan for Guangxi's Opening up of Finance for Southeast Asia (广西壮族自治区建设面向东盟的金融开放门户总体方案).” Gxzf.gov.cn (广西政府网). Retrieved September 17, 2019 (http://www.gxzf.gov.cn/sytt/20181229-729308.shtml).

Pehrson, Christopher. 2006. String of Pearls: Meeting the Challenge of China's Rising Power across the Asian Littoral. USA: Strategic Studies Institute of U.S. Army War College.

Pelinka, Anton. 1990. "Austria," Pp.124-141 in Federalism and International Relations: The Role of Subnational Units. UK: Clarendon Press.

People.com.cn (人民网). 2012. “Hun Jintao's Report at the Eighteenth CCP Congress (胡锦涛 在中国共产党第十八次全国代表大会上的报告).” People.com.cn (人民网). Retrieved June 29, 2018 (http://cpc.people.com.cn/n/2012/1118/c64094-19612151.html).

People.com.cn (人民网). 2014. “1984: Hu Yaobang to Propose Development of the Greater Southwest (1984 年, 胡耀邦提出开发大西南).” People.com.cn (人民网. Retrieved from September 10, 2017 (http://news.ifeng.com/a/20140909/41907443 0.shtml).

People.com.cn (人民网). 2016. “The Opening of the Eighth GMS Governors Forum in Kunming: to Create New Development Situation Together(第八届 GMS 经济走廊省长 论坛昆明开幕：共创合作发展新局面).” People.com.cn (人民网). Retrieved April 1, 2018 (http://yn.people.com.cn/news/yunnan/n2/2016/0611/c228496-28485256.html).

People's Daily Overseas Edition (人民日报<海外版>). 2011. “Yunnan: 'Gateway' to Lead to Future (云南: “桥头堡”上看未来).” People’s Daily<Overseas> (人民日报<海外版〉). Retrieved September 2, 2017 (http://paper.people.com.cn/rmrbhwb/html/201112/26/content 983556.htm?div=-1).

People's Daily Overseas Edition (人民日报<海外版>). 2015. “China-Southeast Asia Expo: To Give New Spirit the Regional Cooperation (南博会 : 激发区域合作勃勃生机).”

People.com.cn (人民网). Retrieved April 1, 2018 
(http://paper.people.com.cn/rmrbhwb/html/2015-06/16/content 1577258.htm).

Percival, Bronson. 2006. "Japan-Southeast Asia Relations: Playing Catch-up with China." Comparative Connections 8 (3): 2-4.

Perkins, Dwight. 1966. Market Control and Planning in Communist China. USA: Harvard University Press.

Peterson, Susan. 1995. "How Democracies Differ: Public Opinion, State Structure, and the Lessons of the Fashoda Crisis." Security Studies 5 (1): 3-37.

Perovic, Jeronim and Andrey Makarychev. 2000. "Institution Building in Russia's Regions: The Challenge of Transformation and the Role of Globalization Forces." Edoc.unibas.ch. Retrieved January 15, 2016 (https://edoc.unibas.ch/9546/).

Piseth, Chea and Chea Sophearin. 2014. "Assessment of Power Trade Benefits from Hydropower Projects in Lower Mekong River Basin," Pp.193-239 in Energy Market Integration in East Asia: Energy Trade, Cross Border Electricity, and Price Mechanism, edited by Fukunari Kimura and Han Phoumin. Indonesia: ERIA.

Platt, Jennifer. 1992. "'Case study' in American Methodological Thought." Current Sociology 40 (1): 17-48.

Posen, Barry. 1986. The Sources of Military Doctrine: France, Britain, and Germany between the World Wars. USA: Cornell University Press.

Potter, James and Deborah Levine-Donnerstein. 1999. "Rethinking Validity and Reliability in Content Analysis." Journal of Applied Communication Research 27: 258-284.

Punch, Keith. 1998. Introduction to Social Research: Quantitative and Qualitative Approaches. USA: SAGE.

Putnam, Robert. 1988. "Diplomacy and Domestic Politics: The Logic of Two-level Games." International Organization 42 (3): 427-460.

Pye, Lucian. 1990. “China: Erratic State, Frustrated Society." Foreign Affairs 69 (4): 56-74.

Qiao, Jian (乔健). 2001. “China's Employment Situation Viewed against the Background of Joining WTO (加入 WTO 背景下的中国职工状况)," Pp.331-346 in In 2001: China's Social Situation Analysis and Prediction (2001 年: 中国社会形势分析与预测), edited by Jiang Liu (江流) et al. China: China Social Sciences Press (社会科学文献出版社).

Qu, Yanlin (屈燕林). 2008. “The Active External Economic and Commercial Cooperation on Yunnan's Border: Thoughts on the Development in External Economic and Commercial Cooperation on Yunnan's Border in 2007 (活跃的云南边境对外经贸合作：2007年云 南边境对外经贸合作发展与思考)”, Pp.304-330 in Southeast Asian Report: 2007-2008 (东南亚报告：2007-2008), edited by Wang Shilu (王士录). China: Yunnan University Press (云南大学出版社).

Qu, Yanlin (屈燕林). 2009. “The External Economic and Commercial Cooperation on Yunnan's Border: Thoughts on the Development in External Economic and Commercial Cooperation on Yunnan's Border in 2007 (云南边境对外经贸合作：2008 年云南边境 对外经贸合作发展与思考)”, Pp.276-297 in Southeast Asian Report: 2008-2009 (东南 亚报告：2008-2009), edited by Wang Shilu (王士录). China: Yunnan University Press (云南大学出版社). 
Raphael, Israeli. 2002. Islam in China: Religion, Ethnicity, Culture, and Politics. USA: Lexington Books.

Rapley, Tim. 2007. Doing Conversation, Discourse and Document Analysis. USA: SAGE.

Ravenhill, John. 1999. "Federal-State Relations in Australian External Affairs: A New Cooperative Era?" Regional \& Federal Studies 9 (1): 134-152.

Reeves, Jeffrey. 2013. “China's Unravelling Engagement Strategy.” Washington Quarterly 36 (4): 139-149.

Reilly, James. 2012. "A Norm-Taker or a Norm-Maker? Chinese Aid in Southeast Asia." Journal of Contemporary China 21 (73): 71-91.

Reilly, James. 2013. "China and Japan in Myanmar: Aid, Natural Resources and Influence." Asian Studies Review. 37 (2): 141-157.

Reisen, Helmut. 2015. "Will the AllB and the NDB Help Reform Multilateral Development Banking?" Global Policy 6 (3): 297-304.

Requejo, Ferran. 2010. "Foreign Policy of Constituents Units in a Globalization World," Pp.11-13 in Foreign Policy of Constituents Units at the Beginning of 21st Century, edited by Ferran Requejo. Spain: Institut d'Estudis Autonòmics.

Richards, David. 1996. "Elite Interviewing: Approaches and Pitfalls." Politics 16 (3): 199-204.

Ripsman, Norrin, Jeffrey Taliaferro and Steven Lobell. 2016. Neoclassical Realist Theory of International Politics. UK: Oxford University Press.

Ritzer, George. 2016. The Blackwell Companion to Globalization. USA: Blackwell Publisher.

Rodrik, Dani. 1998. “Has Globalization Gone Too Far?” Challenge 41 (2): 81-94.

Roger, Hayter and Sun Shenghan. 1998. "Reflections on China's Open Policy toward Foreign Direct Investment." Regional Studies 31 (1): 1-16.

Rosenau, James. 1990. Turbulence in World Politics: A Theory of Change and Continuity. USA: Princeton University Press.

Rosenau, James. 1997. Along the Domestic-Foreign Frontier: Exploring Governance in a Turbulent World. UK: Cambridge University Press.

Ross, Robert. 2013. "US Grand Strategy, the Rise of China, and US National Security Strategy for East Asia." Strategic Studies Quarterly 7 (2): 20-40.

Rubin, Herbert and Riene Rubin. 1995. Qualitative Interviewing: The Art of Hearing Data. USA: SAGE.

Ruggie, John, 1986. "Continuity and Transformation in the World Polity: toward a Neorealist Synthesis" Pp.131-175 in Neorealism and Its Critics, edited by Robert Keohane. USA: Columbia University Press.

Rutan, Gerard. 1988. "Micro-diplomatic relations in the Pacific Northwest: Washington state-British Columbia interactions," Pp.187 in Perforated Sovereignties and International Relations, edited by Ivo Duchacek et al. USA: Greenwood Press. 
Sachs, Jeffrey and Andrew Warner. 1995. "Globalization and Economic Reform in Developing Countries." Brooking Papers on Economic Activity 1: 1-117.

Sandelowski, Margarete. 1995. "Qualitative Analysis: What It Is and How to Begin." Research in Nursing \& Health 18 (4): 371-375.

Sarychev, Sergei. 2001 "Regionalization of Russian Foreign and Security Policy: The Case of Kursk Oblast." Isn.ethz.ch. Retrieved December 18, 2015 (http://www.isn.ethz.ch/Digital-Library/Publications/Detail/?ots591=0c54e3b3-1e9cbe1e-2c24-a6a8c7060233\&lng=en\&id=367).

Schirm, Stefan. 2002. Globalization and the New Regionalism: Global Markets, Domestic Politics and Regional Cooperation. UK: Polity Press.

Schramm, Wilbur. 1971. "Notes on Case Studies of Instructional Media Projects." Eric.ed.gov. Retrieved May 5, 2018 (https://files.eric.ed.gov/fulltext/ED092145.pdf).

Schurmann, Franz. 1971. Ideology and Organization in Communist China. USA: California University Press.

Schwarz, Norbert et al. 1991. "The Impact of Administration Mode on Response Effects in Survey Measurement." Applied Cognitive Psychology 5 (2): 193-212.

Seawright, Jason and John Gerring. 2008. "Case Selection Techniques in Case Study Research: A Menu of Qualitative and Quantitative Options." Political Research Quarterly 61 (2): 294-308.

Segal, Gerald. 1994. "Deconstructing Foreign Relations," Pp.322-355 in China Deconstructs: Politics, Trade and Regionalism, edited by David Goodman and Gerald Segal. UK: Routledge.

Segal, Gerald. 1994. "Introduction: A Changing China and Asian-Pacific Security," Pp.1-19 in Chinese Regionalism: The Security Dimension, edited by Richard Yang et al. USA: Westview Press.

Setzer, Joana. 2013. "Environmental Paradiplomacy: The Engagement of the Brazilian State of São Paulo in International Environmental Relations." LSE Theses Online. Retrieved April 6, 2017 (http://etheses.Ise.ac.uk/839/).

Shambaugh, David. 2013. "Assessing the US 'Pivot' to Asia." Strategic Studies Quarterly 7 (2): 10-19.

Shambaugh, David. 2016. China's Future. UK: Polity Press.

Shambaugh, David. 2018. "US-China Rivalry in Southeast Asia: Power Shift or Competitive Coexistence?" International Security 42 (4): 85-127.

Shee, Poon Kim. 1997. "The Political Economy of China-Myanmar Relations: Strategic and Economic Dimensions." Southeast Asia 19 (1): 33-53.

Shen, Simon. 2007. Redefining Nationalism in Modern China: Sino-American Relations and the Emergence of Chinese Public Opinion in the 21st Century. USA: Springer.

Shiraishi, Masaya. 2009. "Japan toward the Indochina Sub-Region." Journal of Asia-Pacific Studies 13: 13-36. 
Siemiatycki, Jack. 1979. "A Comparison of Mail, Telephone, and Home Interview Strategies for Household Health Surveys." American Journal of Public Health 69 (3): 238-245.

Silverman, David. 2013. Doing Qualitative Research: A Practical Handbook. USA: SAGE.

Singh, Swaran. 2018. Mekong-Ganga Cooperation Initiative: Analysis and Assessment of India's Engagement with Greater Mekong Sub-Region. Thailand: Research Institute on Contemporary Southeast Asia.

Sjöstedt, Gunnar. 1977. The External Role of the European Community. UK: Saxon House.

Skalski, Paul, Kimberly Neuendorf and Julie Cajigas. 2002. "Content Analysis in the Interactive Media Age," Pp.201-403 in The Content Analysis Guidebook, edited by Kimberly Neuendorf. USA: SAGE.

Slaughter, Anne-Marie. 2004. A New World Order. USA: Princeton University Press.

Smith, Katherine. 2006. "Problematizing Power Relations in 'Elite' Interviews." Geoforum 37 (4): 643-653.

Snyder, Jack. 1991. Myths of Empire: Domestic Politics and International Ambition. USA: Cornell University Press.

Sodupe, Kepa. 1999. "The European Union and Inter-Regional Co-Operation." Regional \& Federal Studies 9 (1): 58-81.

Sohu.com (搜狐网). 2016. “The Holding of the Promotion of the Thailand's Chiangrai Economic Special Zone in Kunming (泰国清莱经济特区投资推介会在昆明举行).” Sohu.com (搜狐网). Retrieved March 27, 2018 (http://www.sohu.com/a/109361495 390221).

Sohu.com (搜狐网). 2017. “Tian Jun of the Deputy Party Secretary at the Kunming University of Science and Technology to Visit Yunnan's ORO in Phnom Penh (昆明理工 大学党委书记田军到访金边商务代表处)." Sohu.com (搜狐网). Retrieved March 30, 2018 (http://www.sohu.com/a/213636987 99894402).

Soldatos, Panayotis. 1990. "An Explanatory Framework for the Study of Federated States as Foreign-policy Actors", Pp.34-53 in Federalism and International Relations: The Role of Subnational Units, edited by Hans Michelmann and Panayotis Soldatos. UK: Oxford.

Songwanich, Suwatchai. 2016. "China Tackles the Issues of Greater Mekong Subergion." Nationmultimedia.com. Retrieved August 27, 2018 (http://www.nationmultimedia.com/opinion/China-tackles-the-issues-of-GreaterMekong-Subregi-30288555.html).

Soong, Jenn-Jaw. 2016. "The Political Economy of the GMS Development between China and Southeast Asian Countries: Geo-Economy and Strategy Nexus." The Chinese Economy 49 (6): 442-455.

Sotharith, Chap. 2007. “The Role and Function of the GMS in the CAFTA (在中国-东盟自由 贸易区的地位和作用)," Pp.67-89 in A Study on Economic Cooperation in Greater Mekong Subregion (大涺公河次区域经济合作研究), edited by Chai Yu (柴瑜), Lu Jianren (陆建人) and Yang Xianming (杨先明). China: Social Sciences Academic Press (社会科学文献出版社). 
Sotharith, Chap. 2010. "Trade, FDI, and ODA between Cambodia and China/Japan/Korea," Pp.20-44 in Economic Relations of China, Japan and Korea with the Mekong River Basin Countries, edited by Mitsuhiro Kagami. Thailand: Bangkok Research Center.

Spence, Jonathan. 1999. The Search for Modern China. USA: W.W. Norton.

Spiro, David. 1994. "The Insignificance of the Liberal Peace." International Security 19 (2): 50-86.

Stake, Robert. 2000. "Case Study," Pp.435-454 in Handbook of Qualitative Research, edited by Norman Denzin and Yvonna Lincoln. USA: SAGE.

State Council (国务院). 1984. The Measures for the Administration of Small-Volume Border Trade (边境小额贸易暂行管理办法). China: State Council (国务院).

State Council (国务院). 1992. The Notice of the State Council for Further Opening Nanjiang, Kunming and Five Border Counties (国务院关于进一步对外开放南宁、昆明市及凭 祥等五个边境城镇的通知). China: The State Council (国务院).

State Council (国务院). 2011. “Suggestion on the Support of Yunnan's Construction of the Westward Gateway (关于支持云南省加快建设面向西南开放重要桥头堡的意见).” Gov.cn (中国政府网). Retrieved September 17, 2019 (http://www.gov.cn/zwgk/201111/03/content_1985444.htm).

State Council (国务院). 2019. “The General Plan of China (Yunnan) Pilot Free Trade Zone (中 国<云南>自由贸易试验区总体方案)."Gov.cn (中国政府网). Retrieved from August 31, 2019 (http://www.gov.cn/zhengce/content/2019-08/26/content 5424522.htm).

State Council (国务院). 2019. “The General Plan of China (Guangxi) Pilot Free Trade Zone (中国<广西>自由贸易试验区总体方案)."Gov.cn (中国政府网). Retrieved from August 31, 2019 (http://www.gov.cn/zhengce/content/201908/26/content 5424522.htm).

State Council (国务院). 2016. “Suggestions of the State Council on Supporting the Development and Opening up in the Key Coastal Areas (国务院关于支持沿边重点地 区开发开放若干政策措施的意见).” Gov.cn (中央政府网). Retrieved January 12, 2018 (http://www.gov.cn/zhengce/content/2016-01/07/content_10561.htm).

Stern, Eve. 1994. “Moscow Meltdown: Can Russia Survive?” International Security 18 (4): 4065.

Straitstimes.com. 2018. "Myanmar Negotiated with Chinese Consortium on Deep-Sea Port Project in Rakhine State." Straitstime.com. Retrieved March 22, 2019 (https://www.straitstimes.com/asia/se-asia/myanmar-negotiating-with-chineseconsortium-on-deep-sea-port-project-in-rakhine-state).

Strand, Jonathan. 1999. "State Power in a Multilateral Context: Voting Strength in the Asian Development Bank." International Interactions 25 (3): 265-286.

Strange, Susan. 1996. The Retreat of the State: The Diffusion of Power in the World Economy. UK: Cambridge University Press. 
Strijbos, Jan-Willem et al. 2006. "Content Analysis: What are They Talking about?" Computers \& Education 46 (1): 29-48.

Sturges, Judith and Kathleen Hanrahan. 2004. "Comparing Telephone and Face-to-Face Qualitative Interviewing: A Research Note.” Qualitative Research 4 (1): 107-118.

Su, Changhe (苏长河). 2008. “Internationalization and Global Linkage: A Study of China's Glocalization (1978-2008) (国际化与地方的全球联系一中国地方的国际化研究 <1978-2008 年>)." World Economic and Politics (世界经济与政治) (11): 24-32.

Su, Changhe(苏长和). 2010. Chinese Local Government and Subregion Cooperation: Motivation, Behavior and Mechanism (中国地方政府与次区域合作: 动力, 行为及机 制)." World Economics and Politics (世界经济与政治) 357 (5): 4-24.

Sudo, Sueo. 2009. "Japan's ASEAN Policy: Reactive or Proactive in the Face of a Rising China in East Asia?" Asian Perspective 33 (1): 137-158.

Su, Xiaobo. 2012. "Rescaling the Chinese State and Regionalization in the Greater Mekong Subregion." Review of International Political Economy 19 (2): 501-527.

Su, Xiaobo. 2013. "From Frontier to Bridgehead: Cross-Border Regions and the Experience of Yunnan, China." International Journal of Urban and Regional Research 37 (4): 12131232.

Su, Xiaobo. 2014. "Multi-Scalar Regionalization, Network Connections and the Development of Yunnan Province, China." Regional Studies 48 (1): 91-104.

Su, Xiaobo. 2015. "Nontraditional Security and China's Transnational Narcotics Control in Northern Laos and Myanmar." Political Geography 48: 72-82.

Suehiro, Akira. 2017. "China's Offensive in Southeast Asia: Regional Architecture and the Process of Sinicization." Journal of Contemporary East Asia Studies 6 (2): 107-131.

Summers, Tim. 2008. "China and the Mekong Region." China Perspectives 75 (3): 68-77.

Summers, Tim. 2013. Yunnan-A Chinese Bridgehead to Asia: A Case Study of China's Political and Economic Relations with Its Neighbours. UK: Chandos Publishing.

Sun, Yun. 2012. "China's Strategic Misjudgement on Myanmar." Journal of Current Southeast Asian Affairs 31 (1): 73-96.

Sun, Yun. 2013. "China's Intervention in the Myanmar-Kachin Peace Talks." Asia Pacific Bulletin 200. Retrieved March 26, 2019

(https://scholarspace.manoa.hawaii.edu/bitstream/10125/25997/1/APB\%20no.200.p df).

Sung, Hsing-chou. 2015. "China's Economic Strategy: Toward the Riparian States of the Mekong Region," Pp.23-53 in Impact of China's Rise on the Mekong Region, edited by Yos Santasombat. UK: Palgrave Macmillan.

Suryadinata, Leo. 2007. Understanding the Ethnic Chinese in Southeast Asia. Singapore: ISEAS Publishing.

Swaine, Michael. 1994. "The Modernization of the Chinese People's Liberation Army: Prospects and Implications for Northeast Asia." NBR Analysis 5 (3). Retrieved March 27, 
2019 (https://www.nbr.org/publication/the-modernization-of-the-chinese-peoplesliberation-army-prospects-and-implications-for-northeast-asia/).

Swain, Margaret. 2002. "Looking South: Local Identities and Transnational Linkages in Yunnan," Pp.179-220 in Rethinking China's Provinces, edited by John Fitzgerald. UK: Routledge.

Swaine, Michael. 2012. "China's Assertive Behavior Part Three: The Role of the Military in Foreign Policy." China Leadership Monitor 36 (6): 1-17.

Swj.km.gov.cn (昆明市商务局网). 2019. “The Analysis on Kunming's External Trade Situation in 2018 (昆明市 2018 年外贸运行分析).” Swj.km.gov.cn (昆明市商务局网). Retrieved August 17, 2019 (http://swj.km.gov.cn/c/2019-01-23/2886952.shtml).

Swtzb.yn.gov.cn. 2015 (云南省委统战部). “The Main Tasks of the Yunnan Provincial United Front Work Department.” Swtzb.yn.gov.cn (云南省委统战部). Retrieved February 8, 2018 (http://www.swtzb.yn.gov.cn/bbgk/zyzn/201503/t20150303 306893.html).

Talbot, Ian. 2017. A History of Modern South Asia. UK: Oxford University Press.

Tashakkori, Abbas and Charles Teddlie. 1998. Mixed Methodology: Combining Qualitative and Quantitative Approaches. USA: SAGE.

Tian, Xinqing (田昕清). 2018. “The Facilitation of Trade and Investment under the LMC (澜 湄合作框架下的贸易和投资便利化研究).” International Studies (国际问题研究) 2: 55-67.

Touch, Darren. 2018. "Why Japan is Supporting Cambodia's Election?" Lowyinstitute.org. Retrieved August 20, 2018 (https://www.lowyinstitute.org/the-interpreter/why-japansupporting-cambodias-election).

Tubilewicz, Czeslaw and Kanishka Jayasuriya. 2015. "Internationalisation of the Chinese Subnational State and Capital: The Case of Yunnan and the Greater Mekong Subregion." Australian Journal of International Affairs 69 (2): 185-204.

Tubilewicz, Czeslaw. 2016. "Paradiplomacy as a Provincial State-Building Project: The Case of Yunnan's Relations with the Greater Mekong Subregion." Foreign Policy Analysis: 1-19.

UNDP. 2002. "Economic Cooperation among Developing Countries in the Lancang-Mekong Subregion: An Introduction." Paper presented in the seminar on Lancang-Mekong Subregional Free Trade Experiment \& Demonstration zone, held in Kunming, Yunnan China, 5 April 2002: 19.Vidich, Arthur. 1955. "Participant Observation and the Collection and Interpretation of Data." American Journal of Sociology 60 (4): 354-360.

Vogel, Ezra. 2011. Deng Xiaoping and the Transformation of China. USA: Harvard University Press.

Wade, Geoffrey. 2011 “Wade Could ASEAN Drift Apart?” Yale Global Online 12. Retrieved September 8, 2018 (https://yaleglobal.yale.edu/content/could-asean-drift-apart).

Wallander, Celeste. 2007. "Russia: The Domestic Sources of a Less-than-grand Strategy," Pp.139-176 in Domestic Political Change and Grand Strategy, edited by Ashley Tellis and Michael Wills. USA: The National Bureau of Asian Research.

Malik, Preet. 2015. My Myanmar Years: A Diplomat's Account of India's Relations with the Region. USA: SAGE. 
Walt, Stephen. 1990. The Origins of Alliance: The Origins of Alliances. USA: Cornell University Press.

Waltz, Kenneth. 1979. Theory of International Politics. USA: McGraw-Hill Education.

Wan, Ming. 1995. "Japan and the Asian Development Bank." Pacific Affairs 68 (4) 509-528.

Wan, Ming. 2016. The Asian Infrastructure Investment Bank: The Construction of Power and the Struggle for the East Asian International Order. USA: Springer.

Wang, Shilu (王士录). 2012. "Solidarity, Cooperation and Development Becoming a Theme of the Sino-ASEAN Relationship (团结、合作、发展成为中国-东盟关系的主旋律)”, Pp.249-286 in Southeast Asian Report: 2011-2012 (东南亚报告：2011-2012), edited by Wang Shilu (王士录). China: Yunnan University Press (云南大学出版社).

Wang, Weikun (王玮琨). 2014. “Active Enhancement of Economic Cooperation: The Summary of Yunnan-ASEAN Economic and Commercial Cooperation in 2013 (2013 年 云南省参与大湄公河次区域 (GMS) 合作进展情况综述)", Pp.247-253 in Southeast Asian Report: 2013-2014 (东南亚报告：2013-2014), edited by Lei Zhuning (雷著宁). China: Yunnan University Press (云南大学出版社).

Wang, Weizhong (王伟忠), Wu Yingmei (吴映梅) and Yang Lin (杨琳). 2011. “The ExternallyOriented Economic Development and Strategic Selection of the Central Yunnan Urban Cluster (滇中城市群外向型经济发展分析与战略选择)." Foreign Investment in China (中国外资) 2: 6-8.

Wang, Xin (王欣). 2013. “The Application of Culture in Local Foreign Affairs: The Case of Shanghai (文化外交在地方外适中的影响: 以上海为例). MA, Fudan University.

Wang, Yi (王毅). 2007. Century Negotiations: In the Days Involved with GATT/WTO (世纪谈 判：在复关/入世谈判的日子里). China: Century Party School Press (中共中央党校出 版社).

White, Domas and Emily Marsh. 2006. "Content Analysis: A Flexible Methodology." Library Trends 55 (1): 22-45.

Whyn.gov.cn (云南省文化和旅游厅). “The Holding of Yunnan-Northern Laos WT Meeting in Jinghong (中国云南-老挝北部合作工作组第八次会议在景洪成功举办)."

Whyn.gov.cn (云南省文化和旅游厅). Retrieved March 26, 2019 (http://www.whyn.gov.cn/list/view/1/6249).

Wildhaber, Luzius. 1990. "Switzerland," Pp.245-275 in Federalism and International Relations: The Role of Subnational Units. UK: Clarendon Press.

Wilson, Kate, Brenda Roe, and Lynette Wright. 1998. "Telephone or Face-to-Face Interviews? A Decision Made on the Basis of a Pilot Study." International Journal of Nursing Studies 35 (6): 314-321.

Wong, Audrye. 2018. “More than Peripheral: How Provinces Influence China's Foreign Policy." The China Quarterly 235: 735-757.

Womack, Brantly and Zhao Guangzhi. 1994. "The Many World of China's Provinces: Foreign Trade and Diversification," Pp.131-176 in China Deconstructs: Politics, Trade and Regionalism, edited by David Goodman and Gerald Segal. UK: Routledge. 
Wu, Jialun (伍加伦) and Jiang Yuxiang (江玉祥). 1990. Research on the Ancient Southwestern Silk Road (古代西南丝绸之路研究). China: Sichuan University Press (四 川大学出版社).

Wu, Xingnan (吴兴男). 1997. Yunnan's External Trade: From Traditional to Contemporary Process (云南对外贸易一从传统到近代化的历程). China: The Nationalities Publishing House of Yunnan (云南民族出版社).

Wunderlich, Uwe. 2008. "The EU-A Post-Westphalian Actor in a Neo-Westphalian World?" Uaces.org. Retrieved April 15, 2017 (https://www.uaces.org/documents/papers/0801/2008 JUWunderlich.pdf).

Xiao, Zujing (肖组经). 1988. “The Central Gives Policy, Yunnan Has to be Braver (中央给政 策 云南胆子要大).” Yunnan Daily (云南日报), April 5.

Xie, Benshu (谢本书). 1993. The Contemporary History of Yunnan (云南近代史). China: Yunnan People Publishing Housing (云南人民出版社).

Xinhuanet.com (新华网). 2008. “The Review of the GMS Cooperation (大湄公河次区域境 界合作回顾)." Cri.cn (国际在线). Retrieved February 18, 2018 (http://news.cri.cn/gb/18504/2008/03/28/145@1999184.htm).

Xinhuanet.com. 2013. "China Provides Agricultural Engines Cambodia for Post-Flood Rehabiliatation." Globaltimes.cn. Retrieved June 27, 2017 (http://www.globaltimes.cn/content/829248.shtml).

Xinhuanet.com (新华网). 2016. “Yunnan and Four Northern Vietnam's Provinces to Deepen Cooperation (云南与越南北部四省深化交流合作).” Xinhuanet.com (新华网). Retrieved March 19, 2018 (http://www.xinhuanet.com/world/201612/26/c 129420896.htm).

Xinhuanet.com (新华网). 2017. “The Eighth Conference of Five Provinces of China and Vietnam to Conclude Several Agreements (第八次中越五省市经济走廊合作会议签 署多项协议)." Xinhuanet.com (新华网). Retrieved February 25, 2018 (http://www.xinhuanet.com/2017-11/24/c 1122008173.htm).

Xinhuanet.com (新华网). 2017. Yunnan and the Four Provinces in Northern Vietnam Agreed to Protect Forest and Widelife. Xinhuanet.com (新华网). Retrieved August 15, 2019 (http://www.yn.xinhuanet.com/2016ynnews/20170114/3621740_c.htm).

Xinhuanet.com. 2018. "Lancang-Mekong Countries to Deepen Water Resources Cooperation." Xinhuanet.com. Retrieved August 9, 2019 (http://www.xinhuanet.com/english/2018-11/03/c_137577584.htm).

Xiong, Bin and Wen Shuhui. 2009. "Towards a Better Understanding of the Political Economy of Regional Integration in the GMS: Stakeholder Coordination and consultation for Subregional Trade Facilitation in China." ARTNeT Working Paper Series 77. Retrieved April 12, 2018 (https://www.econstor.eu/bitstream/10419/64264/1/615909906.pdf).

Xiong, Bin and Xuan Juneng. 2013. "Assessing the Impact of GMS Trade on Poverty Reduction in Yunnan Province, China", Pp.59-98 in Assessing China's Impact on Poverty in the Greater Mekong Subregion, edited by Hossein Jalilian. Singapore: Institute of Southeast Asian Studies. 
Yahuda, Michael. 1994. "North China and Russia," Pp.253-270 in China Deconstructs: Politics, Trade and Regionalism, edited by David Goodman and Gerald Segal. UK: Routledge.

Yahya, Faizal. 2003. "India and Southeast Asia: Revisited." Contemporary Southeast Asia: 79103.

Yang, Dali. 1991. "China Adjusts to the World Economy: The Political Economy of China's Coastal Development Strategy." Pacific Affairs 64 (1): 42-64.

Yang, Dali. 1994. "Reform and the Restructuring of Central-Local Relations," Pp.59-98 in China Deconstructs: Politics, Trade and Regionalism, edited by David Goodman and Gerald Segal. UK: Routledge.

Yang, George. 1995. "Mechanisms of Foreign Policy-Making and Implementation in the Ministry of Foreign Affairs," Pp.91-100 in Decision-Making in Deng's China Perspective from Insiders, edited by Carol Lee Hamrin et al. UK: Taylor \& Francis Group.

Yang, Guangbin. 2014. "Decentralization and Central-Local Relations in Reform-Era China," Pp.254-281 in China's Political Development: Chinese and American Perspectives, edited by Kenneth Lieberthal and Cheng Li. USA: Brookings Institution Press.

Yang, Hongchang (杨洪常). 2001. Yunnan and GMS: The Development of Chinese Local Autonomy (云南省与湄公河区域合作: 中国地方自主性的发展). Hong Kong: Chinese University Press (香港中文大学出版社).

Yang, Ming (杨明). 2005. “Analysis on Yunnan's Advantageous Industries for Developing Economic and Commercial Relationship with ASEAN (云南发展与东盟经贸关系的优 势产业分析)”，Pp.222-234 in Southeast Asian Report: 2003-2004 (东南亚报告：20042005), edited by Wang Shilu (王士录). China: Yunnan University Press (云南大学出版 社).

Yfao.gov.cn (云南外办). 2015. “Banteay Meanchey Province of Cambodia (柬埔寨班迭棉吉 省).” Yfao.gov.cn (云南外办). Retrieved March 16, 2018 (http://www.yfao.gov.cn/yhcs1/201510/t20151013 334303.html).

Yfao.gov.cn (云南外办). 2015. “Chiangrai of Thailand (泰国清莱府).” Yfao.gov.cn (云南外 办). Retrieved March 27, 2018 (http://www.yfao.gov.cn/yhcs1/201510/t20151013 334315.html).

Yfao.gov.cn (云南外办). 2015. “Siem Reap of Cambodia (柬埔寨暹粒省).” Yfao.gov.cn (云南 外办). Retrieved March 16, 2018 (http://www.yfao.gov.cn/yhcs1/201510/t20151013 334319.html).

Yfao.gov.cn (云南外办). 2017. “Yunnan Foreign, Hong Kong, Macau Affairs Yearbook: 2018 (2018 年度云南省外事港澳年鉴).” Yfao.gov.cn (云南外办). Retrieved August 11， 2019 (http://www.yfao.gov.cn/ynwb/wsganj/201908/t20190806 882674.html).

Yin, Robert. 1994. Case Study Research, Design and Methods ( $2^{\text {nd }}$ ed). USA: Sage.

Yin, Robert. 2003. Case Study Research, Design and Methods ( $3^{\text {rd }}$ ed). USA: Sage.

Ynada.org (云南省替代种植发展行业协会). “The Introduction of Association (协会简介).” Ynada.org (云南省替代种植发展行业协会). Retrieved August 10, 2019 (http://www.ynada.org/about.xhtml). 
Ynnu.edu.cn (云南师范大学). 2017. “The President of Chiangrai Rajabhat University to Visit Our University (泰国清莱皇家大学校长颂差一行发问我学校).” Ynnu.edu.cn (云南师 范大学). Retrieved March 27, 2018 (http://www.ynnu.edu.cn/info/1099/16270.htm).

Ynqb.net.cn (云南侨办). 2017. “Provincial Overseas Chinese Affairs Office to Visit Poor

Chinese Returnees in Wenshan Prefecture before the Spring Festival (省侨办慰问组到 文山州开展困难归侨侨眷春节慰问走访活动).” Ynqb.net.cn. (云南侨办). Retrieve February 7, 2018

(http://www.ynqb.net.cn/htmlweb/qiaoban/2017/0119/news_2 40973.html).

Ynqb.net.cn (云南侨办). 2018. “The Leaders of the Provincial Overseas Chinese Affairs

Office and the Division of Labors (省侨办领导及工作分工)." Ynqb.net.cn. (云南侨办).

Retrieve February 7, 2018

(http://www.ynqb.net.cn/htmlweb/qiaoban/2018/0119/news 2 78715.html).

Ynstc.gov.cn (云南省科技厅). 2015. “The Holding of the 2015 Conferences of the Council, Steering Committee and Secretariat at the Mekong Institute (湄公学院 2015 年理事 会、指导委员会和协调机构会议在泰国孔敬召开)." Ynstc.gov.cn (云南省科技厅). Retrieved March 2, 2018 (http://www.ynstc.gov.cn/zhisdwgzdt/201507280010.htm).

Yoshimatsu, Hidetaka. 2010. "The Mekong Region, Regional Integration, and Political Rivalry among ASEAN, China and Japan." Asian Perspective 24 (3): 71-111.

Yoshimatsu, Hidetaka. 2015. "The United States, China, and Geopolitics in the Mekong Region." Asian Affairs: An American Review 42 (4): 173-194.

You, Zhong (尤中). 1994. Yunnan National History (云南民族史). China: Yunnan University Press (云南大学出版社).

Yu, Hong. 2017. “Motivation behind China's 'One Belt, One Road' Initiatives and Establishment of the Asian Infrastructure Investment Bank." Journal of Contemporary China 26 (105): 353-368.

Yunnan Daily (云南日报). 2004. “The Holding of the First Conference of the YunnanNorthern Thailand Working Group (云南-泰北合作工作组第一次会议开幕).” Sina.com (新浪网). Retrieved March 19, 2018 (http://news.sina.com.cn/c/2004-0407/12192250079s.shtml).

Yunnan Daily (云南日报). 2007. “The Holding of the First Yunnan-Myanmar Cooperation Forum (滇缅经贸合作论坛第一次会议举行)." Sina.com (新浪网). Retrieved March 27, 2018 (http://news.sina.com.cn/c/2007-06-05/101611962243s.shtml).

Yunnan Daily (云南日报). 2010. “Chinese Businessmen to Play a Big Role in the Construction of the Gateway (建设桥头堡华商大有可为).” Yunnan Daily (云南日报), July 7, p. 5.

Yunnan Daily (云南日报). 2010. "Yunnan and CNPC to Conclude Strategic Cooperation Agreement (云南与中石油签署战略合作协议).” 163.com. Retrieved December 17， 2018 (http://news.163.com/10/0910/06/6G6TLKFG00014AEE.html).

Yunnan Daily (云南日报). 2012. “Yunnan and Vietnam to Sign Seven Bilateral Cooperation Projects (云南省与越南双方签署 7 个双边合作项目)." Chinadaily.com (中国日报). Retrieved March 22, 2018 (http://www.chinadaily.com.cn/hqgi/jryw/2012-0404/content 5604825.html). 
Yunnan Daily (云南日报). 2015. “Catching Opportunity and Expanding Opening: To Take Effort to Become the New Highland of External Opening and South and Southeast AsiaOriented Radiation Centre (抓住机遇、扩大开放：努力成为我国对外开放新高地和 面向南亚东南亚辐射中心)." Yunnan Daily (云南日报), April 9, p. 4.

Yunnan Daily (云南日报). 2016. “Chen Hao to Host the Meeting to Promote the Construction of Cross-border Economic Cooperation Zones (陈豪主持召开跨境经济 合作区建设推进会议)." People.com.cn (人民网). Retrieved March 29, 2018 (http://cpc.people.com.cn/n1/2016/0824/c117005-28662785.html).

Yunnan Daily (云南日报). 2016. “The Holding of the Sino-ASEAN Foreign Ministers' Meeting in Yunnan and the Holding of Welcoming Banquet by Li Jiheng (中国-东盟国家外长特 别会议在云南举行 李纪恒举行欢迎宴会)." Yunnan Daily (云南日报). Retrieved August 8, 2018 (http://cpc.people.com.cn/n1/2016/0615/c117005-28448018.html).

Yunnan Daily (云南日报). 2017. “The New Leaf for the Yunnan and Vietnam to Deepen Cooperation (滇越深化合作开新篇).” Yn.gov.cn. Retrieved December 3, 2017 (http://wldj.yn.gov.cn/NewsView.aspx?NewsID=228271).

Yunnan Daily (云南日报). 2017. “Yunnan's ORO in Phnom Penh: The Bridge of Cooperation between Yunnan and Cambodia (云南驻金边商务代表处：搭建滇缅合作桥梁).” Sohu.com (搜狐网). Retrieved March 26, 2019 (http://www.sohu.com/a/213394878 179633).

Yunnan Daily (云南日报). 2019. “The Total Trade Value of Yunnan in 2018 Reached RMB 19.73 Million (2018 年云南外贸进出口总值达 1973 亿元).” Gov.cn (中央政府网). Retrieved August 17, 2019 (http://www.gov.cn/shuju/201901/16/content_5358275.htm).

Yunnan Provincial Government (云南省政府). 1994. Yunnan Almanac 1994 (云南年鉴 1994). China: Yunnan Almanac Press (云南年鉴社).

Yunnan Provincial Government (云南省政府). 2000. Yunnan Almanac 2001 (云南年鉴 2000). China: Yunnan Almanac Press (云南年鉴社).

Yunnan Provincial Government (云南省政府). 2001. Yunnan Almanac 2001 (云南年鉴 2001). China: Yunnan Almanac Press (云南年鉴社).

Yunnan Provincial Government (云南省政府). 2002. Yunnan Almanac 2002 (云南年鉴 2002). China: Yunnan Almanac Press (云南年鉴社).

Yunnan Provincial Government (云南省政府). 2003. Yunnan Almanac 2003 (云南年鉴 2003). China: Yunnan Almanac Press (云南年鉴社).

Yunnan Provincial Government (云南省政府). 2004. Yunnan Almanac 2004 (云南年鉴 2004). China: Yunnan Almanac Press (云南年鉴社).

Yunnan Provincial Government (云南省政府). 2005. Yunnan Almanac 2005 (云南年鉴 2005). China: Yunnan Almanac Press (云南年鉴社).

Yunnan Provincial Government (云南省政府). 2006. Yunnan Almanac 2006 (云南年鉴 2006). China: Yunnan Almanac Press (云南年鉴社).

Yunnan Provincial Government (云南省政府). 2007. Yunnan Almanac 2007 (云南年鉴 2007). China: Yunnan Almanac Press (云南年鉴社). 
Yunnan Provincial Government (云南省政府). 2008. Yunnan Almanac 2008 (云南年鉴 2008). China: Yunnan Almanac Press (云南年鉴社).

Yunnan Provincial Government (云南省政府). 2009. Yunnan Almanac 2009 (云南年鉴 2009). China: Yunnan Almanac Press (云南年鉴社).

Yunnan Provincial Government (云南省政府). 2010. Yunnan Almanac 2010 (云南年鉴 2010). China: Yunnan Almanac Press (云南年鉴社).

Yunnan Provincial Government (云南省政府). 2013. Yunnan Almanac 2013 (云南年鉴 2013). China: Yunnan Almanac Press (云南年鉴社).

Yunnan Provincial Government (云南省政府). 2014. Yunnan Almanac 2014 (云南年鉴 2014). China: Yunnan Almanac Press (云南年鉴社).

Yunnan Provincial Government (云南省政府). 2015. Yunnan Almanac 2015 (云南年鉴 2015). China: Yunnan Almanac Press (云南年鉴社).

Yunnan Provincial Government (云南省政府). 2016. Yunnan Almanac 2016 (云南年鉴 2016). China: Yunnan Almanac Press (云南年鉴社).

Yunnan Provincial Government. 2016. “Suggestion on Yunnan's Construction of the Financial Service Centre of South and Southeast Asia (云南省人民政府关于建设面向南亚东南 亚金融服务中心的实施意见).” Gov.cn (中国政府网). Retrieved September 17, 2019 (http://www.gov.cn/xinwen/2016-12/11/content 5146437.htm\#1).

Yunnan.cn (云南网). 2009. "The Fifth Anniversary of the Foundation of the China-Northern Laos Cooperation Mechanism: The Gradual Improvement of the Construction of the Mechanism (中老北部合作机制建立 5 年 机制建设不断完善).” 163.com. Retrieved November 15, 2018 (http://news.163.com/09/0709/09/5DP82OF0000120GR.html).

Yunnan.cn (云南网). 2012. “The Meeting between the Yunnan Provincial Party Committee and the Provincial Government and CNPC in Beijing (云南省委省政府与中石油在京举 行座谈会)." Yn.gov.cn (云南政府网). Retrieved March 26, 2019 (http://www.yn.gov.cn/yn_zwlanmu/yn_zwdt/201203/t20120305_3404.html).

Yunnan.cn. 2012 (云南网). “Lu Jiheng to Meet Provincial Governor of Siem Reap Sou Phirin (李纪恒会见暹粒省省长苏比伦).” Yunnan.cn. 2012 (云南网). Retrieved March 16, 2018 (http://yn.yunnan.cn/html/2012-04/05/content 2129717.htm).

Yunnan.cn. 2012 (云南网). "Yunnan and Banteay Meanchey to Sign an Agreement to Jointly Build the Agricultural Technology Friendship Demonstration Park (云南与班迭棉吉签 署协议共建农业科技有意示范园).” Yunnan.cn (云南网). Retrieved April 1, 2018 (http://yn.yunnan.cn/html/2012-04/06/content 2131827.htm).

Yunnan.cn (云南网). 2012. “Yunnan and Vietnam to Promote Cooperation: Yunnan and Four Border Provinces in Northern Vietnam to Sign Police Affairs Memorandums (推动滇越 合作: 云南与越北边境 4 省签署警务备忘录)." Yunnan.cn (云南网). Retrieved March 17, 2018 (http://yn.yunnan.cn/html/2012-06/03/content 2232100.htm).

Yunnan.com (云南网). 2014. "Yunnan Acquires Four Opportunities from the Belt \& Road Initiative (“一带一路'云南迎 4 机遇).” Yunnan.cn (云南网). Retrieved August 15, 2018 (news.ifeng.con/a/20140707/41046234_0.shtml). 
Yunnan.cn (云南网). 2015. “The Launching of the China-Thailand Railway: Yunnan to Become the Hub in the Rail System (中泰铁路项目启动云南将变身铁路枢纽中心)." Yunnan.cn (云南网). Retrieved March 10, 2018 (http://yn.yunnan.cn/html/201512/20/content 4075445.htm).

Yunnan.cn (云南网). 2017. "Yunnan and Myanmar to Share Legal Information to Promote the Investment of Yunnan's Enterprises in Myanmar (滇缅共享法律信息 促进滇企在 缅投资)." Yunnan.cn (云南网). Retrieved March 30, 2018 (http://yn.yunnan.cn/html/2017-11/28/content_5005034.htm).

Yunnan.cn (云南网). 2017. “A New Phase: The Holding of the Fifth Yunnan-Myanmar Cooperation Forum in Kunming (第五届中国云南-缅甸合作论坛在昆举行: 推动滇缅 合作迈向新阶段).” Yunnan.cn (云南网). Retrieved March 26, 2019 (http://yn.yunnan.cn/html/2018-04/04/content 5150306.htm).

Zhang, Hong (张鸿). 2003. "The Accession to the WTO and the Selection of Development Models for the Western Development (入世与我国西部大开发的发展模式选择).” International Business Research (国际商务研究) 1: 25-29.

Zhang, Hong (张鸿). 2003. "The Policy Adjustment for China's Accession to the WTO and Western Development (加入 WTO 与我国西部大开发的政策调整).” Probe (探索) 3:124-126.

Zhang, Huaidong (张怀东). 2014. “Seven Standing Committee Attending High-Level Meeting on Foreign Works, Three Uncommon Signals Indicating Change (七常委超规格开外事 会三大反常信号酿变动)." Dwnews.com. Retrieved September 3, 2017 (http://news.dwnews.com/global/news/2014-11-30/59621246.html).

Zhang, Huaizhi (张怀志) et al. 2014. "The Analysis on the Compatibility between Economic Linkage and Geopolitical Economy in the Central Yunnan Urban Cluster (滇中城市群空 间经济联系与地缘经济关系匹配研究)." Area Research and Development (地域研究 与开发) 33 (2): 16-19.

Zhao, Hong. 2008. "China and India: Competing for Good Relations with Myanmar." The Journal of East Asian Affairs: 175-194.

Zhao, Suisheng. 2008. "China's Global Search for Energy Security: Cooperation and Competition in Asia-Pacific." Journal of Contemporary China 17 (55): 207-227.

Zhang, Guobao (张国宝). 2017. “The Sino-Myanmar Oil and Gas Pipelines: Taking Ten Years to Sharpen a Sword (中缅油气管道十年磨一剑).” Cnpc.com.cn (中石油). Retrieved November 21, 2018 (http://news.cnpc.com.cn/system/2017/05/04/001645382.shtml).

Zheng Yongnian. 1999. Discovering Chinese Nationalism in China: Modernization, Identity, and International Relations. UK: Cambridge University Press.

Zheng, Weidong (郑卫东) and Zhang Zhe (张哲). 2007. Yunnan Serves Grand Diplomacy (云 南服务大外交). China: Yunnan Nationalities Publishing House (云南民族出版社).

Zheng, Yongnian. 1994. "Perforated Sovereignty: Provincial Dynamism and China's Foreign Trade." The Pacific Review 7 (3): 309-321.

Zheng, Yongnian. 2007. De Facto Federalism in China: Reforms and Dynamics of Centrallocal Relations. Singapore: World Scientific Publishing. 
Zhou, Xiaobing (周小兵). 2007. “The Development of Small Regional Cooperation in East Asia (东亚小区域合作的发展)," Pp.54-63 in in A Study on Economic Cooperation in Greater Mekong Subregion (大湄公河次区域经济合作研究), edited by Chai, Yu (柴 瑜), Lu Jianren (陆建人) and Yang Xianming (杨先明). China: Social Sciences Academic Press (社会科学文献出版社).

Zhou, Feiya (周菲娅). 2014. “Let the Blossom of Poppy Become History: Report on Our Province's Undertaking of Substitution Programme in Northern Myanmar and Laos (让 罂粟花开成为历史: 我生在缅甸老挝北部替代种植侧记)." Yunnan Law News (云南 法制报). Retrieved April 29, 2018 (http://www.ynjd.org/PolLawWorks/daitzz/201402193703.shtml).

Zhu, Yinggeng. 1992. “Liberate Thoughts to Accelerate Yunnan's Opening up towards Southeast Asia (解放思想加快云南队东南亚开放的步伐)." The Thought Front (思想 阵线) (4): 19-20.

Zhu, Zhenming. 2010. "Mekong Development and China's (Yunnan) Participation in the Greater Mekong Subregion Cooperation." Ritsumeikan International Affairs 8: 1-16.

Zhu, Zhiqun. 2005. "Regional Influence in China's U.S. Policy Making: The Roles of Shanghai and Wang Daohan," Pp.209-227 in China's Foreign Policy Making: Societal Force and Chinese American Policy, edited by Yufan Hao and Lin Su. USA: Ashgate Publishing Limited.

Zinberg, Yakov. 1995. "Subnational Diplomacy: Japan and Sakhalin." Journal of Borderlands Studies 10 (2): 87-108.

Zuckerman, Harriet. 1972. "Interviewing an Ultra-Elite." Public Opinion Quarterly 36 (2): 159-175. 


\section{Appendices}

Appendix 1: Summary of research question and arguments

\section{Research Question How has Yunnan province in China become an international relations actor?}

Chapter 4

The Chinese central government has motivated Yunnan to conduct

Argument 1

certain external affairs against a background of new domestic

developments.

Chapter 5

Yunnan's empowerment in contending with cross-border economic

Argument 2

and security issue is also driven by a combination of domestic

factors: the stimulation of the open borders policy and the

inefficiency of China in macroeconomic and border management.

Chapter 6

New external affairs powers have enabled Yunnan to leverage its

Argument 3

broad instruments (infrastructure development, economic

statecraft, and diplomatic efforts) to make it more appealing for

neighbouring countries to cooperate with it.

Chapter 7

The increased external capability of Yunnan has driven the

Argument 4

recognition of its international actorness by third parties 


\section{Appendix 2: The list of localities within Yunnan}

\begin{tabular}{|c|c|c|c|}
\hline Division & Area $/ \mathrm{km}^{2}$ & $\begin{array}{l}\text { Population } \\
\text { in } 2010\end{array}$ & $\begin{array}{l}\text { GDP of } 2017(100 \\
\text { million in RMB) }\end{array}$ \\
\hline Kunming city & $21,001.28$ & $6,432,209$ & 4857.64 \\
\hline Qujing city & $28,939.41$ & $5,855,055$ & 1941.12 \\
\hline Yuxi city & $14,941.53$ & $2,303,518$ & 1415.14 \\
\hline Baoshan city & $19,064.60$ & $2,506,491$ & 678.94 \\
\hline Zhaotong city & $22,439.76$ & $5,213,521$ & 832.45 \\
\hline Lijiang city & $20,557.25$ & $1,244,769$ & 339.48 \\
\hline Puér city & $44,264.79$ & $2,542,898$ & 624.59 \\
\hline Lijiang city & $23,620.72$ & $2,429,497$ & 339.48 \\
\hline Chuxiong Autonomous Prefecture & $28,436.87$ & $2,687,169$ & 937.37 \\
\hline Honghe Autonomous Prefecture & $32,167.67$ & $4,500,896$ & 1478.57 \\
\hline Wenshan Autonomous Prefecture & $31,409.12$ & $3,517,946$ & 809.11 \\
\hline Xishuangbanna Autonomous Prefecture & $19,107.05$ & $1,133,515$ & 393.84 \\
\hline Dali Autonomous Prefecture & $28,299.43$ & $3,456,323$ & 1066.55 \\
\hline Dehong Autonomous Prefecture & $11,171.41$ & $1,211,440$ & 356.97 \\
\hline Nujiang Autonomous Prefecture & $14,588.92$ & 534,337 & 141.50 \\
\hline Diqing Autonomous Prefecture & $23,185.59$ & 400,182 & 198.65 \\
\hline
\end{tabular}




\section{Appendix 3: Interview Guide}

\section{Yunnan paradiplomatic activities with neighbouring countries - English version}

Section A. General information about paradiplomatic activities

1. What forms of paradiplomatic interactions are undertaken?

(1). When do they take place?

(3). What kind of activities are they?

(4). What do you think the correlation between the external affairs powers of the Chinese provincial government and Beijing's decentralization and economic reform?

(5). What do you think the correlation of the external affairs powers of the Chinese provincial governments and the vagaries of the external environment?

Section B. Diplomatic resources

2. What diplomatic resources are possessed by the province?

(6). How does Yunnan derive these resources?

(7). Under what circumstances could Yunnan materialize these resources?

(8). Is there a specific department/person in charge of external interactions?

(9). Can you assess whether there are some advantages of disadvantages inherent in Yunnan's paradiplomacy compared to national diplomacy? (10). What are challenges encountered?

(11). What is the scope of autonomy in conducting external affairs?

Section C. Cooperation

3. What issues are involved in the cross-border cooperation? (12). How is the scope of cooperation determined?

(13). What kind of issues dose Yunnan select to undertake?

(14). What strategies does Yunnan choose to attend to these issues?

(15). Do you think China's relations with neighboring countries is influenced by paradiplomatic initiatives; if so, how?

ii. Yunnan paradiplomatic activities with neighbouring countries - Chinese version 


\section{A. 背景信息}

1. 次国家外交有哪些形式?

(1). 什么时间进行这些活动?

(2). 这些活动具有哪些类型?

(3). 次国家外交的兴起同国内政经环境有何关联?

(5). 外部环境如何刺激或影响次国家外交?

B. 外交资源

2. 次国家外交具有哪些资源?

(6). 云南如何获得这些外交资源？

(7). 在什么情况下可以运用这些资源?

(8). 是否有某一机构/个人负责全省的对外工作?

(9). 您能否评估次国家外交的优劣势, 尤其同国家级外交比较? (10). 对外交流中遇到哪些挑战?

(11). 次国家外交自主权的边际在哪里?

C. 合作领域

3. 次国家级政府参与对外合作的领域有哪些

(12). 哪些因素决定这些范畴的选择？

(13). 具体参与了哪些领域的合作?

(14). 参与这些领域合作的策略是什么?

(15). 次国家外交如何影响国家间交往? 


\section{Appendix 4: List of Interviewees}

Category

Academic

Academic

Academic

Academic

Provincial

official

Provincial

official

Provincial

official

Provincial

official

Provincial

official

Provincial

official

Provincial

official

Academic

IGO

IGO

Foreign official
No. Institutional Affiliation

Date

1 International Relations School, Yunnan University

2 International Relations School, Yunnan University

3 International Relations School, Yunnan University

4 GMS Centre, Yunnan University

Kunming, 10/2016

5 Division for Economic and Commerce,

Kunming, 10/2016 Yunnan provincial Development and Reform Commission

6 Division for Key Projects Construction,

Kunming, 10/2016 Yunnan provincial Development and Reform Commission

7 Division for Policy Research, Yunnan Kunming, 10/2016 provincial Foreign Affairs Office

8 International Regional Cooperation Office, Yunnan provincial Foreign Affairs Office

9 International Regional Cooperation

Kunming, 11/2016 Office, Yunnan provincial Foreign Affairs Office

10 Division for Border Affairs, Yunnan

Kunming, 11/2016 provincial Foreign Affairs Office

11 Yunnan provincial Friendship

Kunming, 11/2016 Association, Yunnan provincial Foreign Affairs Office

12 GMS Centre Yunnan University

Kunming, 11/2016

13 Secretariat, Mekong Institute

Khon Kaen $11 / 2016$

14 China-related team, Mekong Institute

Khon Kaen

$11 / 2016$

15 Joint Secretary 1, Myanmar Institute of Yangon 11/2016 Strategic and International Studies 


\begin{tabular}{|c|c|c|c|}
\hline Foreign official & 16 & Myanmar Economic & Yangon 11/2016 \\
\hline Academic & 17 & $\begin{array}{l}\text { Director of Centre for Economy, } \\
\text { Environment and Society, Asia-Europe } \\
\text { Institute }\end{array}$ & Yangon $11 / 2016$ \\
\hline $\begin{array}{l}\text { Provincial } \\
\text { official }\end{array}$ & 18 & $\begin{array}{l}\text { International Regional Cooperation } \\
\text { Office, Yunnan provincial Foreign Affairs } \\
\text { Office }\end{array}$ & Kunming, $12 / 201$ \\
\hline $\begin{array}{l}\text { Provincial } \\
\text { official }\end{array}$ & 19 & $\begin{array}{l}\text { International Regional Cooperation } \\
\text { Office, Yunnan provincial Foreign Affairs } \\
\text { Office }\end{array}$ & Kunming, $12 / 201$ \\
\hline $\begin{array}{l}\text { Provincial } \\
\text { official }\end{array}$ & 20 & $\begin{array}{l}\text { Yunnan provincial Overseas Chinese } \\
\text { Affairs Office }\end{array}$ & Kunming, $12 / 201$ \\
\hline Think tanker & 21 & GMS Logistical Research Centre & Kunming, 12/201 \\
\hline IGO & 22 & $\begin{array}{l}\text { Regional Cooperation and Operations } \\
\text { Coordination Division, Asian } \\
\text { Development Bank }\end{array}$ & Skype, 12/2016 \\
\hline IGO & 23 & $\begin{array}{l}\text { Regional Cooperation and Operations } \\
\text { Coordination Division, Asian } \\
\text { Development Bank }\end{array}$ & Skype, 12/2016 \\
\hline Academic & 24 & $\begin{array}{l}\text { Centre for China Studies, The Chinese } \\
\text { University of Hong Kong }\end{array}$ & Skype, 12/2016 \\
\hline $\begin{array}{l}\text { Provincial } \\
\text { official }\end{array}$ & 25 & $\begin{array}{l}\text { Division for External Trade, Yunnan } \\
\text { Provincial Commerce Dept. }\end{array}$ & $\begin{array}{l}\text { Kunming, } \\
\text { June/2017 }\end{array}$ \\
\hline $\begin{array}{l}\text { Provincial } \\
\text { official }\end{array}$ & 26 & $\begin{array}{l}\text { Division for External Affairs and } \\
\text { International Economy and Commerce, } \\
\text { Yunnan Provincial Commerce Dept. }\end{array}$ & $\begin{array}{l}\text { Kunming, } \\
\text { June/2017 }\end{array}$ \\
\hline $\begin{array}{l}\text { Provincial } \\
\text { official }\end{array}$ & 27 & $\begin{array}{l}\text { Division for Development Zones, } \\
\text { Yunnan Provincial Commerce Dept. }\end{array}$ & $\begin{array}{l}\text { Kunming, } \\
\text { June/2017 }\end{array}$ \\
\hline SOE & 28 & Kungang Group & $\begin{array}{l}\text { Kunming, } \\
\text { July/2017 }\end{array}$ \\
\hline SOE & 29 & $\begin{array}{l}\text { Yunnan Company, China Southern } \\
\text { Power Grid }\end{array}$ & $\begin{array}{l}\text { Kunming, } \\
\text { July/2017 }\end{array}$ \\
\hline SOE & 30 & Yunnan Metallurgical Group Co.,Ltd. & $\begin{array}{l}\text { Kunming, } \\
\text { July/2017 }\end{array}$ \\
\hline
\end{tabular}


Appendix 5: Gross Development Project (GDP) (billion in RMB) in Yunnan and some coastal provinces (1980-1996)

\begin{tabular}{|c|c|c|c|c|c|}
\hline Yunnan & Hainan & Fujian & Shanghai & Zhejiang & Guangdong \\
\hline 84.27 & 19.33 & 87.96 & 311.89 & 179.92 & 249.56 \\
\hline 94.13 & 22.23 & 105.62 & 324.76 & 204.69 & 290.36 \\
\hline 110.12 & 28.86 & 117.81 & 337.07 & 234.01 & 339.92 \\
\hline 120.07 & 31.12 & 127.76 & 351.81 & 257.09 & 368.75 \\
\hline 139.58 & 37.18 & 157.06 & 390.85 & 323.25 & 458.74 \\
\hline 164.96 & 43.26 & 200.48 & 466.75 & 429.16 & 577.38 \\
\hline 182.28 & 48.03 & 222.54 & 490.83 & 502.47 & 667.53 \\
\hline 229.03 & 57.28 & 279.24 & 545.46 & 606.99 & 846.69 \\
\hline 301.09 & 77 & 383.21 & 648.3 & 770.25 & 1155.37 \\
\hline 363.05 & 91.32 & 458.4 & 696.54 & 849.44 & 1381.39 \\
\hline 451.67 & 102.42 & 522.28 & 781.66 & 904.69 & 1559.03 \\
\hline 517.41 & 120.52 & 619.87 & 893.77 & 1089.33 & 1893.3 \\
\hline 618.69 & 184.92 & 784.68 & 1114.32 & 1375.7 & 2447.54 \\
\hline 783.27 & 260.41 & 1114.2 & 1519.23 & 1925.91 & 3469.28 \\
\hline 983.78 & 331.98 & 1644.39 & 1990.86 & 2689.28 & 4619.02 \\
\hline 1222.15 & 363.25 & 2094.9 & 2499.43 & 3557.55 & 5933.05 \\
\hline 1517.69 & 389.68 & 2484.25 & 2957.55 & 4188.53 & 6834.97 \\
\hline 783.27 & 260.41 & 1114.2 & 1519.23 & 1925.91 & 3469.28 \\
\hline 983.78 & 331.98 & 1644.39 & 1990.86 & 2689.28 & 4619.02 \\
\hline 1222.15 & 363.25 & 2094.9 & 2499.43 & 3557.55 & 5933.05 \\
\hline 1517.69 & 389.68 & 2484.25 & 2957.55 & 4188.53 & 6834.97 \\
\hline
\end{tabular}

Source: National Statistics Bureau (NBS) 


\section{Appendix 6: The list of Growth Triangles in East and Southeast Asia}

\begin{tabular}{|c|c|c|}
\hline Cooperation Scheme & Members & Cooperation type \\
\hline $\begin{array}{l}\text { Indonesia-Malaysia- } \\
\text { Singapore Growth Triangle } \\
\text { (Formerly Johor- } \\
\text { Singapore-Riau Growth } \\
\text { Triangle) }\end{array}$ & $\begin{array}{l}\text { Indonesia: Riau, Jamb, } \\
\text { Bengkulu, South and West } \\
\text { Sumatra, Lampung, West } \\
\text { Kalimantan } \\
\text { Malaysia: Johor; Melaka, Negri } \\
\text { Sembilan, Southern Pahang } \\
\text { Singapore }\end{array}$ & $\begin{array}{l}\text { Metropolitan spill over } \\
\text { into the hinterland }\end{array}$ \\
\hline $\begin{array}{l}\text { Northern ASEN Growth } \\
\text { Triangle }\end{array}$ & $\begin{array}{l}\text { Indonesia: North Sumatra, Aceh } \\
\text { Malaysia: Kedah, Perlis, Penang, } \\
\text { Perak } \\
\text { Thailand: Satun, Narathiwat, } \\
\text { Yala, Songkhla, Pattani }\end{array}$ & $\begin{array}{l}\text { Joint development of } \\
\text { natural resources and } \\
\text { infrastructure }\end{array}$ \\
\hline $\begin{array}{l}\text { Brunei Darussalam- } \\
\text { Indonesia-Malaysia- } \\
\text { Philippines-East ASEAN } \\
\text { Growth Area }\end{array}$ & $\begin{array}{l}\text { Brunei Indonesia: Kalimantan, } \\
\text { Sulawesi, Maluku, Irian Jaya } \\
\text { Malaysia: Sarawak, Sahan, } \\
\text { Labuan Philippines: Mindanao, } \\
\text { Palawan }\end{array}$ & $\begin{array}{l}\text { Joint development of } \\
\text { natural resources and } \\
\text { infrastructure }\end{array}$ \\
\hline $\begin{array}{l}\text { Greater Mekong Economic } \\
\text { Subregion }\end{array}$ & $\begin{array}{l}\text { Cambodia, Laos, Vietnam, } \\
\text { Myanmar, Thailand, China: } \\
\text { Yunnan, Guangxi (after 2005) }\end{array}$ & $\begin{array}{l}\text { Joint development of } \\
\text { natural resources and } \\
\text { infrastructure }\end{array}$ \\
\hline $\begin{array}{l}\text { Golden Quadripartite } \\
\text { Economic Cooperation }\end{array}$ & $\begin{array}{l}\text { Laos, Myanmar, Thailand, China: } \\
\text { Yunnan }\end{array}$ & $\begin{array}{l}\text { Joint development of } \\
\text { natural resources and } \\
\text { infrastructure }\end{array}$ \\
\hline $\begin{array}{l}\text { Southern China Growth } \\
\text { Triangle or Greater South } \\
\text { China Economic Zone }\end{array}$ & $\begin{array}{l}\text { Hong Kong, Taiwan, southern } \\
\text { PRC (parts of Guangdong and } \\
\text { Fujian) }\end{array}$ & $\begin{array}{l}\text { Metropolitan spill over } \\
\text { into the hinterland }\end{array}$ \\
\hline $\begin{array}{l}\text { Tumen River Area } \\
\text { Development Programme }\end{array}$ & $\begin{array}{l}\text { Russia: Southern Primorskie Krai } \\
\text { South Korea: Rajin-Sonbong } \\
\text { Free Economic Zone } \\
\text { North Korea } \\
\text { China: southern Jilin and the } \\
\text { area stretching from Yanbian } \\
\text { Autonomous Prefecture to }\end{array}$ & $\begin{array}{l}\text { Joint development of } \\
\text { natural resources and } \\
\text { infrastructure }\end{array}$ \\
\hline
\end{tabular}


eastern Mongolia

\begin{tabular}{|c|c|c|}
\hline Yellow Sea Economic Zone & $\begin{array}{l}\text { China: Liaodong and Shandong } \\
\text { Peninsulas } \\
\text { South Korea } \\
\text { Japan: western and northern } \\
\text { parts of Kyushu and Yamaguchi }\end{array}$ & $\begin{array}{l}\text { Common geopolitical } \\
\text { interests and } \\
\text { geographical proximity }\end{array}$ \\
\hline $\begin{array}{l}\text { Pan-Pearl River Delta }(9+2 \\
\text { initiative) }\end{array}$ & $\begin{array}{l}\text { Hong Kong } \\
\text { Macao } \\
\text { Mainland China (especially } \\
\text { Guangdong but can be extended } \\
\text { to Hainan, Guizhou, Jiangxi, } \\
\text { Yunnan, Sichuan, Hunan, Fujian, } \\
\text { and Guangxi) }\end{array}$ & $\begin{array}{l}\text { Metropolitan spill over } \\
\text { into the hinterland }\end{array}$ \\
\hline Japan Sea Economic Zone & $\begin{array}{l}\text { Japan, East Russia, Northeast } \\
\text { China, South Korea, North Korea }\end{array}$ & $\begin{array}{l}\text { Common geopolitical } \\
\text { interests and } \\
\text { geographical proximity }\end{array}$ \\
\hline
\end{tabular}




\section{University Library}

\section{- MINERVA}

\section{A gateway to Melbourne's research publications}

Minerva Access is the Institutional Repository of The University of Melbourne

Author/s:

Song, Yao

Title:

Beyond the hinterland: exploring the international actorness of China's Yunnan Province

Date:

2019

Persistent Link:

http://hdl.handle.net/11343/227723

Terms and Conditions:

Terms and Conditions: Copyright in works deposited in Minerva Access is retained by the copyright owner. The work may not be altered without permission from the copyright owner. Readers may only download, print and save electronic copies of whole works for their own personal non-commercial use. Any use that exceeds these limits requires permission from the copyright owner. Attribution is essential when quoting or paraphrasing from these works. 